


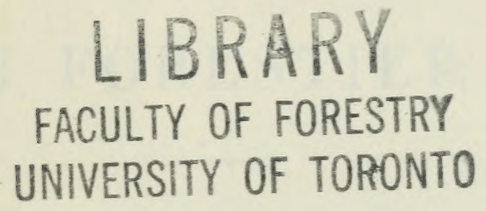


Digitized by the Internet Archive in 2010 with funding from University of Ottawa 
BOUQUET DH LA, GRYE

GUIDE

DU FORESTIER

SuRveillange des forêts et DE LA PÊche 


\section{G U I D E}

\section{DU

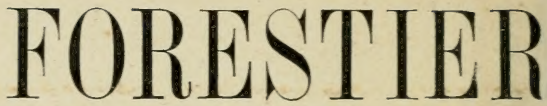

TRAITÉ ÉLÉMENTAIRE

DE

LA GULTURE ET DE LA GESTION DES FORÊTS

SECONDE PARTIE

SURVEILLANGE DES FORETS

SD ET DE LA PÉGHE

B68

1906

PARIS

LUGIEN LAVEUR, ÉDITEUR

13, RUE DES SAINTS-PĖRES, VI

$\overline{1906}$ 


\section{LA SURVEILLANGE}

D 15

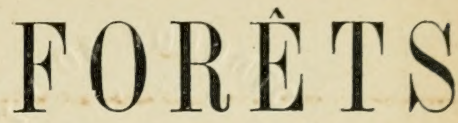

ET DE LA PECHE

PAR

\section{A. BOUQUET DE LA GRYE}

Ancien Conservateur des Forèts

Membre de la Société Nle d'Agriculture de France.

\section{ONZIËME ÉDITION}

Revue et mise au courant des changements survenus depuis la précédente édition

PAR

CH. GUYOT

Directeur de l'École Nationale des Eaux et Forêts

PARIS

LUCIEN LAVEUR, É:DITEUR

13 , RUE DES SAINTS-PÈRES, VI

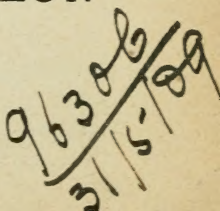


La première Partie du GUIDE DU FORESTIER contient:

\section{LES ÉLÉMENTS DE SYLVICOLTURE}

Un fort Volume avec 70.Vignettes : Prix : 2 Franes 50 


\section{SOMMAIRE DES CHAPITRES :}

\section{CHAPITRE PREMIER}

\section{RÈGLES GẺNÉRALES}

Procès-verbaux. - Écriture. - Signature. - Clôture. - Affirmation. - Enregistrement. - Transmission. - Rédaction des procès-verbaux. - Date. - Age des bois. - Flagrant délit. - Complicité. - Désignation des délinquants. - Récidive. Saisies. - Séquestres. - Visites domiciliaires. - Réquisitions à la force publique. - Délinquants inconnus. - Foi due aux procès-verbaux. - Témoignages. - Bulletins de renseignements. - Conseils........................... 1

\section{CHAPITRE II}

\section{CONSTATATIONS DES DÉLITS}

"Coupe et enlèvement de bois. - Arbres de 2 décimètres et audessus. - Usage de la scie. - Souchetage. -. Identité. Conpe et enlèvement de bois de moins de 2 décimètres, - 
Coupe de plants. - Arrachis de plants. - Vols de bois. Port de scie, etc. - Mutilation, écorcement d'arbres. - Enlèvement de chablis et bois de délits. - Extraction et enlèvement de produits autres que les bois. - Introduction de voitures et bêtes de somme dans les forèts. - Feux à distance prohibée. - Incendies. - Refus de secours. - Elagages. Constructions à distance prohibée. - Exceptions - Scierieś, surveillance. - Pâturage. - Droits de parcours. - Garde séparée. - Marques. - Clochettes. - Commerce de bestiaux. - Nombre de bestiaux. - Défrichement. - Prohibitions. Exceptions. - Coupe à blanc étoe. - Défrichement des bois communaux. - Dégradations. - Usurpations. - Rébellion, injures, menaces. - Tabacs. - Roulage............ 29

\section{CHAPITRE III}

\section{EXPLOITATIONS}

Permis d'exploiter. - Marteaú de ladjudicataire. - Coupe de réserves. - Bris de réserves. - Outre-passe. - Vices d'exploitation. - Travail de nuit. - Dimanches et jours fériés. Ecorcement sur pied. - Loges, fourneaux et ateliers. - Feux. - Faux chemins. - Musèlement des animaux. - Délais d'exploitation et de vidange. - Dépôt illicite. - Délits à l'ouĩe de la cognée. - Coupes affouagères. - Emplois des bois de construction et de chauffage. - Bois mort............. 76

\section{CHAPITRE IV}

\section{CHASSE}

Compétence. - Constatation. - Affirmation. - Saisies. - Visites domiciliaires. - Arrestations. - Permis de chasse. Temps prohibé. - Modes de chasse. - Chasses réservées. Droit de suite. - Cahier des charges. - Observations. - Le braconnage. - Dommages causés par le gibier. - Gratifications. - Louveterie. - Battues.................... 102 


\section{CHAPITRE V}

\section{PÊCHE}

Droit de pêche. - Cours d'eau non navigables ni flottables. Etang 3. - Gardes particuliers. - Cours d'eau navigables et flottables. - Partage d'attributions. - Arljudications. - Gardes pêche. - Constatation des délits. - Saisies. - Pèche sans autorisation. - Pèche à la ligne. - Ligne flottante. - Ligne dormante. - Ligne volante. - Barrages. - Appareils de pécherie. - Filels fixes. - Empoisonnement. - Résidus inclustriels. - Pouissage. - Temps prohilhé. - Pêche de nuit. Exceptions. - Cantons réserrés. - Engins prohibés. - Exceptions. - Modes de pêche interdits. - Dimensions des poissons. - Port d'engins prohibés. - Vente et colportage. Exceptions. - Pèches louées. - Visite des bateaux. - Pêches extraordinaires. - Inscription maritime............. 120

\section{CHAPITRE VI}

\section{CITATIONS ET SIGNIFICATIONS}

Compétence. - But de la signification. - Sa forme. - Remise des copies. - Enregistrement. - Frais de citation...... 1145

\section{CHAPITRE VII}

\section{TRAVAUX. - DÉLIVRANCES. - ADJUDICATIONS}

Travaux en régie. - Par entreprise. - Imposés aux adjudicataires de coupes. - Exécutés par les prestataires. - Par les préposés. - Délivrances de menus produits. - Ventes. Affiches. - Adjudications. - Remises. - Affiche annotée. État des frais 


\section{CHAPITRE VIII}

\section{PERSONNEL DES PRÉPOSÉS DE L'ADMINISTRATION DES FORËTS}

Commission. - Serment professionnel. - Dépüt de l'empreinte du marteau. - Transcription au greffe. - Installation. - Préposés logés. - Cession d'objets divers. - Jardins et cultures des gardes. - Paturage de deux raches. - Panage. - Chauffage. - Conseils. - Traitement. - Retenues. - Perte de mandats. - Changements de résidence. - Tabac de cantine. Indemnités. - Voyages à prix réduit. - Brigadiers. - Lniforme. - Conıés. - Admission dans les hùpitaux militaires. - Mariases. - Médaille dhonneur. - Gardes-pèche des ponts et chaussées................................. 174

\section{CHAPITRE IX}

\section{RÈGLES DE SERVICE DES PRÉPOSÉS}

DE L'ADMINISTRATION DES FORÈTS

Livret dorilre. - Fenilles de prorès-verbanx. - Marteanx. Plaques. - Correspondanee. - Franchise. - Résidence. Incompatibilitis. - Prohibitions. - Privilige de juridiction. Respon-abilité. - Peines disciplinaires. - Marques de respect. ...................................... 210

\section{CHAPITRE $\mathrm{X}$}

\section{RETRAITES}

Droit it pension. - Veures. - Orphelins. - Lipuidation des pensions. - Majorations. - Maximum. - Minimum. - Tarif des pensions. - Mode de ealeul. - Demandes de pensimns. Caises de retraites pur la vieille-we................ 22: 


\section{CHAPITRE XI}

\section{ORGANISATION MILITAIRE}

Service militaire. - Dispositions grénérales. - Organisation des compagnies de chasseurs forestiers. - Traitenent civil. Uniforme, entretien. - Armement. - Grand équipement. Petit équipement. - Munitions. - Changements de résidence. Médaille militaire........................... 247

\section{CHAPITRE XII}

\section{RECRUTEMENT . - AVANCEMENT. - ENSEIGNEMENT}

Gardes domaniaux. - Gardes cantonniers. - Gardes communaux. - Vominations. - Brigadiers. - Conditions d'avancement. - Candidatures.

École secondaire des Barres. - Conditions du concours. - Régime de l'École. - Examens. - École pratique des Barres.. 262

\section{CHAPITRE XIII}

\section{SERVICE SÉDENTAIRE}

- Gardes sédentaires. - Brigadiers sédentaires. - Administration centrale. - Commis temporaires................ 277

\section{CHAPITRE XIV}

\section{GARDES PARTICULIERS. GARDES-CHASSE ET GARDES - VENTE}

Gardes particuliers. - Nomination. - Serment. -- Compétence. - Privilège de juridiction. - Procès-rerbaux. - Exploitations.

- Chasse. - Instruclion professionnelle. 
Gardes-chasse. - Nomination. - Révocation. - Permis de chasse. - Uniforme. - Renvoi.

Gardes-rente. - Yomination. - Serment. - Compétence. Procès-verbaux. - Vérification de réserves. - Demandes de harts. - Délais d'exploitation................... 282 


\section{ANNEXES}

Modeles de procè-verbaux. No 1 Coupe de bois de plus de 2 récimètres, flagrant délit, complicité. - Affirmation. - Signification et assignation. $\mathrm{N}^{\circ} 2$ Coupe et enlèvement d'arbres de plus de 2 décimètres, visite domiciliaire, saisie, séquestre. Affirmation. - Signification et assignation. Yेo 2 bis Bulletin de renseignements. No 3 Coupe et enlevement de bois de moins de 2 décimètres, saisie non effectuée d'instruments de délit. - Signification et assignation. No 4 Mutilation, récidive. No 5 Enlèvement de faines. No 6 Enlèvement de feuilles mortes, complicité, saisie, séquestre. No 7 Extraction et enlèvement de pierres, voiture à deux chevaux. No 8 Faux chemins, bois de moins de dix ans. $\gamma^{\circ} 9 \mathrm{Feu}$ à distance prohibée. No 10 Piefus de secours en cas d'incendic. $\gamma^{\circ} 11$ Construction à distance prohibée. $\mathrm{N}^{\circ} 12$ Chantier non autorisé. No13 Introduction de bois non marqués dans une scierie. N॰ $\mathrm{I}^{\prime}$ Pàturage, saisie, séquestre. No 15 pâturage. No 16 Introduction de bestiaux dans des cantons en défends. No 17 Introduction de bestiaux en nombre excédant celui indiqué par les procès-verbaux de défensabilité. No 18 Coupe de réserves. No 19 Outre-passe. N॰20 
Yices d'exploitation. No 21 Retard de nettoiement. No 22 Retard d'exploitation. No 23 Défaut de permis. Chasse réservée. Io $2{ }_{4}^{\prime}$ Chasse arec engins prohibès, temps défendu. refus de remettre les engins. N $^{2} 25$ Pêche de nuit. temps prohibé, poisson n'ayant pas la dimension. No 26 Procès-verbal de garde particulier. arbres de plus de 2 décimetres. - Nuit. - Scie.

No 27 Réquisition. No 28 Procès-verbal de délivrance. No $29 \mathrm{De}-$ claration de perte de mandat. Y $Y^{\circ} 30$ Commission de garde particulier. No 31 Calepin d'attachement. No 32 Demande de harts. Yo33 Pouvoir pour toucher les mandats. No $3 \dot{z}$ Acte de vente sous-seing privé d'une coupe de taillis sous futaie.

Ecoles des Barres. - Programmes dadmission et d'enseignement . . . . . . . . . . . . . 301

\section{ERRATA}

Page 13, ligne 12, ... feront connaitre l'essence, l'âge...

Page 5f, dernière ligne, lire: Art. 150, an lieu de 140. 


\section{GUIDE DU FORESTIER}

\section{POLICE DES FORETS}

CHAPITKE PREMIER

RÈGLES GÉNÉRALES

Proces-verhanx. - Écriture. - Signature. - Cloture Affirmation. - Enregistrement. - Transmission. - Rélaction des procès-verhaux. - Date. - Ige des bois. - Flagrant délit. - Complicité. - Désionation des délinquants. Récidive. - Saisies. - Séquestres. - Visiles dmmiciliaires. Réquisitions à la force publique. - Délinrquants inconmus Foi due aux procès-rerbaux. - Témoignages, - Bulletins de renseignements. - Conseils.

1. La constatation des délits est la partie la plus importante et la plus difficile du service des préposés lorestiers. Lat conservation des forrits serail en effet bien compromise si les auteur's des dévastations de toute nature qui peuvent s'y commettre n'étaient promptement signalés et punis. Les gardes ont à lutter de ruse avec des délinquants habitués à profiGriye. - Suineillaice. 
ter de toute négligence; ils doivent donc ètre toujours en éveil. étudier les habitudes des maraudeurs, apprendre à les reconnaitre sous les déguisements et les noms dirers qu'ils prennent. les surveiller sans se laisser épier, et déjouer leurs ruses par une vigilance de tous les instants.

Il ne suffit pas que les gardes reconnaissent tous les délits commis dans leurs triages ; il laut encore quils les constatent par des actes rémuliers. qui juennent le $n 0 m$ ile proces-cerbutu.

2. Procès-verbaux. - Les proces-rerbaux dressés par les qurdes sont des actes authentirues auxipuels est altachee une préromption léwale de rérité. Ceux que réligent les prepose de ladninistration des forrt-doirent etre écrit-sur les formules imprimes fournies gal ladministration et transmises aux priposés par le- clrefs de cantommement. Noir chap. 1. \& 243. Les gardes suivont, pour lemploi de as formules. lorelre des mmeros inserits far lagent dore-lier. - Les gardes des particuliers icrivent leurs procis-rerbatux sur des leuilles de plapier timbré.

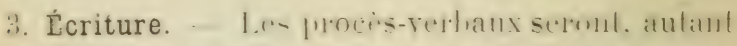

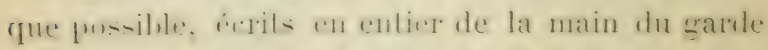

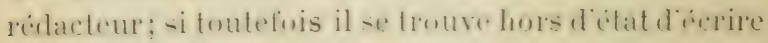
lui-mine -on procis-rerlial, il peut le laire exrire p:tr un lier's. (Voir 


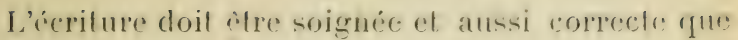
possible.

Il ne sera laisse aucun intervalle en blanc dans le corps de lacte; tous les renrois, ratures ct surcharges seront approurés et paraphés par le ridacteur. - Les dates seront inscrites en toutes lettres et non en chiffres; il en sera de mème des nombres et mesures; les noms propres seront distingués par des caracteres plus gros que le corps du procisverbal et soulignés.

4. Signature. - Dans tous les cas, la signature du préposé ou des préposés qui ont constaté le délit loit ètre apposée sur les actes à la rédaction desquels ils ont concouru. Un procès-rerbal non signé est radicalement nul.

Un procès-rerbal dressé par plusicurs préposés et signné seulement par l'un d'entre eux est considéré comme dressé par ce signataire seul: les autres sont censés n'avoir pas concouru à sa r'édaction.

๖. Glôture. - Les procès-rerbaux seront rédigés et clos le jour mème de la reconnaissance du délit. (Ordon., art. 181.)

Toutefois, si les préposés reconnaissent un délit dont ils ne peurent indiruer les auteurs, sils sont clans la nécessité de faire les recherches qui exiggent un certain temps pour amener la décourerte des délinquants, ils constateront les faits qu'ils auront recon- 
nus et renverront à une époque ultérieure la clòture de leur procès-rerbal en indiquant les motifs de ce renvoi. (Toir exemple $n^{0} 24$. .)

Le jour de la clòture est la réritable date du procès-rerbal; aussi doit-il ètre mentionné d'une manière formelle.

si le procés-rerbal esl clos le jour mème de la reconnaissance du délit. la date de la clòture sera suffisamment indiquée par la formule : Clos ì.... les jour, mois et an que dessus. (Toir Exemple $n^{\circ}$ J.)

si le proces-rerbal n'est pas clos le jour mime de la constatation du délit, on indiquera en toutes lettres la date de la cliture. (Voir Exemple $n^{0}$ 1.)

Les proces-rerbaux seront transcrits en entier sur le lirret: le numéro de la feuille dudit livet sur layuelle le procis-rerbal est porti sera inserit en marge de cet acte, dans la case à ce destinée.

6. Affirmation. - Les cardes aftirmeront leurs procis-rerbaux au plus tard le lendemain de la cloture desdits actes, par derant le juge de paix du canton ou l'un de ses suppléants, ou par devant le maire ou ladjoint. soit le la commune de leur résidence, soit de celle ou le dilit a étécommis et conslate, le toul sous peine de mulliti. (t:. lor., ant. 163.)

Le redacteur d un procis-rerbal, en allirmant cet acte, en certifie lexarlilute-sum la foi du serment.

Lilfirmation doit émaner du grarde rédacteur 
et non du magistral derant fequel elle res faitr.

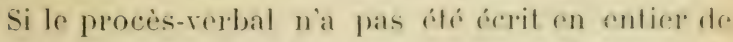
la main du garde, l'officier puhlic qui recerra l'alfirmation derra lni en dommer préalablement lecture et faire mention de refte formalite, fe font a preine de nullité. (C. for., art. 16马.)

Cette lecture a pour but de mettre les preposis qui ne peurent pas rédiger eux-mêmes leurs procisverbaux à l'abri des surprises que pourait entrainer leur défaut dinstruction ou la mauraise foi du rédacteur; elle leur permet aussi de rectifier les indications erronées qui auraient pu leur échapper.

Lorsquin procis-rerlal est dressé par un senl préposé el entièrement écrit de sa main, lacte d'affirmation contiendra seulement la mention de la déclaration du garde rédacteur, comme il est indiqué à l'Exemple no 1 (Affirmation).

Si le proces-verbal est dressé par deux ou plusieurs préposés, l’officier public devant lequel cet acte est affirmé en fera la lecture préalable et mentionnera cette formalité, comme il est indiqué à l'Exemple $n^{\circ} 2$ (Affirmation).

L'acte d'affirmation est daté et signé tant par officier public que par les gardes.

i. Les ratures, additions, renvois et rectifications opérés dans le corps du procès-verbal arant l'affirmation doirent, à peine de nullité, être paraphés 
par lofficier public qui recoit la déclaration des préposés.

Après laffirmation, il ne doit ètre fait aucun changement au procès-verbal.

8. Dans le cas où les officiers de pulice judiciaire auraient négligé ou refusé de receroir l'affirmation des procés-rerbaux dans le délai prescrit par la loi, les gardes rédigeront procés-verbal du refus et adresseront sur le champ ce procès-rerbal au chef de cantonnement. (Ord., art. 18\%.)

9. Enregistrement. - Les procis-rerbaux seront, sous peine de nullité, enregistrés dans les quatre jours qui suirront celui de l'affirmation. iC. for., art. 170).

Il résulte de cette disposition que l'affirmation doit toujours prépider lenregistrement du process. rerbal. et que cet enregistrement pent ètre fait, pour dernier délai, le qualrieme jour apres l'affirmation. Ainsi, un procis-verbal affirmé le 20 pourra ètre enregistré le 2'; mais il serait nul si l'enregistrement était daté dı 25.

Les préposis penvent faire enregistrer leurs procis-rerbaux an burean du recereur do leur résdence ou au bureau le plus rapproché du lien où ils se trourent, mime accidentellement. La loi leur laisse toute latitude à cet igrard.

10. Transmission. - Lorsque le bureau de l'emre- 


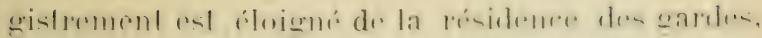

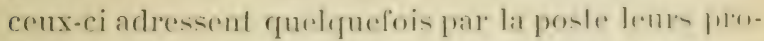
ces-rerluan an precentr. Ce demior les transmet. apres enregistrement, a lasent forestier ehef de cantonnement.

Ce mode de transmission offre de grands ineonvénients: un retard de la poste peut entrainer la nullité du proces-rerbal. Les preposés n'emploierout la roie de la poste qu'autant quils y auront éle formellement autorisés par le chef de cantonnement ef que le recereur y aura consenti ; sinon, ils porleront eux-mèmes leurs actes à l'enregistrement et les expédieront immédiatement après à l'agent forestier leur supérieur.

11. Les préposés mentionneront sur leur lirret l'enregistrement des procés-rerbaux qu'ils ont dressés et l'enroi de ces actes au chel de cantomnement. Cette mention s'opère de la maniere suivante:

(Date)... Fait enregistrer au bureau rle... (nombre) procés-uerbaux, $n^{\circ}$... à... et transmis lestits artes à 11. le..., ¿̀...

12. Les gardes qui, par leur faute, ont occasionné la nullité diun procésererbal pour défaut d'enregistrement dans les délais légaux, sont passibles diune amende de 10 francs (loi du 22 frimaire an VII) ; ils peurent ètre de plus actionnés en responsabilité pour les condamnations encourues par les délinquants. 
13 Rédaction des procès-verbaux. - Yous indiquerons dans les cliapitres suirants les renseignements spéciaux que doivent renfermer les procès-rerbaux, selon la nature des délits qu'ils constatent; mais nous devons d'abord faire connaitre d'une manière générale les indications que ces actes doivent toujours contenir.

Ces indications sont relatives :

10. Au temps ot au lieu des délits ct contraventions;

¿̇o l la désignation des préposés qui lesont constatés ;

$3^{\circ}$ - Lux rimomslances particulieres a chaque constatation;

$4^{\circ}$. I la kérignation des délinquants ;

"jo I la nafure du délit et aux suites de la conslatation.

14. Date. - I a premiere mention a inserire sur le procis-rerhal est relle de la date de la constatation du délit.

Nons avons in an paragraphe ö que cette date froul différer de celle de la rédaction et de la cloture lu procis-rerthal. Il nest en effet pas ahsolument preseril aux prefosio de dresicer leurs procés rephaux le jour mème de la découverte diun délit ; ils fenvent surseoir a rlore res artes jusqua ce quils commaissent les délimpuants : mais ils doivent indi- 


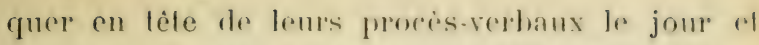
l'heure oit le délil a refe reenmu. I.'hempe doil atre indiquere d'une maniere aussi approchée rue possible.

Il importe surlout que cetle indiration soit exactement domnée quant il s'agil d'un délit commis à une heure rapprochée du lever ou du concher du soleil; comme les peines encourues par les délinquants sont doublées quand le délit a eu lieu la nuit, c'est-à-dire entre le coucher et le lever du soleil, il faut que les procis-verbaux fassent mention ie celte circonstance aggravante.

Le lieu du délit s'indique par le nom de la forêt où il a été constaté.

On fera connaitre si elle appartient à l'État, aux communes, aux établissements publics ou aux particuliers.

On donnera le nom sous lequel le canton où le délit a été constaté est le plus généralement connu, en désignant, pour les forèts aménagées, le numéro de la série et celui de la coupe, le territoire commu. nal sur lequel se trouve ce canton.

13. Age des bois. - Il sera fait mention de l'àge des bois où le délit aura été commis. Dans les forêts traitées en taillis, l'âge se compte par le nombre d'années qui se sont écoulées depuis la dernière exploitation. Dans les forêts traitées en futaie, on 
prendra l'àge du peuplement le plus jeune et non celui des rieux bois qui le dominent.

16. Noms et qualités. - Après les mots nous sous* signés, imprimés sur la formule, le rédacteur inscrira les noms et prénoms de tous les préposés qui ont concouru à la constatation du délit en commençant par celıi du grade le plus élevé; il indiquera la résidence de chacun deux. (Toir Exemple $n^{\circ}$ 2.)

17. Flagrant délit. - Le procès-rerbal relatera aussi exactement que possible les circonstances dans lesquelle le délit a été reconnu. Ainsi il fera comnaitre si les délinquants ont été surpris en flagrant délit.

On appelle flagranl le dílit qui se commet nu riont de se commettre. Ln délinguant occupé à ahatlre un arhre ou charger m arbre abattu est en llagrant dílit; il sera consideri comme en llagrant délit s'il est reneontri dans la forit porteur des bois quil y a compres el des instruments dont il sest servi.

18. Complicité. - Si le délit a chi commis par plusieurs individus, le proci-s-rerlal derra faire mention des cireonstances qui constituent la complicité.

La eomplicité sétablit non seulement par la coopération des prévenus à un mème délit, mais encore 
par laide quils se pretent, soit pour lo commeller, soit pour érhapper il ses consérfuences. Des individus élrangers les uns aux aules qui coupent des arbes, fout pacager des bestiaux, ete., dans $u$ mime canton, seront considérés eomme complices sils se pritent assistance (Voir Exomple $\mathrm{n}^{n} 1$ ), s'ils s'avertissent réciproquement de l'approche des gardes. Les proces-rerbaux derront donc relater tous les faits qui prouvent de la part des délinquants une commune entente, une action concertie. De lexactitude de ces indications dépend lapplication de la solidarité, c'est-à-dire de la responsabilité réciproque de tous les délinquants. - Si la complicité est suffisamment prouvée, chacun d'eux est solidairement responsable des condamnations encourues par tous les autres. Si, au contraire, rien n'établit une entente commune, chacun n'est passible que des condamnations qui lui sont personnelles.

19. Nom, prénoms et domicile. - Les prévenus doiventêtre désignés par leurs noms, prénoms, professions et demeures. - Si l’auteur du délit est une femme mariće, un enfant mineur, un ourrier ou un domestique, les noms, prénoms, professions et demeures des maris, peres, mères ou maitres seront indiqués. Comme les pères, mères, tuteurs, maris, maîtres et commettants sont responsables civilement 
Tes condamnations prononeres contre leurs enfants mineurs et pupilles demeurant arec eux, ourriers, roituriers et autres subordonnés. il importe que les proces-rerbaux contiennent les renseignements propres à faciliter lapplication de cette responsabilité (C. for.; art. 206.)

Il est utile de faire connaitre au moins approximatirement liage des délinquants. Cette indication pent servir à apprécier suils ont agi arec discernement dans le cas ou ils ont moins de 16 ans.

20. Récidive. - Le rédacteur d'un procés-rerbal fera toujours connaitre si les prévenus sont en état le récidive, rest-d-dire si dan-les inuze mois précedents, il a sti remulu contre eux un jugement de condamnation pour contrarention ou délit forestier. La récidive entraine le doublement de la peine encourue. (C. for., art. 200.)

Le proces-rerbal devra mentionner la date du dernier jugement renulu inntre les délinuguants.

Il nest pas toujours possible aux préposis dindiquer exactement cette date. qui peut ne pas leur ètre connue, mais ils ont toujours la facilite de sassurer. au moyen de lexamen de leur livret, sils nut dressi: dans les douze mois précédents des procis-rerhaux contre ces memes delinquants. Ils inseriront la date et le numiro du dernier procic-rerbal. Voir Exemple $\left.n^{\circ} 4.\right)$ 
21. Indications caractéristiques. - Les procis-verbaux contiendront, suivant la nature du délit, tons les renseignemenls qui le raractérisent. Yous indiquerons ces renseignements d'une maniere spéciale dans les chapitres suivants, oì nous examinerons charque délit en particulier. Nous nous bornerons donc à mentionner ici, d’après linstruction placée en tète du livret des gardes, celles de ces indications qui ont un caractère commun de grénéralité.

Pour les enlevements et abatages de bois, les gardes leront comnaître l'àge, la grosseur et la quantité des bois objets du délit;

Les instruments, voilures et attelages employés pour le commettre.

Pour les extractions de produits quelconques, ils indiqueront la nature des productions extraites, coupées ou enlerées, et leur quantité ;

Pour les délits de pàturage, le nombre, l'espèce ct le signalement des animanx trouvés dans les bois, l'âge de ces bois.

S’il s'agit de délits de chasse, l'espèce d'armes, de pièges, de chiens employés et lespèce de gibier pris ou chassé;

S'il s'agil de délits de pèche, l'espèce de filets ou d'engins, les dimensions des mailles, lespèce et la longueur des poissons capturés. 
Dans tous les cas, le proces-rerbal mentionnera les déclarations et areux des prévenus.

Le rédacteur du procés-rerbal fera enfin connaitre les suites données à la constatation des délits, en indiquant sil a été procédé, daprès les règles tracées dans les paragraphes qui suirent, à la saisie et à la mise en séquestre des attelages, bestiaux, bois et instruments du délit.

22. Saisies. - Il est prescrit aux préposés de saisir les scies. haches, serpes, cognées et autres ins. truments de mème nature dont les délinquants ou leurs complices sont trouris nantis. (L. for.. art. 198.)

Les gardes ne sont toutefois pas obligés dopérer dans tous les cas la saisie effective des instruments dont les délinquants sont armés; il- exigeront la remise de ces instruments lorstu ils seront en état de farire respecter leur autoriti, mais ils éviteront de se compromettre dans des luttes corporelles.

si le désamement présente des difficultés, ils se borneront a déclarer la silisie et imbliqueront la nalure. lenombre et la valeur des inslruments. e'n constalant que les délinquants ont refuse de leur en faire la remise. (Voir Exemple n" 3.1

I.es armes, outils et instruments saisis seront leijuscis aux greffes iles lribunaux. Ce dépót es effec- 
tur par les chefs de cantomement, a qui les gandros transmetlent les olyjels caplurés sur les délin. quants.

Afin déviter les erreurs el les réchamalions qui pourraient soblever si, en cas dacequittement des prévenus, la restitulion des objets saisis renait a itre ortonnée, el aussi pour que les greffirsts puissent accepter le dépòt en recomnaissant la valinlité de la capture, les préposés auront soin d'indiquer, par une étiquette altachée à chaque ol,jet, le numéro du procés rerbal qui en a constaté la saisie et le nom du délinquant.

Toute saisie d'instruments, armes et engins quelconques (mème abandonnés par des délinquants inconnus), doit ètre constatée par un procis rerlual en forme.

Les préposés forestiers sonl autorisés à saisir les bestiaux trourés en délit et à les mettre en séquestre. (C. for', art. 161.)

Les roitures, instruments et attelag'es seront saisis et mis en séquestre toutes les fois que les proprićtaires ne seront pas d'une solvabilité notoire.

Les animaux dont les propriélaires sont inconnus, les bois et prouluctions forestieres enlerés par les délinquants seront toujours saisis et mis en séquestre.

23. Séquestre. - On dit qu un oljjet est mis en séquestre lorsquil est contić à la garde d'une per- 
sonne qui soblige rolontairement à le représenter à toute réquisition légale.

On opère la saisie effective des bestiaux en conduisant en un lieu sùr les animaux pris en contrarention. La saisie réelle des bois de délit s'effectue plus rarement, à raison des difficultés du transport. Les préposés ignorent en général quils peurent faire transporter, aux frais de ladministration, les objets quils saisissent jusrqu'au domicile du séquestre. Sils employaient plus souvent ce moyen, les délinquants ne profiteraient pas, comme ils le font journellement, des produits de leurs rols, et la répression se trourerait assurée diune manière bien plus efficace. Les frais de ce transport sont acquittés comme nous lindirquerons ci-dessous pour ceux du séquestre. (Voir Exemple $n^{\circ}$ 2.)

La mission du séquestre est toule lacultative et ne peut ètre imposée.

Les préposés apporteront une grande circonspection dans le choix des personnes quils établiront séquestres et devront sattacher à ce quelles soient solvaloles. Il importe, en effet, que l'administration fuisice exereer son recours contre le síquestre, s'il laisse enlever ou dépririr les objets qui lui sont confiés.

Lorsyue les préposés auront saisi des bestiaux et qu'ils auront trouvé une prosine sure disposic a 
arecpter la mission de séfurstre, ils derrout drese ser lewr frocis vertal, qui rontiondra, apros les renscignements relatifs a la eonstatation du délil:

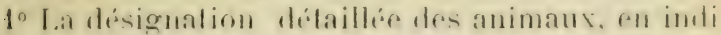
quant l'espece, le nombre, le sexe, la couleur, les marques particulières. le harnachement, s'il y a lieu :

$2^{\circ}$ L indication de la personne rui en est propné. laire, si elle est comme, ou la mention quion na ju la connaitre ;

$3^{\circ}$ Les noms, profession et demeure de lindividu a la garde duquel les bestiaux auront été confiés.

Ce procès-verbal sera fait sans déplacer. Mention sera faite de lheure de sa cloture; le gardien signera le procès verbal, et, sil ne sait signer, il en sera fait mention. (Voir Exemples $n^{\text {ns }} 6$ et 14.)

Le garde fera, séance tenante, deux copies du procis-verbal; il les signera; l'une d'elles sera remise au séquestre qui la signera ; la seconde, aussi revètue de la signature de ce dernier ou de la mention qu'il ne sait signer, sera remise, dans les vingl quatre heures, au greffe de la justice de paix.

Les procès-rerbaux de saisie de bestiaux doivent dre transmis sans délai au chef de cantonnement, qui prend les mesures nécessaires pour faire procéder à la vente.

La mise en séquestre des bois saisis s'opère comme pour les bestiaux; le signalement des animaux est 
seulement remplacé par l'indication exacte des essences, thmensions et quantités des bois.

24. Paiement des frais. - Les frais de transport et de síquestre sont acquittés au moyen diun mandat que le conservateur délirre sur la demande des per somne- qui ont transporté ou gardé des objets saisis. Cette demande loit itre appuyée d'un mémoire taxé par le juge de paix. Si le montant de ce mémoire est de plus ile $10 \mathrm{fr}$, il derra ìtre rédigé sur papier timbré.

20. Visites domiciliaires. - Les gardes sunt auto. risis à suirre les objels enleri- par les délinquants jusque dans les lieux où ils auront ćté transportés. et a les mettre en sidquestre. Ils ne pourront néanmoins sintroduire dans les maisons, batiments. cours atjacentes et onclos. si ce nest en présence soit du juge de paix ou de son suppleant, soit du maire ou de son arljoint, soit du commis-aire de police. (C. for., art. 161.)

Le hroit ronféré par la loi aux préposis de lant. ministration forestiore, de suive et de rechereher les nhjels conlevis, ne sétenu pas an dela du lerri. toire des arrondissements oir ils peurent ligalement

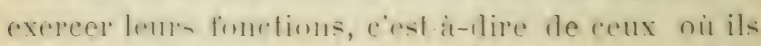
sont aecriblitio par la prestation de serment ef lenrexistrement de leur commission : partont ailleurs ils sont sans qualité. 
La présence diun des fonelionnaires disignes dans larlicle 161 est indispensable pour dommer ans pré posés le droil de sintroduite dans les bitimenls, cours et enclos.

Ce droit ne peut itre excré que pentanl le jomr, c'est-a-dire de 6 heures du matin à fo heures du soir depuis le ter octobre jusquiau 31 mars, el de 4 heures du matin ì heures du soir depuis le $1^{\text {er }}$ avril jusqu'au 30 septembre.

Cependant les gardes peuvent suintrodnire, soit le jour, soit la nuit, dans les fours à chaux et à plâtre, briqueteries et tuileries, loges, baraques et hangars construits à moins d'un kilometre, et dans les scieries établies à y kilometres des bois et forèts, pourvu quils se présentent au nombre de deux au moins.

Ln garde seul peut risiter les établissements mentionnés ri-dessus, šil est assisté des deux témoins domiciliés dans la commune. (C. for., art. Jอั .)

Ce droit exceptionnel de risite ne sétend pas aux fermes et maisons d'habitation. non plus qu'aux scieries qui font partie d'un village ou hameau.

Les gardes forestiers revêtus des insignes de leurs fonctions peurent pénétrer dans l'enceinte des chemins de fer, sans l'assislance des fonctionnaires désignés dans l'article 161 du Code forestier ; mais ils 
sont tenus de sp conformer aux mesures de sureté yni linur seront preserites par les cmployés. (Orel. du 1 ö norembre 18łi, art. 62.)

lis fom tionnaire- rerquis pour asister lis prépo sis lans les risiles quils reulent faire ne peurent refuser leur concours; ils sont tenus de signer le procis verbal de la perquisition faite en leur présence, sauf au grarde. en cas de refus de leur part, à en laire mention au procis verbal. C. for., art. 162.;

La réquisition peut itre verhale: elle ne sera érrite que sur la demante expresse du magistrat. - Lasistance des fonctionnaires désignés dans larticle l6il a pour ol,jet le légaliser l’introduction de gartes dans le domirile des citnvens: ces fonetimnaires ue concoment en rien à la perquisition of a la ronstatation des délits; leur ròle se borue à refuirir. an nom de la loi. lourerture des portes.

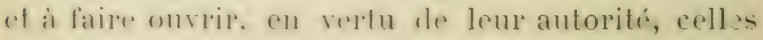
yue lu- habitants refusant douvrir de plein gri. (Voir Exemple n" 2.'

les sarile- peurent procéler à des perquisitions en présence du chef de maison ef sans lassistance les magistrats. si celui-ei n'y met pas olstacle; mais le procis-verhal devisile deva mentionner son consentement.

Ils ne doirent jamais procider sans l'assistance des magistrats si le chef de maison est absent. 
Nous arons eru devorr entrer dans de grands di. lails au sujet du deoit de visite, à raison de la hante importance que pent avoir pour les préposés l'oubli des prescriptions de la loi.

La violalion, mème légale, du domicile des citoyens est un acte sérieux que des motifs graves peuvent seuls justifier.

Certains préposés n'hésitent pas à opérer des visites domiciliaires pour la recherche de délits de peu d'importance et sans autres indications que la découverte des souches laissées sur pied. Alors leur's perquisitions s'étendent sur tout un villagere, au grand mécontentement des personmes dont le domicile est envahi, et des magistrats que leur deroir oblige à assister à des recherches toujours pénibles et souvent sans résultats. Nous ne saurions recommander l'emploi d'un pareil mode de constatation. Les visites domiciliaires ne doivent ètre faites qu'autant qu'il s'agit de constater des délits d'une certaine gravité; elles ne doivent porter que sur les maisons dont les propriétaires sont soupçonnés.

Il y a moins d'inconrénients à laisser quelques délits impunis qu’à froisser les populations par des perquisitions qui les indisposent contre ladministration et le gourernement au nom de qui elles sont fartes.

26. Refus de concours. - Dans le cas où les offi- 
ciers de police judiciaire désignés dans larticle 161 du Code forestier refuseraient, après aroir été léga. lement requis, daccompagner les gardes dans leurs visites et perquisitions, les gardes rédigeront le process-rerbal du refus et adresseront sur-le-champ ce proces-rerbal à lagent forestier, qui en rendra compte au chef du parquet. (Ord., art. 182.) - Ce procis-rerbal derra ètre rédigé de la manière la plus concise et faire connaitre simplement le refus oppose par le fonctionuaire légalement requis.

27. Réquisitions. - Lés préposés de l'administration des forèts ont le droit de requérir directement la force publique prour la répression des délits et contraventions en matiere forestiere, ainsi que pour la rerherehe et la saisie des bois coupés en délit, vendus ou arhetés en fraude. (C. for., art. 164.)

Letur riquisition doit ète adresse au commandant de la foree publique du lieu. Elle peut etre verbale on ecrite. - La gendarmerie ne prète son concour-yfue sur une réquisition écrite, dont nous indiquons la formule an $11^{\circ} 27$ des Exemples.

28. Arrestations. - Les grardes arreteronl et conduiront devant le juge de pais ou devant le maire fout incommu quils auront surpris en thagrant télit d'infraction aux lois forestieres. (C. for., art. 1633.)

Ils arrèteront de mème lout individu coupable d'un crime on d’un délit quelconque. pris en flagrant 


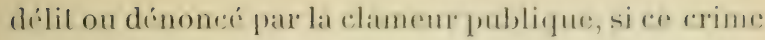
ou délit entrane l'emprisommement ou mur peime: plus grave. (Code d'insl. crim., art. 16.)

lls constitueront prisonnier tout frandeur at colporteur de tabac el le conduiront sur-le-champ devant l'ofticier de police jurliciaire le plus rapproché du lieu d'arrestation. (Loi du 28 arril 1816.$)$

Le droit darrestation conléré aux préposés forestier's a pour objet, soil de faciliter la désignation des délinfuants incomnus, soit de mettre sous la main de la juslice les criminels ou les fraudeurs. Les personnes arrètées sont amenées devant le magistrat. qui s'assure de leur identité et prend à leur égard telles mesures qu'il juge convenables; les préposés rédigent ensuite leur procès-verbal sil sagit de délits forestiers ou de contraventions aux lois doua. nières.

29. Délinquants inconnus. - Les délits dont les au• teurs sont inconnus doivent ètre constatés par des procès-verbaux réguliers.

Quoique écrite dans le lirret des gardes, cette prescription n'est pas suivie à la lettre dans la pratique. On conçoit, en effet, que la rédaction des nombreux procès-verbaux que nécessiterait la constatation régulière des délits minimes dont les auteurs restent inconnus occasionnerait aux préposés un travail considérable et sans utilité. En général, ils se 
contentent dapposer sur les souches l'empreinte de leur marteau et de faire mention sur leurs livrets de la reconnaissance du délit. Ce moule d'opérer est suffisant pour couvrir, dans la plupart des cas, la responsabilité des gardes. Mais s'il se commet dans leur triage des délits importants, les préposés devront les constater par des procés-rerbaux en règle, et justifier des diligences faites pour en décourrir les anteurs.

30. Foi due aux procès-verbaux. - Les procis-rerbaux revèns de toutes les formalités prescrites par les articles 165 et 170 , et qui sont dressés et signés par deux prépostis, font preuve, justuà inscription de faux, des faits matériels relatils aux délits et contraventions qu'ils constatent. (C. for., art. 176.) Ceux qui sont dressés et signés par un seul préposé feront de meme frenve jusfüà inscription de faux, mais seulement lorsque la contravention nentrainera pas une comlammation de plus de 100 fr. (C. lor., art. 177.)

si les combamnalions encourues sélivent à plus de 100 lr., les proces-rerbaux peurent ètre corroborés et combattus par toutes les preuves légales. (C. for., art 178.)

Les procès-rerbaux dressés par les gardes sont des actes authentiques auxquels est attache une présomption ligale de vérité, présomption tellement 
complete, si la romstatalion du drit a éte faile parte denx preposés, el mime par un seml lorsque lis

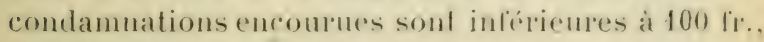
que les prevenus nont mime pas le droit de contester les énonciations de ces actes. Lorsufu, an contraire, un plocés-yerbal qui entraine des condannations supérieures à 100 li. est dressé par un seul préposé, le prérenu peut ètre arlmis à combattre, par les preures légrales, les assertions du garde.

Un congoit aisément que la loi n'ait pas roulu domner à un préposé seul le droit de constater, daus tous les cas, et sans que ses assertions puissent même ètre discutées, des délils qui peuvent ètre suivis de condamnations graves, tandis quelle a admis comme authentiquement élablis les faits avancés par deux préposés, et mème ceux qui sont constatés par un seul lorsque les condamnations encourues sont inférieures à $100 \mathrm{fr}$.

Les préposés doirent se rendre dignes de la confiance que la loi accorde à leurs actes, en les rédigeant arec un soin scrupuleux. Ils troureront dans les Exemples qui terminent ce volume des modèles quill leur suffira d'imiter, en les modifiant suivant les circonstances; mais, pour que cette rédaction, qui exige une attention très sérieuse, soit bien faite, il est indispensable d'écrire d'abord sur un brouillon le procès-verbal, qui ne devra ètre transcrit sur 
le livret et la formule imprimée quaprès une correction consciencieuse. In proces-rerbal ne doit jamais rien contenir qui ne soit de la plus exacte vérité; les indications hasardées en seront complètement bannies: les rédacteurs relatent les faits qu'ils ont rus, les opérations auxquelles ils ont concouru, et rien de plus.

Au reste, cest seulement à raison des faits matériels constatés que les procés-verbaux font foi jusqu'à inscription de faux. Ouand un préposé certifie quil a trouré et recomnu un délinfuant. qu'il a mesuré la grosseur d'un arbre, son assertion est admise comme légalement rraie : mais s'il fait des appréciations, sil evalue la grosseur d'un arbre qu'il n'a pas mesuré, sil aftirme que les bois trourés chez le délinfuant proviennent des sonches recommues en forèt, sans le prouver par un retocage réellement effectue, ou par des indications mécises tirées de sirnes matériels de cette identité. ce sont là de simples appriciations qui peurent itre contredites. Les préposés, en effet, ont pu se tromper dans leurs appreciations, tandis que lerrenr nest pas admis sible quand il sagit de faits qui tombent sous les sens. lie sunt des derniers seulement dont les prérenus ne sont pas admis a contester lexactitude.

Pour que les préposés soient en état de recon- 


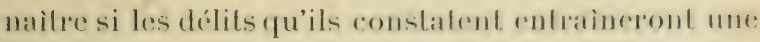
condamnation supérieme it loo fr. ol si, par conséquent, leurs proces-verbaux font foi jusfu'i imscription de faux, il faudrait quils enssent sur la lí. gislation forestiere des connaissances apporofondies que ce recueil n'est pas destinc à leur domner, rt qui leur seraient d'ailleurs inutiles.

Ce qui a été dit au sujet de la foi due aux procis-sverbaux doit suffire pour faire comprendre qu'il est utile que les gardes réclament, quand ils le peuvent, le concours de leurs collègues pour constater les délits de quelque importance. Mais lorsque cette assistance est impossible, le préposé qui aura reconnu le délit dressera son procès-verbal, saul à en appuyer plus tard les assertions par les témoignages qu'il pourra produire.

31. Témoignages. - Le rédacteur d'un procès-rerbal est souvent cité comme témoin pour éclaircir certains faits que cet acte ne prouve pas d'une manière suffisante. Le préposé ainsi appelé devant le tribunal domnera les explications qui lui seront demandées; il évitera les détails insignifiants pour s'attacher aux circonstances principales des délits; il se montrera enfin plus désireux de faire connaitre la vérité au magistrat qui l'interroge que de soutenir les assertions contenues dans son procès verbal. Un garde dont la bonne foi et la véracité sont con- 
nues du tribunal est toujours sùr de roir son témoignage accueilli avec confiance.

32. Bulletins de renseignements. - Les auteurs de délits commis dans les bois soumis au régime forestier peuvent, dans certains cas, itre admis à transaction. Les préposés doivent fournir à Jeur's chef's les renseignements de nature à les éclairer sur la moralité et la position de fortune et de famille des déliuquants.

Ces renseignements sont compris dans un bulletin (roir Esemple $n^{\circ} 2$ his) qui sera rempli par le rédacteur du procès-rerbal et joint à cet acte.

33. Conseils. - La surveillance demande une activité soutenue, une grande fermeté. La constatation exigge de la pénétration et beaucoup de prudence.

C"est sans cris. sansemportement qu'un bon rarle sait sacquitter de ses fonctions; il cloit se montrer sevire, mais jamais violent vis a vis des délinquants. Il évitera les altercations toujours inutiles et sourent dangereuses; il sera ferme sans cesser d'etre poli. Rien nest plus propre a inspirer le respect et la crainte qu'un homme qui ne menace jamais et yui sait accomplir son deroir en restant calme et froid. 


\section{CHAPITRE II}

\section{CONSTATATION DES DÉLITS}

Compe et enlivement de hois. - Arbres de 2 décimètres ef audessus. - Usage de la scie. - Souchelage. - Identité. Conpe et enlevement de hois de moins de 2 derimitres. Coupe de plants. - Arrachis de plants. - Vols de bois. Port de scie, etc. - Mutilation, écorcement d'arbres. - Enlirement de chablis et bois de délits. - Extraction et enlivement de produits antres que les hois. - Introduction de roilures et bètes de somme dans les forits. - Feux à distance prohilice. - Incendies. - Pefus de secours. - Elagages. Constructions à distance prohibée. - Exceptions. - Scieries, surveillance. - Pâturage. - Droits de parcours. - Garde séparée. - Marques. - Clocheltes. - Commerce de bestiaux. Nombre le hestiaux. - Défrichement. - Prohibitions. - Ex. ceptions. - Coupe à blanc étoc. - Défrichement des bois communaux. - Dégradations. - Csurpations. - Réhellion, injures, menaces. - Tahacs. - Roulage.

3\%. De tous les délits qui peuvent être commis dans les forêts, ceux qui sont désignés sous le nom général de délits de coupe et enlèvement de bois sont les plus fréquents. Ce sont aussi ceux dont la constatation présente le plus de difficultés.

Nous allons faire connaître ici les renseignements 
spéciaux que doirent contenir les procés-rerluaux dressés à raison d'infractions de cette nature, en examinant, daprès les textes de la loi, les circonsfances caractéristiques de ces infractions, afin de faire comprendre pourquoi les procès-rerbaux doivent les indiquer.

Il est bien entendu que cet examen ne portera que sur celles de ces circonstances qui sont spéciales aux délits dont il s’agit. et non sur celles plus génémales qui peurent se présenter dans la constatation de tous les délits. Les détails contenus dans le chapitre prédétent nous dispenseront de répéter pour chaque nalure d'infraction ce que nous arons dit relativement aux indiutions à domner sur le lien of l'heure des délits, la désignation des délinquants, les particularites de charue eonlravention et les formalités yui suivent la constatation.

33. Coupe et enlèvement de bois. - Le Corle foresliep dislingue. quant a lappliration de lat peine. dens ralegories de délits de eompe el enlivement de bois, snivant que les arbres ont zácimelres et plus de circonfépence. on yu'ils sont dime dimension inférieure à ă décimètres.

Pour les bois de a derimeldes el an-elessus, la peine se détermine dapris lessence of la rireonlérence des arlues eoupres ou enleves. (C. for.. art. 192.) 


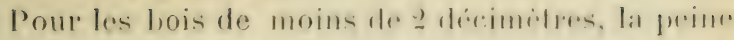
est fixér suivant leur quantite, éralure d'aprós le morle denlevement. (c.. lor., arl. 198.)

Il faut donc que les proces-rertaux lassent exartement eommitre, dans lo premier cas, lessence of la cireonférence de tous les arbres aballus en délil, ef que, dans le second, ils en indiquent exartement la quantité.

Pour fariliter lintelligenere de ees distinclions, nous examinerons un cas assez simple : relui ou m délinguant est rencontré au moment où il abat un arbre de plus de 2 décimetres, et nous déduirons de lexamen du procès-rerbal dressé en ces circonstances les regles qui doivent guider dans les cas plus compliqués.

36. Arbres de 2 décimètres et au-dessus. - Apris avoir fait connaitre le jour, le lieu et l'heure oì il a reconnu le délit et désigné les délinquants, le rérlar. teur du proces-rerbal indiquera le nombre, lessence et la circonférence dos arbres dont labatage est effectué ou commencé.

La désignation des* essences ne doit présenter ancune difficulté, les gardes connaissant les noms de toutes les espèces d'arbres qui se tronrent dans leurs triages.

La circonférence des arbres se mesure à la chaine et s'exprime en décimètres. Les fractions de déci- 
mètre ne snnt pas comptées. Linsi un arhre de i9 rentimetresde tour ne sera compté que pour '́ décimètres.

Le procis-rerbal indiquera d'une maniere précist que le préposé a procridé au mesurage. Ainsi, il ne suffit pas que le rédacteur exprime quil a vu couper un arbe mesurant $ّ$ décimètres de tour; il faut qüil dise qüil a mesuré cet arbre et quil lui a trouré une circonférence de J̆ décimetres.

La circonférence se mesure à 1 mètre du sol siles arbres sont encore sur pied ou suls sont gisants; elle se mesure sur la souche si les bois sont enlerés et façonnés.

Si la sourhe elle-mème est enlerée et silon trouve l'arbre équarri, on mesurela les faces de l'équarrissage; le tour sera caleule dans la proportion d'un cinquirme en sus de la dimension totale des quatre liaces de larbre sifuarri. (C. for., art. 193.)

si enfin la souche et le corps de larbre sont enlevers, la dimension sera donné prar relle des écorces of copeanx trouvés sur le lien du délit, par les traces le lextraction, et entin par les renseignements que le rílacteur du procis-rerbal aura ju se procurer. soit aupres des délinquants eux-mèmes, soit aupres les personnes qui auront vu exploiter, enlever ou laçonner l'arbre. (C. for., art. 193.)

La valeur des arbres doit etre indiquée. On la dé- 
terminera par le pris des bois de meme nature sur le lieu du délil. Le procis verbal fera anssi con. naitre si labalage ou l'enlirement a occasionné du dommage ; il en indiquera le montant. Ce dommage s'eralue d'après l'importance que les bois abaltus pouvaient avoir pour le maintien du massif; il de. pend aussi de l'age et de la rigueur de ces bois. C'est une erreur de croire que le dommage doil toujours èlre évalué au chiffre de l'anende enconrue. Le rédacteur diun proces-verbal n'a pas à se préoceuper de la pénalité que le tribunal infligera; il doit se borner à apprécier, dapres les circonslances, la valeur réelle du dommage causé par le délit. - L'enlèvement debois morts ou dépérissants peut noccasionner aucun dommage ; celui de brins de semis, d'arbres d'avenir ou de porte-graines dess tinés à compléter le courert de cantous à repeupler, cause au contraire un donmage considérable. - Le garde fera connaitre si les bois abattus étaient vif's ou secs.

Son procis-verbal indiquera les instruments employés par les délinquants.

37. Usage de la scie. - Cette désignation est surtout importante si ces derniers ont fait usage de la scic, car lemploi de cet instrument entraine une amende double. (C. for., art. 201.)

Le rédacteur du procès-verbal fera connaitre si la Grye. - Surveillaice. 
saisie des instruments de délit a été effectuée ou suls ont été laissés entre les mains des délinquants. Il indiquera enfin s'il a apposé, sur les bois abattus ou enlerés, lempreinte de son marteau, et si ces bois ont été abandonnés par les délinquants ou sils ont refusé de śen dessaisir. (Voir Exemple $n^{0}$ 1.)

Dans le cas fort simple où le délinquant est trouré en flagrant délit dabatage, tous les ćléments de la constatationse trouvent réunis, et les préposés noont qu à relater les faits dont ils ont été témoins. Mais si, comme il arrive frifuemment, les gardes n'ont pas ru opérer labatage, ils ne peurent établir la culpabilité dé personnes quils trourent en possession des bois culevés qüen prourant lidentité de ces bois arec ecux pris en forit; cette irtentité ne peut sétablir qu’a laide du souchetage on d'indica. tions tellement précises qu elles puissent remplacer cette opération.

38. Souchetage. - Le souchelage, refocage ou rapatronace, consiste a rapprocher de la souche les bois quion suppose en provenir, afin de vérifier s'ils s'y ardaptent. Celte opération est rarement pratifuable done maniere complete, a raison des dilfienllis du lam-port. On y supplie an moyen du rafatronage parliel des copreaux ou écorces dont la enupure. la nuance et les veine- font aisiment reconnaitre l'origine. 
Lor-quin préposi reconnailra que les arberes ond été aballus ol enlevés on didil, il mesurera exartement les soucles, en notera le nomber lessences ct les dimensions; il indiquera si labalage a cha opéré à laide de haches ou de scies, si la découpe presente yuelpues signes particuliers, comme raies et denlelures produiles par les hreches des instruments employés par le's délinquanls. L citat plus ou moins prononcé de fraìcheur de la découpe, sal coloration, leront connaitre lépoque probable du délit. Muni de ces renseignements yui seront tous mentionnés au procéserbal, le garde suiva les traces que ies délinquants auront laissées sur leur passage. Il se renseignera sur la direction qu'ils auront prise, et quand il aura retrouvé les bois, soit au moyen de perquisitions faites arec les formalités indiquées au chapitre précédent, si le produit du délit a été transporté dans des lieux habités, soit par ses recherches dans l'intérieur de la forêt ou dans les champs roisins où ces bois auraient été déposés, il comparera les renseignements recueillis sur le nombre. lessence el les dimensions des souches aree les indications analogues frises sur les bois quil suppose provenir de ces mimes souches.

39. Idertité. - Si lidentifí parait ćablic, il procédera au retucage complet, sil est possible. partiel 
dans le cas contraire. - Il frappera de son marteau les extrémités des pièces de bois retrourées, pour que la découpe n'en soit pas modifiée. Il recherchera parmi les instruments possédés par les détenteurs du bois, s'il s'en trouve dont le tranchant sadapte aux marques laissées sur les souches. Les indications de nature à prourer liudentité des bois derront ètre données diune manière précise, afin que les juges trourent dans le procès-rerbal tous les éléments d une certitude complète. Le garde désignera les détenteurs les bois ainsi enlevés en délit; il saisira ces bois et les mettra en séquestre, suivant les rigles lracées auchapilre précédent. (Toir Exemple n" 2.) Le procis-rerbal qu'il rédigera devra. comme dans le cas frécédent, indiquer la valeur des arbres enlevés et le dommage causé par leur extraction.

\section{Coupe et enlèvement des brius de moins de 2 dé-} cimètres. - Lorsque le délit porte sur des brins de moins de a décimietres de circonférence, la peine se determine, uon plus dapris les dimensions, mais bien dianere la quanlile de- brins exploilés on enlevis. felle quandile sivalue enl lagols, chareses

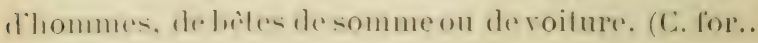
art. 19\%.)

Colle ivalualion me presente aturume difliculté quand les preposés ont vu commette le dílit, ou 
quand les moyens de lansporl soml commus. Si, par exemple, le délinquant est rencontre chargé d'un faix de bois on sil resulte des traces laisseres par les roues que l'enlivement a ćté oprére par une voilure, le mode d'évaluation des bois est tout indiqur: ce sera, dans le premier cas, une charge d'homme, quel que soit d'ailleurs le poids ou le volume des bois ainsi enlevés; ce sora, dans le deuxieme, unc charge de voiture, quand bien mime la voiture naurait transporté qu un fagot; mais, si les bois te délit sont trouvés sur place ou en la possession des délinquants, sans qu'il y ait aucun indice relatif au mode de transport qui sera ou a été employé pour les enlever, la quantité en sera évaluée en charges d'homme, si les bois, objets du délit, ne sont pas en quantité suffisante pour former une charge de bète de somme; en charges de bite de somme, si ces bois ne peuvent former un chargement de voiture; enfin en charretées ou charges de voiture, si les bois exploités sont en trop grande quantité pour être transportés à dos d’homme ou de bète de somme.

Il y a cependant à distinguer le cas où les bois enlerés seraient liés en fagots. A moins de circonstances particulières démontrant que le transport en a été opéré à l'aide de voitures ou de bètes de somme, il y a présomption que les délinquants ont 
transporté ou transporteront les fagots à dos dhomme: le nombre de res fagots derra donc etre indiqué.

Le procés-rerbal fera connaitre, comme nous l'avons dit lans les paragraphes précédents, l'essence et liage des bois abattus, leur valemr. le dommage. - Il relatera, hors le cas de flagrant dé. lit, les preures de l'illentité. et, s'il y a lieu, la sairie et la mise en séquestre.

Lorsque léraluation des bois de moins de 2 décimetres est faite par miture, le proces-rerbal derra faire ermuaitre le nombre dianimaux dont lattelage se compose. (Voir Exemple $n^{0}$ 6.)

41. Coupe de plants. - si les lrins coupés sont de jemnes arberes plantés ou semés de main dhomme depuis moins de einq ans. l'uraluation nin sera plus faite diapris la riogle ditablie four les délits commis dans les reeris naturels. La peine, dans ce ras frartieulior. se letermine par le nombre de brins coupres. C. for., art. 19\%.) I.e procis verbal derra done indiguer exartement lienermes ef le nombre des brins ains explobles: il menlionnera llune ma. niere preise que ces brins proviennent d'un semis

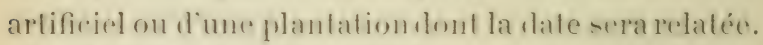

42. Arrachis de plants. - Larrarhis de plants dans

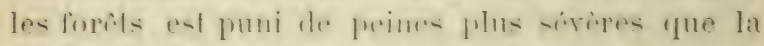
eoupe de ces memes bois; lamende peut varior de 


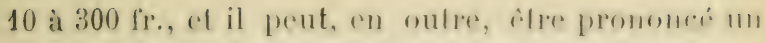
emprisomnement de cind jours. Si le dilil a sle commis dans mo semis on plantalion exirmti de main d'homme, il sera prononci, ontre l'ancude, m cmprisommement de quinze jours a mo mois. (f.. for., art. 193̈.) Les processerloaux toivent, pour faire apprécier limportance du délil, indiquer le montere et lessence des brins arrachés, les instruments à l'aide desquels lextraction a cé faite, la raleur rles brins, le dommage. Ces renseignements, communs a tous ces délits, sont indispensables dans tous les cas. Si les plants ont eté arrachés dans des semis artificiels ou des plantations, le procés vorbal l'indiquera.

43. Vols de bois. - On appelle plus particulierement rol de bois lenlirement frauduleux des bois exploités et faronnés. - Ce délit ne rentre pas dans la classe des délits forestiers proprement dits; il est préru et puni par le Code pénal. Les procésverbaux qui sont destinćs à constater lles infrac. tions de cette nature doivent indiquer la vente doì les bois ont été enlerés, lesauteurs de l'enlèrement, ou du moins les présomptions de culpabilité des individus soupçonnés, les moỹens employés pour détourner ces bois, les personnes qui ont coopéré an délit, soit en recélant les bois volés. soit en facilitant leur vente. 
Ce sont sourent les ourriers ou facteurs qui se? rendent coupables de ces abus de confiance. Les préposés doirent exercer sur eux une surveillance assidue, et s'ils sont sur la voie de quelque détour. nement, ils prériendront. soit les facteurs, soit les adjudicataires, et se concerteront arec eux pour découvrir les coupables.

44. Port de haches, scies, etc. - Lart. $146 \mathrm{du}$ Cocle forestier punit d'une amende de 10 fr. 'fuiconque est trouré dans les forèts, hors les roules ef rhemins ordinaires, munide serpes. harhes. scies ct autres instruments de meme nature. La confiscation desulits instruments est une conséfuence de la condamnation des contrevenants.

Cette disposition a pour ohjet de prévenir les dé. lits en écartant des forets les maraudeurs qui sy introrluisent aver des instruments d abatage.

Il sulfit quim indivilu soit rencontré dans les forits. hors des routes et rhemins ordinaires. et portenr dinstruments propres a eomper le bois: pour qüil soit en contravention. Par poutes et chemins ordinaires. on entend les routes nationales. dipartementales. leschemins vicinaux, ruraux ef les sentiers grevés de droit de passage. Les lignes et laies sommieres fitablies pour le seul service diss forets ne sont pas des themins ordinaires. et nul ne fent les traveroer avec des instruments dahatage. 


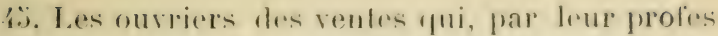
sion, sont obligés de süntrodure dans les forets sont naturellement exceples des prohibitions de larlicle 146. si les individus fromvés en étal de contravention aux dispositions de col article seprí tendent employés aux travaux des roupes, les pró. posés derront s'assurer de l'exactilude de leur asserlion et rerbaliser si elle est recommue fausse. Les procés-rerbaux dressés à raison de contraventions de cette nature leront connaitre le nombre et lespèce dinstruments dont les prévenus ont éti trourés munis, et le lieu précis oi ils ont été rencontrés, en spécifiant, quand c'est sur une laie som mière, un sentier ou une ligne, que cette voie n'est pas publique, mais bien ourerte pour le service exclusif de la forêt.

La saisic des instruments derra être opérée et constatée sur le procès-verbal.

46. Mutilation, écorcement d'arbres. - Ceux qui, dans les bois et forèts, auront éhoupé, écorcé ou mutilé des arbres, ou qui en auront coupé les principales branches, seront punis comme s'ils les araient abattus par le pied. C. for., art. 199.)

Les procès-verbaux rédigés pour des délits de cette espèce doivent contenir les mèmes renseignements que ceux dressés à raison de délits de coupe et enlèrement de bois. Ainsi ils indiqueront l'es- 
sence et la grosseur des arbres mutilés. écorcés ou ébranchés. leur valeur etle dommage qui leur a été causé. (Voir Exemple n 4.)

S'il s’agit d'ábranchements, le rédacteur du procès-rerbal devra en outre faire connaitre la grosseur des branches coupees, en mentionnant que ce sont des branches principales. On considere comme branches principales celles dont l'abatage est de nature à occasionner à larbre un dommage appréciable. Lienlevement de menues brindilles constitue ie délit de coupe de bois de moins de 2 décimètres, et doit ètre constati suivant les regles tracées au $\S 40$.

4i. Enlèvement de chablis et bois de délit. - L'en. lirement des bois rompus par le vent ou autres aceidents, celui des hois de délit, est puni des mimes freines que le mirme délil rommis sur des bois sur pied. (C. lor., art. 197., Les proces-verbaux devront done contenir toutes les indicalions que nous arons déjà mentionnies. - 11 est évilent que lenlèrement des chablis. de mime que celui des bois ahattus par d'autres délinquants noccasiome atueun dommage; il n'y atura done pas lieu divaluer le montant du dommane anusi: mais la valeur des bois enlevés derra itre imlique. Lentivement des boiste lignes ronstilue le diblit prevu par larticle 197.

L'enlivement des chablis. volis, bois de lignes ef 
aules bois aballus conslitue le dílil qualifie de oo de bois, si ces bois onl ate mis en adjudicalion ol vendus.

48. Extraction et enlèvement des produits autres que les bois. - Toule extraction, Ioul enlivement re produits queleonyues des forits opéré sans laulorisation préalable du conservalenr constitue le délit funi par l'article 144 du Corle foreslier, l'une amende de 10 a $30 \mathrm{fr}$. par voilure el par bite allelée; de 5 it $15 \mathrm{fr}$. par charge de bete de somme, et de 2 à $6 \mathrm{fr}$. par charge d'homme. Il pourra en outre itre prononcé un emprisomnement de trois jours au plus. Les termes : produils quelconques comprennent non seulement les productions végétales, comme feuilles. graines, herbes, genèts, mais encore les matériaux, lels que terres, pierres, sable, lourbe, etc., qui peuvent être extraits du sol forestier.

Le fait seul de lextraction ou du ramassage de ces productions constitue le délit, quand même l'enlèvement ne serait pas encore effectué.

Les procès-rerbaux que les gardes auront à dresser à raison de ces infractions derront indiquer la nature des produits extraits, ramassés ou enlerés, leur quantité; la quantité se détermine d’aprís les rígles exposées au $\$ 40$. On évaluera en charges Whomme les produits qui ne sont pas en quantití suffisante pour former une charge de bite de 
somme, en cliarges le bètes de somme ceux qui ne suffiraient pas à former un chargement de voiture et enfin en charretées ceux qui sont trop lourds ou trop rolumineux pour itre transportés dune autre manirre. - Lorsque le mode d'enlèvement est connu, le rédacteur du procès-rerbal se bornera à mentionner le moyen de transport employé. Si, jar exemple, les préposés rencontrent des délinquants chargés des objets frauduleusement extraits ou transportant les mimes produits à l'aide le bites de somme ou de voiture, la seule mention du moyen de transport sulfit pour déterminer la peine. - Mais si, au contraire. les productions extraites sont trouvées sur le lieu mime du délit ou au domicile des prévenus, sans que rien fasse connaitre le moyen quils emploieraient ou quils ont employé pour les enlever, l'évaluation devra etre faite dapris les rigles tracées plus haut.

49. Le proci--verhal indiqure la valeur des objets enleves. les instruments a l'aide desquels lextrac. tion a iti laite, et le dommage qui en est la consequence. Le dommage s'apprécie suirant les eas; il est nul lorsuge les produits enlevés nont pas d'importance au point de vue forestier, et que dailleurs leur extraction sopeere sans dígats pour le sol (voir Exemple n" i); ainsi l'enlerement des herbes, mousses, ronees, peut n'oceasiouner aucun dommage. 
Les extractions de matériaux, feuilles norles, semences, causent sonvent un dommage important, dont on tiendra comple en indiquant au proci-s-rerbal la dépense a faire pour rétablir les lieux dans l'état où ils étaient avant le délit. (Voir Exemple $n^{\circ} 7$.)

Si l'enlèrement est opéré à l'aide de voitures, le rédacteur du procès-verbal indiquera le nombre ct l'espèce des bêtes attelées.

La saisie et la mise en séquestre des objets du délit, des bêtes de sonme, roitures et attelages sera opérée si les prérenus n'offrent pas de garanties de solvabilité. (Toir Exemple $n^{\circ} 6$.) On se dispensera de procéder à la saisie dans le cas contraire. (Voir Exemple $n^{\circ}$ 7.) Lorsque les préposés n'auront pas rencontré les prévenus en flagrant délit et qu'il leur aura fallu procéder à des perquisitions pour retrou. ver les productions enlevées, ils devront mentionner avec soin les preures tirćes des traces de l'enlèvement, des témoignages recueillis et celles déduites de la comparaison des objets du délit arec les productions similaires de la forèt, pour en établir lidentité. - On ne peut, pour des produits de cette nature, procéder au rapatronage comme pour des arbres enlerés; mais le plus ou moins de fraicheur, la couleur, lapparence extéricure, sont des signes précieux qui, réunis à d'autres indications, permettront d'établir l’origine frauduleuse des her], ages, 
graines et matériaus trourés chez les célinquants.

50 . Introdaction de voitures $\in t$ de bêtes de somme dans les forèts. - Ceux dont les roitures, bestiaux, animaux decharge et le monture sont trourés dans les forèts hors des chemins ordinaires seront condammés. savoir : prar chaque roiture à une amencle de $10 \mathrm{fr}$. pour les hwis de dix ans et au-dessus, et de $20 \mathrm{fr}$. pour les bois au-dessous de cet igre; par chaque tète de bestiaux non attelés, aux amendes fixées pour delit du paiturage; le tout sans prejudice des dommages-intérits. (1.. Por.. art. 1.t.

Linfraction privue par larticle pricite se ennstate de la mime maniere que les dilits de paiturane, lorspue les bestiaux, bites de somme ou de monture. sont thouvés non atlelés dans les forels. Vous renroyons done au $\$ 62$ pour toutes les indications que dermont renfermer les fonceserbax dressés dans ce cas.

51. L'introduction de vifures dausl'intirieur des massifs el sur les roies de vidauge et chemins non publirstablis pour le service der forels constitue le

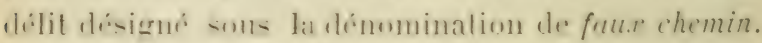

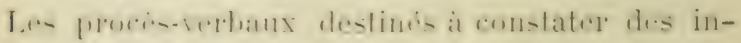

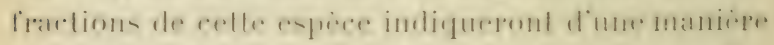

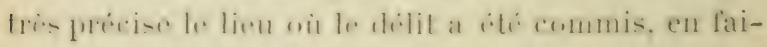
sanl comnaitre a les voifures ont penctré daus lintirieur des massil- on si elles ont seulement 
smive des chemins protiques, mais mom molites.

Nous avons précielemmenl explique ce ques lin doil entendre; jar chemins ordinuires. (loir \$4 Ce sont les seules voies dont la fréruentation rel libre pour tout le monde; les laies sommieres, chemins de vilange et de desserte sont spécialement affectés au service des lorets, et aucune voiluro ne doit y passer, a lexception de celles employies au service des rentes. Nous traiterons, au chapilre suivant, des ol,ligations auxquelles les adjudicataires sout assujettis pour se servir de ces voies re transport, et les peines qu'ils encourent lorsqüils s'en écartent. L infraction dont nous avons à nous occuper actuellement est celle qui est commise par des personnes étrangères aux exploitations.

Le rédacteur du procés-rerbal fera connaitre, quand les roitures auront pratiqué des chemins noureaux, le montant du dommage causé, en éraluant le nombre de brins, cépées et arbres brisés ou foulés. Il indiquera la longueur du parcours. Làge des bois traversés est un des éléments de la peine, puisque l'amende est double lorsqu'ils sont au-dessous de dix ans: le procis-rerbal derra laire connaitre ce renseignement. Tous avons tracé au

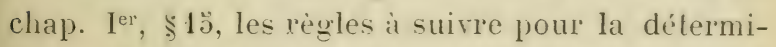
nation de l'àge des peuplements. Jous renvoyons a ces indications. 
52. Feux à distance prohibée. - Il est défendu de porter ou allumer du feu dans l'intérieur et à la distance de 200 mètres des bois et forèts, sous peine d'une amende de 20 à $100 \mathrm{fr}$. (C. for., art. 148.)

Le fait seul d'aroir porté ou allumé du feu dans lintérieur ou à moins de 200 mètres des forêts constitue le délit préru par l'article 148, quand bien mème il n'en serait résulté aucun accident.

La distance se mesure en ligne droite, du point où le feu a été allumé à la limite la plus rapprochée de la forèt.

Les procis-rerbaux qui constatent ces délits en désigneront les auteurs; ils feront connaitre en mesures métriques la distance a la foret des foyers les plus rapprochés de sa limite. et si les bois destines a alimenter le feu provienuent des forèts. ils contiendront les renseignements relatils aux délits d'enlivement de bois. (Toir Exemple ne 9.)

53. Ecobuages. - Les écobuagges sur les terres situées a moins le 200 metres des forèts ne peurent stre pratiquis sans autorisation préalable.

C.est an lrefel quil appartient daccorter ces auIorisations. - Les conditions imposées anx cultivateurs sont indiquies dans larreté qui est communiqué au garde du triage.

Ce dernier doit itre prérenu du jour oil les lourneaux seront allume; ; il fera prendre les pricautions 
convenables pour surveiller la combustion et éviter. les accidents.

Ö́. Incendies. - Lomsque des foux allumbis dams lointeriemr on a me distance furelconque des bois auront occasionne un incentie, le garte du triage prendra de suite les mesures nécessaires pour en arrêter les progres : il réclamera le concours des riverains, organisera le phus pouptement possible les secomrs, en formant des esconades de travailleurs. - Les incendies dans les taillis peuvent étre sourent arrités au moyen de longues perches arec lesquelles on bat les cépées pour empecher la propagation du feu. Dans les hois résineux, il est quelquefois nécessaire d’ouvrir des tranchées destinćes à séparer la partie incendiée des cantons roisins. - On profitera des chemins ouverts pour cerner le feu dans un canton déterminé; tous les secours seront alors dirigés de maniere à préserver les aulres parties de la forêt. - Les femmes et les enfants seront employés à éteindre les matières enflammées qui, projetées au loin sur les gazons desséchés, propageraient l'incendie sur les parties préservées.

Tout en s'efforçant d'arrèter la marche du feu, les préposés ne négligeront pas d'en recher'cher l'origine. Ils examineront le point de départ de l'incendie ; ils s'assureront si le foyer primitif na pas été 
allumé par malveillance. Il y a présomption que l'incendie est le résultat de la malreillance sill est allumé dans les cantons peu fréruentés, s’il y a plusieurs foyers primitifs, si les résidus carbonisés de ces foyers offrent des traces d'arrancements faits de main d'hommé.

Les gardes prendront aupres des personnes qui ont parenuru la forêt le jour du sinistre les renseignements nécessaires pour connaitre aussi exactement que possible le point et l'heure nit le forl a ché allumé, le- inulivilus qui ont élé rus dans les environs. les cireonstances qui peurent laire dirigrer les soupcons sur certains dentre rux. - Le garde du Iriage dans lecquel un incendie a celaté doit en informer sans dibai le chef de cantomnement. si le sinistre prend des proportions considirahles, il lui enverra $n$ expres : la préspredes agents, loujours tris ulile pour les mesures urentes et pour la constatation de l'incendie, devient indispensable lorspue le fen a occasiomni de grants digats. - Tans ee cas, cest le rhef dreanlommement qui rédige le processerbal. si, au contraire. l'inerndie a été éteint avanl d'avoir camsi de grands tommages. le grarde

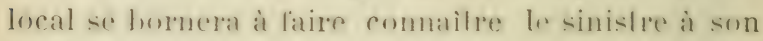
chel, ef il ridigera lui-mime le procis-rerdal. Cet arte derra rontenir lous les ronsiguements relatifs a la constatalion en clle-mime, ot at la désignation 
des compables, s'il y a lien; il fera de plus commaitre létendue des parlios incentiés of le monlant du dommage.

5.). Refus de secours. - Les perionnes qui, sans motifs légitimes, refusent on négligent de porter secours en cas d'incendie dans les forets sont passibles d'une amende de כ้ à $10 \mathrm{fr}$. (C. pén.. art. 47.).) si ces memes personnes ont droit diusage dans lesdites forèts, elles peuvent ètre privées do ces droils pendant un an au moins et cinq ans auplus. IC.. for., art. 149.)

Les procès-verbaux que les garles sont dans le cas de rédiger contre ceux qui, en étant requis, refuseraient de porter secours en cas d'incendic, derront indiquer d'une manière expresse que la réquisition a été faite, car il faut cette circonstance pour motiver l'application de la peine. - Ces actes indiqueront en outre la qualité d'usagers, si les prérenus jouissent le quelques droits de cette nature dans la forêt incendiée. (Voir Exemple $\left.n^{\circ} 10.\right)$

36. Élagages. - Dans le droit ciril, tout propriétaire a le droit de contraindre son roisin à élaguer les branches qui s'arancent sur son terrain. En matière forestière, ce droit est restreint à l'élagage des arbres qui araient moins de 30 ans en 1827. (C. for., art. 140.) - Au surplus, le riverain n’a jamais le 
droit de faire de son chef élaguer les arbres qui s'avancent sur son terrain.

Cette opération, quelle que soit la situation des arbres relativement aux propriétés riveraines. ne peut ètre faite sans l'aulorisation du conservateur.

Tout élagage pratiqué sans cette autorisation rentre dans la classe des délits ordinaires et doit être constaté comme ceux-ci.

:3i. Constructions à distance prohibée. - Les dispositions prohibitives contenues dans les articles 15ั1, 152, 15\%. 1\%\% du Code forestier peurent se résumer ainsi :

Il ne peut ètre établi sans autorisation:

1. Aucun four à chaux ou à platre. aucune b!riquetterie, luilerie, maison sur perche, loge, baraque ou hangar dans l'enceinte et à moins d'un kilomitre de distance des bois et forêts ;

2- Aucune usine a srier le bois dans lenceinte et at moins de a kilomètres des forits;

$3^{\circ}$ Aueun ateider à facommer le bois, aucum magasin ou chantier destini an rommere des bois dans ses maisons situés a moins de 800 metres.

Les matoms dhathitation, usines, aleliers ou magasius qui font partie de villages ou hameaux for. mant me population agglomiree ne sont pas soumis aux prohilitions qui prexielent. Ces eonstrurtions peuvent ère ćlevés sans autorisation, quelyue 
pen distantes qu'olles soient des limiles des forrits (C. fort., art. 156.)

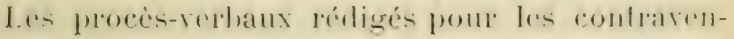
tions eomprises aux $u^{\circ} 1$, 2 et ä doivent, antanl que possible, etre dressés flar denx gardes; ils indiqueront la nature de la ronstruction, sa destination et la dislanee oil clle se frouve de la foreit la plus voisine. (Voir Exemple $\left.n^{\circ} 11.\right)$

Cette distance se mesure en ligne droite, à partir de la limite du bois la plus rapprochée de la construction.

Il est important que les procés-rerbaux dressis à raison de constructions on d'établissements d'industrie à distance prohibée fassent comnaitre la date du commencement des traraux et leur degri d'avancement.

Au reste, les préposés feront bien de prérenir, dès le commencement des constructions, les propriétaires qui ne seraient pas munis d'autorisation, de faire suspendre les travaux. Ils en référeront immédiatement au chef de cantonnement, qui prescrira les mesures à prendre.

En ces matières, comme en toutes celles où il s'agit de délits permanents d'une certaine gravité, il convient que les gardes attendent limpulsion de leurs chefs arant de dresser leurs procès-rerbaux. Il n'y a aucun inconvénient à retarder la constata- 
tion. quand le corps du délit ne peut ètre ni enlevé ni dissimulé, et il y a de grands avantages à ne recomrir aux roies de répression qu'autant qu'il est impossible d'agir autrement.

58. Les proprietaires ou locataires de maisons situées à moins de .00 mètres des bois soumis au regime forestier ne peurent y établir sans autorisation aucun atelier. chantier ou magasin propres à faconner, débiter ou faire le commerce de hois. a moins que cette maison ne fasse partie de villages ou de hameaux formant une population agrglomérée.

Les antorisations que délive le prefet doirent précéder l'ctablistement des chantiers on ateliers. Elles sont personnelles et doivent itre renouvelées en cas de changement de proprictaire ou de locataire.

Les procis-rerbaux rédigés pour ces contratentions feront connatre si la personne qui a citabli latelier ou le magasin est proprietaire ou locataire de la maison, et la distance de cette maison au bois le plus rapproché.

II u'rot le plus sourent pas nécessaire de donner cxactement le rhiffre de cette dislance; il est évident yue si la maison esl à $50,100,200$ métres de la forit, il ne peut y avoir derrenr; il suftia done dindiyuer dans ce cas la distance approximative; mais 
si la maison an loome pros des limiles dn ra! ond de prohibition, entre 800 ef 600 midres far exemple, une indication approximalive n'me plus suftisante: il devient mime nécessare de procéler à un verilable chanogre si la mesme prise dialwol an par laisse quelque doute.

Celle observation sapplinge it toules les cireonslances ou il y a lien de délerminer les distances lígales en matière forestière.

Les procis-rerbaux derront enfore farre comnaitre la nature de l'atelier ou du commerce ćlabli, la quantité des marchandises faconnées ou disposées pour le travail et la raleur de ces marchandises.

Pour recueillir ces renseignements, il est indispensable de visiter létablissement, et, comme nous l'avons vu précédemment, les emplerés forestiers ne peurent s'introduire dans les maisons servant à l'habitation sans l'assistance d'un des fonctionuaires désignés en l'article 161 du Code forestier ; ils procéderont donc comme pour les risites dorniciliaires ordinaires et déclareront la saisie des bois serrant au commerce ou à la fabrication illicites. (Toir Fxemple $n^{\circ}$ 12.)

59. Scieries. - Les usines à scier le bois, lorsqu'elles ne font pas partie de villages ou hameaux el qu'elles sont situćes à moins de 2 kilomètres des forêts sont soumises à certaines mesures de surveil- 
lance rendues nécessaires par la grande facilité avec laquelle les bois de délit peurent y ètre dénalurés. Jous arons ru, chapitre I. § 2̆, que ces établissements peurent itre risités par les gardes sans lassistance des fonctionnaires dénommés en l'article 161. pourvu que le préposé soit assisti dun de ses collingues ou de deux témoins domiciliés dans la commune; ils sont de plus assujettis à ne débiter aucun brois qui ne soit au préalable reconnu et marqué par les employés forestiers. (C. for., art. 15\%8, Urd., art. 180.)

60. Les formalités relatires à celte reconnaissance sont les suivantes:

Le propriétaire remet à lagent local une déclaration détaillée des arbres, billes ou tronces qu'il veut faire transporter dans la scierie ou dans les bàtiments et enclos qui en lépendent; cette déclaration indigue la provenanee des hois, leur nombre et le lieu du dépôt.

Lagent transmel celle déclaration an garde du triage durpuel dépend la stierie. Celui-ci procide immeiliatement a la reconnaissance des bois. dont la quantité et les dimensions doivent etre conformes a la déclaration faite. Cette reconnaissance a pour but de s'assurer que les bois ne proviennent pas de délits : elle doit ctre faite dans les cinq jours de la déclaration; passé ce délai. le propriétaire de la 
scierie pent enlever el laire dibiler ses bois. I. garde doit apposer l'empereinte de son mallean sur chaque bille.

Si, dans les visites qu'ils sont lemus de faire des seicries sommises à leme surveillance, les preposés reconnaissent que des billes nom marqures du marteau du garde local ont bé introduites dans les cours, chantiers ou batiments de l'élablissement, ils doirent constater cette contravention par un procesverbal qui indiquera le nombre ef les dimensions des billes non marquées, et le lieu où clles étaient déposées. (Voir Exemple n 13.)

61. Pâturage. - Les délits de pàturage peuvent être commis soit par des usagers qui ne se conforment pas aux règles de police sur l'exercice de leurs droits, soit par des individus qui n'ont aucun droit d'introduire des bestiaux dans les bois. Yous examinerons d’abord les délits dont ces derniers peurent se rendre coupables; les contraventions aux règlements commises par les usagers et les habitants des communes propriétaires de bois feront l'objet d'un paragraphe séparé.

62. Le fait seul de l'introduction dans l'enceinte des bois, de porcs, chèrres, moutons, bœufs, chevaux ou autres bètes de somme, constitue le délit de pâturage, quand même il n'y aurait aucun abroutissement. 
Lamende encourue par le propriétaire se regrle d'après le nombre d'animaux, leur espece et l'àge des bois ou ils ont été trouvés; elle est fixée à 1 lir. pour un cochon, $2 \mathrm{fr}$. pour une bète à laine. 3 fr. pour un cheral ou une autre bète de somme, $\{$ fr. pour une chevre. "f fr. pour un beruf, une rache ou un veau. Cette amende est double si le bois est àgé de moins de dix ans.

Il pent y aroir lieu a les dommages interéts si le procès-rerbal constate gu il y a cu un prejuctice causé. (C. for., art. 159.)

Le paturage des bestiaux dans les vides, chairieres, chemins de vilange. et en général dans tous les terains qui font partie des bois, constitue le délit prévu par l'article 199.

Les poris-rertanx redigés pourles délits de celte nature indiqueront les noms. prenoms et demeures des proprictaires de bentiaux, ceux des patres. l'heure et le lien du dilit, le nombre et lesprece des animatux loourés dans lenerinte des bois. Le signalement deschevaux, hunfs, ou autres bestiaux devara itre lommi, si re renseignement est nícessare pour fatre recomnatre le proprichaire des animaux.

63. Les gardes distingueront le paiturage exeree sous la direction et la surreillance des bergers, de celui auguel se livent les bestiaux échappés; le 
premier est dil à garde faile ou it brilon planté : il areuse rhez le patre l’intention de rommeltre délil; le palturage par éhappée feul, an romflatre, Ale oceasionné par des circonstances aceidentelles, malgré la volonte du patre ou du proprictaire des bestiaux.

64. Les hestiaux trourés sans cardien dans les bois doivent ètre saisis ef mis en séfuestre ; ils deveont l'stre concole quand mime le propriétare en serait connu, s'il n'est pas diune solvabilité notoire.

L'àge des bois du canton où a ché commis le délit de pàturage sera indiqué. (Voir, pour la détermination de cet ìge, le $\$$ 1\%, chap. ..)

Enfin, le rrocès-rerbal fera connaitre sil y a cu dommage causé, soit par l'abroutissement, soit par le passage des bestiaux. (Voir Exemples $11^{\text {os }}$ 1' et 1 .

6ว. Droits de parcours. - Les habitants des communes proprićtaires de bois, les usager's dans les forèts d'Etat ou des communes, ont le droit d'envoyer leurs bestiaux au parcours en se conformant aux règlements sur l'exercice de ce droit.

Le pàturage ou le panage ne peuvent être exercés que dans les cantons qui auront été déclarés défensables par l'administration forestière. (C. for., art. 67.) 
Les chemins par lesquels les bestiaux devrunt passer pour aller au paturage ou au panage, ef en revenir, seront désignés par les agents forestiers.

La déclaration des cantons délensables et la désignation des chemins sont faites au moyen diun procés-rerbal de reconnaissance approuré par le conservatenr el signifié au maire de la commune ou aux usagers jouissant du droit de parcours en vertu d'un titre distinct.

66. Lorsque les pores et hestiaux des usager's seront trouvés hors des cantons désignés ou hors des chemins indiqués pour s’y rendre, il y aura lieu contre le patre à une amente de 3 a $30 \mathrm{fr}$; en cas de récidive. le patre pourra itre contamné à un emprisonnement de ciny à quinze jours. (C. for., art. 76.)

Pour assurer l'exécution de ces dispositions. les preposés doirent dabord premble une connaissance parfaite des limites des cantons délensables el des chemins désignés pour le passage des hestiaux; ils amoteront à cet effel sur leur recristre les indications du procés-verbal de défensahilite, qu’ils signifient au maire de la commune usagere ou aux usagers.

S'ils rencontrent les troupeaux admis aux parcours hors des limites ou des chemins désignés, ils dresseront un proces-rerbal qui fera commailre le 
nom du patre, celui du eanton oil lus bestians ond éte trouvés en délit, en mentiommant qu’il na pas dé déclaré délensable, et le nomber d'animaux donf se eompose le frompeau lonver dans les cantous do défens; le procès-rerbal devra aussi mentionner, s’il y a lieu, la circonstance de la récidive, l'age des bois et le dommage causé. (Voir Exemple $n^{\circ}$ 16̈.)

67. Le troupeau de chaque rommune ou section de commune derra ette conduit par m on plusiems pàtres communs, choisis par l'aulorité municipale' en conséquence, les habitants des communes usagìres ne pourront ni conduire eux-memes ni faire conduire leurs bestiaux à garle séparée, à peine d'une amende de 2 fr. par tète de bítail.

68. Les por'cs et bestiaux de chaque commune ou section de commune usagère formeront un troupeau particulier et sans mélange des bestiaux d'une autre commune ou section de commune usagrere, sous peine d'une amende de ò à $10 \mathrm{fr}$. contre le pâtre, el d'un emprisonnement de cinq à dix jours en ras de récidive. (C. for., art. 72.)

Des cantons distincls doivent itre désignés pour chaque commune ou section de commune jouissant du droit de parcours en vertu de titres spéciaux; les troupeaux doivent rester dans les limites qui leur sont assignées. Les préposés veilleront à la stricte observation de ces prescriptions et constateront 
toute contravention par des procés-rerbaux qui feront connaitre les noms des paitres dont les troupeaux ont été indùment réunis, celui de la commune ou section qui les emploie, et le canton où ils ont été rencontrés; si ce canton n'est pas lćclaré délensable, le procès-rerbal derra contenir les mèmes renseignements que pour le délit de pàturage hors des cantons ourerts au parcours.

69. Garde séparée. - Les habitants des communes usageres ne peurent conduire eux-mèmes leurs besliaux au pareours; c'est toujours sous la garde d'un pàtre nommé par la commune que ces animaux doivent être introduits dans les bois.

si les lustianx palmrant à garde séparée sont louvís dans les cantons délensables. lamende se rigle dapres le nombre des animaux; romme il n’y a pas de dommage causé dans ce cas, il suffira que les prores-rerbaux indiquent le nom ulu propriétaire du troupean el celui du patre. en mentionnant que ce dremier na pas dé nommé par la commune et qu'il n'i par consífuent pas qualite pour conduire les animaux au parcours.

Le nombre el l'espère des besliaux ainsi gardés seront mentionnés.

si les cantons dans lespuels de trompean gardé par le proprictaire ou par un pitre non désigné par la commune ne sont pas défensables, le procés- 


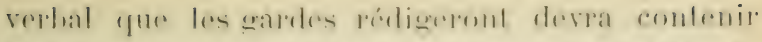
les memes rensedgnemenle que pour non delil de fallurage commis par des imblividus qui non andoun droil d'introdure des lustianx daus les lonis.

70. Marques. - Les pores al besliaux seronl marques diune margue spéciale; refle matrue deria stre différente pour chafue (a)mmmne ou section de commune usagère. ( 6 . for., art. 73.)

Celte obligation noest pas imposée pour les pores ol bestiaux des habilants qui exercent le droil de pareours dans les bois possídés en propre par la commune.

Le nombre des animaux marqués ne doit jamais dépasser celui des animaux admis au parcours. d'aprós le procès-rerbal de délensabilité.

C'est une erreur de la part des acents ou prépoposés qui procèdent à la marque des bestiaux des usagers de rroire quils peurent marquer, dans la prérision quils n’iront pas tous simultanćment au paturage, un nombre d'animaux plus grand que celui fixé par le procés-rerbal de défensabilité.

il. Clochettes. - Les usagers mettront des clocheltes au cou de tous les animaux admis au parcours.

Toutefois, ils ne sont pas tenus de mettre des clo. chettes au cou des porcs admis au panage. IC. for., art. 75.) 
I.es contraventions à res prescriptions sont punies, pour la premiere, d'une amende de $3 \mathrm{fr}$. pour un animal non marqué ; pour la deuxième, de $2 \mathrm{fr}$. par bite trourée sans clochette dans les forits.

Les procès-verbaux auxquels pourraient donner lieu les infractions à ces deux articles derront indiquer, apris le nom du pàtre, celui de la commune dont il surreille les troupeaux, le nomlor des animaux non marqués ou dépourvus de clochettes, et le nom de leur propriétaire.

72. Commerce de bestiaux. - Les usagers ne peuront jouir de lemrs droits de paturage et de panage que pour les bestianx à leur propre usage el non pour cenx dont ils font le rommerece (c.. for., art. 70.) - Les préposís derpont reiller à ce que l's animaux yuisont lobjet d'un commere ne soient pas conduils an pailurage ou a la grantée. On ne consilère pas comme arle de rommerce liblevage des bestiaus, quoiqu'ils soient destinés a ifre rendus. Les propriétares ou fermiers peurent done envoyer an paturage dans les bois les animanx més on élevés daus la lerme. mais ils ne doivent pas y envoyer ceux quils achiotent pour les revendre.

73. Chèvres et moutons. - Le pailurage des montoms est interdit d'une manicre genérale. (C.. for., art. 78.) A moins d'un dieret qui lautorise, le pa- 
cage des montons doit itre reprime comme délit; les proces-verbaux qui le constalent doivent contenir les memes renseignements que pour les fait- de pâturage illicite.

L'introduction des chevres dans les bois est 11\%0hibée d'une manière absolue.

7'. Nombre de bestiaux. - Le nombre de bestiaux admis au paiturage ou des poles admis au panage est indiqué par le proces-rerbal de défensabilité; ce nombre ne peut ètre dépassé, à peine, pour l'excédent, de l'application des dispositions de l'article 199. (C. for., art. 77.)

Les préposés connaissent, d'après le procés-verbal de défensabilité qu'ils ont signifié, le nombre d'animaux dont l'introduction dans les cantons défensables est autorisée; ils peuvent done vérifier dans leurs tournées siles troupeaux conduits au parcours ne sont pas plus considérables ru'il ne doivent l'ètre.

Lorsque les troupeaux appartiennent à des communes simplement usagries et non propriétaires des bois ou s'exerce le parcours, cette rérification sera facile. Il suffira d'examiner si tous les animaux sont marqués, car la marque faite sous la surveillance des agents ou préposés forestiers ne doit comprendre au plus que le nombre d'animaux fixés par le procès-rerbal de défensabilité; le nombre des bestiaux ou porcs exceidant celui que détermine ceł

Grye. - Sunveillaxce. 
acte sera mentionné au procés-verbal, et les pros priétaires en seront désignés.

Loliligation de faire marquer les animaux admis au parcours nétant pas imposée aux habitants des communes proprictaires de bois, on ne pourra désigner le nom des possesseur's des bestiaux trourés en excédent. si le troupeau est plus nombreux qu il ne derrait l'ètré, les préposés compteront le nombre de bètes envorées au parcours par chaque propriétaire. puis. en consultant l'état de répartition dressé par l'autorite municipale, ils reconnaitront quelles sont les persomnes yui ont envoyé au bois plus de bestiaux quelles n'araient le droit de faire. (Voir Exemple $\left.n^{0} 17.\right)$

73. Défrichements des bois des particuliers. - L'ar. licle 21! du Cocle forestier prohibe tout défrichement opire sans autorisation préalable. Lautorisation est accordie par le ministre: toutelois, il nest pas hesoin dautorisation pour délricher:

1" Les lerrains semés ou plantes de bois depuis moins de vingt ans, à moins que ces terrains naient ali plantis ou semés en exécution diun jugement four remplacer les bois défrichis;

20 Le's bois de moins de 10 hectares. s'ils ne font pas partic d'un massil dont la contenance excède 10 lectares et sils ne sont pas situeis sur le sommet ou la pente d'une montagrie; 
3. Les pares ou jardins clos of affenant aux habibitations. (C. for., art. 224.)

76. Pour itre en mesure de constiler les délits dr délrichement, les préposés lorestierstoivent prendre une connaissance complete des hois des particuliers situés dans leur circonscription, les parcourir de. lemps a autre pour s'assurer qu'il ne s'y effectue aucun défrichement illicite; s'ils reconnaissent dans leurs visites que des défrichements sont pratiqués sans autorisations dans des bois ne rentrant pas dans les exceptions indiquées ci-dessus, ils dresseront un procès-rerbal indiquant les nom, prénoms et domicile du propriétaire, la contenance du terrain dé. friché, et, quand le bois a moins de 10 hectares, s’il forme avec des bois roisins un massif de 10 hectares; le proces-rerbal derra indiquer si le bois est situé sur le sommet ou le penchant d'une montagne. Si le défrichement est consommé, le procès verbal fera conmaître la date approximative des derniers travaux.

Les indications relatives aux nom, prénoms et domicile des propriélaires peurent itre prises au besoin sur les matrices cadastrales; la contenance des terrains défrichés s'exprime en hectares, ares et centiares.

77. Lévaluation d'une surface exige des connaissances le plus sourent élrangires aux préposé 
aussi ceux-ci derront-ils, s'ils ne peuvent mesurer eux-mèmes la contenance des terrains défrichés. consulter les plans cadastraux et prendre dans ce document les éléments de leur procès-rerbal.

Si le bois défriché comprend une ou plusieurs parcelles entières, ils indiqueront les contenances cadastrales de ces parcelles, leur's numéros et la section dont elles font partie. Si les terrains défrichés sont des portions de parcelles, ils donneront les mèmes renseignements, en indiquant si le défrichement a porté sur le tiers, le quart ou la moitié, ou toute autre fraction de la parcelle désignée. Dans tous les cas où ils nauront pas procédé euxmèmes au mesurage, ils mentionneront que leur évualuation est faile d'aprés le cadastre ou approxi. mativement, suivant les circonstances.

78. Coupe à blanc étoc. - Ce n'est pas seulement le défrichement, éest-à-dire larrachis des arbres et la mise en rulture du sol, qui constitue le délit préru par larticle 219; toute exploitation ayant pour but de transformer un bois en terres, pàturages ou cultures quelconques est considéré comme un défeichement. Ainsi le fait de couper à blane étoc des hois résineux peut, dans certains cas, itre regardé comme un délit, s’il est accompagné de circonstances ' qui indiquent l'intention manileste de transformer le bois en patturage. Le défrichement 
peut, au contraire, n’ètre pas un délit. Ainsi, par exemple, le propriétaire qui fait ourrir un chemin de vidange a travers sa foret, quoiqu'il fasse peellement défricher une portion du sol boise, ne commel aucun délit, el le mème propriétaire ne pourrait cependant faire défricher une parcelle quelconque de la même forit, pour en faire une prairie ou une. terre arable.

79. La coupe à blanc étoc des bois résineux est considérée comme un défrichement, si elle est pratiquée sur des étendues considérables et de manière à rendre le repeuplement naturel impossible, ou si les troupeaux sont introduits dans les parties récemment exploitées. En général, il y a délit de défrichement toutes les fois que des exploitations abusives accusent de la part du propriétaire l'intention manifeste d'empècher la régénération du bois.

On a considéré aussi comme défrichement le fait d'avoir arraché les souches et cultivé un terrain dépendant d'une forèt, quoique ce terrain soit complètement déboisé.

Enfin, le défrichement d'un terrain forestier, quoique pratiqué arec l'intention manifeste de reboiser, peut encore ètre regardẻ comme un délit. Il est toujonrs difficile d'apprécier, en ces matières délicates, la culpabilité des propriétaires qui font 
dans leurs bois des opérations telles que l'écobuage, le sartage, l'extraction des souches, etc. Aussi nous pensons que. dans la plupart des cas, les contraventions de cette nature ne peurent ètre bien constatées que par les chefs de cantonnements. Les préposés derront done les prérenir et attendre leurs ordres pour agir.

80. Défrichements des bois communaux. - Les communes ou étahlissements publics, propriétaires de bois, ne peuvent les faires défricher sans autorisation. (C.. for., art. 91.) - Tout défrichement dans les bois de cette ratégorie, yüils soient ou non soumis au régime forestier, doit ètre constaté. Toule. fois, il y a lieu de distinguer les défrichements opérés par les ordres de la commune ou de larlministration des cilablissements publics, de ceux qui sont pratiqués sur des terrains communaux boisés par des délinquants agissant pour leur propre compte. Ces délinquants défrichant un terrain yui ne leur appartient pas ne peuvent itre poursuivis comme le seraient les propriétaires récls; ils ne commettent pas, à proprement parler. le délit de défrichement, mais bien celui de coupe on extraction de bois, de sourhes ou de gazon. C"est don" seulement sous ce point de rue que les gardes deroul róliger les frocis-verbaux. si les terrains hroists sont defriches par les ordres des administra. 
lions locales ef pour le comple des commumes. sections de commmose on blablissements publics. les proces-verbaux dressies par les gardes drement indiquer les noms des personmes qui onl pris parl aux travaux par leur coopération immérliate, of de relles qui les onl ordonnés el aulorisés.

81. Les préposés doivenl aussi assurep liexiention des jugements qui ordonne le reboisrment dur terrains illicitement défrichés; si les propriétaires ne sacquittent pas ou s'acquillent mal des obligations qui leur ont áté imposées, ils en informeront le chef de cantonnement.

82. Dégradations. - Les préposés doivenl veiller à la conservation des bornes, fossés, murs, harribres et poleaux de leurs triages; ils signaleront au chel' de cantonnement tous les dégaits qui peuvent y itre commis afin qu'il puisse prentre les mesures nícessaires pour les faire réparer. - Les dégradations seront constatées yar des prorés-verbaux. La rédaction de ces actes est surtout nécessaire lor'squ'il s'agit de comblements de fossés ou de déplac'ements de bornes, parce que ces délits compromettent le maintien des limites et facilitent les usurpations. 83. Usurpations. - L'usurpation par les riverains de parcelles dépendant des for'êts ne constitue un délit forestier qu'autant qu'elle est accompagnéc l'extraction d'arlures, souches on autres produits, 
d'enlèrement de gazons, herbes, genits, etc.; dans ce cas, les préposés n'auront qu’à se reporter aux indications relatives aux délits particuliers auxquels elle a donné lieu.

Si le riverain s est borné à cultiver une portion du sol forestier complètement dégarnie de bois et s'il n'a enleré ni herbes ni gazons, ils rédigeront un procès-rerbal indiquant la situation et l'étendue du terrain ainsi usurpé. et toutes les circonstances qui établissent qu'il y a eu usurpation.

84. Rébellion, injures, menaces. - Si les préposés sont injuriés ou menacés dans l'exercice ou à l'occasion de l'exercice de leurs fonctions, s'ils sont lobjet de violences de la part des délinquants, si ceux-ci méconnaissent leur autorité, il derra ètre dresse un procis-rerbal distinct relatant les injures ou menaces proférées, la nature et la gravité des actes le violence exercis, et toutes les circonstances dans lesquelles se sont passés les faits dénoncés.

Ceproces-rerbal, soumis aux formalités ordinaires, sera transmis au chef de cantonnement, qui saisira e ministère public de la plainte.

8.. Tabacs. - Les préposés forestiers sont tenus de rechercher les plantations frauduleuses de tabacs qui se font dans les forits et d'en informer le directeur des contributions indirectes: ils participent à la répartition dı montant de lamende si les dé- 


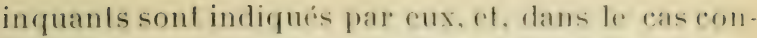
traire, il est acenede une erratifiealion aux garder qui ont signalé les semis ou plantalions. (Circ. fio, 119, 178.)

Ils doivent aussi leur assistance aux préposés rle la régie ef des domanes pour la répression de la fraude en matiope de tabac of diallumettes chimiques.

Le droit de partage est assurć aux próposcis dans toutes les saisies et confiscations auxquelles ilpourront contribuer, et il sera sévi contre ceux qui, par négligence ou une coopération coupable, s'écarteraient des obligations qui leur sont imposées. (Cir. 227.)

Les procès-rerbaux rapportés par les préposés forestiers pour constater des contraventions en matière de douane doivent être rédigés dans les mèmes formes que ceux qu'ils dressent pour leur service ordinaire; ces actes sont transmis au chef de cantonnement aussitôt après l'affirmation et l'enregistrement.

Il est arcordé à tous les indiridus qui arrètent et concourent à l'arrestation des colporteurs ou rendeurs de tabac de fraude une prime de 1 ว̆ $\mathrm{fr}^{2}$. par personne arrêtée ; mais cette prime n'est acquittée qu'autant que les contrevenants ont été constitués prisonniers. 
Outre cette prime, il est alloué aux préposés étrangers à la régrie des contributions indirectes une gratification extraordinaire de $12 \mathrm{fr}$. par chaque colporteur saisi hors du rayon des douanes et ayant au moins 30 kilogrammes de tabac, et de 3 fr. par rhaque chien chargé de tabac qu'ils amont détruit. Les tabacs saisis doivent itre transportés dans l'entrepot au chef-lieu de l'arrondissement dans lequel la saisie a été effectuée. oì ils sont expertisés pour le prix en itre réparti entre les rerbalisants.

La moitie des amendes payées par les contrevenants est allonée aux employés qui ont opéré la saisie. (Cir. 3วัว, 644.)

Il est allowe une prime de $10 \mathrm{fr}$. pour l'arrestation des persomnes qui fabriquent ou vendent en fraude les allumettes chimiques. (Décrets des 10 anoit 18 i: et 6 aoùt 1895\%.)

86. Roulage, automobiles, bicyclettes. - Lart. 14 de la loi du 30 mai 18.41 confëre anx préposés forestiers le droit de constater les enntrarentions aux reglements sur la police du roulage. La police du roulage est dailleurs un accessoire trop secondaire du service forestier pour quil soit utile dentrer ici dans un examen détaille de la lécrislation en cette matière.

Les voituresautomobiles sont soumises aux rigles ordinaires de la polire thu roulacre. Il n'en est pas de 
mime des rélocipides (bicyclelles, molocyeles, folc.):

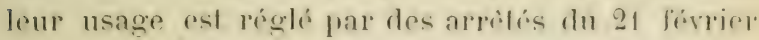
1896 et du 1:̈ juin 1897, donl les dispositions ne snut pas les mèmes que relles de la loi du 30 mai $18 . j 1$. Volamment, le droil de dresser des procres-rerbaux pour contravention a ces arrotris n'apparticnt pas aux préposés forestiers. 


\section{CHAPITRE III}

\section{EXPLOITATIONS}

Permis dexploiter. - Marteau de l'adjudicataire. - Coupe de réserves. - Bris de réserves. - Outre-passe. - Vices d'explnitation. - Travail de nuit. - Dimanches et jours fériẻs. Ecorcement sur pied. - Loges. fourneanx et ateliers. - Feux. Faux chemin. - Musèlement des animaux. - Délais d'exploitation et de vidange. - Dépót illicite. - Délits à l'ouïe de la cogne.e. - Coupes affouagères. - Emploi des Jois de construction et de chauffage. - Bois mort.

87. Les adjudicataires ou entrepreneurs des coupes dans les bois soumis au régime forestier sont assujettis à lobservation de règles sérères pendant tout le temps qui s'écoule depuis la délivrance du permis d'exploiter jusqu’au récolement; les délits ou contrarentions qu'ils commettent sont punis de peines plus graves que ceux des délinquants ordinaires. Ces délits peurent itre constatés par les agents el les gardes pendant toute la durée des exploitations. Ils peurent encore l'etre, mais par les agents seuls, au moment du récolement. 
Le droit que la loi a laissé aux agents de constalen an récolement les contratentions dont les arljudicalaires ont pu se rendre coupables ne dispense pas les préposés de lobligation de surveiller les exploitations, car beaucoup de délits resteraient impunis sils nètaient constatés au moment ou ils viemmenl de se commettre.

Les gardes doivent donc visiter journellement les coupes en usance; ils sassureront que les ourriers n'exploitent pas les arbres désignés pour être réservés, qu’ils se conlorment aux prescriptions du cahier des charges en ce qui concerne l'abatage des bois, etc.; ils signaleront au facteur de la coupe ceux d'entre eux qui, par leur négligence ou leur maladresse, pourraient attirer contre l'adjudicatair' des poursuites onéreuses.

En ces matières surtout, il raut mieux prévenil que punir, et souvent quelques avertissements donnés à propos suffisent pour imprimer aux exploitations une direction convenable.

Nous allons examiner en détail les obligations diverses imposées aux adjudicataires ou aux entrepreneur's qui leur sont complètement assimilés, en faisant connaitre les renseignements que derront contenir les procès-verbaux dressés pour chaque espèce de contravention.

88. Permis d'exploiter. - Les adjudicataires des 
coupes assises dans les bois soumis au régime forestier ne peuvent commencer l'exploitation arant d'aroir obtenu de l'agent forestier chef de service un permis dexploiter, qui leur sera délirré sur la présentation des pièces établissant qu'ils ont satisfait aux obligations imposées. (C. lor., art. 30; Ord., art. 92.) Ce permis est présenté au chef de cantonmement. qui dome l'ordre au garde local de laisser commencer les exploitations.

Les préposés ne derront donc autoriser les adjudicataires ou leurs ourriers à procéder à l'abatage des arjores quautant qu'ils auront reçu cet ordre; si ceux-ci persistent à commencer leur exploitation sans justifier de l'obtention du permis, les gardes derront constater la grosseur, l'essence, le nombre et la valeur des arbres exploités, comme s'il sagissait d'un délit ordinaire; ils ne dresseront toutefois leur procés-verbal quapres s'etre assurés auprès du chef de cantomement de la date du permis dexploiter.

Il pourrait, en effet, arriver que ce permis, quoique non présenté au garde du triage, soit d'une date anterieure au commencement de l'exploitation, el dans ce cas il n'y aurait pas de délit.

Ce délit est au reste assez rare, les adjuclicatairey n'ayant aucun intereit à ne pas se conformer aux reglements sur ce puint; il pourrait cependant so 
presenfer pour les coupes affonagires, dont les enIrepreneurs ignorent somvent les obligations andquelles ils sont assujettis.

Aucun abatage de bois, mème ceux qui seraient nécessaires pour le lotissement des coupes entre les ouvriers, ne doit etre toléré avant la délivrance du permis d'exploitre.

89. Marteau de l'adjudicataire. - L'article $32 \mathrm{du}$ Code forestier, qui imposaità tous les adjudicataires des coupes des bois soumis an régime foresticy lobligation d’avoir un marteau, a été abrogé; mais comme ils ont intérèt à marquer d'un signe parti culier les bois qui sortent de leurs ventes, il est probable que beaucoup d'entre eux se serviront encore de marteaux, seulement ils seront dispensés d'en déposer l'empreinte au greffe et pourront s'en servir à leur guise. Les gardes n'auront done plus à s'occuper de savoir si les adjudicataires ont un ou plusieur's marteaux et comment les acheteurs marquent leurs bois. Ce sont des détails commerciaux dans lesquelsle service forestier u'a plus à intervenir.

90. Coupe de réserves. - L'adjudicataire est tenu de respecter tous les arbres marqués ou désignés pour demeurer en reserve, quelle que soit leur qualification, lors même que le nombre en excéderait celui qui est porté au procès-verbal de martelage, et sans quion puisse admettre en compensation 
d'arbres coupés en contravention d'autres arbres non réserrés que ladjudicataire aurait laissés sur pied. (C. for., art. 33.)

Dans les coupes marquées en réser'e, l'empreinte du marteau de l'Etat est appliqué sur les arbres qui sont exceptés de la rente; dans les coupes en délivrance, au contraire, ce sont les arbres à abattre qui portent cette empreinte; dans certaines coupes, enfin, les arbres réservés ou abandonnés sont simplement griffés ou mìme désignés par leur essence ou leur grosseur.

* Quel que soit le mode de martelage ou de désignation employé, les adjudicataires ne doirent exploiter que les bois qui leur sont abandonnés.

Les préposés veilleront assidùment à ce que les prescriptions des procès-verbaux de martelage soient strictement exécutées.

91. Dans les coupes dont les arbres réservés sont marqués du marteau de l'Etat, griffés ou simplement désignés par leur essence ou leur grosseur, ils constateront l'abatage de tout arbre portant l'empreinte du marteau, criffé on désigné pour la réserve. Le proces-rerbal fera connaitre le numéro de la coupe où le délit a été commis, l'exercice auquel elle appartient, le nom de l'adjudicataire, l'essence et la grosseur de l'arbre ainsi exploité, en mentionnant qu'il faisait partie de la réserve. 
Dans les coupes oi les arbres à abattre sont marqués du marteau de l'Etat, grriffés ou désignés, ils constateront au conlraire l'abalage de tout arlure qui ne portera pas lempreinte du marleau ou la grriffe, ou qui ne sera pas désigné pour ètre exploite; le procès-rerbal contiendra les mèmes renseignements que ci-dessus. (Voir Exemple $n^{\circ}$ 18.)

C'est surtout dans les coupes marquées en délirrance que les adjudicataires peurent faire disparaitre les traces d'une exploitation frauduleuse; c'est sur celles-là que les préposés derront apporter une surveillance plus active.

Les adjudicataires des coupes de bois de l'Etat sont tenus d'ébrancher sur pied les arbres marqués pour la marine et de les abattre de manière à laisser la culée entière. Les pièces rebutées et les éboutures ne leur appartiennent pas, mais ils peurent disposer des branchages. Les préposés s'assureront que l'abatage des arbres réservés pour la marine se fait comme il est prescrit, et ils veilleront à ce que les pièces soient laissées intactes dans toute leur longueur. (Circ. $n^{\circ} 7$, nouv. sér.)

92. Bris de réserves. - Le délit d'abatage de réserves ne doit pas être confondu arec le bris de réserves occasionné par l'exploitation. Les réserves brisées ou endommagées par la chute des arbres voisins sont considérées comme chablis, l'adjudica-

Grye. - Surveillance 
taire est seulement tenu de parer le dommage; il ne peut enlever ni faire exploiter les arbres ainsi hrisés. Les préposés doirent tenir note des accidents de cette nature, marquer de leur marteau les quilles et houppiers des arbres cassés. qui doirent ètre représentés au chef de cantonnement lor'squ'il procede à l'eraluation de l'indemnité due par l'arljudicataire.

93. Outre-passe. - On appelle outre-passe l'exploitation de hois situés hor's des limites de la coupe. Il ne peut y aroir outre-passe que dans les coupes délimities sur le terrain par des lignes ou des hornes, piquets ou corniers. Ce délit, préru par l'article 29 du Code forestier. entraine pour l'adjudicataire une amende imale an triple de la valeur des hois abattus en dehors des limiles de la compe, soils ne sont pras plus agers ni de meilleure nature ou yualité que ceux de la rente. Si les hois sont de meilleure nature ou qualite que ceux de la vente. il paiera lamemle comme pour les hois coupés en délit ef une somme double a litpe de dommagesintérèts.

Le deilit d'outre-passe doit. antant que possihle, itre constate par deux prepo-is. S'il y a incertitude sur la limile rielle de la coupe, il en sera réfiré au chef de cantonnement: dans le cas contraire, le proces-rerbal pourra itre dresses immediatement. 


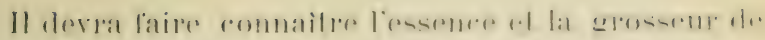

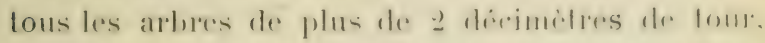
exploites en deleors des limites, la quantitio en chargesthommes, de beites de somme, oll de vollure. des brins de moins de 2 décimitres, la valeur ders hois ainsi exploités. (Voir Exrmple $11^{\circ}$ 19.)

94. Modes d'exploitation. - Les cahiers dere rhareres générales ou spéciales, les procis-rerlatux d'adjuliration mime règlentle moded exploitation; rest par un examen attentif de res locuments et de l'afliche en cahier qui leur est remise que les prepromis pompront se rendre compte des obligations imposios aux entrepreneurs ou adjudicataires.

Les dispositions du rahier des charges grinerales doivent ètre exécutées toutes les fois qu'il n’y est pas dérogé d'une manière expresse par les clauses spéciales ou l'acte d'adjudication.

Celles de ces dispositions qui sont relatives au morle dabatage et de netroioment sont les suivantes:

"A moins de clauses contraires, les bois seront exploités à lire et aire, à la cognée, le plus près de terre que faire se pourat de maniere que l'eau ne puisse séjourner sur les souches; les racines derronl ètre entières.

"Les coupes seront netloyées, saroil : en ce qui concerne le ravalement des anciens étocs el l'enlive. ment des épines, ronces et autres arbustes nuisibles. 
arant le terme fixé pour l'abatage; en ce qui concerne le façonnage des ramier's, arant le $\mathcal{L}^{\text {er }}$ juin de l'année qui suit l'adjudication.

"Les laies séparatives des coupes seront entretenues et les étocs recépés par les adjudicataires. qui, à mesure del'exploitation, feront enlerer les bois qui tomberont sur ces laies, afin quielles soient toujours libres.»

9\%. Ious pensons quen général les préposés doirent sabstenir de constater de leur propre mourement les contrarentions relatires au mode dexploitation. lorsque cette constatation peut être faite par les agents au moment du récolement. Les traces dine exploitation vicieuse subsistent toujours, et cest aux agents plutót qu'aux préposés quil appartient de reconnaitre sil y a lieu d'intenter des poursuites. I.es gardes derront seulement engager les adjudicataires ou leurs facteurs à prescrire aux ourriers de se: conformer aux elauses de leur adjudication, pour ce qui concerne la maniere de couper les bois sur pied, el donner aris au chef de cantonnement de l'état de la coupe.

Il nen est pas de mime pour les contraventions qui ne laissent pas de traces matérielles; si, par exemple, les arlures sont ahattus arant detre éhranchés quand l’ábranchement est prescrit, si lexploitations'effectue en jardinant au lieu d'être faite à 
lire el aire, si l'abalage des laillis ent lait end deux fois, si les racines sont arrachees; s'il est lait usagre de la seie pour l'abalage, fuand l'emploi de cef instrument n'est pas autorisé, les préposés doivent verbaliser. Voir Exemple n" 20.

96. Le nettoiement des coupes, le ravalement des étoes doivent ètre terminés à l'époque fixée pour les délais d'exploitation, e'est-à-dire au 1:jarril, s’il n'est pas autrement stipulé. Les préposés veilleront a ce que les adjudicalaires ne se laissent pas mettre en retard pour ces travaux. Si, malgré les avertissements qu'ils reçoivent, ceux-ci négligent de faire recéper les vieilles sonches ou de faire enlever les épines et autres arbustes, quand cet enlevement est ordonné, s’ils laissent les lignes de coupes encombrées de ramiers, et si le façonnage de ces ramiers n'est pas terminé à l'époque prescrite, le garde dı triage derra constater la contravention par un procès-verbal indiquant exactement en quoi elle consiste et l'importance du préjudice qu'elle a pu causer. (Voir Exemple no 21.)

97. Travail denuit. - Les adjudicataires ne pourront effectuer aucune coupe ni enlèvement de bois avant le lever ni après le coucher du soleil. C. for., art. 33̈.

Cette disposition a pour but d'empècher les ouvriers de s'introduire dans les bois au moment où les délits sont plus faciles à commettre impuné- 
ment: elle sapplique non seulement aux ouvriers employés directement par l'adjudicataire, mais encore anx voiturier's des acheteurs qui chargeraient ou enlèreraient du bois pendant la nuit.

Les procès-verbaux que les préposés peuvent ètre lans le cas de rédiger à raison de contraventions de cette nature doivent indiquer la coupe doù proviennent les bois exploites ou enlevés nuitamment, et le nom de ladjudicataire; car c'est ce dernier qui est mis en cause, et non les ouvriers ou voituriers, upui sont considérés comme agissant daprès ses ordres. L héure vù le délit a été constaté doit ètre indiquée.

98. Dimanches et jours fériés. - 11 est preserit aux adjudicataires par le cahier des charges de sabstenir de faire travailler dans les coupes leurs employés, ourrier's ef roiturier's, les dimanches et jours firicis. sans lantorisation de lagent chel de service. ol de n'employer les ouvriers de nationalité étran. gire yur dans les proportions fixies par les clauses spéciales.

En ca- l'infrartion a ins prescriptions. les gardes doivent rappeler aux adjudicataires les dispositions du cahier des chareges et des clauses spéciales; ils drivent ausi en prirenir le chef de cantomement. anquel il appartient de provoquer, sil y a lien, les simtions provures patr les reglements. 


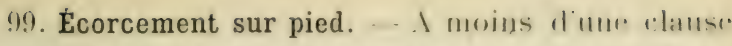
expresse dans le procis-rerbal dadjudication, il est interdit de peler ou écorcer sur pied anrmu des bois de la coupe, sous peine de 50 a 500 franes damencle. (C. for., art. 36.)

L'écorecment sur pied est seul prohibe par cette disposition; les adjudicataires ont le droil de faire écorcer les arbres abattus; mais, si le procis-verbal dadjurlication me mentionme pas quil y a faculté d'écorcement, ils ne jouissent pas de la prorogation de délai d'exploitation accordée pour les coupes ou cette faculté est réservée.

Les procès-verhaux rédigés pour les laits d'écorcement sur pied doirent faire connaitre la quantité et la valeur des hois et écorces ainsi façonnés en délit, et en constater la saisie.

Cette saisie n'est pas effective, cest-i-dire qu'il n'y aura pas lien de faire transporter les hois pelés et les écorces hor's de la rente et de les mettre en séquestre; les gardes se borneront à déclarer la saisie à l'adjudicataire, et à apposer l'empreinte de leur marteau sur les bois et écorces dont ladjudicataire na plus le droit de disposer.

100. Loges et ateliers. - Il ne porrra itre établi de fourneanx, fusses à charbon, loges on ateliers dans les ventes que dans les lieux qui seront indiqués par écrit par liagent forestier, al peine l'uns 
amende de כّ0 francs, pour chaque fosse, loge ou atelier établi en contravention à cette disposition. (C. for., art. 38.)

La désignation de l'emplacement des loges, fourneaux ou ateliers est faite par le chef de cantonnement ou le brigadier délégué; il est marqué un témoin à proximité de chacun des emplacements indiqués; les préposés s'assureront que les ouvriers n'établissent pas leur's atelier's, loges ou fourneaux arant cette désignation, et qu'ils les placent aux lieux prescrits.

En cas de contravention, ils rédigeront un procèsrerbal qui fera connaitre le nombre des loges ou ateliers ainsi élablis sans autorisation.

101. Feux. - Il est interdit aux adjudicataires, entrepreneurs et à leurs facteur's ou ouvriers, d'allumer du feu ailleurs que dans les loges ou ateliers, sous peine d'une amende de 10 à 100 francs, sans préjudice de la réparation du dommage qui pourait résulter de cette contravention. (C. for., art. 42.

Cette disposition s'applique au cas où les adjudicataires ou leurs ourriers allument, sans pour cela Chalile d'ateliers on de lommeanx a charbonner, des leux hors des emplacements désignés à cet effet. La comstatation de cette contrarention ne présente ancune difficulte; il suffira de faire comnaitre que le point où le feu a été allumé n'a pas élé désigné 
pour l'étahlissement d'une loge on d'un fournean. 102. Faux chemins. - Lal traite des bois se fora par les chemins désignés au cahier des charges, sous peine, contre ceux qui en pratiqueraient de nouveaux, d'une amende dont le minimum est de 40 franes et le maximum de 200 francs, outre les dommages-intérèts. (C. for., art. 39.)

Les chemins par lesquels doit s'opérer le transport des produits de la coupe sont indiqués frar le procès-rerbal d'adjudication; ils sont mentionnés dans l'affiche en cahier, dont les préposés ont un exemplaire entre les mains.

Non seulement les adjudicataires ne doivent pas pratiquer dans les coupes des chemins nouveaux, mais il ne leur est mème pas permis de se servir des voies de vidange existantes qui ne leur sont pas signées; ils ne peurent non plus s'écarter des chemins indiqués, quand bien même ils seraient tout à fait impraticables. C'est à eux à faire réparer les dégradations qui en rendent le parcours difficile, ou a s'adresser au conservateur pour obtenir qu'il leur en soit désigné d'autres.

L.es roies de transport dont la désignation doit ètre faite dans l'acte d'adjudication sont les routes forestières, lignes, laies ou chemins de vidange établis sur le sol forestier: mais il nappartient pas à l'administration forestière d'imposer aux adjudica- 
taires des limites a leur droit de libre circulation sur les chemins publics.

Les dispositions de l'article 39 sappliquent aux faits de passage illicite, commis tant par les adjudicataires ou leurs ouvriers que par les voituriers des acheteurs.

Lorsque les gardes constatent des délits de cette nature, leurs procès-rerbaux doivent faire connaitre quels sont les arljudicaiaires des coupes dont les produits sont ainsi enlevés par des chemins défendus, et limportance du dommage causé, s’il y a lieu.

Si les roitures on hestiaux trouves hors des chemins ordinaires nappartiennent pas a ladjudicataire ou a ses ourriers, si elles ne sont pas employées a la traite les hois, le kélit rentre dans le cas yue nous aroms examiné au chapitre $\mathrm{n}$, ș 50 et suivants.

\section{Musèlement des animaux de trait ou de bàt. -} Le cahier des charges délend aux adjudicataires dintroduire ces animaux dans les coupes sans les museler. Linoliservation de cefte précaution renIrant ladjudicataire passible des peines de lart. 199, C. for. Cette contravention doit ère constate par proce-rerbal, dans les mimes conditions que your le délit ordinaire de pàturagge $\left(\mathrm{n}^{\circ} 61\right)$.

10\%. - Délais d'exploitation et de vidange. - Lia 
coupe des bois el la vidange des ventes seroul lidiles dans les delatis fixes par le cahier des charges, it moins que les adjudicataires naient obtenu du conservatem des forets une prorogation de délai, a peine d'une amende de 50 à 500 francs el, en outre. de dommages-intérets dont le montant ne pourra ètre inférieur a la valeur des bois restés sur pied ou gisant sur la coupe; il y aura lieu à la saisie de ces bois a titre de garantie pour les dommagesintérèts.

La constatation des contraventions relatives aux retards dexploitation ou de vidange est plutrit du ressort des agents que de celui des préposés; à moins de prescriptions contraires, ceux-ci ne doivent rédiger les procis-rerbaux relatifs à ces contraventions qu'après en avoir réf'éré au chel de canlonnement.

A moins de dispositions différentes dans le cahier des clauses spéciales ou l'acte d'adjucation, les délais fixés sont, your l'abatage, le 1 ă arril qui suit l'année de l'adjudication, et le suivante pour la vidange.

A la premiere de ces dates, tous les bois de lat vente doivent ètre abattus; la coupe doit être complètement vidée au 1 ă arril de l'année suivante.

Dans les coupes rendues arec laculté d'écorcer, ces délais sont prorogés, pour lahatage, jusqu'au 
$1^{\text {er }}$ juin, et pour le façonnage des ramiers jusqu'au 1 Ju juillet; le délai de vidange reste le mème.

Lorsque les préposés reconnaissent que l'exploitation languit faute dourriers, ils doivent avertir l'adjudicataire de se mettre en mesure, soit en actirant ses travaux, soit en sollicitant une prorogation de délai; c'est surtout aux entrepreneurs des coupes affouagères quil importe de réitérer ces avertissements, car ils ignorent souvent les conditions qu'ils ont acceptées.

Au terme fixé par le cahier des charges, la vidange doit ètre complètement terminée, les copeaux, sciures et autres rémanents doivent ètre enlerés, les loges et baraques démolies et leurs matériaux transportés hors de la forèt. Il ne suffit pas que les bois soient déposés hors des coupes, sur des places vides, chemins de vidange, etc.; il faut qu'ils soient transportés hors de la forêt.

103. - Les procés-verbaux que les gardes peuvent ètre dans le cas de rédiger pour les contraventions de cette nature derront indiquer la valeur des bois restés sur pied, s'il sagrit d un retard dexploitation; celle des bois gisant dans la coupe, sil sagit d'un retard de vidange. Listimalion des bois grisants ne présente aurume difficulte : il suffira de procéder au dénombrement des produits non encore enlerés et d'appliquer aux quantités trouvées les prix de 
la localité. L'estimation des bois restes sur pied peul efre faite par arbere, si la compe a flí marquée en délivrance; dans en cas, le proces-rerhal fera connaitre lo nombre et la valeul des arbres désignés pour etre exploites qui noul pas éte abattus.

S'il sagit d'une coupe marfuée en réserve, les gardes ne pourraient arriver à connaître l'estimation des bois non exploités quà l'aide de calculs qui nte sont pas de leur compétence; ils se borneront, dans ce cas, à faire connaitre le rapport de la surface de la partie non exploitée à la contenance totale de la coupe, en indiquant, par exemple, qu'il reste à abattre le tiers, le quart ou telle autre fraction de la coupe; ils évalueront approximatirement sa raleur.

Le procès-verbal devra constater la saisie des bois restés sur pied ou gisant dans les rentes. Cette saisie n'implique pas le transport et la mise en séquestre des bois ainsi enlerés à la libre disposition de l'adjudicataire, elle est purement nominale ; mais, après que le procès-verbal a été dressé et revètu des formalités légales, l’adjudicataire n’a plus le droit de faire acte de propriété sur les objets saisis. Les bois restant sur pied ne peuvent être exploites; les produits restant sur le parterre de la vente ne peuvent être enlevés. 
106. Dépôt illicite. - Les adjudiøataires ne pourront déposer dans leurs rentes d'autres bois que ceux qui en proviement, à peine diune amente de 100 à 1:000 francs. (C. for., art. 4 4.

Les proces-rerbaux qui constatent cette contrarention fort rare doirent indiquer les circonstanees le ce lépoit illicite et faire connaitre comment il a ité établi que les bois dont lorigine est controrersée ne proviennent pas de la eoupe ou ils sont déposés.

107. Délits à l'ouie de la cognée. - Les adjudicataires sont responsables, non seulement des délits commis tant dans les rentes qu ä l'ouïe de la cognée par les ouvriers, bucherons et roituriers, mais encore de ceux qui sont commis dans le mème périmitre lyar des délinquants trangers; toutefois dans cedernier cas, leur responsabilité cesse si les grardesventes constatent res délits par dos proces-rerbaux réguliers remis a lagent forestier dans le dilai de cinq jours. (C. for., art 40 et 46 .)

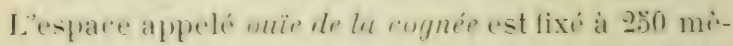
tres a partir des limites de la coupe (t.. for., art. 31); fous les délits rommis dans le rayon ainsi determiné sont rensis l'aroir ele far l'auljulieataire ou se's onvriers, et pour que celui-ci soit lécharge de la pes[unsabilite qu'il enrourt, il faut que son garde-rente les ait constatés régulièrement. 
105. Il ne sulfit pas que lo facfeur informe le gande oul les agents fu'mu délit vient dese commettre; il ust indispensalile quiil duesse lui-même le procèverhal ef quil le transmelfe dans les ciny jours. Ce préposé de l'adjudicataire est spécialement chargé de la surveillane de la compe ef de ses abords : il est présumé y citre toujours présent, et, comme la zone sur laquelle sitend la responsabilité de l'adjudieataire est déterminée par rette considération qur lon peut entendre de la rente les bruits quoccasionnent les délits qui s'y commetlent, e'est à lui quil appartient de les ronstater d'abord. (Voir rhap xur.

Il est évident que, si les délits sont commis par les ourriers de l'adjudicataire, le proces-verbal que dresse le facteur ne décharge pas ce dernier de sa responsabilité.

109. Si les gardes reconnaissent lexistence de délits dont la date remonte à plus de cinq jours dans la rente ou à l'oüe de la cognée, et si ces délits nont pas été constatés par le facteur, ils rédigeront leur procès-rerbal dans la forme ordinaire; seulement ils n'auront pas it en rechercher les auteurs: il suffira d'indiquer qu ils ont été commis dans le rayon de louïe de la cognée depuis plus de cinf jours.

S'ils trourent ies délinquants en flagrant délit, ils indiqueront leurs noms et qualités, afin que l'agent 
supérieur de l'arrondissement puisse les poursuirre directement sil le juge convenable.

Ence qui concerne les délits commis dans les rentes ou à l'ouïe de la cognée, la responsabilité des adjudicataires ne cesse quaprès le récolement.

110. Coupes affouagères. - Les coupes délirrées en affouge aux usagers dans les bois domaniaux et aux habitants des communes propriétaires de bois sont exploitées par des entrepreneurs responsables qui. assimilés complètement aux adjudicataires des coupes rendues, sont soumis aux mèmes obligations qu'eux.

Les hahitants des communes usagères ou propriétaires de bois exploitent souvent eux-mèmes la coupe régulierement délirrée à un entrepreneur responsahle agréé par l'agent chef de service. Cet entrepreneur fictif, puisqu'il ne fait pas opérer à son compte les traraux de lexploitation, est, aux yeux de l'administration, assujetti aux mimes conditions que s'il faisait faconner les bois par des ourriers à sa solde.

111. La loi ne prohibe pas les arrangements qui peuvent itre pris par la commune ou les usagers aree ces entrepreneurs pour diminuer les frais de l'exploitation, mais c'est à la condition que les affouagistes ne feront aucun partage sur pied. La coupe délivrée en hloc doit être exploitée à tire et 
aire, et non pas individuellement par chaque ayant droit; ce n'est quapres lentier abatage des bois qu'il doit être procédé au partage. Tout partage anticipé est puni de la confiscation des bois afférents aux contrevenants; les préposés qui toléreraient ces partages seront punis d'une amende de 30 lirancs, et encourent la responsabilité de la mauvaise exploiLation et de tous les délits qui peuvent aroir été commis. C. for., art. 81. Toutefois, le préfet peut, sur la demande du Conseil municipal el lavis du conservateur, autoriser le partage sur pied. I)ans ce cas, lexploitation se fera sous la garantic de trois habitants solvables, choisis par le Conseil municipal et agréé par le chef de service. Ces habitants sont solidairement soumis à toute la responsabilité qu'aurait à subir l'entrepreneur.

112. Il ne faut pas confondre le partage sur pied arec le lotissement que font les ourriers de la coupe pour répartir le travail entre eux. Ce que la loi prohibe, c'est seulement l'exploitation individuelle par chaque affouagiste des bois qui lui sont dérolus; mais, lorsque aucun des habitants ne sait d'arance à qui reviendront les bois qu'il façonne, puisqu'il ne sont partagés qu'après l'exploitation, il n'y a pas contravention.

Les procès-verbaux que les préposés peuvent ètre dans le cas de dresser pour les délits de partage sur

Griye. - Surverllayce. 
pied doirent faire connaitre les circonstances dans lesquelles ce partage a été fait; ils constateront la saisie des bois ainsi indùment partagés.

113. Pendant la durée des exploitations des coupes affouagères, les gardes nont de relations directes qu'arec les entrepreneurs: c'est à eux qüils doivent adresser toutes les observations utiles pour la bonne direction des travaux; c'est contre eux que doivent être rédigés tous les procès-verbaux de délits commis par des affouagistes employés à l'exploitation dans les coupes ou à l'ouïe de la cognée.

Toutes les contraventions relatives au mode dexploitation, au nettoiement, a la vidange, se constatent comme dans les coupes rendues: cest à lentrepreneur à reiller à ce que les ourriers ou affouagristes quil emploie s acruittent convenablement de leurbesogne; cest a lui à prendre les mesures nécessaires pour que la vidange soit terminée en temps utile. Si lus lots n'itaient pas enleris al'expiration des delais, ejest eontre lui quion deessera procesrerbal et non contre les possesseurs des lots restés dans la vente; cest encore lentrepreneur qui sera mis en poursuite si les affoulgisles noperent pas la traite des bois far les chemins disignis an permis d'exploiter.

Les preposés forestiers nont pas at s'immiscrer dans les questions relatives a la répartition des bois 
entre les affouagisles, an paicment des laxes d'alllouage, a l'enlevement des lots afferents a chatem des ayants droit; cest à lentrepreneur a faire lus lols d'affouage, a veiller à re qu’ils ne soienl enleves quaprès paiement des laxes et par les individus auxruels ils sont dévolus. Les gardes n'ont qu'i soccuper de faire exécuter les lois et riglomenls forestiers; mais, dans les compes affonagères. comme dans les coupes rendues, la délivrance des produits exploités échappe à leur compétence.

\section{4. - Emploi des bois de construction et de chauf-} fage. - Il est cependant des circonstances où l'action de l’adninistration forestière ne cesse pas, lorsque les produits des coupes ont été transportés au domicile des affouagistes.

Les bois qui sont délirrés aux usagers soit pour leur chauffage, soit pour la préparation de leurs maisons, sont affectés à leur usage personnel; ils ne peuvent ètre ni échangés ni rendus, et les bois de construction doivent ètre employés dans le délai de deux ans. (C. for., art. 83 et 84.)

Cette prohibition ne s'applique qu'aux usagers et non aux habitants dos commmnes popriélatres de bois où l'on délive les coupes en nature. Cies dex. niers peuvent disposer, comme ils l'entendent. des bois qui leur sont délivrés.

Les procés-verbaux que les préposés peurent dre 
dans le cas de dresser contre des usagers, à raison de faits de rente des bois délivrés, doirent faire connaitre les circonstances de la rente ou de l'échange et la valeur des bois ainsi vendus ou échangés.

Si les bois de construction n’ont pas été employés dans le délai de deux ans depuis la délivrance, le procès-verbal devra indiquer la date de cette délivrance et constater la saisie des bois, qui, jusqu'après le jugement à intervenir, ne pourront ètre ni détournés ni employés par l'usager.

115. Bois mort. - Ceux qui nont dautre droit que celui de prendre le bois mort, sec et gisant, ne pourront, pour l'exercice de ce droit, se servir de crochets ou ferrements d'aucune espèce, à peine d'une amende de $3 \mathrm{fr}$. (C. for., art. 80.)

116. Ln certain nombre dindividus sont annuellement autorisés, en vertu d'une décision ministérielle du 19 septembre 1853 , à ramasser dans les bois soumis au régime forestier le bois mort gisant. Cette autorisation est accordée aux indigents par le chef de service sur la présentation des listes dres. sées par les maires des communes roisines des torêts.

Les personnes ainsi autorisées sont munies de cartes sur lesquelles sont inserits leurs noms, prinoms, domicile, et les conditions sous lesquelles la permission est accordée. 
Ces cartes doivent ètre prisenties at toute réruisition des gardes.

Si les permissionnaires profitaient de la toléraner quion leur accorde pour couper et briser des bois rerts ou secs, les gardes constateront le délit, car la permission n'a pour objet que l'enlevement du bois mort gisant.

Les porteurs de cartes ne doivent employer aucun lien ou hart provenant des forêts; ils ne peuvent être munis d'aucun instrument propre à couper le bois, à peine d'être poursuivis en vertu des dispositions de l'article 146. (Voir chap. II, § 44.) 


\section{CHAPITRE IV}

\section{CHASSE}

Compritenre - Constalation. - Aftimation. - Saisies. - Yi. -ites doniciliaires. - Arrstations. - Permis de chasse. Temps pruhihi. - Modes le chasse. - Chasses réservées. Drnit de suite. - Cahier des charges. - Observations. - Le l.racomnage, - Dommages ransis par le gribier. - Gratifica. lions. - J.ouveterie, - Battues.

117. Compétence. - Les préposés forestiers sont chargés diassurer lexécution des lois et reglements sur la police de la chasse dans les bois de leurs triages.

La competence des préposis de l'administration forestiore en matière de chasse est limilée aux délits qui portent préjulice aux intérèts quils ont mission de carantir. En général, ils n'ont qualité que pour constater les délits commis sur le territoire forestier compris dans leur triage; cependant ils peurent comstater, quoigue commis hor's du sol forestier. 
eretains délits qui tendent a la destruelion du gibier. provenanl des forets, comme laffiul de nuil ans abords des hois, l'emploi de nappes, collels el autres engins.

La chasse de plaine noesl pas sommise à la surveillance des préposés de ladministration forestiere: les proces-verbanx quils dressent pour des dilits de cette nature ne sont considérés que eomme de simples renseignements, sulfisants cependanl pour servir de fondement à des poursuites.

Les gardes des forits de l'Elat et des communes ne se détourneront pas de leur service pour rechercher, hors des bois qu'ils surveillenl, les délits qui ne portent pas une atteinte directe à la conservation du gibier des forêts; si rependant ils se trouvent, dans leurs tournées, en présence de contrerenants, leur devoir, comme officiers de police judiciaire, les oblige a constater les infractions aux lois sur la chasse, quand mème elles seraient sans intérèt au point de rue spécial de la surveillance qüils exersent sur les forèts.

Les gardes des particuliers dont la compétence s'étend à la fois sur des bois et des terres surveillent la chasse sur toute létendue des propriétés pour lesquelles ils sont commisciomnés.

118. Constatation. - La constatation des contraventions aux lois ef règlements sur la chasse est 
soumise à toutes les règles indiquées au chapitre Ior, saul les modifications suirantes.

119. Affirmation. - L'affirmation des procès-rerbaux sera faitedans les vingt-quatre heures du délit. (L. Chasse, art. 24.)

Ces procès-rerbaux derront donc indiquer l'heure de la constatation du délit, et l'acte d'affirmation devra renfermer la preuve que cette formalité a été remplie dans les délais voulus.

120. Saisies. - Les délinquants ne pourront être saisis ni désarmés. (L. chasse, art. 2У.) Cette disposition, insérée dans la loi pour ériter des conflits dangereux, s'applique seulement à la saisie faite contre la volonté des chasseurs; si ceux-ci remettent de plein gré les armes, les préposés agiront comme il a été indiqué au chapitre $1^{\mathrm{er}}, \S 22$. Si la saisie n'a pas été réellement effectuée, les procèsverbaux feront connaitre la nature des armes ou engins laissés entre les mains des délinquants; ils en donneront la description exacte et feront connaitre leur valeur.

Le siniple soupcon ne peut, mème dans une forèt, antoriser le garde à fouiller les vêtements d'un individu porteur d'engins de chasse prohibés ; le procés-rerbal coristalant la saisie d'engins découverts par suite d'une telle perquisition est nul comme enlaché d'abus de pouvoir. 
121. Visites domiciliaires. - Les préposís sont antorisés a faire, avec l'assistane des fonctionnaires désignés au rhapitre $1^{\mathrm{er}}$, $\$ 22$, des visites domiriliaires chez les aubergistes, restaurateurs, marchands de comestibles, pour la recherche du gibier mis en rente quand la chasse est close.

122. Arrestations. - Les gardes arrèteront les délinquants déquisés ou masqués et les délinquants inconnus; s'ils refusent de faire connaitre leurs noms ou s'ils n'ont pas de domicile connu, ils seront conduits immédiatement derant le maire ou le juge de paix, qui s'assurera de leur individualité. (L. chasse, art. 25.)

123. Permis de chasse. -- Nul ne peut chasser s'il ne lui a été délivré un permis de chasse. (L. chasse, art. $1^{\mathrm{er}}$.)

Ces permis sont accordés par les préfets et souspréfets; ils sont valables pour une année.

Il a été décidé que le délai d'une année pendant lequel le permis est valable commence à partir du lendemain de la date du permis; par conséquent, un permis daté du 28 août est valable jusques et y compris le 28 aoùt de l'année suirante.

La quittance délirrée par le percepteur pour constater le paiement du prix du permis ne peut remplacer ce permis.

Le permis de chasse doit être présenté à touteré- 
ruisition des gardes. Il est exigé non seulement four la chasse au fusil. mais enore pour les chasses qui se pratiquent à l'aide de pieges, tendues. gluamx, etc. Toutefois, il nest pas obligatoire pour les personnesqui se bornent à aider, par leur travail ou leur surveillance, un chasseur muni d'un permis de chasse.

Les préposés sassureront si les chasseurs qu'ils rencoutrent sont munis le permis réguliers. Ils riclameront l'exhibition de ces permis et rérifieront s ils ne -out pas périmés, s’ils sont réellement délirrés aux individus qui en sont porteurs, ce dont ils pourront sassurer, quand ils $n \geq$ comnaissent pas personnellement les chasspurs, au moyen de l'examen du signalement inscrit en marge du permis. Si res actes prexentent quelyues signes de grattages ou de sureharges, ils les retientront ef les joindront à leur procès-verbal.

Les procés-rerbaux dressés pour les délits de chasse sans permis feront connaitre, apres les indications relatives au lien, a l'heure ol aux personnes, l'espèce d'arme, engins. les pipges et chiens employés par les chasseurs. - Les armes doivent être exactement. dérrites et lemr valeur alproximative doit mème stre indiquée. (Voir Exemple n" 2.3.)

12't. Temps prohibé. - Nul ne peut chasser si la rhasce n'est ourerte. (L. chasse, art. 1er.) Lépoque 
de louverlure at de la clobure de la chasse esl lisere

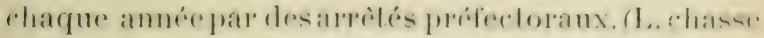
art. 3.)

Les préfets déterminent par des arritis to temps pendant lequel il serapermis de chasser les oiseaux de passage, lo gibier dieau dans les marais, sur les blangs, fleures et rivieres; ils peurenl aussi, par leurs arrètés. interdire la chasse en temps de neige, (L. chasse, art. 9.)

Les préposés prendront eomnaissancerie cesriglements et en assureront l'exécution.

Il est particulièrement recommandé aux préposés de veiller à la conservation des oiseaux utiles à l'agriculture en s'opposant à la destruction des nids et couvées.

Ils constateront tout fait de chasse acempli pendant le temps ou la chasse est interdite.

Leurs procès-verbaux contiendront tous les renscignements indiqués au paracraphe précédent.

120. Modes de chasse. - La chasse de jour à tir ct à courre est seule autorisée d’une manière générale. Cependant l'emploi de furets et bourses est autorisé pour la chasse du lapin, et les préfets peuvent permettre certains modes spécianx pour la chasse des oiseaux de passage. (L. chasse, art. 9.)

L'examen de ces règlements locaux, dont ils doivent avoir un exemplaire, permettra aux préposés 
de connaitre les procédés de chasse permis et de constater les contraventions. (Toir Exemple $n^{\circ}$ 24.)

126. Chasses réservées. - Nul n'aura la faculté de chasser sur la propriété d'autrui sans le consentement du propriétaire oul de ses ayants droit. (L. chasse, art. $1^{\mathrm{er}}$.)

Le droit de chasse, dans les bois soumis au régime forestier, appartient à l'État, aux communes ou aux établissements publics.

Ce droit est concédé par adjudication à des fermiers qui peurent seuls l'exercer.

Si la chasse n'est pas amodiée, elle sera interdite d'une manière absolue.

Les procès-verbaux d'adjudication déterminent le nombre des fermiers, co-fermiers et des personnes qu'ils peuvent s'adjoindre.

Les gardes reilleront à ce que la chasse ne soit exercée que par les fermiers et les personnes, en nombre déterminé, auxquelles ils ont donné des permissions de chasse érrites, spéciales ct nominatives. Ils rerbaliseront contre tout individu chassant dans les forêts n'étant ni fermier ni permissionnaire. Ils rerbaliseront aussi contre les fermiers qui auraient délivé des permissions en nombre supérieur à celui qu'autorise leur procès-verbal d'adjulication.

127. Droit de suite. - Le droit en vertu duquel tout chasseur pouvait suivre et chasser, mème sur 
le terrain d'autrui, le gribier lancé par des chiens courants a été abrogé par la loi dı 30 avril 1790. L'ancien droit de suite est aujourd'hui restreint a la laculté, pour le chasseur au chien courant, de suirre ses chiens dans les propriétés non closes, dans le but de les rompre, par conséquent sans les appuyer, sans faire enfin acte de chasse. - Si le passage des chiens occasionne un dommage, le chasseur en est responsable.

128. Cahier des charges. - Le cahier des charges de ladjudication de la chasse dans les bois domaniaux impose aux fermiers l'obligation d'être munis, indépendamment du permis de chasse, d'un permis spécial délivré par l'agent forestier chef de service. Ils seront tenus d'exhiber ce permis à toute réquisition des préposés. (Cahier des charges, art. 17.)

129. Observations générales. - Les procès-verbaux dressés pour délits de chasse indiqueront clairement la nature des infractions qu'ils ont pour but de constater.

Ces infractions peuvent ètre distinctes, quoique simultanées. Ainsi, un individu, chassant en temps prohibé, sans permis, dans un bois où il n'a pas le droit de chasser, commet en même temps trois contraventions différentes. Le rédacteur du procès-verbal devra mentionner avec soin toutes les circonstances qui caractérisent ces diverses infractions. 
130. Le braconnage. - Le braconnage doit ètre l'objet d'une surveillance actire; les préposés parcourant les lisières des bois examineront arec soin les passées où peuvent ètre placés des collets; sils reconnaissent une tendue, ils ne la détruiront pas immédiatement, mais ils s'établiront en embuscade pour saisir l'auteur en flagrant délit.

131. Les préposés se croient toujours obligés d’interpeller directement les chasseurs pris en flagrant délit et de leur déclarer procès-verbal.

Cette interpellation directe, qui est ordinairement sans danger lorsqu'elle est faite à des délinquants forestiers, devient parfois la cause de conflits sanglants lorsquielle s'adresse à des bracomiers.

Presque lous les assassinats qui ont amené des chasseurs au bagne ou à leéchafaud ont été commis au moment ou les garles, arrivés à peu de distance des délinquants, commençaient à prononcer les mots sacramentels : Je le déclare procés-berbul.

On ne saurait trop répéter aux prépost's de tout grade qu'ancune disposition de la loi ne les oblige a exposer leur vie pour faire cette inutile déclaration.

In délit peut etre trés dument conslaté sans fute le redacteur du proces-verbal ait dit un mot, sans qu il se soit mime montré au délinquant.

Dinsi un garde qui, sélant eaché dans un buisson. 
voil en aclion de rhasse un fracomber qu'il fereonnait, peul partaitement rester coi ot rédiger le soil son procès-verbal.

Le hraconnier ne satura qu'il a cite vu qu'en recevant son assignalion, mais il sera condammé tont aussi bien que si le garde se fùl dressé subilement. devant lui pour déclarer, au risfue dese laire assassiner, qu'il va dresser procès-verbal.

Au lieu de se précipiter imprudemment à la poursuite des chasseur's, les gardes arriveront hien plus surement à leurs fins rn les observant sans s* monlrer, en s'embusquant sur leur passage pour voir leurs traits et en les suivant jusque dans les villages, oì il sera facile de sassurer de leur identité.

Par une circulaire en date du 12 juin 1888, la dilection des forèts a bien lurescrit aux gardes qui constatent un délit de chasse de déclarer verbale. ment leur procès-verbal au délinquant toutes les fois qu'ils peuvent s'approcher de lui et de mentionner sur leur procés-verbal que celte déclaration a été faite.

Cette prescription, qui a pour but de permettre à ladministration de requérir le cumul des peines, dans le cas où le braconnier serait poursuiri pour un noureau délit, est conlorme à la jurisprudence : elle est recommandée par une circulaire du 12 juil 
let 1889. Nous pensons néanmoins quil vaut mieux laisser aux braconniers la chance d'éviter une aggraration de peine que d'exposer les gardes à receroir un coup de fusil pour déclarer au délinquant qu'ils lui dressent procès-verbal.

132. Le braconnage le plus difficile à réprimer est celui qui se pratique la nuit, soit à l'affùt, soit arec le filet dit drap de mort.

Les affùteurs, postés sur les lisières des bois, attendent le gibier au moment où il ra au gagnage dans la plaine; ils tirent presque à coup sùr. cachent de suite l'animal tué et l'arme dont ils se sont servis, puis ils viennent plus tard chercher leur fusil et leur gibier.

Quand les gardes entendent, quelques instants apres le coucher du soleil, un coup de fusil sur la lisiere des bois, ils peurent ètre surs que cest un affuteur qui vient de tirer. Il est presque toujours inutile de courir dans la direction du coup. Le chasseur sera loin quand le garde arrivera. C'est en allant se poster prés des chemins qui conduisent aux cabarets fréquentés par les braconniers que les gardes ont le plus de chance de les voir rentrep la nuit arec le produit de leur chasse.

Les plus dangereux des bracomiers sont les panneauteurs, qui ront, au nombre de quatre ou ciny, tendre leurs filets dans les chasses les plus gi- 
boyeuses. Cesont des hommes déterminés, qui font. du hraconnage une industric lucraive; ils emploient des filets dont le prix est éleve, et ils ne reculent. pas devant un crime pour éviter de les voir saisir.

Quand les individus qui se livrent à ce mode de chasse ont jeté leur dérolu sur un canton que leurs affidés leur ont signalé comme giboyeux, ils vont pendant la journée le visiter avec soin, puis, la nuit venue, ils déballent le filet qu'ils ont expédié à l'avance et ils le traînent sur les plaines qu'ils dépeuplent en une seule nuit.

Comme ces panneauteurs sont le plus souvent étrangers au pays, qu'ils arrivent à l'improviste, il est difficile de se mettre en garde contre eux. Un homme isolé qui se risquerait à les poursuivre quand ils sont en chasse affronterait un véritable danger. Quand les gardes s'aperçoivent que des étrangers rôdent dans les chasses réservées, en étudiant la configuration du sol ; quand ils savent qu'il y a des relations entre ces visiteurs d'apparence suspecte et les cabaretiers connus pour servir de recéleurs, ils devront prévenir sans bruit les gardes voisins; quand ils se seront assuré leur concours, ils iront, en nombre et bien armés, s'embusquer dans les fossés et attendront le moment opportun pour se montrer. S'ils jugent qu'il y a danger à le faire, ils laisseront les braconniers terminer paisi-

Grye. - Surveillance. 
blement leur chasse, mais ils établiront une surreillance continue pour saroir où ils ront remiser leurs filets et leur gibier, afin de pouvoir opérer à coup sùr la saisie des coupables et des engins dont ils se sont servis.

- Le procédé suivant que nous empruntons au journal officiel de la Société des chasseur's de France nous parait tres propre à écarter les bracomniers.

Chaque nuit, sur chaque chasse, tournée du garde, seul ou accompagné.

Consigne formelle aux gardes, fussent-ils en nombre, de ne point chercher à prendre les filets.

crdre formel d'emporter une trentaine de cartouches, au moins, et plusiemrs gros feux de bengale rouges et verts.

Les montres de tous les reilleurs sont d'aceord. A certaines hemres convenues ils tireront chacun un comp de fusil. A d'autres heures convenues, ils allumeront des feux de bengale dont la couleur signifie: toul est tranyuille, tandis que. d'une autre teinte, ils voudraient dire : alerte! danger!

Les bracomniers sont-ils bien récllement là?... Consigne formelle au veilleur de battre en retraite. mais en tirant quantité de coups de fusil, tout en se rapprochant du cóté ou il sail trouver du secours et d'où répondent. sympathiquement. les fusils des autres veilleurs. 
A lui seml, aree vingl rompe le fusil rharges a la pondre noire, ef tirés en moins de dis minules, re veilleur assure un trerilile tapage qui dreange fout le gibier à deux kilometres a la ronde, fait hurlel. les chiens et lerep les villageois, et rend impossilite le succes du pamean, lors mome que les baronniers ne seraient pas démoralisis et ne s’enfuiraient pas.

Combien de nuits manquées faudrait-il aux braconniers pour les dégonler du métier?

Très peu, car les frais sont énormes.

Quant au chasseur, son hut aura été atteint ainsi sans danger pour le garde, et sans dépenses sensibles.

Le panneautage ne se pratique aisément que dans les plaines nues; il suffit de quelques buissons pour empècher l'emploi du drap de mort; la conservation des haies et des brousailles est done le moyen le plus sùr d'éloigner les panneauteurs.

Dans les pays de grande culture, où les haies vives ont disparu, les propriétaires des chasses font planter çà et là des branchages d'arbustes épineux; c’est ce quion appelle épiner. Cette précaution est utile, mais il faut que ces obstacles artificiels soient tris multipliés, sans cela les panneauteurs peurent sans grand peine les enlerer arant de trainer leur. filet. Il serait bien plus arantageux de conserver 
quelques arbres épars et des touffes d'arbrisseaux sur les points où ils peurent croitre sans dommage pour les récoltes.

133. Dommages causés par le gibier. - Quand les gardes s'aperçoirent que le gibier des chasses louées est derenu trop alıondant et qu'il cause des dégâts dans les bois, ils doivent en donner avis à leurs chef's, afin que ceux-ci mettent les locataires en demeure d'arrèter cette multiplication exagérée.

Les riverains des bois réclament souvent des indemnités à raison des dommages que les lapins causent aux récoltes. Ces réclamations sont quelquefois justes, mais sourent aussi elles sont très exagérées. Il y a mème des cultirateurs peu scrupuleux qui accusent les lapins d'aroir déroré des récoltes qui n’ont jamais été semées. Ceux-là labourent tant bien que mal les terres quils ont à proximité des lıois, ils y jettent de mauraise fenasse, puis au printemps ils font passer les moutons sur les terres ainsi ensemencées. Comme le peu d herbe qui a levé est abrouti, le proprictaire attribue le manque de récolte aux lapins, il demande une expertise, jette par précaution quelques poignées de repaire de lapin dans ses champs et finit souvent par obtenir une indemnité.

Les garles soncieux des intérits de ceux qui les emploient déjoueront aisément ces ruses, s'ils exa- 
minent de pris les procédés de cullure des riverains comnus pour abuser de leur situation. Dis ru'ils auront conçu quelques doutes sur la légitimité des plaintes, ils préviendront le propriétaire de la chasse et lui feront connaitre les moyens employés pour lui extorquer des indemnités exagérées.

134. Gratifications. - Les préposés forestiers qui constatent des infractions à la loi sur la chasse reçoivent une gratification de 10 franes par condamnation prononcée. (Circ. 430.)

Il ne peut itre alloué qu'une seule gratitication, lors mème que plusieurs gardes auraient concouru à la rédaction du procès-rerbal constatant le délit. En cas de condamnation prononcée, mème solidairement, pour la mène infraction contre plusieurs prévenus, il y a lieu à autant de gratifications qu'il y a de délinquants.

La gratification est mandatée par le préfet sur. la proposition de l'inspecteur. S'il y a eu transaction avant jugement, l'extrait de la décision qui :ıtorise la transaction suffit pour assurer aux prér,osés le paiement de la gratification qui leur est d te. Cet extrail est fommi par l agent forestier chef de service.

133. Louveterie. - Les lieutenants de louvele.ie ont le droit de chasser deux fois par mois et à cour re le sanglier dans les bois domaniaux de leur circons- 
ription. Ils ne penvent exercer re droit que pendant que la chasse est ouverte.

Les fermiers et co-fermiers peurent détruire, mais au moyen de pioges seulement, les animaux nuisibles, dlans le temps où la chasse est prohibée.

Les préposés ne sopposeront pas à lexercice de ces droits.

136. Ils doivent de leur còté cherrher à détruir', soit au moyen de prèges soit arec des appats empoisonnés. les loups, renaris, putois, fouines et chats sauvages.

Quiconque a détruit un loup ou une loure non pleine a droit à une prime de 50 francs: la prime est de i.j france pour une louve pleine, de 20 francs pour un loureteau animal pesant moins de 8 kilogrammes); elle est le 100 franc-s il est prouré que le loup s'est jeté sur des fitres humains. (L. du 31 mars 1903, modifiant celle du ‘ avril 1882.) La demande de prime doit stre écrite sur papier timbré et présentev dans les vingl-quatre heures, arec le corps entier du loup, an maire de la commune sur le territoime de laquelle il a titu tué. C'est seulement apres la rérification faite par le maire que le réclamant peut fare céponiller laninal pour en garder la

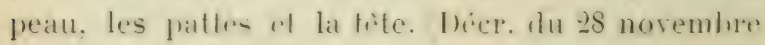
1882.)

13i. Battues. - Lorspre le- billtues seront ordon- 
nées par le prélet, les préposís forrentiers y s.ponf appelés; ils dirigeront les raballems of weilleront i a a. qu'on ne tire que sur les animaux derelarés muisihlus.

Les préposés devont prendre toutes les mesures nécessaires pour la reussite de cens chasses: ils ac:compagneront les piqueurs ou, à lemr délant, foront le hois au point hu jour, pour relenver l'enereinte ou sont remis les animanx signalís; ils placeronl les tireurs, en prenant toules les présaulions possibles pour éviter les accidents,

Les gardes de ladministration rom onrent ainsi aux battues ordonnées par le préfel, mème en dehors des bois soumis au régime forestier. Lem présence est absolument nécessarre pour que la batlue soit régulière.

Si le lieutenaut de loureterie prend part à la battue, la dirertion de lopération lui appartient, ef le garde n'est plus chargé que de la surveillance des délits qui pourraient ètre commis, pour inobservation des conditions de larrêté préfectoral.

Dans les battues aux loups et aux sanglier's que les maires peurent organiser en temps de neige L. du כ̆ arril 1884, art. 90), la présence des gardeforestiers de l'administration n'est plus nécessaire: ils doivent néanmoins s'y rendre lorsque ces battues sont faites dans les bois snumis an régime lorestier. 


\section{CHAPITRE V}

\section{PÊCHE}

Droit de pèche. - Cours deau non navigubles ni flottables. Étangs. - Gardes particuliers. - Cours d'eau navigables et flottables. - Partage d'attributions. - Adjudications. - Gardespêche. - Constatation des délits. - Saisies. - Pèche sans autorisation. - Pêche à la ligne. - Liğne flottante. - Lignne dormante. - Ligne volante. - Barrages - Appareils de pécherie. - Filets fixes. - Empoisunnement. - Reisidus industriels. - Rouissage. - Temps prohibé. - Pìche de nuit. - Exceptions. - Cantons réservés. - Engins prohilués. - Exception- - Modes de pèche interdits. - Dimensions des poissons. - Port dengrins prohibés. - Visite des bateaux. - Vente et colportage. - Exceptions. - Péches louées. - Visite les bateaux. - Pêches extraordinaires. - Inscription maritime.

138. Droit de pèche. - Les propriétaires riverains des cours d'eau qui ne sont ni navigables ni flottables ont, chacun de son côté, le droit de pêche jusquau milieu du cour's de l'eau. (L. de 18:9, art. 2.)

Ce droit est exercé au profit de l'État, sur les tleuves et rivières depuis le point où ils sont navi- 
gables ou llottables par trains ou radeaux et sur les canaux dont l'entretien est a la charge de l'Étal, jusqu'aux limiles de l'inscription maritime. Ce droit s'étend sur les bras, nones, boires et fossés qui tirent leurs eaux des rivières navigables ou flottables et dans lesquels on peut, en tout temps, pénétrer librement en bateau de pècheur. (L. de 18\%9, art. $1^{\mathrm{er}}$.)

Dans les limites de l'inseription marilime la pèche est libre en ce sens qu'elle s'exerce sans fermage ni licence, mais sous la condition que celui qui s'y livre soit inscrit sur les matricules de l'inscription maritime et qu'il se conforme aux règlements de police. (Décret du 9 janvier 1852.)

Il n'y a, pour les préposés chargés de la surveillance de la pèche, aucune difficulté à connaître les points précis où les cours d'eau deviennent navigables ou flottables et ceux où ils entrent dans le domaine de l'inscription maritime, car ces points sont fixés par des signes apparents.

\section{Cours d'eau non navigables ni flottables.}

D'après l'art. 2 de la loi de 1829 , chacun des riverains des cours d'eau non navigables ni flottables a le droit de pêcher jusqu'au milieu du cours d'eau : il s'en suit que si les deux rives d'un cours d'eau, ruisseau ou rivière, appartiennent au mème propriétaire, son droit s'étend sur toute la largeur du 
cours deau. Lorsque les ruisseaux ou rivières non navigables ni flottables traversent ou bordent des forèts domaniales ou communales. l'État et les communes ont, comme de simples particuliers, leur droit de péche sur ces cours d'eau.

Le droit de pèche reconuu aux riverains est absolu en ce sens quion ne peut y prendre du poisson. de quelque manière que ce soit, sans le consentement le celui auquel la piche appartient. Ainsi la pèche à la ligne ne peut mème pas ètre pratiquéc dans ces cour's deau sans lassentiment des proprićtaires riverains.

Mais la pèche y reste soumise à toutes les dispositions de police édicties par la loi de 1829 pour la conservation du poisson.

Il en est de mème de la pèche dans lés canaux creusis dans des propriétis privés et entretenus par les propriétaires.

140. Etangs. - Les lispositions de la loi de 1829 ne sont pas applicables a la peche des citangs qui, est completement libre. Ainsi on peut y pècher en toute saison, la nuit comme le jour, et par tous les moyens.

Les poisons provenant ditangs peurent itres colprortés et mis en rentr quelle quesoit leur espece of quoiruails naient pas les dimensions réglemenfaires. 
Mais il lant pour cela qu'il sagrisse dialange completement fermés on equre closes, et nom de ceux qui ne sont que l'épanonisiement dim cours deau dont la refentere forme more masse dean a laquelle les regles de police de la loi de 1829? peuvent ère applicables. Certaius de cos changs jouissent d'une immunité de lail résultant de l’in certitude produite par lahsence d’une définition légale; avant de dresser des procés-verbaux daus des eaux où la loi de 1829 n'a pas encore été appliquée, les gardes doivent consulter leurs chefs et n'agir que d'après leur's instructions.

141. Gardes particuliers. - Les propriétaires rivelains peuvent avoil des gardes spécialement chargés de la pèche ; ils peurent ansis rommissionner le même individu comme garde-chasse, garde forestier. et garde-pèche. Ils penvent mème se réunir pour ronférer au mème garde la surveillanere de la pèche dans leur's propriétés.

Ces gardes-pèche sont en tout assimilés aux gardes forestiers des particuliers. L. de 1829, art. 6วั.)

142. Cours d'eau navigables ou flottables. - L'Étal, à qui appartient le droil de feche sur les flenrex, rivières el ranaux navigables ou flotlables, jouil du même droil sur les nones, boires et fossés qui en sont les dépentances. L. 1829, ar. 1.) Mais, pom 
qu'il ait ce droit, il faut qu'un bateau de pècheur puisse pénétrer dans ces laisses d'eau, en tout temps. mème par les plus basses eaux. Si cette condition n'est pas remplie, le droit de pèche appartient aux riverains. Ce droit des riverains subsiste mème dans le cas où la noue resterait en communication avec la rivière, mais par un canal trop peu profond pour laisser passer un bateau de pèche.

\section{Partage d'attributions. - L'exploitation et la} police de la pèche se partagent entre deux administrations: a celle des ponts et chaussées sont attribués les canaux et les parties canalisées des fleures et des rivieres: l'Administration des forèts est chargée de l'exploitation et de la surveillance des parties non canalisées des cours d'eau navigables et flottables. C'est à clle qu'incombe spécialement la charge de faire observer les regglements de police sur les cours deau dont la pèche appartient aux riverains. (Décret du 7 novembre 1896.

Le partage des fleuves, des rivièr's et des canaux entre les ponts et chaussées et les forêts a été fait de concert entre ces deux services. Les limites des cantonnements de peche sont indiqueses par des po. traux qui ne laissent ancme incléision.

La preble dont l'Etal es proprichate est affermie a son profit par adjudication on par roie de licence si ladjudication a élé lentée sans succès. 
144. Adjudications. - Ces adjudirations sonl failes suivant les règles sprériales a charmone des alministrations entre lespuelles sont partageis les rourc d'eau. Les condilions en sont fixces par des cahier's des charges dont chaque préposé doit avoir un exemplaire.

14ว. Gardes-pêche. - Les gardes-peche rommissionnés par l'Arministration des ponts el rhanssées et les éclusiers sont chargés de la police des parlies des cours d'eau et des canaux affectés à ce service.

Les gardes-pèche et les gardes forestiers font la police des autres cours d'eau. Nous renvoyons au chap. vir tout ce qui concerne le personnel de ces préposés.

146. Constatation des délits. - Les règles générales tracées dans le chapitre I $^{\mathrm{r}}$ au sujet de la rédaction des procés-verbaux, de l'affirmation, etc., sont applicables en matière de pèche. La seule différence consiste en ce que les gardes-pèche ne peuvent, sous aucun prétexte, sintroduire dans les maisons et enclos y attenant, pour y rechercher les filets ou engins prohibés. (L. de 1829, art. 40.

147. Saisies. - Mais ils peuvent saisir sur les routes et dans les lieux publics les filets et engins ainsi que le poisson pris en délit.

Les gardes qui ont saisi les poissons doivent porter sans délai leur procès-verbal régulièrement 
affirmé au juge de paix ou au maire qui feront procéder à la rente ou, sil y a urgence. à la délivrane a un établissement de bienfaisance. L. de 18:9 art. 42.)

Après les remseignements comernant l'hemre, le lieu du délit. le nom et le domirile du délinquant, son àge, ete. le rérlartem du prorès-rerbal devra inclirpuer l'espere de filet on d'engin employé et la dimension des mailles du filet. Il indipuexa en outre l'espèce et la longueur du puison rajituré. Toir Exemple $n^{\circ}$ 20.)

148. Gratifications. - Les cramles qui ont dressé des proves-rerbaux en matiere de perche fluviale peuvent obtenir des gratifrations dans les mèmes conditions qu'en matiere de rhasse $n^{\circ} 13$ t ; senlement le taux est différent. Il est le g franrs pour un délit de probe ordinaire, le ö franes pour un délit de

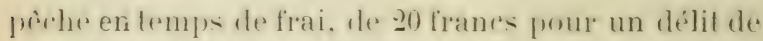
pèche la nuit. enfin de 2.j franes pour un lélit de pèrhe la muil rn temps de frai, jour rmpoisonnement de rivieres, pèche a la dynamite on antres matieres explosibles. L. du 13 arril 1898

149. Pèche sans autorisation. - Tout individu yui se livereat a la prohe sans la permision de celui a

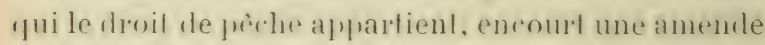
de 20 a 100 franes. Il doit ètrecondamné a la restifution du prix du poissnn perche en délit. La confiscation 


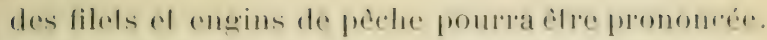
(I. 1829, art. 5.)

Les permissions de pecher dans les coms dean non navigables ni floflables sont domnéps par low riverains ou lems ayants droit. Celles qui roncerpnent les flemves of rivieres navigables ou flollables dont la pèche as affermée, sonl données par les fermiers; olles ne sont valables que si elles sont visées par l’inspecteur des fords on l'ingénieme en chef. Il en est de mème des lirences délivrées en ras d'insuccès des adjudications.

150. Quoique lart. 36 de la loi de 1829 donne aux gardes-poche de l'administration des forêts, aussi bien quà ceux qui dépendent du service des ponts el chaussées, le droit de constater les délits de pèche sans autorisation, quand ils sont commis sur les cours d'eau dont la pèche appartient à des particuliers, nous pensons que ces préposés doivent laisser aux gardes des particuliers, aux gardes champêtres et aux autres officiers de police judiciaire le soin de constater ces délits qui portent atteinte à des intérêts privés.

Les gardes de l'administration ne sont. en effet, pas en mesure de saroir à qui appartient le droit de pèche sur les petits cours d'eau et si ceux à qui ce droit appartient ne l'ont pas cédé soit gratuitement, soit à prix d'argent. 
C'est seulement dans le cas où ils en seraient reruis par le propriétaire qüils peuvent utilement intervenir. Mais ils doivent, sans aftentre d'y etre invités par le propriétaire du droit de pêche, constater toutes les contrarentions aux règlements sur la pèche, qui se commettent sur les cours d'eau non navigables ni flottables.

15̈1. Pêche à la ligne. - Il est permis à tout le monde de pècher à la ligne flottante tenue à la main dans les fleuves et rivières navigables et flottables, le temps de frai excepté. L. de 1829, art. วั.)

Le législateur n’a pu accorder cette liberté que sur les cours d’eau du domaine public, c'est-à-dire sur ceux qui sont navigables et flottables. Quant aux cours deau dont la pèche appartient aux riverains, la pèche à la ligne ne peut y ètre pratiquée qu'arec le consentement du riverain.

15.. Ligne flottante. - La ligne est dite flottante parce quelle est en général munie d'une flotte. Mais lexistence de cette flotte n'est pas indispensable pour caractériser la ligne dont l'emploi est permis. En fait, toute ligne, même dépourvue de flotte et garnie de plombs, est permise si l'amorce dont elle est chargée n'est pas fixée au fond de l'eau et si, d'ailleurs, elle est attachée à une canne destinée à ètre tenue à la main. Le pècheur n'est même pas obligé de tenir toujours cette canne à la main, il 
peut la poser sur le sol, a ses colies, ef ne la relever que s'il roil au momrement de la llotle qu'm poinson a mordu à l'hameçon.

153. Ligne dormante. - Lexperesion de ligne: 17,1lante est usilée par opposition à celle de ligne dor. mante qui sapplifue à un engin composé d'une rordelette plus ou moins forte, it larpuelle sont altachés des hamecons garnis dappals. souvent vivants, celle ligne est allaches anx ravines des arbres du rivage el munic de plombs qui la mainliennent au fond. Elle est placée le soir el relevée à laurore.

La ligne dormante n'est pas un engin prohibé, mais elle ne peut ètre employéc que par les porteur's de licences, fermiers de la pèche. el les personnes auxquelles ils doment des permiscions; si, d'ailleurs, ce mode de peche nest pas interclit par les arrêtés préfectoraux.

13\%. La ligne volante, dont l'apprat est le plus souvent une mouche naturelle ou artificielle, est considérée comme flottante.

Les pècheurs à la ligne se servent, pour amener à borl le poisson pris à l'hamegon. d'un petit filet connu sous le nom d’épuisette. L’emploi de l'épuisette est permis et il n'est pas inutile de rappeler que les dimensions de ses mailles ne sont soumises à aucune restriction. 
15... Barrages. - Il est interdit de placer dans les cours deau aucun harrage ou appareil quelconque de pècherie ayant pour objet d'empècher entièrement le passage des poissons. (L. 1829, art. 24.)

Tout assemblage de nasses ou filets qui a pour effet de mettre obstacle à la libre circulation du poisson est considéré conme un barrage: toutefois. les barrages industriels qui ont pour objet d'amener les eaux à une roue hydraulique ne sont pas soumis aux restrictions de la loi sur la piche.

156. Appareils de pècherie. _ sont compris sous la dénomination d'appareils de picherie et interdits : les gords. nasies praniers et filets fixes places aux écluses. ramnes et coursiers des usines. (Déeret du כ̌ septembre 189т.)

Les filets fixes ou mobiles et les engius de toute nature cmployés à la prible ne peurent excéder. en longueur ni en largenr, les deux tiers de la largeur monillée des cours d'eau dans les emplacements ou on les emploie.

Plusieurs tilets ou engrus ne peurent ètre employés simultanćment quà une distance au moins triple de leur développement.

Lursquin ou phusemp des engins emploves sont en partie fixes of en partie mobiles, les dislances ('ntre les parties fixies à demeure doivent itre au moins friples du téveloppement total. des praties 
fixes ef mobiles mesureses bout a hout. (Dereret du ¿ septembre 1897.)

Ces prescriptions pruvenl se résumer cu ces quelques lignes. Les filels ne doivent jamais barrel completement les cours d'eau. I.e tiers au moins llu cours d'eau doit ètre laissé libre. Oulland on se sert en mime temps de plusieurs filets, on doit les placer assez loin les uns des autres pour que le poisson puisse circuler entre eux. Cette distance est triple de la longueur du filet.

Les filets fixes employés à la pèche derront ètre retirés de l'eau et déposés à terre pendant trente-six heures de chaque semaine, du samedi à six heures du soir au lundi à six heures du matin. (Décret du o septembre 1897.)

157. Empoisonnement. - Il est interdit de jeter dans les caux des drogues ou appats de nature à eniver lés poissons ou à les détruire. (L. 1829, art. 25.)

L'empoisommement qui se pratique principalement dans les petits cours d'eau est le délit le plus grave et celui dont la constatation est la plus difficile; aussi les garfes doirent-ils y consacrer toute leur attention.

Les substances toxiques les plus communément employées sont : la chaux, la coque du Levant: le suc de tithymale, la noix vomique. 
La chaux est plus nuisible que les autres poisons, parce que son action sítend au loin, tanclis que celle de la corfue et de la tithymale ne s exerce que dans un rayon restreint.

On reconnail qu'un ruisseau a été empoisonné avec de la chaux, à la coloration laiteuse de l'eau et au dépòt blanchàtre qui se forme sur les bords. On le reconnait plus sùrement encore quand on $y$ roit flotter un quantité de poissons morts que les pècheurs ont négligé de recueillir, à cause de leur petilesse.

Le poisson pris à laide de la chaux ou d'autres poisons est décoloré; il a les oües ternes, sa chair ramollie est de mauraise qualité, il se gàte très vite.

Quand les gardes reconnaitront quion empoisonne les cours d eau de leur triage, ils chercheront, par Lous les moyens possibles, à prendre les pècheurs en flagrant délit. Il est assez rare quils puissent voir jeter dans leau les substances déléteres, mais ils surveilleront les parties des cours d'eau où ces substances ont été jetées, afin de saisir les délinyuants lorsquils viendront ramasser le poisson yui flolte à demi-mort à la surfice de leau.

Les gardes recueilleront aver soin les indiees yui prouvent la culpabilité des precheurs, tels que des traces de chaux ou de délris de coque dans leurs 
vetements; ils en feront mention dams lemes poriesverbaux. Ces actes doivent dans fous les cas faire comnailre leespere el les dimensions des poissons capturés.

Le fail de perber en jelanl dans more liviere des earfouches de dynamile dont l'explosion élourdil le poisson, quand elle ne le tue pas, constitue le dólit. prévu par l'article 25 précité.

158. Résidus industriels. - Lisinier qui déverse dans un cours d'eau les résidus de son industrie commet aussi le délit d'empoisomement si ces résidus sont de nalure à donner la mort aux poissons.

Les arrètés préfectoraux prescrivent les mesures à observer pour l'évacuation dans les cours d'eau des matières et résidus susceptibles de nuire au poisson et provenant des fabriques ou rtablissements industriels quelconques.

159. Rouissage. - C'est aussi anx préfets qu'il appartient de régler la durée du rouissage du lin et du chanvre dans les cours d'eau et de fixer les emplacements où cette opération peut être pratiquée avec le moins d'inconvénients pour le poisson. (Décret du כ septembre 1897.)

Les préposés sassureront que les usiniers ont pris toutes les précautions prescrites par les arrètés préfectoraux et ne verbaliseront que si l'inobservation de ces mesures a causé la mort du poisson. 
Ils veilleront à ce que le rouissage ne soit pratifur que sur les emplacements désignés par les arrètés et que sa durée ne lépasse pas le temps fixé.

160. Temps prohibé. - Pour protéger la reproduction du poisson, le lógislatem en a interlit la pèche jendant le temps de la fraie, mais comme tous les poiswons te notre pays ne frayent pas aux mèmes éporques.il a fixé ainsi qu'il suit l'époque et la durée de l'interdiction pour les diverses espèces. (L. de 1829, art. 27.)

La pèche du saumon est interdite du 30 septembre (xclusivement au 10 janvier inclusivement. Celle de la truite ot de lombre-chevalier, du 20 octobre exclus au 31 janvier inclus. Celle du lavaret du 1.j novembre exclus au 31 décembre inclus. Celle de tous les antres poissons el de lécrevisse est interdite du lundi yni suit le 13 arril inclus au dimanche qui suit le 15 juin inclus.

si le lumli qui suit le 1.5 arril est un jour féric, l'interdiction est retardie de 2't hemres.

Les interdictions prononcées dans les paragraphes précédents sappliquent à tous les procédés de piche, mine a la ligne flollante. (I. de 1829, art. 27, décret du כ̌ septembre 1897.)

161. Pêche de nuit. - La pèrhe nest permise que depuis le lever jusquau coucher du soleil. Les filets el engins ayant les dimen-ions réglementaires peu- 


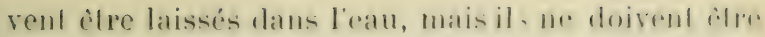

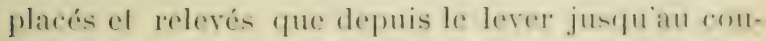

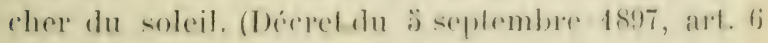
cl. 7.)

162. Exceptions. - Ites arrêlés preferloraux pril. vent auloriser la prehe de la lamproic el de l'écrevisse appes le coucher el aranl le lever du solvil. Ces arrotés désignent la nalure el les dimensions des engins dont l'emploi est aulorisé pour ees pêches.

La piche du saumon el de lalose peul aussi ilre aulorisée par desarêtés prélecloraux pendanl deux heures au plus aprés el arant le coucher et le lever du soleil. (Décret du כ̆ septembre 1897, art, 6.)

Less préfets peuvent en outre : interdire exceplionnellement la pèche de loutes les espèces de poisson lorsque cetle interdiction est nécrssaire pour protéger ies plus utiles; augmenter la durée des périodes d'interdiction; permettre la pèche de l'alose, de l'anguille et de la lamproic pendant la période qui dure du 1 ơ avril au 1 ¿ juin; enfin, fixer une periode d’interdiction pour la pèche de la grenouille. (Dérret du $\check{~ s e p t e m b r e ~ 1897, ~ a r t . ~ 2 .) ~}$

163. Gantons réservés. - La pieche peut être absolument interdite par décrets, dans les parties des fleures, rivières, canaux et cours d'eau réservís pour la reproduction. (Loi dı 31 mai 186ว.) 
La perehe à la ligne est même interdite dans res réserves.

Il est aussi défendu de pêcher dans les parties des rivières, canaux et cours d'eau dont le niveau serait accidentellement abaissé soit pour y opérer des curages ou traraux quelconques, soit par suite du chomage des usines ou de la navigation. (Décret du כ septembre 1897, art. 17.)

161. Engins prohibés. - Les seuls engins de pêche dont l'emploi est permis sont : les filets, les nasses, les rerveux et la ligne.

Les mailles des filets et l'érartement les verges des nasses et des rerveux diffèrent suivant que ces engins sont destinés a la pèche des poissons de grandes ou de petites espèces.

Les mailles des filets destinés à la proche du saumon doivent avoir an moins 40 millimètres. Celles des filets ou nasses deslinés à la pièche des autres prossons : rarpes, brorhets, ete., pourront n'avoir que 27 millimilres. Enfin les mailles des filets on l'éarlement des verges des nasses en usage pour la perhe des petits poissons : goujons, ablettes, etr.. auront au moins 10 millimètres. (Dérret du š seplembre 1897 , art. 9.)

La mesure des mailles est prise sur le filet monillé. Cefte mesure ainsi que celle de l'espacement des verges est prise a laide de calibres fournis par 
latministration of poinconnes par elle (T)epel du 26 aoul 186:); il esl areoldi une lolépanre d'un dixième. (Id., art. 9.)

Il est inlerdil demployer simultaniment al la piohe des filels an angins de rategorie diffripentr. (Id., arl. 9.)

Les filels trainanlo sonl prohibés, ainsi que les lacels ou collets. Ie petit épervier jelé à la main ed manrurré par un seul homme n'est pas ronsirlere comme un filet traînant.

163. Exceptions. - Ces prohibitions penvent itre modifiées par des arrêtés préfectoraux qui réduisenl les dimensions des mailles et l'espacement des verges des engins employés à la pêche de l'anguille, de la lamproie et de l'écrevisse. (Décret du כ̌ sej)tembre 1897, art. 10.)

Les préfets peuvent en outre autoriser, à titre exceptionnel, l'emploi de rertains filets traînants à mailles de 40 millimetres pour la pèche de poissons d'espéces délerminées. (Id., art. 13.)

166. Modes de pêche interdits. - Il est interdit : $1^{\circ}$ d'accoler aux écluses, barrages, chutes naturelles, pertuis, vannages, coursiers d'usines et échelles à poisson, des nasses, paniers et filets à demeure; $2^{\circ}$ de pêcher avec tout autre engin que la ligne flottante, dans lintérieur des écluses, barrages, vannages, coursiers d'usines ou échelles à poisson, 
ainsi qu'à une distance moindre de 30 mètres en amont ou en aval de ces ourrages; $3^{\circ}$ de pècher à la main, de troubler l'eau ef de fouiller au moyen de perches sous les racines ou autres retraites fréquentées par le poisson; to de se servir d'armes à feu, de poudre, de dynamite ou de toute autre substance explosive. (Décret du כ̆ septembre 4897, art, 1ว.)

167. Dimensions des poissons. - Les dimensions au-dessous despuelles les poissons et les écrevisses ne peurent etre péchés, mème à la ligne flottante, el doirent îre rejetés à l'eau sont déterminées ainsi yu'il suit, pour les direrses espèces : les saumons, 40 centimètres, et les anguillas 20 centimètres de longueur. Les truiles, ombres-cheraliers, ombres communs, carpes, brochels, barbeaux, brèmes, meuniers, muges, aloses, perehes, gardons, tanrhes, lottes, lamproies et lavarets, 1'́ centimètres. Les soles, plies et carrelets, 10 centimètres. Les écrevisses à pattes rouges, 8 centimetres; celles à pattes blanches, 6 centimètres.

La longueur des poissons se mesure de lacil à la naissance de la queue; celle des écrevisses de l'wil à l'extrémité de la puene déployée. (Déeret du כ septembre 1897, art. 8.)

Liobligation de rejeler en rivie e les poissons capturés au filet, lorstu'ils nont pas les dimensions lé- 
gales, se justifie par l'intér.r. qu'il y a a laissor virre des poissons qui feuvent grandir at arepuerir une plus grande valeur alimentaire. Il neen est pas de meme pour les poissons pris a la ligne. Cemx-lit sont blessís grierement par l'hamecon of vouis a une mort presque certaine. Il semble bien dur d'obliger le pêcheur à la ligne à rejoler a l'anu le poisson qui a mordu à son hamecon, alors quil n'avait aucun moyen de l'en ćcarter of que perm l. prendre il a dù lui arracher avec l'hamecon tune partie de la gorge.

\section{Port d'engins prohibés. - Sont considérés} comme délinquants les individus trourés, hors de leur domicile, porteurs d'engins ou instruments de pêche prohibés, à moins que le porteur ne prouve qu'ilssont destinés à la pìche d'étangs ou réservoirs. (L. de 1829, art. 29.)

Les gardes qui rencontrent, sur la voie publique ou dans les lieux ouverts au public, des persomnes munies de filets ou engins quelconques de pèche ont le droit d'en exiger la vérification. Le refus du porteur est puni d'une amende de s0 francs. (Loi de 1829, art. 41.) Si le porteur allegue que le filit ou l'engin incriminé est destiné à pècher dans un étang ou réservoir où il a le droit de pècher, le garde s'assurera de l'exactitude de cette excuse, et, si elle est ralable, il s'abstiendıa de verbaliser. Dans 
le ras contraire, il déclarera la saisie des engins et en donnera la description dạns son procès-verbal. 169. Visite des bateaux. - Les contremaitres, employés du balisage et mariniers ne peurent aroir dans leurs bateaux aucun filet ou engin de pèche, même non prohibés. Ils sont tenus de souffrir que les préposés chargés de la police de la pèche visitent leur bateau aux lieux où ils arborderont. Ceux qui sopposeraient à cette visite encourent une amende de 50 franes. Les filets ou engins sont confisqués. (Loi de 1829, art. 33.)

170. Vente et colportage. - Il est défendu de mettre en vente, transporter ef colporter du poisson pendant le temps où la pèche est interdite. (Loi du 31 mai 186ว.) Cette détense s’applique aussi aux poissons mìme pèchés en temps non prohibé, mais nayant pas les dimensions exigées par l'article 8 du décret du š septembre 1897 .

Sont exceptées de res dispositions les ventes de poissonsprovenant d'étangs ou réservoirs. Cesétangs qui sont des propriétés privées, sont reux dont il a été question ri-tessus, $n^{\circ} 140$; la perche y est romplitement libre; mais lo poisson yui en provient ne peut atre transportí el mis en rente que s'il ast arrompagné d’un certifieat d'origine délivré par le maire du lien de lextraction.

La recherche du poisson peut elre faite, en temps 
prohibé, sur les marhés, ehez les aubergistes, las marchands de comestibles el daus les lieux ouverls au public.

171. Les procis-verbaux qui constateronl les lails de transport de poisson pris en délil devont laire commatre si le lransport seffectue par batraux, roilules ou bèles de somme, circonstances agreratvantes qui peuvent entrainer une condamnation de dix jours à 11 mois de prison. Loi du 31 mai 186.).

172. Exception. - La délense de peicher en temps prohibé a été levér cu lareur des agents de l'Étal, ingénieurs et forestiers, qui peuvent faire capturer les poissons destinés à la reproduction, mème dans les réserves. Ils sont mème autorisés à recueillir el a transporter en tout temps la montée d'anguilles, en se servant d'engins prohibés par les riglements. (Loi du 31 mai 186ว, décret du ว̀ septembre 1897.)

173. Pêches louées. - L'État, qui possède le droit de pèche sur les canaux, et les fleures et rivieres déclarées navigables ou flottables el leurs dépendances, en tire profit en l'amodiant soit jar voie d'adjudication publique, soit par licences, lorsque larljudication a été tentée sans succès.

Les gardes forestiers el les gardes-peche ne peuvent ni prendre part aux adjudications, ni receroil de licence.

Aucun adjudicataire, cofermier, compagnon ou 
porteur de licence ne peut se livrer à la pêche avant d'aroir obtenu du chef de service, ingénieur en chef ou inspecteur des forets, un permis qui doit ètre présenté à toute réquisition.

17'́t. - Les fermier's de la peche, et les porteur's de licence et en général tous les pècheurs qui exercent leur industrie sur les cour's d'eau déclarés navigables ef flottables, sont tenus d'amener leurs bateaux et de faire l'ouverture de leurs loges, bannetons, huches et boutiques à poisson, à toute réquisition des agents el préposés des administrations des forits ou des ponts et chausiées à peinc diune amende de 50 francs. Loi sur la pèche, art. 33 .

Les fermiers, cofermier's, porteur's de licence et leurs compagnons sont soumis à toutes les pres. criptions concernant les temps prohibés, les modes de peiche, la dimension des filets et autres engins, etc. Ils sont en outre tenus d'exécuter les clauses des cahiers de charges quils ont acceptés et dont charpue préprosé doit aroir un exemplaire.

Le nombre des compagnons ne jourra excédel deux par baleau. Lees compagnons ne pourront exerere la pirhe quen accompanant les fermiers. les cofermiers ou les permisionnaires. Ciah. des charges, art. 10i)

17i.). Pèches extraordinaires. - Sur la demante des adjudicataires de la prehe des cours d'eau navigahles 
oul llotlables, ol sur colle des proprictairm de la

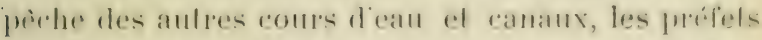
penvenl anloriser, dams des emplatements dibre.

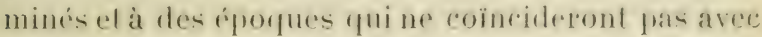

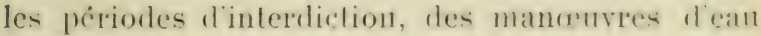
el des péches exlraordinaires pour délruire cerlaines especes, dans le but d'en propager d'auldes plus précieuses.

Ils peuvent également, en eas de vidange des biels, sur la popposition, suivant les cas, nes ingrinieurs ou des lonctionmaires de larministration des forch, autoriser les fermiers on les propréétaires du droit de peche à se servir exceptionnellement d'engins n'ayant pas les dimc'nsions réglementair's pour s'emparer du poisson menacé de périr. Décrel du כ้ septembre 1897, art. 18.

176. - Il résulte du résumé qui précide rae les prescriptions des décrets sur la peiche peuvent ètre modifiées par des arrétés des prélets. C'est donc à ces derniers actes que les préposés doirent recoulin afin de saroir quels sont leurs deroirs. En cas de doute, ils peurent loujours sadresser à leur chefs, ingéniens ou officiers forestiers, rui lem lonneront les indications nécessaires.

17i. Inscription maritime. - Dans les limites de linscription maritime, ou la pêche peut etre exercée sans licence, mais par les inscrits seulement. 
la police est faite sous la direction supérieure des préfets maritimes par les commissaires de linscription, les inspecteurs des pèches, les syndies des gens de mer, les gendarmes et gardes maritimes.

Ces fonctionnaires. qui dépendent du ministre de la marine, sont autorisés à étendre leur surveillance en dehors des limites de linscription maritime, jusquiau point où les eaux cessent d'ètre salées pour y faire observer les règlements de la pèche còtière. Ils sont aussi chargés de faire observer les lois et règlements sur la pèche fluviale dans les cours d'eau douce compris dans linscription maritime. Mais les gardes-peche commissionnés par ladministration des forcts ou par celle des ponts et chausisées nont pas à śoccuper de la pèche de ces cours d'eau; leur compétence sarrete aux limites de l'inscription maritime. 


\section{CHAPITRE VI}

\section{CITATIONS ET SIGNIFICATIONS}

Compétence. -- But de la signification. - Sa forme. - Remise des copies. - Enrecristrement. - Frais de citation.

178. Compétence. - Les préposés de l’ałministration forestière peuvent, dans les actions intentées en son nom, faire toutes citations et significations d'exploits. (C. for., art. 173.)

Ils ne peuvent néanmoins instrumenter que dans l'arrondissement des tribunaux près desquels ils sont accrédités, soit par le serment, soit par l'enregistrement d'un serment antérieur.

Les actes à raison desquels les préposés ont l'occasion de délivrer des exploits sont,

En matière correctionnelle :

Les assignations à comparaìtre devant les tribunaux correctionnels et la Cour d'appel ;

Les significations de jugements par défaut;

Grye. - Strueillayce. 
Les citations à témoins ;

Les arertissements aux délinquants admis à transiger.

En matière administrative :

Les citations à récolement;

Les significations d'arrètés préfectoraux ordonnant la délimitation ou le bornacre ;

Les significations de procis-rerbaux de reconnaissance des cantons défensables;

Les notifications d'actés relatits aux défrichement

Les significations d'arrélés préfectoraux mettant les entrepreneurs on adjudicataires en dememre d'exícuter dans un délai déterminé les traraux à leur charge ;

Et en crénéral les notifications de tous les actes administratifs relatifs a la gestion des bois communaux et a l'exereice des droits d'usage dans les bois de l'Etat.

179. But de la signification. - La signification a jour but de meftre en demeu!e lapersonne à qui elle ext faite soit de se présenter derant les tribunaux jour répondre sur les faits quelle a commis ou ru commettre (assignations, cilations à témoins), soit dètre présente aux opérations auxquelles elle a intérèt à assister ceitalions à rérolement, délimitation, bornagel, soit, enfin, de se contormer aux obligalions imposies par la loi nu les décisions prises con- 
formemenl anx lois (opposilions an défrichement.

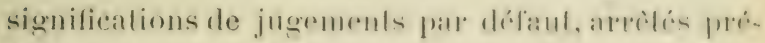
fectoraux).

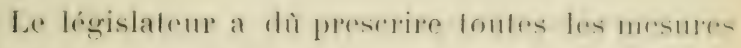
néressaires pour que les parlies ne puissonl ignorer les assignations quiles eonerment ; ceses prourquoi il a exige que la remise de ees actes soil laile direetemenl aux interessés, autant fue possible, of dans tous les cas à leur domicile. Ce nest quen cas d'impossibilité que la remise à la personne on an domicile peut ètre remplacéc par des lormalités que nous indiquerons en examinanl sucessirement les différentes circonslances qui jeuvent se prisenter.

180. Remise des copies. - Les agents transmellent aux préposés les originaux et les copies des actes qu'ils doivent signifier; le pòle de ces dernier's se borne à faire aux personnes désignées la remisedes copies qui leur sont destinées.

Les gardes citateurs s'assureront dabord que les copies sont en toul conformes aux originaux el lisiblement écrites; puis ils procéderont à la remise de ces copies aux parties inléressées.

On doit constater celte remise tant sur l'original que sur la copie, en inscrivant, après les mols parlant à, les noms et qualités de la personne à qui cette remise est faite.

Les originaux, comme les copies, doivent êlre da- 
tés et revètus de la signature du citateur. La date doit itre complète. rest-i-nlire indiquer lo jour, le mois et l'année.

si le garde citatemr rencontre en son domicile la personne citée. il lui remet la copie de lexploit apris aroir rempli. comme nous lavons dit plus haut, le parlant it. mentionné la date de celle remise pl signé ; les mèmes mentions sont inseriter sur loriginal. (Toir Exemple $n^{\prime \prime} 1$, verso, art. 1"ex

181. Si la prepsonne est absente du domicile, mais sil sy troure, soit un membre, soit un serriteur de la famille, le citateur indiquera, tant sur loriginal que sur la ropice, les noms de la personne ainsi trouve au romirile. ef tout an moins les relations qui existent entre elle et la partie assignée; si le carde commait les noms de la personne à qui il laisse la ropie ot les rapports qu elle a arec la partiecitée. il les imlinfuera comme a l'article 2 le l'Exemple $n^{\mathrm{n}} 1$, verso. Il faut, pour yue la citalion soit valable. pue la eopie de lixploit soit remise an domicile de la personne citéc et non ailleurs.

s'il rommail sentement lés liens de parenté. d'alliance ou de domesticite qui existent entre celte frersonne el la parlie assignće, le citateur se bornera a mentionner la nalure de ces rapports, comme a lartirle 3 de lexemple $n^{\circ} 1$; si, enfin. il n'a pas une connaissance personnelle de ces rapports, il 
sulfira dindipuer, romme daus les Exemples ${ }^{\prime \prime} 1$,

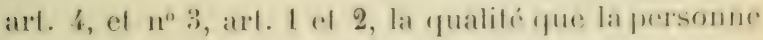
ainsi lrouvée an domicile sest altribure, en faisanl suive relle menlion des mols: ainsi déclaré.

Les cilateurs ne sont pas obligés de soissurer de lexactitule des réponses failes frar les personnes it qui ils laissent la copie : du moment fue res persommes somb frourées au domicile de la parlie assigme et quelles affirment quelles font partie de la maison, soit comme parents, soif romme domesliques, il y a présomption que leur assertion est exacte. Le citatem n'a quà constater la réponse.

182. Si la persome assignée est absente du domicile, et s'il ne sy troure aucun de ses parenls ou serviteurs, le citateur, après aroir constaté qu il 11 a trouvé persomne au domicile de la partie el mentionné cette circonstance sur son exploit, fera la remise de sa copie à l'un des plus proches roisins, en l'invitant à signer loriginal. (Toir Exemple 11 " 2, art. 1, verso.) - La signature du voisin est exiggée, a peine de nullité. - Si le voisin ne sait pas ou ne reut pas signer, sil ne veut pas receroir la copic, le citateur l'indiquera sur son exploit et remettra lia copie au maire de la commune, qui derra signer l'original. (Voir Exemple no 4, art. 3.) Le refus yar une personne de la maison de receroir la copie au domicile de la partie ne dispense pas le garde cita- 
teur de sadresser au roisin arant de recourir au maire.

En cas d'absence du maire, le préposé fera la remise de la copie à ladjoint, et, enfin. en l'absence de ce dernier. aux conseillers municipaus, en suirant l'ordre d'inscription.

183. Toutes les fois que la copie est remise à une fersonne autre que la partic elle-mème ou le procureur de la République, elle ne doit ìtre délivrée que sous enrelople fermée, ne portant dautre indication, diun coté que les noms et demeure de la fratice et de lautre que le eachet de ladministration. Il doit itre fait mention du tout, tant sur l'origrinal que sur la ropie de la citation. (Loi du 1 février 1899 et circ. วั73.)

Les gariles recoivent divance des envelopjes spé ciales pour signifeations dexploits. sur lespuelles est apposé le eachet de ladministration. Cette for. malilé n'est d'ailleurs repuise que pour les citations en matière correctionnelle.

18'. Enfin. il peut se présenter un dernier cas. éest celui ou le tomicile de la pratie assignée est mal indiqué. Le propose citateur devra, dans celle rironstane, renvoyer loriginal el les eopies qui y sont jointes au chef de eantonnement, en accomfagnant ces pieses diun certificat du maire constalanl yue la prersome assignce nhabite pas ou n'ba- 
bile phus la rommume, el indiguam soit son domicile atcluel, soil l'impossibiliti de le rommailre.

Les nolifications anx maires romsideres commo représentants des commumes doivent idre latiles it la personne ou au domicile de ces magistrals. L mirginal doit ifre signe par la personne at yni la repper de l'exploit est remise.

En cas dabsance ou de relus, le visa doil ilr donné par le juge de pais ou le chef du parpuet.

18\%. Les citations en matière correctionmell. peuvent dre faites les dimanches ef jours fórics.

La remise des exploits a la persomme ou au domicile doit itre laite par les citateurs eusmèmes. Ceux qui confieraient à des liers la remise des copies, quand bien mime cette remise aurail lieu en leur présence, sont passibles de poursuites devantle tribunal correctionnel ou la Cour d'assises.

186. Les exploits doivent itre écrits à l'encre et d'une manière lisible; les indications faites au crayon sont considérées comme nulles.

Les préposés derront mettre la plus grande célérité à signifier les actes qui leur sont transmis; les délais légaux sont quelquelois jrès d’expirer quand on leur adresse les actes; le moindre retard peut entraîner des nullités.

Ils inscriront sur leur livret les significations faites 
par eux, comme il est indiqué au chapitre $\mathbf{X}$, $\$ 2$; ils renverront sans retard les originaux dùment enregistrés au chef de cantommement.

186. Enregistrement. - Lorsque la remise des copies est terminée, loriginal de la signification doit itre soumis à lenregistrement dans le ciélai de quatre jours.

Les préposés citateurs qui laisseraient passer ce délai sont passibles dune amende de j fr. (loi du 16 juin 182.t, art. 16) ; ils encourent de plus la responsabilité des instances que leur négligence a pu laire périmer.

187. Frais. - Les rétributions dues aux gardes de ladministration des forits four les citations et significations dexploits sont laxées romme pour les actes faits par les huissier's.

Cette partie du service est ordinairement confiée aux brigadiers: mais les gardes simples peuvent aussi faire les significations lorsyue, à raison des distances on de tout autre emprehement, les brigadiers ne peuvent en être chargés.

Il est attribué aux brigadiers ef gardes 30 centimes par chaque citation, signification ou avertissement; il n'est pas alloué de frais de voyage aux préposés, à moins que le déplacement n'ait été ordonné par un mandat spécial du ministère publicet dont le motif sera rappelé dans l'état de frais aucuel 
ce mandal deval itre annexe. (I) ine minisl. dn 7 mar's 1834.)

Ancun préposé ne peul recevoir plus de 200 fir. pour frais de citations, quel que soil le nombere de relles quil a faites. - Ces rétributions sont payous a la fin de chaque année. (Circul. dı go mars 1887 , 11081.) 


\section{CHAPITRE VII}

\section{TRAVAUX - DÉLIVRANCES - ADJUDICATIONS}

Travaux eli rérie. - Par enlreprise. - Imposis aux adjulieataires de cumpes. - Exicutés par les prestataires. - Par les préposés. - Délirrances de menus prouluits. - Ventes. - Iffiches. - Adjulications. - Remises. - Affiche annotee. État des frais.

188. Les travaux forestiers peuvent itre faits: lo en régie ou lar économie; - par les entrepreneurs a prix d'argent ; 3" par les adjullicataires ou entrepreneurs des conpes; $4^{\circ}$ par les concession. naires de menus produitsel parlescondamnés insol. vables : כّ" par les gardes et les cantonniers.

Lintervention des préposis variant suivant le mode adopté, nous indirpuerons suceessivement la nature de leur coopération dans les travaux de chacune de ces cinq classes.

189. Travaux en régie. - Les lravaux en régie, dits aussi par économie, sont cenx yue des ouvriers a la journée ou a la tache font sous la direction des 
agents of la smrveillance immédiate des garrles. (1) exétule ainsi : les peliles réparalions dont le rout ue

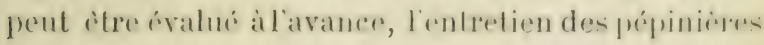
ef les pepenplements qui exigrent des soins parlin'uliers, les tratanx qui nont pas tromvé dientrepre. neur ; quelquefois le farennage des bois de chante fage à déliver aux préposés ; enfin relui des rompes d'erlaircie qui nont pu itre domnées à l'enlrepriso. Les travaux abandomnés par les entrepreneurs peuvent itre également exécutés en régie.

Pour les améliorations ainsi exérulées, les préprosés remplissent le rôle de conducteur's res atoliers; ils organisent les chantiers, dirigent les ourrier's, tiemnent note des journées ou des tàches faites jar charun d'eux, des quantités de matériaux recus et employés; ils rendent comple au chef de cantonnement du nombre des journées faites, au moyen d'un état d'aftarhement qui lemr est remis jar le directeur des travaux. (Formule 10 29.) C'est sur leurs indications que s'opère l'abatage et le faconnage des bois, après que les agents ont donné des instructions convenables sur la marche de l'exploitation. Les travaux ainsi exécutés doivent être l'objet d'une surveillance assidue; pour que les ourriers utilisent tout leur temps, il faut que les gardes soient constamment arec eux et qu'ils montrent b eaucoup de fermeté à leur égard. 
Dans les travaux en régie, autresque les travaux de lexploitation forestière, le préposé chargé de la surveillance duchantier doit se ronformer, en cas daccident arrivé ḋ un ouvrier. aux prescriptions des lois du 9 arril 1898 et 2.2 mars 1902. Il doit faire une déclaration de laccident à la mairie de la commune où le fait a eu lieu, et demander un récépissé decette déclaration. La formalité doit itre remplie dans le délai de 48 heures; sil y a un ou plusieurs jours lériés danslinterralle, le délai est augmenté dautant de fois 24 heures.

Le préposé doit en outre prévenir immédiatement le chef de cantonnement, en lui faisant connaitre notamments il estime que la victime pourra reprendre son travail dans les quatre jours. (Circ. 621.)

190. Travaux par entreprise. - Les travaux exécutés par des entrepreneurs, à prix dargent, comprennent : la construction des maisons forestieres, des scierics, des routes, ponts et ponceaux, les éclaircies, les grands repeuplements, louverture des fossés de périmetre ou d'assainissement, et en général les améliorations de toute nature; ils sont faits sous la direction des entrepreneurs et la surveillance des agents. En ce qui concerne les travaux dart, les préposés n'ont qu’à assurer lexécution des prescriptions de leur chefs et à leur donner avis de toule infraction a leurs recommandations. La sur- 
veillane des gardes doil s'exereer notamment sme la confection du mortier et des macommeries, et, 1.11 génciral, sur la qualite des matérianx quil ne plus plus possible de rérilier apris l'exécution des travanx. Toute irrégularité dans laceomplissement des obligations de lentrepreneur, foute négligenee on malfacon doit itre immédiatement signalée au chef de. cantonnement.

191. Quand il s'agit de travaux de repeuplement tels rue semis, plantations, binages, etc., le role des gardes devient plus actil. Ils s'assurent de la qualití des graines et des plants; ils rérifient si l'emploi en est lait avec les précautions convenables.S ils s'apercoivent de quelque frande ou de quelque négligence, ils en préviennent de suite lagent directeur des tra. vaux.

Les exploitations faites par entreprise exigent aussi une surveillance assirlue de la part des préposés. C'est à eux qu incombe le soin d'indiqueraux ourriers les brins à abattre et la manière dont ils doirent être débités. Ce dernier point surtout demande une attention de tous les instants. Les entrepreneurs ou leurs ouvriers sont naturellement portés à débiter des bois de la manière qui leur est le plus profitable; ainsi, s'ils ont intérèt à faire du bois de corde plutòt que du bois d'industrie, ils découperont des brins qui, conservés dans leur lon- 
gueur, auraient eu une valeur bien plus grande que réduits en bunches. Si, au contraire, la façon des perches leur est mieux payée, ils laisseront entiers des brins qui ne sont bons qu’à brùler et rendront par suite dilficile la rente des lots formés de bois mal assortis.

Un forestier doit connaître toutes ces ruses et s'appliquer à les déjouer; cest en suirant de près les exploitations et en maniant, au besoin, la serpe et la hache, quil apprendra ce quion peut exiger des ouvriers.

192. Travaux imposés aux adjudicataires ou entrepreneurs des coupes. - Dans les bois domaniaux, aucun travail d'amélioration n'est mis en charge sur les coupes; les adjudicataires sont seulement obligés de réparer lés dégaits oceasionnés par l'exploitation et la vidange. Ainsi ils doivent faire réparer les fossés dégradés, combler et niveler les ornières des ehemins de vislange, rétablir les ponceaux, barrières et glaris endommagés, ot enfir, si le cahier des charees les y oblige, repiquer les places a charbon et ateliers. Cos divers travaux, dont le détail et lévaluation sont portés sur les alfiches, doivent itre complietement terminés à l'époque du récolement. Le's gardes s'assureront si les arljudicataires ont satisfait a toutes ces obligations, et, en cas de retard. les inviteront a le faire. Ils virifieront 
la qualite des plants employés, alin que les ruviders ne se eontentent pas, commerela a eu lien sonvent, demelle en lerpe des branehages sams anrune rarine, quelques jours avant le récolement. Ils signa. leront au chef de cantonnement les fravaux non treminés afin que celui-ci prenne des mesures four les laire achever.

193. En outre des réparations qüils sont fenus de faire comme les adjudicataires des coupes domaniales, ceux des compes communales peuvent ctre chargés de certains travaux indiqués dans l'affiche en cahier ou le permis d'exploiter. Cescharges sont de nature très variable, suivant les lieux et les circonstances; ce sont des repeuplements à effecturer dans les places vides ou les clairières, des fossés à ouvrir ou à curer, des bornes à placer, des fournilures de pierres pour l'entretien des routes.

Quels que soient res traraux, ils sont désignés dans les actes de vente, portés à la connaissance des préposés locaux, el ceux-ci doivent en surreiller l'exécution comme ils surveillent celle des travaux à prix d'argent.

Lorsque les coupes sont délivrées en affouage et exploitées par un entrepreneur responsable, celui-ci est considéré comme un adjudicataire ordinaire; c'est à lui de faire exécuter, soit par des ouvriers à ses frais, soit par les affouagistes, les travaux ordon- 
nés. C'est donc à lui que les préposés derront adresser les observations qu'ils auront à faire, puis. quil est seul responsable de la honne exécution des travaux.

194. Travaux exécutés par les prestataires. - Les travaux faits par les concessionnaires de menus

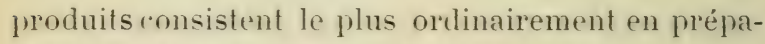
rations de terrains, semis, plantations of ouvertures de lossés: ils sont faits sous la direction des préposés, comme reux quion exécute par économie; seulement les ourriers sont payés avec les produits concédés, au lieu de l'ètre en argent. Comme l'enlèrement de ces produits précide le plus souvent l'exécution des travaux, les gardes devront reiller d̀ ce que les concessionnaires remplissent toutes les obligations quils ont contractées; ils annoteront, sur la liste des personnes qui ont joui de la conresion arcordée, celles qui ont fommi leurs journées de travail, of signaleront au chef de cantomnement les indiridus negligents ou indociles, afm quils soient à lavenir exclus des concessions.

Les lravaux faits par les concessionuaires de terrains, à charge de culture et de repeuplement, sont surveillés de la nème maniere que reux exécutés par entreprise à prix d'argent.

Les délinquants insolrables peurent êre admis a se libérer, moyennant des journées de prestation, 
des condammalions quils ont ancomrues. (Loi dn 18 juillel 18.i9). Dans le ras où a mode de libéralion serait adopté, les préposés nolilient lavertiscement, au vu duquel les combamnés doivent exéculer salns relard la tàche qui leur est imposée. L'origrinal de ces averlissements est renvoyé au chef de cantonnement par le garde ou le brigadier, qui indique si le travail prescrit a été lail. (Circ. 814.)

Ce mode de paiement des amendes au moyen de journées de prestation est fort peu usité.

19ð. Travaux faits par les préposés. - Des préposés spéciaux, désignés sous le nom de cantonniers forestiers, sont chargés des travaux de main-d'curre qu’exige l'entretien des forèts. Cies cantomniers sont sous les ordres des agents, qui leur indiquent les travaux à exécuter; ils inscrivent chaque jour sur leur livret la tàche qu'ils ont faite.

Chaque mois, une copie de ce livret est remise au brigadier, qui la vise et la remet au chef de cantonnement. Les cantonniers doivent rester à leur station toute la journće.

Les gardes et les brigadiers doivent aussi exécuter par eux-mêmes les travaux d'amélioration dont la nécessité se fait sentir. Yous arons indiqué, dans la première partie de cet ouvrage, la manière de faire ces travaux et limportance qu'il y a à ne pas les négliger. (Voir Sylviculture.)

Grye。 - Surveillance. 
196. Délivrance de menus produits. - Dans les bois régis par l'arlministration des forìts, les délirrances des menus produits sont autorisées par le conservateur. Ord. 's déc. 18't'.) Ciest en vertu des arrètés de ce chel que les gardes recoirent de leurs supérieurs immérliats l'ordre de laisser ramasser les herbes, mousses ef hruyères: extraire les matériaux ou minerais de toute espèce. Tout enlèrement ou extraction quelconque non autorisé est un délit.

Il y a deux espéces de délirrances; les unes sont faites à des personnes nominatirement dérignées: les autres sont générales el concernent tous les habitants dune commune qui souserivent lengagement de remplir certaines obligations.

Les délivrances nominatives peurent itre accordées moyennant des prestations ou a charge de redevances en argent.

Les permis dextraire les menus produits movennant des journes de prestalion ou des rederances en argent sont accordic par l’inspecteur. Ces permis sont transmis par les chefs de cantonnement aux wardes, qui les renvoienl en certifiant que le concessommaire a oprere l'extraclion autorisée.

Quand la permission est aceorder moyemnant des jomrnes de prestation. le garte lait commaitre en

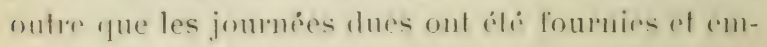
ployées. 
Les reslevances on arerent impories anx concensiommaires de menus produils à exlmaire des fuis domaniaux doivent alre payées aranl foule extras-

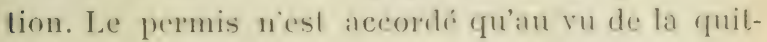
fance délivere par le receremr des domanes.

Les permis indirquent tonjours les comblitions inposées anx concessionnaires; les preporis sont chargés de veillex a ce que ees condilions relatives au mode dextraction et d'enlivement des produits, aux chemins at suive, cte, soient remplies.

197. Lorsqu'il y aura lieu de dresser un procisverbal de dénombrement des produils délivrés, cet acte sera signé par le concessiomnaile ou son délégué et par le garle du lriage. La forme de ces procès-rerbaux doit ilre aussi simple que possible, et. lon doit, pour éviter les frais de timbre, les rédiçer sur du papier de la dimension des feuilles de o fr. 60. Tous arous domné, sous le $n^{\circ} 28$ des formules, un modèle d'acte de ce genre.

11 peut servir pour lés délirrances de pier'es, sables, bruyères, elc., autorisées à prix d'argent. Lorsque la délirrance ne peut s'opérer en une seule fois, comme pour les harts, par exemple, qui doivent ètre coupées par les ourriers de l'adjudicataire au fur et à mesure de's heroins, mais toujours en frésence des gardes, il est inulile de dresser un procis-reubal de chaque délirrance partielle. C̈est 
seulement à la fin dés exploitations qu il est fait une récapitulation des quantités délirrées. L'administration de's forêts a fait préparer, pour les délirrances de cette espèce, des formules imprimées qui sont distribuées aux adjudicataires, et qui comprennent la demande, l'autorisation et le dénombrement. (Toir Formule no 32.) Les gardes à qui ces formules sont enroyées, arec les risas des agents forestiers, n’ont quà indiquer dans le tableau qui qui y est joint les espèces et quantités de harts délivrées.

Le procés-rerlual de délirrance doit ètre soumis à l'enregistrement.

198. Les autorisations d'extraire des herbes, des genrits, mousses, etc., accordées à tous les habitants d'une commune, it charge de prestations en nature, indiquent ordinairement les conditions imposées aux concessionnaires.

Le's listes de ceux des habitants qui ont souscrit l'engagement de fournir le's journées de travail, des eraines, ele., pom oblenir la permission d'extraire cerlaines productions du sol forestier, sont remises aux priposes locaus, qui doirent veiller à ce que les persomnes insrriles profitent seules de celte auforisation, el yui assurent l'exécution des conditions de police sous lesquelles elle est acentelé.

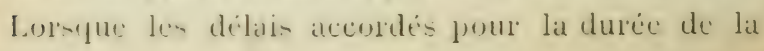


concession sont expiris, ils renvoienl la lisk an chef de cantommemenl, en indiquant reux des signataires inserits qui, par suite de reireonstanees parliculieres, noul pas joni de la firmlle arcordie of qui peuvent ête dispensés de fournir la prestation imposée.

199. Les particuliers areordent somrent, à litre de tolérance, des permiscions de ramasser dans leurs forèts des bois morts, de l'herbe et des feuilles. Tant que lis indigents profitent seuls de ces permissions, elles ne présentent pas de grands inconvénients. Mais auprès des grands centres de population elles amenent dans les bois un grand nombre de ragabonds sur lesquelsil est bon d'avoir l'reil ouvert; car, si le bois mort vient à manquer, ils savent bien en faire.

Les enlerements d'herbes et de feuilles mortes donnent lieu à une foule d'abus de toute nature. Il faut les interdire autant que possible, et, si l'on ne peut refuser de donner quelque satisfaction en ce point aux obligations qu impose l'humanité, il faut au moins prendre les précautions nécessaires pour que les indigents hors d'état de travaillersoient seuls admis à participer à ces aumônes.

Les propriétaires de forèts qui autorisent les enlèvements de feuilles, herbes, bruyères, etc., ne derraient jamais donner que des permiscions per- 
sommelles; car, sils commettent la faule te permella d une maniere cinérale à tous les habitants d'une commune de ramasser ces produits. ceux-ci finis. sent par considérer cette faveur comme un droit.

De toutes les délirrances, la plus nuisible aux forrits est crelle des feuilles mortes, quand elle n'est pas restreinte dans des limites étroites. Les feuilles sont le seul engrais des sols Jonisús; éest de leurs débris quest formi le terreau qui donne à ce sol toute sa fertilite; re sont les feuilles qui mettent les racines des jemes plants à l'abri du froid et du soleil; ce sont elles qui conservent l'humidité. Lorsquion les enlive, le terrain sappanrit, sa surface durcit, devient aressible à loutes les influences extérieures, et -a fertilité se détruit peu à peu.

Dans les furits ou smlirent régulierement les feuilles mortes et les mousses, on roit. au bout de quelques annees, la crois-ance des arlores se ralentir et le peuplement se degarnir. Il est done imfortunt de ne pas laimer sintrombire, dans les pays o:d il nexiste pas. l'u-age de ramanser les leuilles et lew mour-a des forits pour les employer comme litière.

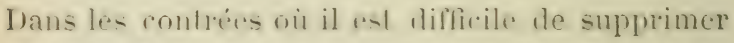

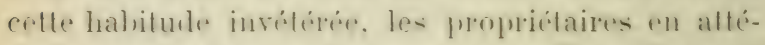
meront les fàcheux effels en me promellant de ramasser lies feuille- yur daus les forsis. les rhemins 


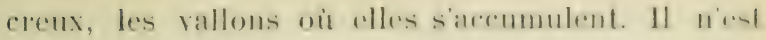

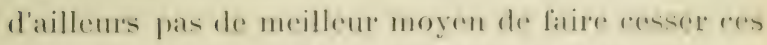
molivements que de faire ramatsser par des ourriers a la journée foul re pui peul l'èles sans dommagne pour le sol forestice, olde methe ensule on rente les tas de litiere ainsi recueillis. Les cullivateurs it qui refte litière est nécessiare la paieront ce qu'elle vaut pour eux, ils ne seront pas fondes it se plaindre car le proprictaire de la forcit n'est pas teru de leur domner pour rien l'engrais qu'il enleve à ses bois au profit de leurs rultures. Lorsqu'ils se verront obligés de débourser de l'argent, ces eultivaleurs qui prisont si haul la liliere quand elle ne leur coute rien, calculeront birn vite qu'ii y a plus de protit à faire des fomrages, of ils renonceront peu à pruà demander à la forèt l'engrais qu'ils peurent obtenir par l'amélioration de leur's cultures.

200. Ventes. - Les rentes des produits des bois soumis au régime forestier sont laites sous la dirertion des agents de l'administration des forêts; it l'exception du cas particulier que nous examinerons plus loin, les préposés n'ont à y concourir que pour contribuer à leur domer la publicité nécessaire.

201. Toute adjudication doit ètre annoncée au moins quinze jours à lavance par des affiches apposées au chef-lieu du département, dans les lieux de a vente, dans la commune de la sifuation des bois, 
et dans les communes environnantes. (C. for., art. 17, 53.).

Les affiches à placarder dans les communes sont transmises aux préposés; ceux-ci les remettent immédiatement aux maires et se font délirrer des certificats d'apposition qu'ils renvoient an chef de cantonnement.

Ces enrois se font ordinairement sans, lettres. Il suffit qu'un jréposé reçoive une affiche pour quil sache quielle lui est envoyée pour itre remise au maire contre un récépissé.

L'apposition desaffiches doit ètre faite sans retard. afin quil $\mathrm{y}$ ait toujours entre la publication et la vente, le dilai de quinze jours fixé par le Code forestier.

202. Les préposés sont aussi chargés de remettre aux narchands de bois, maitres de forges et autres acquéreurs habituels des coupes, les affiches en cahiers qui leur sont destinées.

Ils doivent, en remettant resaffiches, donner tous les renseignements qui leur sont demandés sur la siluation des compes assises dans lemrs triages ef se mettre, autant que possible, à la disposition des arquéreurs. pour les aecompagner dans la visite de ces coupes.

Les transports d'affiches ne donnent droit à aucune rétribution. Les services que les préposés rendent 
anx presommes qui desirent arheler les enmpes doivent itre complefement graluils; il leme est former lement interdit alexiger puoi que re soil pour prix de leur assistance.

Les rentes des buis des parlinuliers se fonl parr adjudication on à l'amiable. Les adjudications sont faites par-elevant notaires. Les ventes amiables perlvent èlre constatées par un contrat notaric ou par un acte sous seing privé.

In modèle dacte de ce genre est inséré à la fin de re volume. sous le n" 34 des formules.

Les propriélaires qui veulent saffranchir de lobligation demployer un notaire pour faire la vente de leurs compes doivent s'assurer aver soin de la solvabilité des acquéreurs. Les garles se mettront en mesure de fournir sur ce point des renseignements précis. Ce sont eux qui font annoncer la mise en vente dans les villages ef qui fournissent aux amateurs toutes les indications qui leur sont nécessaires.

203. Adjudications. - Les brigadiers peuvent ètre autorisés à remplacer les agents, dans les ventes sur les lieux : des produits principaux et accessoires des bois communaux et d'établissements publies (Ord. 13 janvier 18,7) et des produits des bois domaniaux quand leur évaluation ne dépasse pas 500 francs. (Circ. du 4 avril 1888, nº 396.) 
In brigadier chargé diune adjudication doit d'abord s'assurer de la bonne exécution du lotisse. ment et rérifier par lui-mème si chaque lot est désigné, sur l'affiche et sur le terrain, de manière à ètre facilement distingué par les amateurs.

Cette rérification est indispensable pour éviter les réclamations que les acquéreurs ne manquent pas defare, sil y a la moindre incertitude sur la désignation de leurs lots.

Les conditions relatives au mode diexploitation ou denlerement des produits, aux époques des paiements et aux graranties à exigrer des adjudicataires, sont inséréessur un projet de proces-rerlual d'adjudicalion que le chef de cantommement prépare et transmet au préposé qui le remplace. Ce dermier. aura soin de faire connatre ces conditions aux amateurs ot de veiller à ce quidles soient inscrites au frocis-rerbal; il derra en outre donner tous les renseignements nécessaires pour éclairer les amateurs -ur la nature et limportance des lols mis en rente.

La mise à prix de chaque lot, préalablement arrétie par le conservateur, est communiquée au représentant de ladministration des forcts. qui en fait connaitre le chiffre au prisident de la rente. Celuici ne doit pas trancher lauljudication au-desious du chiffre ainsi fixé.

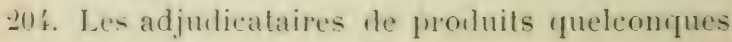




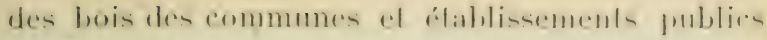
nonl a payer, on sus du prix dadjudicalion, qure les droils de limbre el demregistrement des acles de: vente.

Les frais de limber sonl de 1 fr. 80 par fruille de la minute du procis-rerbal. Ces liais se réparlissent entre lous les acquérems des articles qui fignrent sur celte minute.

Les frais de timbre de l'expédilion remise au recereur municipal se répartissent de mime entre les acquéreurs des lots portís sur cette expódition. si la rente comprend des produits de forits communales faisant partie de recettes différentes, une expédition doit etre remise à chacun des comptahies pour les articles qui les concernent.

Chaque adjudicataire paie le timbre de l'expédition de lacte de vente qui lui esl remise, sil le demande.

Les droits denregistrement sont de 2 l'r. pour $100 \mathrm{fr}$. sil n'y a pas de caution, et de $2 \mathrm{fr}$. 50 pour $100 \mathrm{fr}$. s'il y a caution.

Ces droits se percoirent sur les prix de rente de $20 \mathrm{fr}^{\mathrm{r}}$. en $20 \mathrm{fr}$. inclusivement et sans fraction. (Loi du 27 ventóse an IX.) Ainsi, pour un lot de 1 à $20 \mathrm{fr}$., le droit se perçoit comme pour 20 fr.; pour un lot de $20 \mathrm{fr}$. à $40 \mathrm{fr}$., il se percoit comme pour $40 \mathrm{fr}$, et ainsi de suite. S'il y a un certificateur de caution, il est dû en outre un droit fixe de $3 \mathrm{fr}$. 
A tous ces droits il faut ajouter deux décimes et demi. (Lois des 23 aout 1871, 30 décembre 1873.)

Quel que soit le délai accordé pour le paiement du prix de rente, le dixième de ce prix doit toujours itre payé comptant dans les rentes communales.

20.). Remise en vente. - Si les lots mis en adjudication ne sont pas tous rendus, le président de la vente pourra, sur la proposition du représentant de ladministration forestière, renroyer stance tenante et sans nourelles affiches, ladjudication à quinzaine. Après cette seconde séance, les lots invendus ne pourront ètre remis en adjudication quaprès de nouvelles publications.

206. Affiche annotée. - Les préposés délégués pour assister aux adjudieations signeront le procèsverbal et renverront, immédiatement aprés la stance, au chef de rantonnement, une affiche anmotée indiquant les résultats de la rente.

207. Etat des frais. - Ils joindront à ce document litat des frais d'adjudication dument arrité par le président de la vente.

Cet état est dressé sur des formules imprimées indiquant exactement le détail des dépenses, qui sont arquittées par des mandals délirrés au nom des parties prenantes.

Le délégue de l'administration forestiere retirera les expéditions destinées an chef de service, au re- 
THAVAU. WELLHANCES. ADJUDICATIONS.

ceveur municipal, el les extrails destinos aux adjudicalares. Il les lramsmellra sans délai au chef de cantonnement.

I.e roble de crieur est somvent rempli par un príposé forestier, dans les ventes faites a la diligence de l'administration des forêts.

La rétribution allouée pour ce service est payée au moyen d'un mandat délivé́ au nom du préposé. par le conservateur. 


\section{CHAPITRE VIII}

\section{PERSONNEL}

Commission. - Serment professinnnel. - Déprit de lempreinte du marteau. - Tran-eription au wreffe. - Installation. - Priposés lngé-. - Cession dohjet divers. - .Tardins et cultures des fariles. - Paturage de denx raches. - Panage. - Chanflaze. - Conseils. - Traitement. - Retemues. - Perte de mandals. - Changements de resilence. - Talac de cantine. - Inrlemnites. - Voyages à prix réluit. - Brigaliers. - Lniforme. - Congés. - Almi-son dans les hriplatix militaires. - Mariage- - Medaille dhonnemr. - Gardespede des ponts et chaussées.

208. Les preposés de ladministration des forde forment deux categories distinctess, suirant que les propriélés quils sureillent appartiennent a l'Elat ou aux communes of stahlisicements puhlics. On apr-

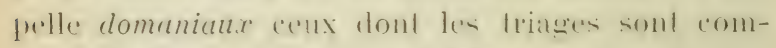

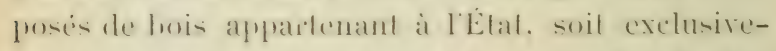
ment. soit par indivis aree les communes on les parliculiers.

Les gardes cantomniers. les gardes du reboise- 


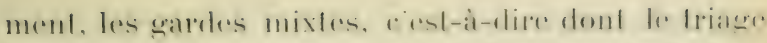

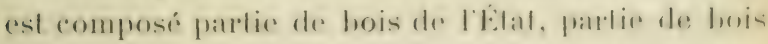

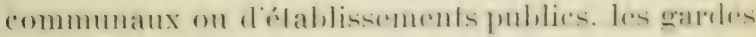

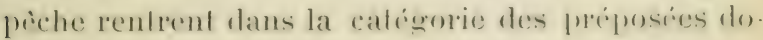
maniaux.

Tous les préposis de relle calrgorie soml mommmen par le ministle de lagriculture ef commiscionncis par lui. (Décrels des 23 octohre $18 \times 3$ et 7 norembre 1896.)

Les rardes el hrigadiers tont le triage est exclusirement compose de hois appartemant aux communes ou aux itablissements publics sont dils communaux. Ils sout nommés par les péfets sur la pró. position des conservateurs, qui délirrent leurs commissions. (C. lor. art. 95; déc. du 2\% mars 18\%ّ ; déc. min. dı 18 mai 18 š3 circ. dı \& juillet 1866.)

Les préposés communaux sont assimilés aux gardes domaniaux en ce qui concerne leurs devoirs et leur's attributions; ils sont soumis à l'autorité des mêmes agents. (C. lor., art. 99.)

209. Commission. - Les préposés de foute catigorie recoivent leur commision par l'infermédiaire du chef de cantonnement.

Lagent forestier, en remetlant la commission au préposé nourellement nommé. lui fait connaile le jom et lheure choisis pour la prostation du serment. (C. for., art. ̈.) 
210. Serment. - Les préposés de ladministration des forêts sont tenus de prèter. derant le tribunal de première instance de l'arrondissement, le serment prescrit par larticle כ̆ du Corle forestier.

Arant d'ètre admis à ce serment, le préposé nourellement promu derra soumettre sa commission au timbre de dimension. On timbre a l'extraordinaire dans les bureaux établis au chef-lieu du département ; dans les chefs-lieux darrondissement, la formalité est remplie au moyen d'un timbre mobile apposé par le recereur d'enregistrement. - Le droit à payer est de $1 \mathrm{fr} .20$.

La commission ainsi timbrée est remise au greefier du tribunal par le préposé qui demande à prèter serment: et, sur la réquisition du ministère public, le tribunal, après lecture de la commission, reçoit le serment dont la teneur est indiquéc par le président.

Le greffier en fait mention sur la commission remise au garde.

L'enregistrement de cet acte coule $̈$ fr. 63. - Il 11 est hì an greftier que 0 fr. 20 pour le timbre de la mention au répertoire; sroit en loul ö fre 88. (ire. du minislre de la Jusliee du a juin 1888.)

211. Dépôt de l'empreinte du marteau. - Lés fl'tílusés sassureront si l'empreinte du marteau affecté au triagge ou ils ront suinstaller a été déposée au 


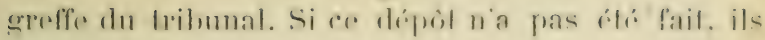
l'effectueront. (C. lor., anl. 7.)

lacte de dépol de lempereinte nirel assujelli it

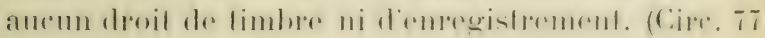
du 20 novembre 1867.)

212. Transcription au greffe. - Si lo Iriage diuns lequel il doit exereer ses fonctions est comprisdans un seul arrondissement, lo prépose na pas a remplir dautres formalités avant son installation. Mais si le triage sétend sur plusiems arrondissements, ou s'il est roisin d'antres arrondissements sur les. quels le garle peut itre obligé de faire quelques actes de son ministère, comme perquisitions, citations, elc., il devra faire transerire sa rommission el lacte de prestation deserment an greffe du tribunal ou des tribunaux dans le ressort desquels il peut être appelé à exercer.

Tout préposé qui change de résidence sans chanyer de grade doit de mime faire inserire sa commission au greffe du tribunal ou des tribunaux dans le ressort destuels il remplit ses fonctions. (C. for., art. ว.) Il est fait mention de cet enregistrement sur la commission par le greffier. Certe formalité est complètement gratuite.

Cet enregistrement a pour objet de foumir au tribunal le moyen de s'assurer si les procès-rerbaux et exploits dressés par les gardes sont l'ceurre de fonc- 
tionnaires régulièrement investis de l'autorité néces. saire.

213. Installation. - Comme les gardes sont responsables des délits rfu'ils n'ont point constatés, il importe gu' e'n arrivant dans un triage ilsen rérifient létat, afin ufun ne puisse pas plus tard imputer à leur négligence les délits commis antérieurement à leur prise de service. Il importe aussi au garde sortant he faire reommaitre l'état dans leyuel il laisse le triage à son successeur.

Cette rérification contralictoire se fait en présence du chef le cantonnement ou du brigadier délexué at cet effet. Il en est dresse un proces-rerbal. qui est revitu de la signature des grardes entrantet sortant.

Les preposés doivent, arant refte rérification eontradictoire, parcomriret visiter avec soin les limites des friages, les coupes et les lieux exposto aux dio lits, afin te simnaler au rhed qui procèle à l'installation les délits non recomnus. - Ils profiteront de retle visile eomplite du friage pour se faire dommer tous les pensoignements indispunsables sur les róritables limites des bois, lat situation des exploitations, ies hahitules des roverains. ele. de maniere à avoir, sur les hommes et les rhoses qu ils aurout à surveiller, des nolions ausi précises que possible. Lors de leur entré enfonclions, les preposis doivent se 
présenterdevant le mairede lemr risidence. (Cirr, du

\section{i1 avril 1867.)}

214. Conseils. - La reconnatissance du triagr faite pour l'installation a permis an momvean garde de. prendre un premier aperecu des forets dont la surveillanee lui est confié Il derra, an debut de son service, compléter ces notions en visilanl aver soin les compes en exploitation, en s'assuranl de la situa fion des bornes, fossés of arbmes de lisciere qui deferminent les limites des bois; il pareomra les bois de particuliers afun d'en vérifire la ronsistaner. pour etre à mème de constater ultériemement les défrichements qui pomraient y che faits; il derra rnfin s'attacher à comnaìtre les habiludes des populations riveraines des bois, les délits les plus lirequents et les moyens employéspour les commette.

Les préposés nourellement installés dans un triage ne samraient apporter trop de réserve dans leurs relations arec les habitants. Ceux qui leur font le plus darances sont sourent les délinguants les plus altoits. Lu garele prudent saura, sans affectation de sévérité, éviter au début les connaissances intimes et ne se mêler en rien aux querelles locales afin de conserver l'indépendance et l'impartialité qui sont indispensables à tout agent de lautorité jour s'acquitter convenablement de ses deroirs.

215. Maisons forestières. - L installation des 
préposés logés en maisons forestieres doit etre précidée diune reconnaissance de l'état des lieux faite par le chef de cantonnement.

Les obligations imposées aux préposés logés ont été déterminées par un arrèté en date du 16 arril 1846, dont la teneur suit :

"A lavenir. tout employé logé en maison fores" tiere souscrira, au pied du proces-rerbal de son " installation, lengagement, pour lui et ses héri" tiers, de se conformer aux conditions prescrites " par ladministration en ce qui concerne soit la " prise de posscsion, soit la remise de la maison et « du terrain en déprentant. L' employé sortant sera * tenu aux réparations locatives dont l'état sera * dressé par le chef de cantommement.

" La prime d'assurance sera payée par l'employé " sortant et celui entrant, dans la proportion du " temps de loecupation de la maison par chacun " deux (1). Il en sera de méme de l’impòt des porteset " fenetres. La contribution persomnelle et mobiliere "sera payee en entier par lemployé sortant. * A prartir du jour de la notification de la déci"sion qui le changerait de résilence on le révorue. " rait. le préposé occupant ne pourra plus faire acte

(1 Ladministration nexige plus que les préposio fassent assurer enntre les risques dincendie les maisons forestieres quils monent. elle leur basse le soin de faire a wurer lem mubilier. 


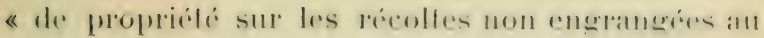
" moment de son changement.

"Les pailles et fumiers resteront sans indemuite " a la disposilion de l'employé entrant; ils ne pour" ront itre detournés de leur destination dans an" cun ras et sous quelque préleste que resoit.

" Liemployé entrant recerra la maison el le tro" rain en dépendant dans l'état où ils se trouveront " a la sortie de son prédécesseur, sans que celui-ci "ou ses héritiers puissent réclamer autre chose que «les frais de culture ef la valeur des semences.

"En cas de difficulté pour la fixation des frais de " culture et du prix des semences, le conservateur. "statuera au ru du rapport du chef de cantonne" ment et des observations de l’inspecteur. "

L'ordonnance intérieure ou extérieure de la maison ne doit pas ètre modifiée par les préposés, à moins d'une autorisation spéciale. Les loges, hangars, etc., construits par les préposés près des maisons forestieres, doirent itre courerts en tuiles ou autres matieres incombustibles. (Circ. $1^{\circ}$ วั92 bis.)

216. Cession d'objets divers. - Le garde sortant doil remettre à son successeur : la plaque et le marteau affectés au triage, le livret ou registre destiné à la transcription des procès-verbaux, ordres de service, etc., et les feuilles de procès-rerbaux non employées. Les plaques des gardes et brigarliers domaniaux 
appartiennent a l'arlministration qui les fournit. Le garile entrant na rien à rembourser à son predecessenr pour la remi-e le cet insigne.

Les plarpestes garles communauxaplartiement soit aux preposis. soit aux communes. Lans le pre. mier cas seulement, le trarte doit en payer la valeur à celui qu'il remplace.

Le martean est affecte au triace dont il porte le numero. mais lactui-ition en est laiste a lacharge he- prepo-is, ausi la raleur doitelle en itre remboursée au garde sortant.

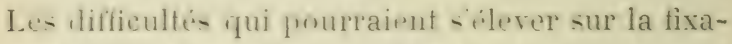
tion du prix du marteau ou de la plargue doivent

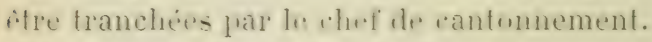

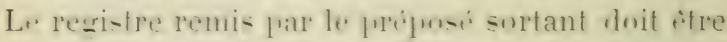
arrate et risi par lagent pui procede a loinstallation

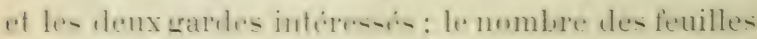
de proces-rethanx lainsia all pripose entrant est inserit -n1 le regi-tre of hoit repre-enter exactement

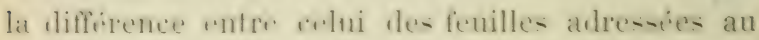
gamle sndant par le chef de cantonnement et celui de- fenilles dont lemploi est justifie.

I.e prepus: sortant wit encore remettre a soli sule. ceneur le anciens regretres, le- omles giniraux he -ervice in-truetiuns et cirsulaires yni hui ont ete lais-s- par son pridiceseur, ain-i que ceux quil a recus pendant sa gestion, 
217. Jardins et cultures des gardes. - Les fmandis domaniamx logés en maison forestiole onl la jonis-

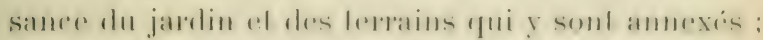
la confenanere des ferrains al jardins ast de mo

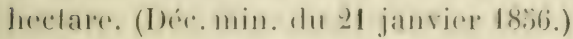

La cloture of lentrelion en sont it la rharge dere

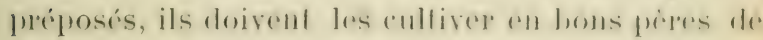
lamille; les produils destimis à lompelien du mónage ne doivent pas être vendus.

Les próposís domanianx non logés pertent oblenir la jonissance d'un terrain dont la eonlenanes nexcede pas un heclare. Colle mesure neet prise qu'en favenr des préposés qui en font la demande. (Circ. du 18 octobre 1871.)

Les préposés tronveront dans mo pelil livere intilulé la Maison du Garde (1) des comseils lres uliles sur la tenue du ménage, la cullure du jardin, l'entretien des animaux. elc.

218. Pâturage de deux vaches. - Les prejosies domaniaux logés ou non en maison forestiere ont le droil dinholuire deux raches au paturage; le pàturage ne doit itre excré que sous la surveillanee de gardiens et dans les cantons décignés par le chef de service, qui en fait mention sur le livet des garles.

(1) Lu Muison du Frurde: Hygienc, Eromomie domestique, Agriculture, par Th. Poncin (consertuteur des Forests). En rolume aree 1 t: grarures; prix $3 \mathrm{li}$. 51 . - J. Rothschild, éditeur. 
Il est formellement interdit aux gardes de faire commerce de lait ni de beurre. ces produits derant ètreconsommés pareuxou leur famille.(Circ.3ł1, 148.)

Les préposés domaniaux sont autorisés à récolter le fourrage nécessaire pour nourrir leurs vaches fendant linver. Les lieux où lherbe derra itre récoltée seront désignés à chaque brigadier el garde par le chef de cantonnement ; cet agrent déciderasi lherbe devra itre fauchée. coupée à la faucille ou arrachée à la main.

Il est interdit aux brigarliers ef gareles de rendre ou d'echanger l'herbe ainsi récoltée, de lemployer a ancun antre usage quà la nourriture de leurs bestanx ot dien abandommer quelque partie que ce soil pour prix de la eoupe on de la récolte (Décis. minis. du 18 juillet 1851.)

219. Panage. - Les prépusés domaniaux sont autorisces a introduire chacun deux pores en foret, dans les cantons défensables. Ces cantons, ainsi que lépoque, la durée ef les autres conditions de lexereice du panage sont intiques, pour une ou plusieursannees, dans un procés-rerbal dressé par le chef de service; un extrait de ce procés-verbal sera inserit sur le livet de chaque préposé. Le panage ne peut itre exerec, a moins diune autorisation spéciale délivrée par le chef de service, que sous la surveillance d'un grardien. (Cire. ill.) 


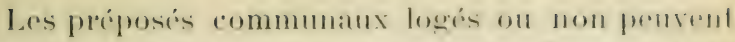
ètre admis à jonir dravantages analogures si fr conseil municipal les y aulorise par moe déliberatlion régulierement approurér ; ils sont alors assiljellis aux memes condilions que les brigaliers of gardes domaniaux.

220. Chauffage. - Les préposés forestiers domaniaux du service actil recoivent pour leur chaullage une délivrance dont la quotité est fixéc à 8 stères al 100 fagots. Cette délivrance est réduite, pour les gardes mixtes, proportionnellement à la portion de traitement quils perçoirent sur le Trésor; elle est aussi réduite pour les préposés domaniaux ef mixtes qui regoivent des bois de chauffage à titre daffouagistes ou d'usagers. Cette quotité peut ètre augmentée en raison de cerlaines exigences climatériques. (Circ. 120̈ du 18 octobre 1871.

Les bois délivés aux préposés sont mis en charge sur les coupes; ils doivent ètre de qualité marchande et sont recus sur la coupe par le chef de cantonnement, qui appose lempreinte de son marteau sur chaque extrémité des bùches. Ils doivent être livrés par ladjudicataire au domicile des préposés; il est dressé procès-rerbal de cette lirraison, cet acte signé par le garde sert de décharge à l'adjudicataire. (Déc. min. du 23 juin 1837.)

S'il n'y a pas de coupe, les bois sont exploités et 
transportés au domicile des gardes aux frais de ladministration. (Déc. min. du 29 mai 1850.) Les bois ainsi lirrés sont destinés à l'usage exclusif des préposés ou de leurs familles. ils ne peurent itre ni cédés ni rendus. En cas de départ pour quelque motif que ce soit. la portion restante doit ètre remise au successeur.

Les préposés du servire du reboisement recoivent une intemnité équivalente au prix du bois de chauffage rui ne pent leur ètre délivé en nature. (Déc. du 9 août 1861.)

Les preposés communaux à qui des délivrances de bois de chanffage sont faites d'après l'autorisation des conseils municipanx sont soumis aux mémes obligations que les gartes inmaniaux.

221. Traitement. - Le traitement des gardes forestiers domaniaux ef mixtes des eantomniers et des gardes-pedele de ge classie est de 700 francs. Ceux de $1^{\text {re }}$ elasce regoirent 800 framr-: toutefois ceux des cardes-peche de fre classe dont le traitement nélait

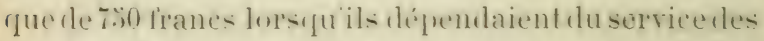
ponts et chausseses conserreront cememe traitement.

Les hrieadiers hors classe recoivent 1.200 francs.

Ceux de le elasse. 1.100 francs: ceux de de classe. 1.000 franes : ceux de $3^{\mathrm{e}}$ classe. 900 franes.

En Alerier, les preporis dus service actif regoirent. à titre de supplément eolonial, en plus du traitement 
de leur grade on france. un quard de ce trailentend. Les trailements ainsi majores sont : pour les gartes

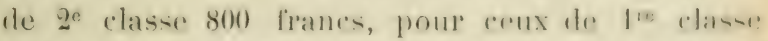

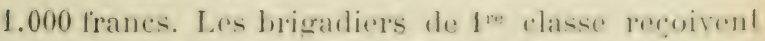

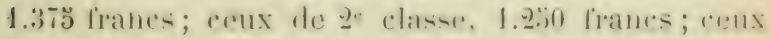
de $3^{\mathrm{e}}$ classe, 1.125 francs.

Les gardes indigines de ge rlasse tonchent

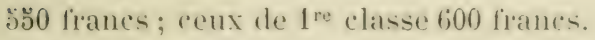

Nous indiquons an $\$ 230$ les allocations direrses

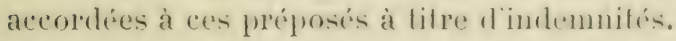

Les préposes décores de la médaille forestiere lecgoivent un supplément de traitement de go francs par an. (Arrèté du 26 arril 1889.)

Les traitements des préposés domaniaux sont ar:quittés charue mois au moyeen de mandats délivrés par le conservateur et payables chez les comptables du Trésor. Les préposés niont pas à parer le timbre de quittance. (Déc. minis. du 3 arril 1834.) Le traitement court à partir du jour fixé par l'arrèté de nomination ; il est liquidé par jour de service; le jour de l'installation, comme celui de la cessation du service comptent dans la liquidatiọn. Charque mois est compté pour trente jours.

222. Retenues. - Le traitement des préposés domaniaux et mixtes est soumis à des retenues de direr'ses natures, dont le montant est affecté au service des jensions de retraite; ces retenues sont : 
$1^{\circ}$ วั p. 100 sur les sommes payées à titre de traitement;

2. Douzième du traitement lors de la première nomination ou dans le cas de réintégration, et douzieme de toute aucrmentation ultérieure;

$3^{\circ}$ Retenues pour cause de congés et dabsences ou par mesure disciplinaire. (Loi du 9 juin 185ั3.)

La retenue de ò j). 100 sopère sur le montant des sommes allouées à raison du service fait. On force les décimales sil y a des fractions de centimes; ainsi, par exemple : pour un traitement annuel de 700 francs dont le douzieme est de $58 \mathrm{fr}$. 33 on déduira de cette derniere somme $2 \mathrm{fr}$. 92 au lieu de $2 \mathrm{fr} .916$, qui est le montant exact du $ّ$ p. 100.

La retenue du donzirme du premier traitement ou des augmentations ultérieures est exerée par quart sur les quatre premiers mandals dus jour un mois entier.

En cas de décès, de démission ou de rérocation -urvenu avant que la retenue du douzieme ait été folalement versie, la moitié non recourrée est préleves sur les rétributions restant dues. (Décret du 28 juillet 1897.)

Les retenues pour cause de congés et mesures disciplinaires seffectuent de la mème maniere.

223. Les traitements des préposés communaux sont soumis a des retenues dont le montant est 
rerse a lemp profil dams la Caison des rebailes pour la vieillesse; les relenues sont :

f. Lne somme anmuelle de go franes pour les laitements de 300 à 499 liranes;

Une somme annuelle de 30 franes pour les lraitements de כั00 à ว99 franes;

Une somme annuelle de 40 frants pour les trailements de 600 franes of an-desilus;

qo Lors de lientrée en fonctions des préposís noulvellement nommés :

Une somme de 20 francs pour les traitements de 300 à 499 francs;

Lne somme de 30 franes pour les traitements de 500 à 599 franes;

Une somme de 40 francs pour les traitements de 600 francs et au-dessus;

$3{ }^{\circ}$ Lors dine augmentation de traitement:

Lne somme de 10 franes pour une augmentation de 50 à 100 francs;

Une somme de 20 francs pour wne augmentation de 100 francs et au-dessus.

Le coût du lirret ( $0 \mathrm{fr}$. 2.) est prélevé en augmen tation de la première retenue effectuée.

Les préposés mixtes et ceux dont le traitement est inférieur à 300 francs ne sont point obligés de supporter les retenues ci-dessus déterminées.

Il est préléré en outre, pour lentretien de l'uni- 
forme des préposés compris dans les compagnies de chasseurs forestiers, une retenue dont nous indiquerons le montant dans le chapitre XI.

224. Les traitements communaux se reglent tous les mois. (Circ. du 14 avril 1894.)

Les retenues pour entrér en fonctions ou augmentation seffectuent par quart sur les premiers mandats délirrés après la reprise de service ou l'augmentation.

La retemue annuclle soprère par moitié sur les mandats du deuxieme et du quatrieme trimestre.

Les retenues de 30 francs seront reparties saroir : 16 franes sur les mandats de juin et l't frans sur eeux de décembre.

Les retenues de masse dentretien se font par quart. (Voir \& 277.)

Chacun des rersements faits à la Caisse des retrailes pour le eomple d'un préposé élibataire ne pourant ilre inferieur à šfranes, ef ceux d'un préposé marié mointre de 10 franes. on répartit la reteinte an muelle de maniere à opérer les versements par nomberes rombls de 8 ou 10 frances. Ces retentes sont alor's impulés. suirant les cas, sur un seul ou sur deux mandats.

29:3. Il est loisible aux préposis daugmenter les rersements dont le reglement preicites a seulement fixé le laux minimum. Les préposes pour qui les 


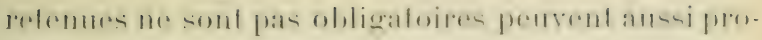

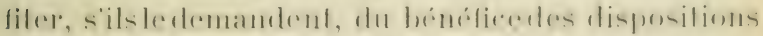

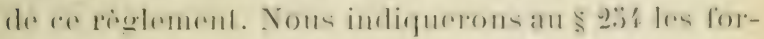

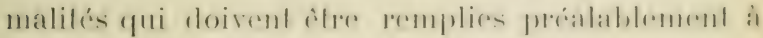

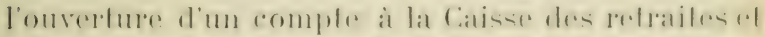

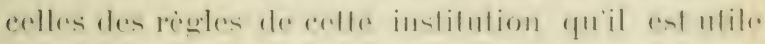
aux préposés de connailte.

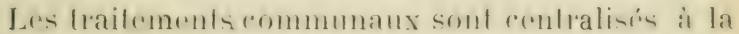

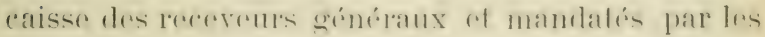

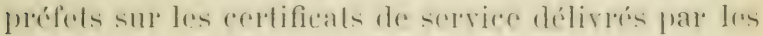
agents forestiers. Ces mantals sont payables clure les recerentrs particulicers el les pereceptems.

226. Perte de mandats. - Si 111 mandal vionl i

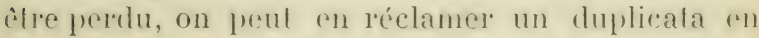
atressant un erelificat du complable rhez leyuel il chail payable, constalant que lo paicment lien a pas be coffertue. A recertifreat deit etre jointe une dé. claration motirie. (Toir modi.l( no 29.)

Il convient, pour la régularité de la complalsilité et pour éviter les pertes de mandats, yue les préposés en touchent le montant dans le courant du mois où ils les reçoirent.

„27. Changements de résidence. - Dans le cas lle changement de résidence, il est accordé aux préposés. pont se rendre à lemr noureau joste, un délai de dix jours à partir de la ressation de leur service. L'administration se réserve de fixer un plus long 
délai quand la dislance à parenurir lexigge. (Circ. du 11 arril 1867.)

Pendant le délai acrorté pour le rhangement de récidence, les trailements domaniaux continuent à itre liquiclés comme si le préposé était resté à son ancien poste; la partie commmale des traitements mixtes et la Iotalité du traitement des gardes communaux reviennent au préposé charcé du serrice.

238. Tabac de cantine. - Les préposés forestiers peurent se procurel du tabac de cantime aux mèmes conditions que les troupes de terre. Il leur est délirré à cet effet, par leur's chefs, des bons au moyen desquels ils peurent arheter ce tabac. dans les débits désignes a raison de 0 fr. 1.; les 100 grammes.

229. Indemnités. - Les intlemnités de tommécs nu de miscions allouétes aux prépusés sont réglées par journées de déplacement el suivant la distanee parcourue.

Il leur est allome pour frais de route 0 fr. 07 par kilometre lorsque le royage sieffectue par ehemins de. lep ou hateaux of 0 lr. 10 lorspu il se fait sur les voies de terre; pour frais de sijum "̈ franes par jour à Paris et $3 \mathrm{fr}$. 33 partout ailleurs.

Aneme indemnite nest allomé : lo pour les distances parcourues a pied : 2) pour trajets en chemin de fer. roilures ou hateaux lorspue les distances pareourues nexident pas fij kilomitres en un jour 
on lorsque les préposés onl une carle de cimenlalion

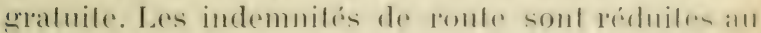

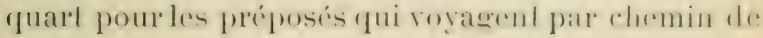
ler avec feuille de roule.

Les préposés déplacés pour faire mu infrim onl droil anx indemnités de loule el de séjonte, mais lindemnilé de séjour ne leur esl payie infersalemenl que pendant un mois; à partix du deuxirmo mois, elle est réduile aux deux tiers.

Les préposés appelés hors de leur hrigade pour concourir aux opérations relatives aux coupes iecgoivent une indemnité de 3 financ's pai joul pour lous frais, s'ils sont tenus de découcher.

Les préposés employés comme ourriers aux lravaux d'aménagement entrepris au comple de l'Élal. soit dans les forèts domaniales, soil dans celles rles communes, reçoirent une indemnilé de 1 flane par jour sils peurent rentrer chez eux et de? francs sils sont obligés de découcher. Les préposés qui sont chargés de surveiller l'exploitation des bois destincis à l'artillerie lecoirent les indemnités suirantes : par fascine poul saucissons el par cent de harls. o fr. 0 j; par fascinc pour gabions. 0 fi. 12 ; ; par grande perehe.

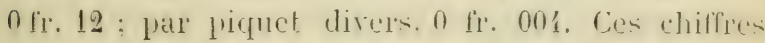

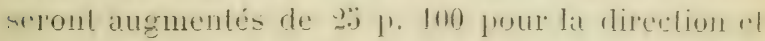
la surveillance du transport de ces bois. (Cric. du 12 mai 1891.) 
230. Les préposés du service du reboisement peurent obtenir des indemnités quand ils sont chargés de la surveillance de traraux qui leur occasionnent des fatigues ou des frais exceptionnels.

Ces indemnite's sont alloures exclusirement :

$1^{\circ}$ Aux préposés qui, sans découcher, effectuent chaque jour un trajet te plus de "j kilomètres ou une ascension d'au moins 600 mètres de hauteur resticale pour se rentre au chantier quils surreillent ainsi fu à ceux yui découchent pour sinstaller d̀ pied diceuvre sous une tente ou une baraque établie aux frais de l'administration.

La somme à allower rarie, suirant les circonstances, de 0 frr. 50 à 1 franc par jour.

2. Aux préfosés rui, étant ohliggés de découcher, sont contraints de payer leur gite.

Inans ce dernier cas, lintemnilé peut sélerer à 3 francs par jour.

Le montant total te lindemnite allouée pour sur veillanee extraorelinaire de travaux ne doit pas dipasser L̆̈0 frances par an fuand le préposé 11 a pas de grite à payer el 300 liances quand il est temu de se loger à ses frais.

Les preposés domanianx qui ne sont pas logés an maison forestiere regoivent me indemnite de logement de 90 franes par an.

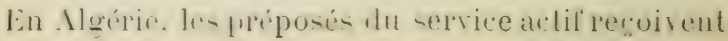




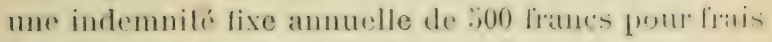
d'entrelien du cheval.

Ceux qui ne sont pas logís en maimon forestibe reçoivent 200 franes a litre dindemmite de logement.

Les gardes indigines regoivent 400 liancs pour l'entretien du cheval.

Tous les préposés nourcllement nommés, ou appelés de la métropole dans le service lorestier de l'Algérie ont droit à une indemnité de première mise de 300 francs.

Ces préposés ont droit à des indemnités de déplacement réglées d'après le tarif de France, lorsqu'ils sont appelés à sortir de leur circonscription pour des missions autorisées. Arrèté du 30 décembre 1885.)

Les gardes-pèche commissionnés par le ministre de l'Agriculture recoirent une in temnité amnuelle fixe de 100 franes s'ils résident dans une ville de

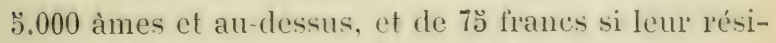
dence n’a pas une population de 3.000 àmes.

Les préposés de l'administration des forèts sont admis à roygager à quart de place sur le réseau des chemins de fer de l'État; pour profiter de cetle réduction, ils derront, pour charpue royage, formuler une demande spéciale par la roie hiérarchique; ils lecerront par la meme voie les autorisations en 
vertu desquelles les gares et stations leur délirreront des billets à prix réduits.

Ces demandes ne derront viser qu'un seul trajet aller et retour ; elles pourront toutefois être renourelées autant de fois quil sera nécessaire. Elles devront diailleurs ètre rédigées de la manière la plus simple, sous forme de lettres ou de simples notes.

Il ne sera pas nécessaire dindiquer les motifs du déplacement, ladministration se réserrant de surseoir à lenroi de toute demande qui ne concerne. rait pas un diplacement de service ou un royage à cffectuer en rertu d'un congé. (Circul. du $1^{\text {er mars }}$ 1897.)

Sur les chemins de fer autres que ceux du réscau le l'Etat, la réduction est de moitié seulement. Les demandes sont faites comme ci-dessus, et le conservateur accorde de la mème maniere les autorisations nécessaires. (Circ. วั21-วั95̆.)

231. Vélocipèdes. - Les préposés de l'administrafion joniscent de liexemption de la taxe établie sur les vélocipèdes par la loi du 28 avril 1893 , lorsquils se servent habilnellement ponr lemr service dere moyen de transport. (Cire. 607.) Ils doivent, à cet effet. arlescer chaque année, dans le courant de janvier, une demante qui ent transmise par l'agent chef de service. en suite de laquelle il leur 
est déliver des plaques do eonfrold spredalus. (Circ. 5วั้.)

232. Brigadiers. - Ies brigadiers sont les infermédiaires entre les gardes of les eluefis de cantomuement.

Ils exereont leur surveillane sur les galderies de leur brigade el sur la conduite administrative et privée des gardes.

Indépendamment de leurs fonctions de surveillance et de la notification des procis-verbaux ou jugements qui leur est ordinairement confiée, les brigadiers sont chargés de reconnaìtre et marfuer les lieux ou derront itre établis les fosses ou fourneaux à charbon, les loges et ateliers.

Le procès-rerbal de délivrance est rédigé et signé par le préposé ayant opéré. (Cire. du 16 janvier $\left.1890, \mathrm{n}^{\circ} 416.\right)$

Ils s'occupent de la délivrance des menus produits, tels que plantes, harts, ete., toutes les fois que cette délivrance ne peut-ètre faite sans la surveillance du garde local.

Ils marquent, lorsque le conservateur en aura donné l'autorisation, les porcs et bestiaux admis au parcours dans les cantons défensableś. (Circ. วั8̈.)

Ils peuvent remplacer les agents forestiers dans les ventes sur les lieux des produits principaux et accessoires des forèts communales et d'établisse- 
ments publics, et dans les rentes sur les lieux des produits principaux et accessoires des forèts domaniales, quand le montant de l'estimation ne dépasse pas 200 francs. (Cire. du 4 arril 1888.)

Ils surveillent le travail des gardes cantonniers. dont ils risent les livrets: ils doivent signaler les absences non autorisées de ces préposés.

Ciest aux brigadiers qüineombe le soin de faire exécuter par les gardes tous les menus traraux dentretien, tels que: nettoiement des laies sommières et des lignes d'aménagement obstruées par les branchages, les ronces et les herbes, dégagement des semis de chène dans les jeunes taillis, émondage des baliveaux, etc.

Enfin ils prennent, lorspue les circonstances lexigent. la direction des tournées de nuit qui sont sourent nécessaires pour réprimer les délits de pàturage ou de chasse.

Ils veillent à la tenue des gardes, sassurent par des verifieations frequentes que leurs armes sont bien entretemues ot que les munitions qui leur sont confiées sont à l'abri de l'humidité.

Ils doivent informer sans délai le chef de cantonnement de tout fait intépessant le service ou le persomnel. pui arrire i leur connaissance.

I es lurigadiers sonf sourent phargés de la surreillanee spéciale d'un triage : ils remplissent alors, 


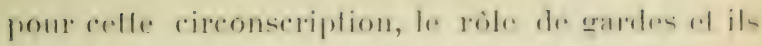

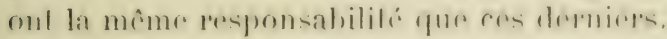

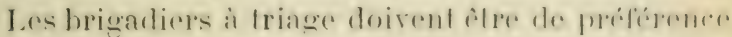
appelés anx posters de brigarliers sams lriage. (Cire. n०552 bis.)

Lesbrigadiersdu servier destumes quisontohligés drese pourvoir d'un cheval peuvent pecevoir mo indemnité anmuelle de 300 franes. (Arr. min. du 20 avril 1833; Instruction générale du 12 décembre 1882.)

Le traitement des brigadiers communaux varie suivant l'importance duservice el surtout d'après l.s dispositions des conseils municipaux.

233. Tenue, - Les préposés, dans l'exercice de leurs fonctions, doivent toujours être revêtus des insignes de leur emploi. (Ori., art. 34.)

La plaque est l'insigne distinctif des fonctions des préposés forestiers ; ils doivent la porter d'une manière ostensible.

L'habillement de petite tenue des brigadiers et gardes forestiers de toute catégorie est réglé ainsi qu'il suit :

$1^{\circ}$ Blouse bleue en coutil treillis de coton, sur le devant de laquelle est pratiquée une ouverture de $0^{\mathrm{m}}, \mathbf{4 0}$ de longueur, garnic d'une parementure en éloffe pareille de $0^{\text {n }}, 0$ de largeur.

Au milieu de cette parementure est ourerte une boutonnière avec un bouton grelot d uniforme col- 
respondant. Le collet est rabattant, arrondi aux angles et fermé par une agrafe noire.

Au-dessus de l'épaulette est fixée une patte en étolfe semblable à celle de la blouse, doublée et pirquée sur les bords; l'extrémité supérieure de cette patte est pourvue diune boutonnière à larquelle correspond unbouton grelot diniforme. Les parements des manthes sont fermés à l'aide d'un bouton noir cousu à plat.

20 Gilet it manches en drap rert foncé fermant droit sur la poitrine au moven de onze petits boutons grelots duniforme: ce gilet porte un collet rabattant dit à la chevalière, arrondi des houts, passepoilé de jonquille et garni de chaque coté d'un cor de chasse brodé en laine jonquille. Le dos et les manches sont en croisé noir doublé en coton écru.

3. Pantalon en drap eris bleuté, passepoilé de jonquille pareil a celui de la grande tenue pour lhirer. En itt. pantalon en coutil rayé bleu dÉreux, de mème forme et dimension que celui en drap.

$4^{\circ}$ Képi souple ielentique à celui de la grande lenue (arec la coearde en moins). Les hrigadiers forleront sur le képi afferté a la petile tenue. exclusitement un galon en argent de cing millimetros, plaré autour du banteau, au-dessous du passepoil jonquille. 
PERSONNEL

3o Cravate blene en roton "modible diofrounance ".

Les vètements al coiffures de grande frome ne doivent pas alre portés en petite tenur, tant quilis n'auronl pas fait le lemps de service réglementaire.

11 est expressément intertit d apporter ancunc modifieation de fantaisie à la grande comme à la petile tenue, notamment en er qui roncerne les insignes de grade et accessoires.

Les préposés de toul grade doirent en outre itre munis des objets suivants :

10 Sac de chasse, dit carnier aree bantoulière ('n cuir noir ;

\section{$2^{\circ}$ Plaque ;}

$3^{\circ}$ Marteau;

$4^{\circ}$ Livret ;

5 Chaîne métrique.

L'administration fournit aux préposés la plarque ot le livret; les autres objets sont achetés et payés directement par les gardes aux fournisseurs désignés par le conservateur ou le chef de service.

23'. Les chefs de cantonnement rérifieront la tenue dans leurs visites en forèt et signaleront à l'inspecteur les objets d'habillement et d'équipement dont les préposés auraient à se pourvoir. L'inspecteur transmettra ces rapports avec son avis au conservateur, qui statuera. Si, dans le mois qui suivra 
la notification de la décision du conservateur, les préposés ne justifient pas qu'ils ont formé la commande des objets reconnus nécessaires, le conserrateur les suspendra de leurs fonctions et en référera à l'administration. (Circ. วั90.)

A moins de circonstances exceptionnelles dontlad. ministration sera juge. les préposés qui ne seront pas pourvus, dans les trois mois de leur installation, des objetsdhabillement et d'équipement prescrits, seront considérés comme démissionnaires. (Mème circ.)

Il est important que, dans lexercice de leurs fonctions, les préposés soient toujours revêtus de leur potite tenue et pourrus de leur plarque; le port le ce costume et des insignes distinctifs de l'emploi no permet pas de mérommaitre la qualité des gardes et prérient ainsi les riolenees auxruelles ils pourraient être exposés.

Nous indiquons au chapitre XI les dispositions relatives à la grande tenue el à l'armement, qui se raftachent a l'oreanisation militaire du corps des chasseurs forestiers.

29.5. Congés. - Aurun préposé ne loit quitter son poste sans un concé régulier. (Arrêté ministériel du 25 arril 185\%)

Les eongés des préposís domaniaux of mixtes sont aceordés par los conservateurs. (Cireulaire 90 . 
Le conservatenr aceorde anssi les rongés des gar. des communaux.

Les employés ne peurent obtenir chaque anner. un congé ou une autorisation d'alsence de plus dre quinze jours sans subir une retenue. Toulefois 111 congre d'un mois sans relenue peul itre accorde it ceux qui n'ont joui d'aucune autorisalion d'absener pendant trois années conséculives.

Pour les congés de moins de trois mois, la relenue est de la moitic ou des deux liers au plus du traitement.

Après trois mois de congés consécutifs ou non, dans la mème année, l'intégralité du traitement est retenue, et le temps excédant les trois mois n’est pas compté comme service effectif pour la pension de retraite.

Sont affranchies de toute retenue les absences ayant pour cause l'accomplissement d'un des deroirs imposés par la loi.

En cas d'absence pour cause de maladie dument constatée, le fonctionnaire ou l'employé peut être aulorisé à conserver l'intégralité de son traitement pendant un temps qui ne peut excéder trois mois ; pendant les trois mois suivants, il peut obtenir un congé avec retenue de la moitié au moins et les deux tiers au plus du traitement.

Si la maladie est la suite d'un acte de dérouement 
dans un intérêt public ou d'une lutte soutenue dans lexercice de leurs fonctions ; si clle esl déterminéc par un accident grave résultant notoirement de lexercice de leurs fonctions, les préposés peurent conserver l'intégralité de leur traitement jusquà leur rétablissement ou leur mise à la retraite. (Décret du 9 nov. 1853 , art. 16.)

L'emploỵé qui s’est absenté ou qui a dépassé la durée de son congé sans autorisation peut être privé de son traitement pendant un temps double de celui de son absence irréguliere. (Mème décret, art. 17.)

Toute demande de congé doit énoncer le motif de labsence et le lieu où le réclamant a lintention de se rendre (Arr. minist. du 2ّ arril 18ว4) : elle doit être transmise par la voie hiérarehique.

Toute demande de enngé sans retenue, pour eause de maladie, doit ètre appurée d'un certifieat de méderin; dans le cas où la maladie est de nature à entrainer un déplacement, la nécessité doit en ètre constatée par un certificat d'un médecin désigné par le préfet et assermenté. (Mème arrèté, art. 16.)

Les congés cessent dietre ralables suil n'en a pas che fait usage dans les quinze jours de leur notification. (Id, art. 2.)

Quand des rirconstanres graves nécessitent un départ immédiat, les préposés peurent quitter leur 
poste sans avoir obtenu un conge, mais non salls aroir prevenu leur suprerem hiérarehique. (Circulaire $\left.n^{\circ} 91.\right)$

236. Admission dans les hôpitaux militaires. - I M préposés du service domanial ou mixle qui su foront transporter dans un hoppital, ou qui se rendront aux eaux pour cause de maladie dument constatée on par suite de blessures reçues dans l'exereice de leurs fonctions pourront ètre admis dans les hopplaux mililaires; ils y seront traités comme les sous-officiers de larmée. Les frais de séjour dans ces élablisse. ments sont payés par ladministration.

Les demandes d'admission dans les établissements d'eaux thermales didmélie-les-Bains, de Bareges, de Bourbonne, de Bourbon l Archambault, du Gua. gno, de Plombières et de Vichy sont adressées au ministre de la Guerre el transmises par la voie hiérarchique. Elles doivent parrenir à l'administration des forèts arant le 10 mars pour les deux premières saisons de tous les établissements, excepté Bourbonne, el avant le 10 mai pour les dernieres saisons, pour les demandes dadmission à l'étaJlissement de Bourbonne ees dales sont reculées de Lö jours. (Cire. du 9 sept. 1889, n 414 .) Un certifirat du médecin roit y ille joint. (Circulaire $\left.11^{\circ} 17,152.\right)$

237. Mariages. - Aucun préposé, domanial ou 
mixte, ne pourra se marier sans en aroir référé par la roie hiérarchicue au conservateur sous les ordies duquel il est placé.

Si le conservateur estime que le mariage projeté ne peut nuire au service, ni porter atteinte à la con. sidération du préposé, il informera ce dernier par la mème voie, qu'il ne soppose pas au mariage. Si le conservateur estime quil y a lieu de s'opposer au mariage, il transmettra la demande arec ses observations, et son avis motivé au directeur qui statuera.

Il ne peut ètre statué sur les demandes en autorisation de mariage formulées par des préposés nou liberres du service militaire quau ru d'une permission émanant de lautorité militaire. (Cir. $n^{\circ}$ รั0.)

Le préposé qui se mariera malgré lopposition du directeur sera réputé démissionnaire. Pourra également être considéré comme démissionnaire le préposé qui se mariera sans en référer à l'adminis. tration ou sans attendre sa décision. (Cir. no 800.)

238. Médaille forestière. - Lnu décret en date du 13 mai 1883 a institué une médaille d'honneur des. tince à récompenser les préposés lorestiers.

Celte médaille nest accordée qu’aux préposés yui complent ringt ans de scrvices irréprochables, ou qui se sont sigualés par des actes de dérouement 


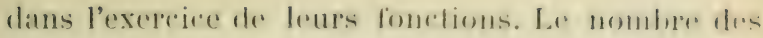
proposés médaillés ne pourra siblever an des-lls de 290. Dans ce nombre sont compris les lo proposis sédentaires qui ponront rerevoir la mérlaille. (.1rrêté du 30 juin 1891.)

Lat médaille forestiore est allarlese a un ruban rayé vert el jonquille. Le ruban ne peut ilre porté sans la médaille.

Lautorisation de porter la médaille peut ètre suspendue pourmotifs graves par le ministre de lidgri. culture.

239. Gardes-pêche des ponts et chaussées. - I Les préjosés chargés de la surveillance des cananx of des parlies canalisées des rivieres navigables ef flollables se divisent en brigadier's ef grardes. Ils sont sous les ordres des ingénieurs des ponts et chanssées.

Ils sont nommés par le ministre des traraux julblics et commissionnés par lui.

Les gardes sont choisis : l" parmi les sous-officiers juésentés par la commission de classement du ministre de la guerre; 20 parmi les anciens sons-officiers àgés de moins de 33 ans et à défaut de sous. officiers parmi lescandidals cirilsn ayant pas tépassí l'àge de 3ə̆ ans et àgés de 2马̈ ans au moins.

Les brigadiers sont choisis parmi les gardes ayant au moins deux ans en cette qualité.

Toutes les prescriptions relitives : an serment 
(§ 210 et 212), aux incompatibilités § 249-50), aux peines disciplinaires (ș 25\%). sappliquent au personnel des ponts et chaussées.

La réprimande, la retenue sur le traitement, la suspension, sont prononcées par le préfet; le changement de résidence, la descente de grade. !a rérocation, sont prononcés par le directem des ponts et chaussées.

Les traitements alloués aux préposés de la pèche sont les mèmes que ceux des préposés de l'administratıon des forèts (roir \$ 221), arec cette seule dilférence que les gardes de $1^{\text {re }}$ classe ne recoirent que $\dddot{0} 0$ francs: mais ils peurent ètre appointés à 800 francs quand ils ont 10 ans de service. (Décr. du 11 janvier 1884.)

Les prél osés de la pèche au service de's ponts et chauscées regroirent une indemnité de logement de 100 francs sils résident dans une rille de $ð .000$ àmes et au-dessus ; lindemnité est réduite à 75 francs lorsque la population de leur résidence est de moins de วั.000 âmes.

Cápréposés noul pas d'miforme ; comme insiEnes de leurs fonctions ils portent une playue qui leur est fournic par ladministration des ponts et chausien, anns fue le gabarit pour la me-ure des filets et un revolver avec sa gaine.

Les ingénieurs ordinaires peurent accorder aux 
preposes sous leurs orderes des pormissions d'aldsence de 10 jours au plus.

Cest anx prefels qu'il apparlicent d'areopeler des congés de 10 jours à un mois. Les congés de plus d'm mois sonf areorlés par la direction dees ponds ol chaussées. (Cir. du 20 novembre 183̈.)

Les retraites des gardes perehe sont liquideres eonformément aux dicposilions de la loi du 9 juin 1833.

Toutes les règles grénérales de la rédarlion dres procès-verbaux, de laffirmation, elc.e contenues dans le chapitre $I^{\text {er }}$ sappliquent au service de la pêche comme à celui des forêts. 


\section{CHAPITRE IX}

\section{RÈGLES DE SERVICE DES PRÉPOSÉS}

\section{DE L'ADMINISTRATION DES FORÈTS}

Lirrel dordre. - Fenilles de procis-verhaux. - Marleanx. Plaruu - - Corre-pondance. - Franchise. - Résidence. Inempatihilites - Prohitritions. - Privilige de juridietion. Rimsponsabilite. - Peine- listiplinaires. - Marryus de respect.

2'0. Livret d'ordre. - Le lirret dont chaque prépose es muni wt destiné à inserire, jour par jour ef sans lacume : les procies-rerhanx de délit. la recon. nais-sane deschabliset rolis. les délivances dument antorisés de harts. plants. fenilles terres piepres. sables et en gréneral de toutes les productions du sol forestier. les ritations et signifieations. en désigrnant leur olijel et le nom de la personne à qui la copie de l'exploit a été remise, et les opérations auxquelles les gardes concourent. 
Si. dans le coms de leme lourne jommaliere. Jan

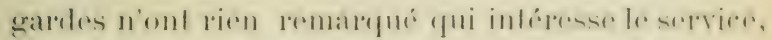
ils le disent sur leur livret.

Le liven doit alpe soigmensement frout sous an-

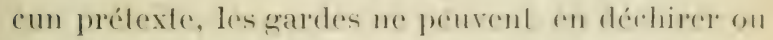
en enlever les fenilles, pui sont numérotés ol para. phées.

24. Les procis-verhanx de délils doivent y deb franserits dans leur enlier. le jour meme de la ré. daction; laffirmation of lenregistrement doivent être mentionnés à leur date.

La reconnaissance des chablis ef volis doit efre inscrite à sa date de la manière suivante :

Reconnu, au canton de..., forêt de..., deux chẻnes chablis de $0 \mathrm{~m} .60$ à $0 \mathrm{~m} .80$ de lour, que nous avons marqués de notre marteau.

L'inscription des délirrances des menus produits doit toujours mentionner la décision qui les a autorisées; cette inscription pent être faite dans la forme. suivante :

Déliuré au sieur. N..., dans la forêt de..., au canton de..., la quantité de..., suivant décision du... inscrile à notre livret, folio ..., $n^{\circ} \ldots$

Les citations et significations s'inscrivent à leur date, ainsi qu'il suit :

Signifié au sieur..., demeurant à..., un procès-terbal de délit..., $n^{\circ} \ldots$, parlant à... 
La mention des tournées et pérations se fera d'une manière sommaire. mais complete. Ainsi il ne suffit pas dinsopire an livpet: tournée, rien de noutruu: il laut indiquer les canlons pareourus, les compes risitées.

20.2. Les ordres généraux de service doirent aussi etre transerits sur le lirpet. ainsi que les arrètés et décisions qui autorisent les délirrances de menus produits. Pour faciliter les recherches, il sera utile de former. au commencement du livet, une table dans laquelle les ordres généraux de service seront mentionnés diune façon sommaire. arec renvoi aux pages du liveet sur lesquelles ils sont transcrits.

243. Feuilles de procès-verbaux. -- Les feuilles de proces-rerbaux sont transmises aux gardes par le chef de cantonnement: clles sont numérotées; la remise ou la réception doit en être mentionnéc au livret dans la forme suivante :

Remis ou reçu pour le service du triage $n^{\text {os }} .$. les fenilles de procés-verbaux de délit portant les $n^{\circ} \ldots$, i....

Les gardes doivent justitier de lemploi de toutes les feuilles recues. Ils sont tenus de représenter celles qui, par accitent. soraient déchirées ou hors de service.

2'4. Marteau. - Le marteau des gardes et des 


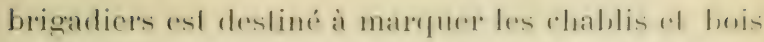
de délil. Lempreinte on est quadrangulaire ef forte, aree les leflees iniliales de la fonclion, le numéro du cantommement ef relui du triage. Les arteres aballus on rompus par les rents, les sonches provenand des délils doivent èlre, au moment mème de la recomnaissance, lirappés de l'empreinte du martean. Cette marfue sert a prouver la vigilance du préposé; elle permel en outre de recomnailre ultérienrement les bois qui riendraient à ètre chlerés par les délinquants. Il ne sulfit pas, cependanl, pour qu'un préposé soit à l'abri de lout reproche et déchargé de loute responsabilité, qu'il ait apposé l'cmpreiute de son marteau sur les souches des arjores enlevés en délit; il faut encore qu'il fasse mention de la découverte de ces délits sur son livre, en incliquant lessence et la dimension des souches, et quil justifie des recherches quil a faites pour arriver à connaitre les délinquants.

240. Plaques. - La plaque est linsigne des lonclions des préposés forestiers. Ladministration des forèts fournit les plaques des gardes domaniaux et mixtes; celles des gardes communaux et d'établissements publics sont payées par les communes et établissements ou par les préposés. - La plaque se porte ostensiblement.

246. Correspondance. - Les gardes embrigadés 
correspondent directement avec leurs brigadiers; ceux-ci et les gardes non embrigadés correspondent arec leur chef immédiat, garde général ou inspecteur adjoint.

11 est interdit aux préposés dadresser directement, et sans lintermédiaire de leurs chef's immécliats, à ladministration et aux agents supérieurs. foute demande, réclamation ou lettre quelconque relative a leurs fonctions. Il leur est interdit de faire des pétitions collectives.

247. Franchise. - Le mode de correspondance en fianchise a été réglé par un grand nombre de décisinns dont nous indiquerons seulement les disposilions qui intéressent les préposés.

Les brigadiers sont autorisés à correspondre en franchise sous bande, avec les conservateurs, inspecteurs, inspecteurs adjoints. gardes généraux, gareles el cantomiers, dans l'étenclue de la conservation a larpuelle ils sont attachés.

Les gardes forestiers et les gardes cantomniers sont autorisis a correspondre de la mème manière arec leurs brigadier's, dans létendue de la circonscription de ces derniers, arec les conservateurs, inspecteurs, inspecteurs adjoints ef gardes généraux dans l'étendue dela conserration.

La signalure de lexpéditeur doit stre écrite a la main aprés la désignation de sa qualité. 
Les paquels confresignes doivent itre remis an

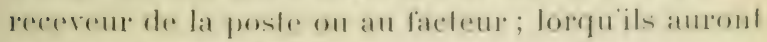

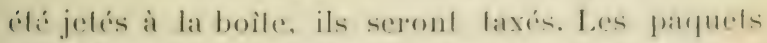
de service pourroml alle jetés dans les boiles rurales des communes ou il n'y a pas de burean de poste.

Les lefles ef papuels contresignés el mis soms bandes ne pourlont itre recus et expédiés en lranchise, si la largeur des bandes excede le tiers de la surface des lettres et paquels.

Il est défendu de comprendre dans les dépèches expédiées en franchise des lettres, papiers ou ohjets queleonques itrangers au service.

En cas de soupcon de fraude ou d'omission d'une seule des formalités prescrites, les préposés des postes sont antorisés à taxer les lettres et paruets en totalité, ou à exiger que le contenu soit rérifié en leur présence par les persomnes auxquelles ils sont adressés; s’il résulte de celte rérification qu il y a fraude, ils rédigeront un procès-verbal qui sera transmis à l'arlministration supérieure.

Tout paquet contresigné dont le poids excéderait 1 kilogramme pourra etre refusé par le directeur de la poste.

248. Résidence. - Les préposés résideront dans le voisinage des forèts ou triages confiés à leur surveillance. 
Le lieu de leur résidence sera indiqué par le conservateur. (Ord., art. 2丂.)

'Toutefois, le conservateur ne peut changer un garde de triage ni déplacer un garde logé en maison forestière sans en référer à ladministration. Le droit conféré au conservateur par larticle 2o de lordonnance réglementaire se réduit à pouvoir autoriser un préposé à résider dans un village ou hameau autre que celui qui lui a été assigné pour résidence.

249. Incompatibilités. - Liemploi de garde forestier est incompatible aree toute aule fonction administrative. (C. for., art. 4.)

Celte incompatibilite est absolue surtout pour les gardes domaniaux ou mixtes: non seulement cenxci ne peurent occuper aucun emploi rétribué, mais ils ne peurent accepter aucune fonction gratuite: ainsi. ils ne peuvent itre maires, aljoints, membres du Conseil municipal : ils ne doivent accepter aucune misson. meme temporaire. sans laulorisation de ladministration. Cepentant, dans la pratique. certains gardes, notamment les gardes communaux peurent ètre autorisés par le conservateur à surveiller des propriétés, soit communales, soit particulières; mais ces autorisations. de pure tolérance, sont révocables à volonté.

250. Prohibitions. - Les parents ou alliés d'un 
garde ne penvent ille facterms des conpes de som triage. Il est interdil aux gardes :

$1^{\circ} \mathrm{De}$ latide commere de bois, direstement ont indirectement; de premde part ans adjurleations de coupes, chablis, glandés et autres menus marehres queleonques (Orel., arl. 31 ; C. lor', all. 21) ;

2o De lenir auberge ou de vendre des boissons en détail (idem) ;

3" De rien receroir des adjudicataires on de lontes autres persomnes, pour objet relatif à leurs fonc. tions (art. 35.) ;

$4^{\circ}$ De disposer des bois chablis on de délits gisant en foret el d'aucun produit forestier ;

Jo De chasser. - Ils ne peurent obtenir le permis de chasse. (L. chasse, art. 7.)

Ces dispositions, inscrites au lirret des préposés, n'ont besoin daucun commentaire; elles doivent itre exécutées strictement. Toute infraction entraine la révocation du garde, sans préjudice des poursuites qui pourraient ère dirigées contre lui dans le cas où il se serait rendu coupable de concussion ou de prévarication.

251. Privilège de juridiction. - Les préposés forestiers poursuiris à raison des crimes ou délits commis dans l'exercice de leurs fonctions ne peurent ètre jugés que par la Cour d'appel ; si le fait incriminé entraîne la peine de la forfaiture ou une autre 
peine plus grave. linstruction est faite par le procureur général et le président de la Cour ou par les magistrats spécialement délégués par eux.

Le jugement de la Cour est sans appel. (C. instr. crim., art. 479. 483, 484.)

Les préposés forestiers ne peuvent ètre actionnés derant les tribunaux cirils pour faits accomplis dans leurs fonctions d'officiers de police judiciaire que par la roie de la prise à partie. Ainsi un garde cité devant le juge de paix ou tribunal civil pour répraration de dommages causés par lui dans l'exercice de ses fonctions doit récuser la compétence du tribunal ou du juge de paix, et se préraloir des dispositions des articles 309 et suirants du Code de procédure civile. (Circ. no 269.)

252. Toutes les fois qu un préposé est poursuivi en justice pour des faits commis, snit dans lexercice de ses fonctions, snit à raison de ces mèmes fonctions. il doit. quel que soit d ailleurs le tribunal devant lequel il est cité, en informer immédiatement son chef de cantomnement. qui lui indiquera la marehe à suive pour sauvegarder ses droits.

253. Responsabilité. - Les gardes sont responsables des délits, dégrats, abus et abroutissements qui ont lieu dans leurs triages, et passiblesdesamendeset indemnités encourues par les délinquants, lorsqu'ils n'ont pas dùment constaté les délits. (C. for., art. 6.) 
Noms arous vo, all chapilere VIII, comment um prepose fail eomstaler, an moment de som inslallalion, l'blat du triage qu'il en appelé it surveiller. Tous les délits commis depuis celle comslatation, of qui nauraient pas éle lobjel de proces-rorhanx réguliers, sont mis a la charge du propose negligent. Il ne sulfit pas meme, pour que sa responsa. bilité soil comrerte, quil ail recommu el maryur de: son martean les sonches des arbres ; rigoureusement, il derrait y aroir constalation par un procès-rerbal, ainsi que nous l'arons dit précédem. ment.

La rédaction de ces actes niest pas exigre d'une manière absolue pour les délits qui n'ont pas une grande importance, et larministration nuse du droit quelle a de poursuirre les gardes quautant qu'il y a de leur part un oubli grave et répété de leurs deroirs. Cependant les préposés derront ne jamais oublier les conséfuences que peut entrainer leur négligence à constater les délits.

Les gardes poursuivis comme responsables de délits non constatés sont cités derant le tribunal de police correctionnelle et condamnés aux mèmes peines et dommages quils auraient encourus suls avaient eux-mèmes commis les délits qu'ils n'ont pas constatés.

L'action en responsabilité ne peut pas ètre exercée 
contre les préposés sans une autorisation du direc. teur des forêts. (Circ. $n^{\circ}$ 148.)

Les préposés ainsi poursuivis ne sont pas considérés comme auteurs des délits non constatés; aussi ne jouissent-ils pas du privilège d'ètre jugés par la chambre cirile de la Cour d appel, comme lorsqu ils sont poursuiris pour erimes ou délits commis dans l'exercice de leurs fonctions.

¿öx. Peines disciplinaires. - Les préposés forestiers de toute catégorie sont soumis au contròle et à la surveillance de leurs supérieurs hiérarchiques. Comme conséquence de cette subordination. ceuxci ont le troit de leur infliger certaines punitions. dans le cas où il se seraient rendus coupables de quelyue faute contre la discipline ou les règlements forestiers.

Les preines disciplinaires sont : 1" La réprimande simple, verhale ou écrite; - 2 La réprimande arec mise a lordre du jour; - $3^{\circ}$ La retenue sur le

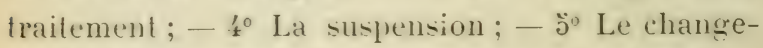
ment de résidence ; $-6^{\circ}$ La deseente de grade : To Le remplacement pur et simple; - So La rérocation.

La réprimande verbale ou écrite peut ètre in lligée aux préposés par tous leurs chefs. - La réprimande avec mise à l'ordre du jour dans la brigade, par les chefs de cantonnement, les inspecteurs et le 
conservalentr. - Ia repremande comtere les briga-

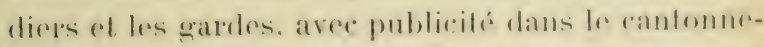

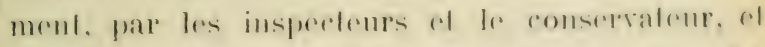
dans linspection par le conservateme seul. - La

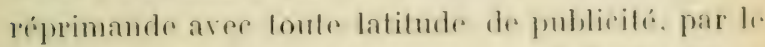
direcleur général. - La relenue sur le traitement ronter les brigadiers el gardes pour rimy jours an plus. par linspecteur, à charge d'en rendre comple au conservateur; pour quinze jours an plus, par le conscrvateur à charge dien rentre comple au directeur pour les préposés domaniaux, au préfel pour les communaux.

La retenue sur le traitement de plus de quinze jours, par le directeur général, pour les préposés domaniaux; par le préfet pour ceux des rommunes; la retenue ne peut excéder deux mois te traitement. (Déc. du 9 nov. 1853, art. 17.)

La suspension, par le conservateur, à charge d'en rendre compte immédiatement au directeur ou au préfet, suivant qu’il s’agira de préposés domaniaux ou communaux.

Le changement de résidence, la descente de grade ou de classe, par le directeur général on par le préfet, chacun pour les employés à sa nomination.

Le remplacement pur et simple et la rérocation, par le directeur général après délibération du Conseil d'administration pour les gardes domaniaux; 
par le prefel pour les garles communaux. (Circ. n 6\%̆. modifiée par lic décret du 250 mars 1852.

Le mode d'instruction des plaintes dont les gardes et brigadier's sont l'objet a été réglé par les circulaires $n^{0:} 15{ }^{\prime}$ et 620 . Il n'est statué sum la plainte qu'après que les préposés inculpés ont été mis en demeure de fournir leurs moyens de justification.

25ั5. Marques de respect. - Tout préposí les forêts doit. mème hors du service. de la déférence et du respect aux fonctionnaires forestiers d'un grade supérieur au sien et aux offeiers de larmée de terre et de mer. La marque du respeet est le salut. que l'inférieur doit toujours faire le premier.

Les préposés sans armes salurnt en portant la main droile au côté droit de la risiere du képi ; s’ils sont assis. ils se lèrent. Les honneurs dus par les hommes sous les armes sont indiqués dans le riglement militaire anmexé au livet dont tous les chas. seurs forestiers sont munis.

Tout préfosé interrogé par un agent doit se tenir delonut. le képi d̀ la main. jusıüa ce yu’il recoire la permision de se courrir. Quant un préposé reut parler à un agent, il doit porter la main à son képi ef attentre lautorisation de prenclre la parole.

En marehe, les gardes of hrigaliers doivent se tenir a dix pas en arriere des agents. a lexception 
du garle du triage, qui mareler on avant four mon. trep le chemin. Pendanl les halles. les proposin soinstalleront a quelques pas des agente, afin de laisiser ces derniers s'enlrelenir librement. 


\section{RETRAITES}

Droit at pension. - Veures. - Orphelins. - Liquidation des pensions. - Majorations. - Maximum. - Minimum. - Tarif des pensions. - Demandes de pen-ions. - Caisse de retraitepour la vieillesse.

2966. Droit à pension. - Les préposés forestiers lomaniaux et mixtes ont droit à une pensinn de retraite lorsqüils ont :0 ans dìge of 20 ans de service. (Loi du 13 avril 1898.)

Le prejosi qui est reonnu par le ministre hors ditat de continuerses fonctions pent obtenir une p+n-ion quoiqu il nait pas วั0 ans. jourvu qu’il ait

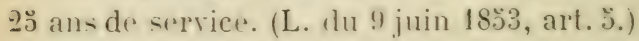

Pexrent ausai ohtenir me pension quels que soient lenr àge el la durér de lemr activité :

1 Les préposés qui auront été mis hors détat de contimuer leur service. soit par suite din acte de déronement daus un intérèt public ou en exposant 


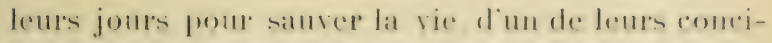
loyens; soil par suile de lulleson combals sombenus dans l'exeredec de leme lomelions;

2" Ceux quin accident grave resullanl notoirement de lexercice de leurs lonelions mel dans limpossibilité de les continuer.

Peuvent également obtenir pension, sils romptrut 4.) ans d'àge et 1. ans de service dans la partic artire. ceux que des infirmités graves, résultant de l'exercice de leurs fonctions, mettent dans l'impossibilité de les continuer ou dont l'emploi aura été supprimé. (Id., art. 11.)

9.;7. Veuves. - La veuve du préposé qui a oblenu une pension de retraite ou qui a accompli la durée de service exigée par l'article 46 de la loi du 13 arril 1899 a droit à pension pourru que son mariage ait été contracté 6 ans avant la cessation des fonctions du mari.

Le droit à la pension nexiste pas pour la reure dans le cas de séparation ou de divorce prononcé sur la demande du mari. (Loi du 9 juin 18ə3. art.13.)

Ont aussi droit à une pension :

10 La veuve du préposé qui, dan- lixereiere ou à l'occasion deses fonctions, a perdu la vic dans $u$ naufrage ou dans un des cas spécifiés au paragraphe 2 de l'article 11 précité, soit immédiatement, soit par suite de l'événement;

Grye. - Stroveillance. 
2. La reure dont le mari aurait perdu la vic par un des accidents prérus au ge paragraphe de l'article 11 ou par suite de cet accident.

Dans les cas spécifiés ci-dessus, il suffit que le mariage soit antérieur à lérénement qui a amené la mort ou la mise à la retraite du mari. (Id., art. 14.)

La reuve de tout préposé décédé postérieurement au 14 arril 1898 après 20 ans de service aura droit, si elle compte six ans de mariage, à une pension égale aux quatre dixièmes du traitement dont le mari jouissait depuis deux ans au moins.

2.58. Orphelins. - Lorphelin ou les orphelins mineurs diun préposé ayant obtenu pensiou ou ayant accompli la durée de service exigée, ou avant perdu la vie dans un des cas prévu par larticle 11 de la loi du 9 juin 18:33, ont droit à un secours annuel lorsque la mère est décédée ou déchue de ses droits.

Ce secours est, quel que soit le nombre des enfants, égal à la pension que la mère aurait obtenue ou pu obtenir; il est partagé entre eux par égales portions et payé jusquà ce que le plus jeune des entants ait atteint liage de 21 ans accomplis; les parts de ceux qui décéderaient ou celles des majeurs faisant retour aux mineurs.

s il existe une reure of un ou plusieurs entants mineurs provenant diun mariage antérieur du pré- 


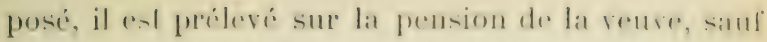

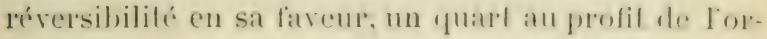
phelin du premier lit, s'il 11 en existe folu $u$ en ìges de minoriti, el la moitic s'il en existe plusieurs. (I.oi du 9 juin 1853, art. 16.)

259. Liquidation des pensions. - La liquidalion de: la pension pour ancienneté on infirmitésest itablic d’après le dernier traitement du préposé s'il en a joui depuis deux ans, ou s'il a touché pendant mne partie de ses deux dernieres années d'activité un traitement plus élevé que son traitement final. Si aucune de ces conditions n est remplie, la pension est liqui dée sur le pied du traitement immédiatement inférieur.

Pour opérer la liquidation de la pension, il est fait un total des années de serrices effectils, tant cirils que militaires, si ces dernier's n'ont pas été rémunérés par une pension; on ajoute à ce total les campagnes complées comme celles des militaires de l'armée de terre ou de mer.

Pour chacune des 2ü premieres amées il est alloué un vingt-cinquième du munimum de la pènsion militaire afférente au grade, et pour rhacune des années suirantes un vingtieme de la différence entre le maximum et le minimun de cette pension.

260. Majorations. - Aux chillies ainsi obtenus on ajoute pour chaque année de service postérienre à la 
quinzieme une annuité de 18 francs pour les brigadiers et les gardes de $1^{\text {re }}$ classe et de 1 francs pour les autres préposés.

Cette majoration ne sapplique quand annés de services effectifs dans la partie active de ladministration des fortits, en sus des 1.j ans de services militaires ou forestiers. Les priposés forestiers yui ont aceompli la durée de services domnant droit au maximum de la pension tel quil est fixé par les lois der 28 lérrier 1857 et a mai 1892. Bénéficient d'une majoration d'un trentième de ce maximum pour charfue anne entipe de service aceomplie depuis qu ils ont droit à ce maximum et au delà de 50 ans d'àge.

Cette majoration ne peut aroir pour effet de porter la pension à une somme supérieure soit à la pension maximum calculie dapres les laril's militaires de la gendarmerie.soit aux neul dixiemes du traitement obtenu depuis deux ans au moins. (Loi du 13 arril 1898, art. 46.)

261. Maximum. - La pension ne putrrat dans ancun cas dépasser les neul dixièmes du traitement affepent an grable orempe depuis denx ans an moins.

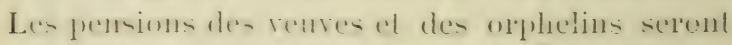
Eqales aux quatre dixiomes de ee maximum: elles seront ancmentices de motici dans les cas mention. nés au fraragraphe lov de larlicle 11 de la loi du 9 juin 
18:38 of de demx cinquiemes dano les eas prérus

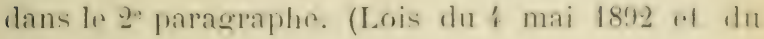
13 arril 1898.)

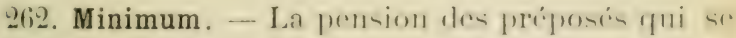
fromrent dans les ras prérus par le paragraphe for de l'artirle 11 de la loi du 3 juin 1833 me pomra stre inférirure an minimm alférenl an crate. pour 2.; ans de service.

Elle ne ponra elre inférienre anx trois quarts dre ee minimum dans les ras menliommís an $2^{\circ}$ paragraphe du même article.

263. Tarifs militaires. - Les laril's pembus applicables au caleul des pensions des préposís foresticrs domaniaux et mixtes par la loi du to mai 1892 sont les suivants :

Brigadiers hor's classe . . min. $900 \mathrm{fr}$., max. 1.200 Brig. de $1^{\text {re }}$ et $2^{\mathrm{e}} \mathrm{cl}$. . . . - $800-1.000$

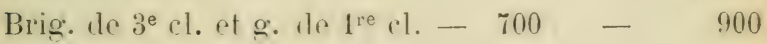
Gardes de 2e cl. ot ranton. - $600 \quad$ -

Ares ces chiffres et les renseignements contenus dans les pages précélentes, tout préposi derrait pouroir calculer assez exactement le chiffer de la pension à laquelle il peut prétendre. Mais la loi dh 13 arril 1898 doit itre combince aree les dispositions des lois de 1833, de 1887 et de 1892, travail quaucum préposé n'est en état de faire : heureusement ce calcul peut, dans la plupart des cas, ètre tres simplifí par 
suite de la disposition qui réduit, dans tous les cas, la pension aux neuf dixièmes du traitement des deux dernières années de grade.

Il ne faut pas oublier de tenir compte du supplément de 50 franes alloué aux préposées décorés de la médaille militaire. Ce chiffre vient en augmentation du traitement.

26't. Les préposés forestiers ne peurent prétendre à une pension d'ancienneté liquidée d'aprés les disfrositions de la loi du 4 mai 1892 que sils comptent ב̈ ans au moins le serviees entièrement pendus dans l'armée on l'administration des forêts. dont 10 ans au moins dans la prartie active de cette administration. (Déeret du 47 aoùt 1892, art. 8.)

Si des serviers civils sédentaires nu actifs acenmplis dans d'antres administrations śajoutent à la periole d'au moins 20 ans de serviees militaires nu actifs des forèts. ils seront liquidés également d'aprex les tarifs mililaires. mais il nentreront pas dans le raleul de la majoration. (Iel., art. 9.)

Les fractions de mois of de franes sont négligées dans le dieompte des pensions. (I1)., art. 10. )

Le lectem a pu remarquer que nous n'arons pas fait eomuaitre romment eres eampagnes sont eompfers. Coest quen effet il serait très difficile dexpliyuer. sans entrer dans des details infinis, comment le defrartement de la fincre sivalue les campagmes. 
Il en est qui eomptent double. telles auldes simplu, d'autres pas du toul: des dérisons ministerielles reglent, apres eharue rampagne, la valent qui lıi sera altribuće.

Celle lacmone n'a du beste pas gramble impurtance. ear il arrivera tres rarement que la duree des rampagnes entre utilement dans lo ealeul à raison de la limilation obligatoire de la pension aux menf dixièmes du dernier traitement.

Les préposés forestiers qui onf éfé retraités avant le 4 mai 1892, recerront chaque ammée un suppliment de pension afin que le tolal de la pension of de l'allocation égale pour chaque intéressé lo chiffre qu'atteindrait la pension de son grade liquidée d'après les larifs actuellement en vigueur. (Circ. 16 avril 1894.)

263. Les gardes-peche commissionmés par le ministre des Travaux publies ne faisant pas partie du corps des chasseurs forestiers ne jouissent pas de la majoration accordée aux préposés forestiers. Leurs retraites sont liquirlées conformément aux dispositions de la loi du 3 juin 4833. Ceux de ees préposés qui ont passé du serrice des ponts et chaussées à celui des forits, seront retraités. comme les forestiers, dés qu'ils seront enrégimentés dans le corps des chasseurs.

266. Toute demande de pension doit etre adressée 
au ministère du département auquel appartient le fonctionnaire. Cette demande doit, à peine de déchéance, être présentée arecles pièces à lappui dans le délai de cinq ans à partir. saroir: pour le titulaire. du jour où il aura été admis à faire valoir ses deroits à la retraite ou du jour de la cessation de ses fonctions, sil a été autorisé à les continuer.

Les demandes de secours annuels formulées par les orphelins doirent être présentées dans le même délai, à partir de la promulgation de la loi du 9 juin 183ั3. ou du jour du décès de leurpère ou de leur mère.

La jouissance de la pension commence du jour de la cessation du traitement ou le lendemain du désès du fonctionnaire : celle du secours annuel, du lendemain du décès du fonctionnaire ou du décès de la reuve: il ne pent. dans aurun cas. y avoir rappel de plus de trois années diarrérages antérieurs à la date de l'insertion au Bulletin des lois du décret de concession. (Id., art. 25.)

Les pensions sont incessibles; aneune saisie on retenue ne peut itre oprére du vivant du fonctionnaire que jusquà concurrence d un einquième pour débet enrersl'Etat ou pourdes eréances privilégiées. aux termes de l'article 2901 du Code Napoléon. et d'un tiers dans lescirconstances prevues par lesarticles 203, 20.), 206. 207 ot 21' du mime Corle. (Iil., art. 26.) 
Toul foneliommaire ou enploye demisciommaire destilue, revorpé demploi, perel sese droils a la pronsion : s'il est remis en activile. son formier servier. lui est compté.

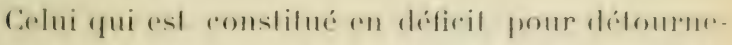
ment de deniers on de matieres on eonvainende de malrersalion. perel sess droils it la pension, lors mème qu’elle aurait élé liquidée on inserile.

La mème disposition est applicable an fonclionnaire eonvaineu de sietre démis de som emploi it prix d'argent et à relui qui aura été comslamné à une peine infamante ou afflictise; si, dans ce dernier ras, il y a réhabilitation, les droits a la pension seront rétablis. (Id., art. 27.)

Le fonctionnaire atmis à faire raloir ses droits à la retraite pour ancienneté, continue à exercer ses fonctions jusquà la délirrance de son brevet de pension, à moins de décision contraire. Il peut mème être maintenu momentanément en activité après la délirrance de son brevet de pension. mais dans ces deux cas, il ny a pas supplément de liquiclation. (Décret du 27 mai 1897.)

267. Le fonctionnaire admis à la retraite doit produire, indépendamment de son arte de naissance et d'une déclaration de domicile :

$1^{\circ}$ Pour la juslification des services rivils : un extrait dument certifié des registres et sommiers de 
l'administration ou du ministère auquel il a appartenu. énonçant ses nom et prénoms, sa qualité, la date et le lieu de sa naissance, la date de son entrée dans l'emploi arec traitement. la série de ses grades et services. l'époque de la cessation d'activité et le montant du traitement dont il a joui pendant chacune des six dernières années de

Lorsqu'il n'aura pas existé de registres ou que tous les serrices administratifs ne se troureront pas inscrits sur les registres existants, il y sera suppléé. soit par un certifirat du chefou des chefs compétents des administrations où l'emplnyé aura serri, relatant les indirations ci-dessus énoncées, snit parextrait des comptes et états d'émargement certifié par le greffier de la Cour des comptes.

Les services cirils rendus hors deurope sont constatés par un certifieat distinct délivé par le ministre competent. Ce certifieat, conforme au modèle annexé au décret. énonee. pour chaque mutation demploi. le traitement normal du grade ef le supplément acroplé a titre de traitement colonial.

A défaut de rese justifieations, ef lorsque, pour rause de lestruction des arehives dont on aurait pu les extraire, on du deces des fonetionnaires supériems. limposibilité de les produire amra été pronré les serviers pouront itre constatés par arte de notoriété. 
20 Pour la justifiention des serrices milibares de lerre et de mer :

In eertifieal dipectement smané du ministire de la Guerre ou de la Marine.

Les arles de notoriéti. Les congés de riforme ol les actes de lieconciement ne somt pas admis prome la

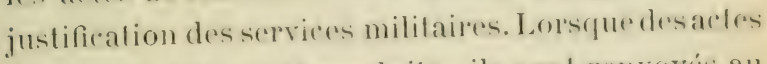
de eette nature sonf produits, ils soml penvoyes an ministere de la Guerre ou à relui de la Marine, qui les remplace, s'il y a lieu, par un eretifical authenlique.

Les reures prétendant à pen inn fommissent. indépendamment des piécesque leur mari aurail été tenu de produire :

$1^{\circ}$ Leur acte de naissance;

$2^{\circ}$ Lacte de décès de l'emplorí ou dupensionnaire; $3^{\circ}$ L'acte de célébration du mariage ;

$4^{0}$ Un $^{\top}$ certifical de non-séparation de corps et un certificat de non-divorce établi sur papiertimbré, soit par le maire. sur la déclaration de deux témoins signataires, soit par le greffier du tribunal de première instance;

5o Dans le cas nù il y aurait eu séparation de corps ou divorec, la veure doit justifier que le jugement a été prononcé sur sa demande.

Cetle justifieation se fait au moyen d’une expédition sur timbre du jugement de séparation ou d'un 
certificat également sur timbre délirré par le greffier du tribunal.

Les orphelins prétendant à pension fournissent, indépendamment des pieces que leur père aurait été tenu de produire :

$1^{\circ}$ Leur acte de naissance:

2. L'acte de décès de leur père;

$3^{\circ}$ Lacte de célébration de mariage de leurs pire et mère;

4o Lne expédition ou un extrait de lacte de tutelle;

"jo En cas de prédécis de la mipe, son acte de décès ;

En cas de séparation de enrpi ou dirorece expeidilion du jugement ou rertificat du greffier du tribunal qui a rendu le jugement ;

En cas de second mariage, acte de rélébration.

268. Les reuves ou orphelins prétendant à pension produisent le brevet délirré à leur mari ou pere, lorsquil est déédé en jouissane de pencion. on une déclaration ennstatant la perte de ce titre.

Les enlants orpleelins des fonctionnaires décédés pensionnaires ne perrent obtenir de seenours at litre de reversion quautant que le mariage dont ils sont issus a prérété la mise a la retraite de leur pére.

Dans les cas spécifies aux paragraphes fer el 2 de l'arlicle 14, fer ef 2 de l'artirle l'́ de la loi du 9 juin 
1833, lérénement dommant ouverture an droil a pen-

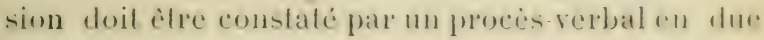
forme dresse sur les lieux el an moment ou il es strevenu. A délant de pores-rerbal. celle comslatalion

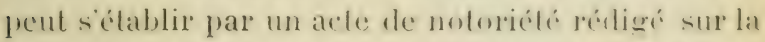
déclaration des témoins de lérénement ou des persomnes qui ont été à mime den comnaitre el den apprécier les comsinfuences. Celte arte dril alre coproboré par les aldeslations conlormes de lantorité municipale el des supurieurs inmédials des fonctionnaires.

Dans le cas dintirmités préru par le paragraphe 3 de larticle 11 de la loi du 9 juin, ces infirmités et leurs causes sont constatées par les médecins qui ont donné leur's soins au fonctionnaire el par un médecin désigné par ladministration et assermenté. Cés certificats doirent ètre corroborés par l'atlestation de l'autorité municipale et celle des sipérieurs immédiats du fonctionnaire.

269. Tout titulaire d'une pension inserite au 'Trésor' doit produire pour le paiement un certificat rle vie, délivré par un notaire, conformément à lordonnanec du 6 juin 1839, lequel certifical contient, "n exécu-

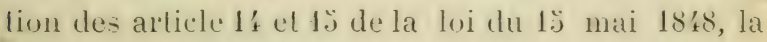
déclaration relative au cumul.

La rétribution due au notaire pour la délirrance des certificats de vie, est, 
Pour chaque trimestre a perceroir :

De 600 francs et au-dessus. De 600 à 301 francs.

De 300 à 101 francs.

De 100 à 50 francs.

Au-dessous de 50 francs.
50 cent.

35 -

$35-$

$20-$

$20-$

11 a été décidé par le ministre des Finances que les certificats de rie peurent ètre établis sur papier non timbré. (Circ. 24 août 1896.)

Il est important que les préposés conserrent arec soin leurs commissions, pour ètre en mesure de les représenter lorsquils feront valoir leurs droits a la retraite.

Si, sur les commissions qui leur sont délivrées, les noms et prénoms ne sont pas inserits conformément à l'acte de naissance. ils les renvermont à leur supréreur immédial. en demandant quil y soit lait les rectifications conrenables. De simples transposilions dans les prénoms nécessitent parlois des kémarches et des liais, si elles ne sont pas corrigéces immédiatement.

Il est ausit tres imporlant pour les préposés de faire comstaler, dans les lorme, inflefues par lar-

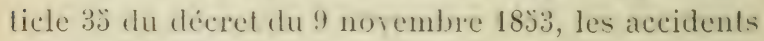
graves pu ils épourent dans lexereice ou a linecasion de lexercice de leurs fonctions. Cette consla- 


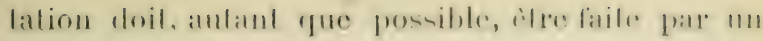

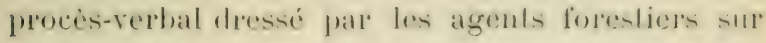
les lieux et att moment oil l'erémement eat suxvenu;

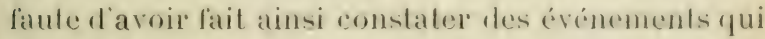
plus tard peurent dommer les droils a mo refraile cxceptionnelle, il faut recomir a 111 acte de nolos riélé, qu’il esl coùteux el dillicile de se procurer.

2T0. Caisse des retraites pour la vieillesse. - L'iıslitution de la Caisse des relraites pour la vieillesse a pour but d'assurer, au moyen de modirfues prélirements sur les salaires, une pension sulfisante pour protéger les rieux jours des travalleurs contre la misere. L'administration utilise cette institution pour assurer une relrate aux préposés communaux, ainsi qu'il sera exposé ci-après.

Cette Caisse est mise sous la garantie de l'Elat. Elle recoit les versemunts faits au protit de toute per. sonne âgée de trois anis.

Chaque rersement donnant lieu à une liquidation distincte, ils peurent ère interrompus ou continués au gré du déposant.

Les versements effectués par des déprosants mariés el non séparés de biens profitent par moitié à chacun des deux conjoints.

Les rersements antérieurs au mariage lestent propres à celui qui les a laits.

La Caisse desretraites ne recoit pas de somme infé- 
rieure à ว̆ francs; les versements ne doivent jas comprendre des fractions de franc. Les versements laits au profit de deux conjoints doivent ètre de 10 francs au moins et multiples de 2 francs.

Les rersements à la Caisse des retraites de la rieillesse sont reçus à Paris, par la Caisse des dépòts et consignations. et dans les départements par les receveur généraux et particuliers des finances. Les versements peurent itré faits, soit arec aliénalion, soit avec réserye du capital.

Pour le premier cas, la totalité des sommes rersées reste acyuise à la Caisse. dont la seule obligation consiste à fournir au déposant une rente viagère lorsquil aura atteint l’àge fixé par sa déclaration.

Dans le denxième cas, la Caisse assure une rente viagère au déposant qui atteint l'àge fixé et remJourse à ses héritiers, lor's de son décès, la totalité des sommes versées.

L'éporque d'entrée en jouissance est fixée, au choix du díposant. depuis 80 ans jusqu'a 6.; ans accomplis.

Les conditions fixées à l'égard d'un versement ríyisiont non seulemenl ce versement, mais ceux yui le suivenl, à moins d'une déclaration spéciale indiquant que le déposant reut modifier les conditions précédemment choisies.

Tous les versements fails antérieurement restent 
soum is anx eonditions fixeres. Toutefois moyennant

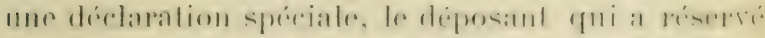

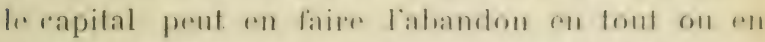

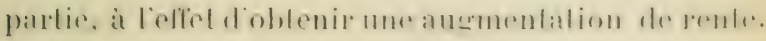
(Loi du 12 juin 1861.)

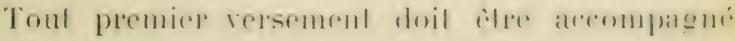
d'une déclaration souscrite par le déposanl. Cefle. divelaration cunonere dans fous les cas:

$1^{\circ}$ Les nom, prénoms, date el lien de naissaner, qualite rivile, profession ef domireile du filulaire de la rente qu'il s'agit d'acquérir ;

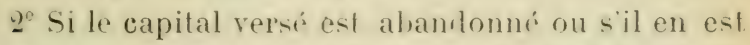
lait réserve au profit des béritiers du titulaire de la rente ;

3" A quelle annéc dige arommplie. depuis la vinfuantaine, le titulaire doil entrer en jouissance de la rente viagère.

Lorsque le versement doit profiter à deux époux. la déclaration doit comporter les mèmes énonciations à l'égard de chaque conjoint. Si la déclaration ne conlient ruiune scule slipulation au sujet de l'abandon ou de la réserve du capital et de l'àge d'entrée en jouissance, elle est réputre commune aux deux conjoints.

L'Elat intervient de la manière suivante pour améliorer la refraite des préposés communaux telle qu'elle résulterait des versements ri dessus. effer-

Grye. - Surveillaxce. 
tués conformément à l'arrêté du 26 décembre 1859 .

En rertu du décret du 20 décembre 1897, il est fait au profit de ces préposís, et sur les fonds alloués par l'Etat, des rersements à la Caisse des retraites Egaux à ceux prorenant les retenues qui leur sont réglementarement imposées : seulement, il n’y a pas de rersements de lEtat correspondant à ceux qui sont effectués par les préposés pour entrer en fonctions et pour augmentation de traitement. Ces allocations sont continuées aux préposés qui subissent des retenues après l'àge de 60 ans.

On a vu $m$.222) quil n'e-t pas fait de retenues aux préposis commmanx lont le traitement est inférieur à 300 franes. Toutefois. un dereret du 20 juin 1904 assure une lonification de l'Etat aux titulaires de petits traitements yui effectueront volontairement a la cainse les versements annuels suivants:

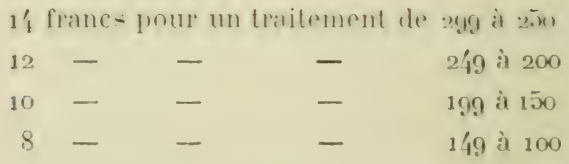

Alors la part contributive de letat consiste en une somme igale anx repsements ainsi effectues.

Unenomvelle déclaration derient nécessaire lorsque le défusant reut soumelte dauters rersements a d'autres conditions que colles des rersements ante- 


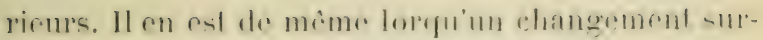
vient dans l'élat civil du titulaire.

Aux déclarations doivent slre annexés, snivanl les cireonstaneres. les pièere justifiealives ci aperes:

Acle de naissance du déposantou des dens cipoux si le versement profite à denx conjoints.

En cas de sefparation de birus par comleal on par jugement. extrait du contrat ou du jugement.

Acle dedéces. si l'un desconjoints est mort.

Toutes ces pieces doivent ille légalisées. An sulplus. les comptables entre les mains de qui sont faits les rersements indiquent aux déposants la nature et la forme des pieces qu'ils doivent fournir.

Le premier versement effectuć au profit d'un individu donne lieu à l'émission d'un livret revêtu du timbre de la Caisse des dépôts et consignations. Le prix de ce lirret est de 2.j rentimea, qui sont payés par le déposant.

271. Parmi lesdispositions réglementaires qui précèdent et s'appliquent aux déposants de toute qualité. l'administration forestière a choisi celles qui lui ont paru présenter le plus d’avantages. et. par un règlement approuré le 26 décembre 1859, le ministre des finances a imposé aux préposés communaux l'obligation de se constituer une retraite aux conditions suivantes :

Les versements dont le montant a été indiqué au 
paragraphe 223 snnt faits aver aliénation du capital, quel que soit létat ciril du préposé.

Lientrée en jouissance est fixér à 60 ans.

Les rersements faits par les garoles marics florfitent pour moitić à leur's femmes. Ainsi. lorsqu'un préposé marié rerse 20 francs par an. il y a 10 franes d'imputés à son compte et lo francs au compte de sa femme. Lentrée en jouissance de la pension dr la femme doit coüncider arec l'entrée en jouissance de la pension du mari, à moins quà cette époque la femme nait pas encore $\breve{0} 0$ ans ou ait dépassé 6ว ans.

Dans les ras de blessures graves ou d'infirmités prématurés régulierement constatées. pntrainant incapacité absolue de travail. la pension pourra etre liquidée mime avant ŏo ans ef en proportion des versements faits.

272. Bonifications. - Les pensions ainsi liquidées pourront itre lonifieses à laide d'un crédit ourert chaque année au ministre de l'Intérieur. La pension bronifiéne peut itre supérieure à 360 francs ni dépassrele triple du produit de la liquidation normale.

si le prépose est maintenu en fonctions apres 60 ans, le préfet pourra. sur lavis du conservateur. reculer d'année en année. jusqu’à $6: 3$ ans, l'époque dela liquidation de la pension.

L'entréc en jonissane pourra ìtre intégralement 
reculer jusqu il tio ans pour les gardes acturllement en fonetions ayant dépasse lage de tä ans. ol qui anront demandé à profiler des dispmsilions de res règlement.

Les rersements sont opérés pour le romple des préposés an moyen de relenues lates surleurs mandats.comme il a étexpliqué auparagraphe 223) ilssont effectués par l’intermédiaire d'un agent forestier qui demeure chargíteremplir foules les formaliles rxigées. Les préposés n’ont yu à fommir. lors du fremier rersement, les pièces qui lem sont réclamces.

Les retenues exercées après 60 ans peurenl, all gré du préposé, itre déposées en son nom à la Caisse dépargne, ou rersées à la Caisse des retraites de la vieillesse.

Enfin, une dernière bonification, r'sultant du décrel du 10 décembre 1898, s’applique aux préposés qui quittent le service communal àgés de 60 ans au moins, après 20ّ ans au moins de services tant militaires que forestiers; alors il est fait à leur profit un versement unique à la Caisse des retraites. avec jouissance immédiate. Le quantum en est calculé de telle sorte que l'augmentation de pension qui en résulte, jointe à la majoration déjà produite par l'effet du décret de 1897, atteigne une somme qui, jusqu'à nouvel avis, est fixéeà 100 francs. (Circ. כ̌ว̆2.)

Toutes sommes versées en dehors des retenues 
obligatoires accroitra la rente dans une proportion d'autant plus élerée que ce rersement sera fait à une époque plus éloignée de l’àge de la retraite.

Lorsqu un préposé quittera l'administration ou jassera dans le service domanial ou mixte, il ne perdrapas le bénéfice des rer'soments qu il aurapu faire à la Caisse de la vieillesse; il restera titulaire de son livret et des rentes qui s'y trouveront inscrites en raison des rersements effectués.

Les détails dans lesquels nous avons dù entrerau sujet de la Caisse des retraitespour la vieillesse sont justifiés "par l'importance de cette institution, non seulement pour lés préposés de l'administration des forets, mais aussi pour les gardes des particuliers. Ces derniers. plus isolés encore que les gardes communaux, ignorent, pour la plupart. l'existence d'une institution qui présente pour eux un très grand intérêt. 


\section{CIIAPITRE X1}

\section{ORGANISATION MILITAIRE}

Service militare. - Dispositions générales. - Oroanisation des compagnies de chasseurs forestiers. - Trailement civil. Uniforme, entretien. - Armement. - Grand équipement. Petit éruipement. - Munitions. - Changements de risidence. - Médaille militaire.

273. Service militaire. - Tout Français qui n'est pas reconnu impropre au service militaire fait partic de l'armée depuis 20 jusqu'a io ans. Tout homme appelé fait partie, d'abor'd de l'armée active puis de la réserve de l'armée active, ensuite de l'armée territoriale; enfin de la réserve de l'armée territoriale.

Les hommes qui font partie de la réserve de larmée active sont assujettis à prendre part, pendant la durée de leur service dans cette réserve, à deux manceurres, dont chacune ne peut dépasser quatre semaines.

Ceux de l'armée territoriale sont appelés pour 
une période dexercices d'une durée de deux semaines. Les hommes de la réserve de l'arméc territoriale ne sont astreints yu'à une revue d'appel. (Loi du 21 mars 190ð.)

1. armée territoriale est formée les hommes qui ont accompli le temps de service prescrit pour larmée active et la réserve. Elle ne peut ètre appelée ¿ lactivité que sur lor"lre de lautorité militaire.

Tout homme inscrit sur les registres matricules qui change de domicile est tenu d'en faire la déclaration a la mairie de la commune quil quitte et à celle du lieu où il va s'établir.

Ces dispositions, communes à tous les Français, ont été modifies. cn ce qui concerne les préposés des forets. par divers deret dont le dernier, en late du 18 norembre 1890 , a organisé le personne] des forits en compagnies de chasseurs lorestiers.

274. Chasseurs forestiers. - Ce's compagnies. lormées des préprosés lorestier:- de toute catégorie rn état de porter les armes, sont destinées à seconder les armées operant dans la rigion du service de paix des prépost's qui les composent; elles sont commandées par des officier's pris dans le personncl foresticr; les sous-officiers sont pris parmi les brigadiers et les caporaux parmi les brigadiers et les gardes ile $1^{\text {re }}$ classe. Les gardes ont rang de soldats de $1^{\text {re }}$ classe. 
Dans chacun des departements de lidgerie, les chasseurs forestiers sont organisis en seetions correspondant, antant que possible, aux inspertions forestières. (Instr. min. du t avril 1892.)

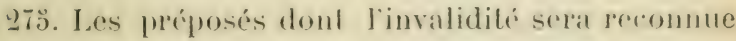
seront élimincs du corpes des chassenes forestiers sims cesser foul rela d'appartenir a l'arlmmisfration des forèts. Les conservalems délivreront aux préposés ainsi affranchis du service mililaire un certilicat d'élimination.

Ces préposés sont obligés. en cas d'appel à l'activité des compagnies ou sertions de chasseurs foresliers de leur région, de verser immídiatement dans le magasin de troupe désigné à l'avance, leurs armes et effets militaires, mème ceux d'unilorme qui leur appartiennent. Il leur est domné reçu de ces objets. A partir de l'ordre de mobilisation, les préposés qui ont cessé de faire partie du corps des chasseurs forestiers ne doirent plus porter que la plaque pour tout insigne.

Les préposés qui sont investis du grade de sergentmajor dans le corps des chasseurs forestiers devront aussi verser. au moment de l'appel à l'activité, les fusils dont ils sont pourvus pour leur service ordinaire, dans le magasin de troupe de leur circonscription. (Circ. du 6 octobre 1883.)

A dater du jour de l'appel à l'activité, les compa- 
gnies ou sections de chasseurs forestiers font partie de l'armée et jouissent des mèmes droits, honneurs et récompenses que les corps de troupe qui la composent. Ces compagnies, appelées à l'activiti, sont assimilées à l'armée active pour la solde et les prestations, allocations et indemnités de toute nature.

276. Traitement civil. - En outre de ces allocations, qui sont à la charge du ministère de la Guerre, les chasseurs forestiers mobilisés continueront à jouir de leur traitement civil. (Décis. min. 29 juin 1876.)

Ils peurent déléguer. en ce cas, tout ou partie de ce traitement à leur's femmes ou à leurs autres parents.

Cette délégation se lait sur papier libre. Nous donnons sous le numéro 33 des formules un modile en blanc d'acte de cette espèce.

277. Uniforme. - Un arrèté ministériel en date du כّ juin 1891 a réglé ainsi quiil suit l'uniforme des chasseurs forestiers, uniforme qui sera à l'arenir la grande tenue des gardes et brigadiers.

to Jaquette ajustée en drap rert finance, croisant sur la poitrine et garnic de dix boutons grelots en ctain, ciny de chaque còté également espacés; derants d'un seul morceau arec poches munies d'une patte extérieure rectangrulaire; manches larges et parements droits; le tout passe-poilé en drap du 
fond ; collel droil, pasce-poile en drap jontuille aree deux cols de chasse de mime couleur aux angles de derant, paltes d'épaule en drap doubli de basane. igalement passe-poilées de jonquille ol munies chatcune d'un bonton; patle de ceinluron en drap du fond passe-poilée de mème, placée à granche sur la hanche; sa tète est percée dume boutonniere laite en drap pour recevoir un bouton duniforme, la patte est doublée en dray du fond et de plus, a partir du bas de la boulonnière, garnie d'une bande en veau noirci; la doublure de la jarfuette descendant jusqu'au bas du vêtement;

2. Pantalon modele d'infanterie en drap grisbleuté clair arec passe-poils jonquille;

$3^{\circ}$ Képi en drap vert finance avec passe-poils jonquille et cor de chasse sur le bandeau, rentouses sur le còté, visière et jugulaire en cuir verni fixée par deux boutons;

$44^{\circ}$ Collet a capuchon en drap gris bleuté, passepoils couleur du fond, ruatre boutons sur la poitrine;

$\breve{o}^{\circ}$ Cravate longue en tissu de coton bleu de ciel foncé, modèle d'infanterie.

Luniforme des préposés forestier's de l'Algérie a été réglé par un arrèté ministériel en date du 3 aoùt 1892. Il diffère de celui des préposés de la métropole en ce que la jaquette est remplacée par un 
dolman se boutonnant droit sur la poitrine. Le pantalon est du modèle de la cavalerie. Le liépi, le collet et la cravate sont pareils à ceux de la métropole. mais les forestiers d'Algérie ont en outre une reste de treillis, fermant sur la poitrine.

278. Les marques distinctires des grades sont :

1" Pour les brigadiers, un galon de 6 millimètres de largeur formé de trois traits de soie verte espacés sur un fond argent, composé de trois traits:

$2 \circ$ Pour les gardes de $1^{\text {re }}$ classe, une tresse en laine jaune et noire en mélange, placée comme il est dit ci-dessus.

Les marques distinctires de grade des préposés qui remplissent les fonctions de sous-officiers et caporaux dans les compagnies de chasseurs sont les suivantes :

Sergent-major. - Trois galons en argent de 22 millimitres de largeur, façon dite ì la lézarde, séparés de 3 millimetres l’un de l'autre, placés sur chaque arant-juas de la jaquette plongeant de dehors en dedans, l'extrémité supérieure à 150 millimetres de loritice de la manche et l'extrémité inférieure immédiatement au-dessus du bord du parement.

Sergent. - Deux galons de mème nature et de meme dimension que ceux de sergent-major, et placés d'une manière illentique. 


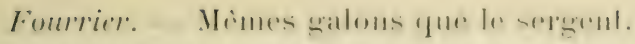

Caporal. In galon dirgent de mime dimension que rens dusereent of plaré de la mime maniere.

Les dispositions concernant la fomprifure el lentretion des affets d'habillement des préposés se Irourent dans les arritis ministiriols des 20) tobre 1893 et dı 2o mai 1903.

279. Fourniture des effets d'habillement. - Tous les préposés recoivent à titre graluit, anx frais du Trésor, les effets dits de premirre mise dont la nomenclature suit; la durée de ces offets est pareillement réglée de la manière suivante:

\section{Nanteau}

Jaquette

Pantalon de drap.

Képi de grande tenue

to ans Képi de petite tenue.

5 ans

2 ans

Deux rravates dont une renourelable tous les

5 ans Gants (une paire) .

2 ans

2 ans

2 ans

Les insignes de gratles sont également délirrés à titre gratuit au frais du Trésor.

Les effets de premiere mise ne sont la propriété du préposé qui en est détenteur qu'après une année écoulée à dater de leur réception. Tout préposé qui quitte la carricie moins d'une année aprós aroir 
recu ses effets, doit les remettre à son chef immédiat.

Les effets renourelés arant les époques fixées cidessus, par suite de détériorations survenues dans un service commandé ou de destruction provenant d'un cas de force majeure (incendie, inondation, etc.), sont à la charge du Trésor. Si le renourellement anticipé a pour cause la négligence ou lïncurie, il donne lien it une retenue spriciale sur le traitement du préposéd dapres la valeur de lieffet remplacé et pour le temps pendant leguel il aurait dù rester encore en service.

En dehors des purindes de renouvellement, les préposis ont la farulte. arer l'assentiment de leurs chefs. de commanter. à titr particulier, des effets d'habillement. dont le prix est remboursé au moyen d'une retenuesur leur traitement apris délivance.

2२0. Entretien. - Il est pourvu aux dépenses dentrotien de l'habillement, aux époques prérues cidesins au moyen de retenues oprérées sur le traitement des preposis. Cessetenues, dont le chiffre est fixé à l.j frances. ont lien par douzieme: elles sont exercés, pour la premire fois à partir du mois qui suit la délivance du premier hahillement.

Les retenues opérées sur les mandats de traite ment des preposís. dans les diverses rirronstances qui précedent, sont centralisées, par les soins des 


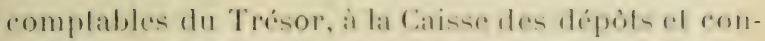
signations soms la subrique a Masse genémale d'onIrelien pour l'uniforme des préposés des ratux ol forêts de France».

Les relenues faitesne peurent domner lien it repétilion de la part des inféressés ol sont dífintivement acquises à la masse d'entretien.

\section{Effets d'habillement.}

Manteau (suivant la taille, de $31 \mathrm{fr}, 28$ à $33 \mathrm{fr}, 12$ Jaquette . . . . . . . . $23 \mathrm{fr}$. "

Pantalon de drap. . . . . . . 1' 1 fr. $7^{2}$

Képi de grande tenue . . . . . . 4 fr, 51

Pompon arec cocarde tricolore. . . . o fr. 64

Gants de coton (1 paire) . . . . . o fr. 55

Cravate en laine . . . . . . o fr. 64

Insignes de grade militaire (pose comprise).

Jaquette : Sergent major . . . . 12 fr. 42 Sergent fourrier . . . $10 \mathrm{fr} .58$ Sergent. . . . . 8 fr. 28 Caporal. . . . . . 4 fr. 14 Clairon . . . . . $1 \mathrm{fr} .38$

Manteau : Sergent major . . . . . 2 fr. 07 Sergent et fourrier . . . $1 \mathrm{fr}, 38$ Caporal. . . . . . . o fr. 69 
281. Armement. - Len rlasseur's forestiers ont enmme armement un fusil modile 1886 aree som acessonires, épér-baïonnette, fomreau, baguette et nécessaire diarme. L'armement du sergent-major se compose dim rerolver et tiun sabre dadjudant. Les sergents-majors (brigadier's) pourvus de fusils pour leur service ordinaire, doivent. en ras de mobilisation, rerser ces armes dans un magasin de troupe désigné dés le temps de paix.

Les armes confiées anx préposis apprartiennenl a lEtat: reux qui en sont détenteurs doivent les entretenir soigneusement. Les réparations qui deviendraient nécessaires par suite du défaut d'entretien sont à la charge des préposés: il en est de meme des pieces de rerhange of des frais de transport. Ces dépenses font lobjet dinne retenue exerér. sur le traitement. Toutes los réparations sont faites par les rhef's armuriers des corps désignés par le rommandant de corps diarmée. sur la demande du conservateur.

282. Grand équipement. - Le déparlement de la Guerre pourvoit an grand équipement deschasseurs forestiers, qui comprend les objets suivants:

10 Bretelle de fusil :

2" Cartouchieres dinfanterir (deux par homme):

$3^{\circ}$ Sachets pour virres de riserve (deux par homme) : 


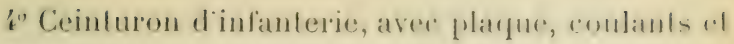
verrou ;

(i) Ceinturon de sergent-major, aver plapure;

6" I)ragonne de sabre de sereenl-major ;

$7^{\circ}$ Etui de revolver en cuir verni;

8o Porte-épéc-baïonnette ;

9e Havie-sac, avec courroies;

10" Clairon, arec cordon(mup section militaire);

Ces divers oljets apparliennent a l Elat, les gardes qui en sont détenteurs doivent les entretenir avec le même soin que les armes.

283. Petit équipement. - Le département del Agrriculture fouruit à tous les préposés les objets de petit équipement dont la désignation suit :

10 Cravate;

2o Trousse ;

$3^{\circ}$ Gamelle individuelle ;

$4^{0}$ Quart.

Les chasseur's forestier's doivent en outre se jourvoir des autres effets du petit équipement dont le détail est indiqué sur leur livret indivicluel.

284. L'administration désigne les fournisseurs auxquels lescommandes dhabillement doivent itre faites par l'intermédiaire des conservateurs. Les mesures sont prises par les tailleurs délégués des fournisseurs; les effets, soumis dabord à un premier examen à Paris, sont essayés en p résence du chel de canton- 
nement et définitivement recus, comme ceux que l'administration délivre aux chasseurs des compagnies actives, par une Commission composée de deux agents forestiers et d'un brigadier désigné par le conservateur.

Les conservateurs sont chargés dassurer le paiement des fournisseurs.

Les marchés passés arec les fournisseurs de l'administration déterminent les prix auxquels sont portés les diver's objets diabillement des préposés lorestiers.

Il est prescrit anx chasceurs forestiers de lenir toujours leur equipement en itat, afin quau premier apree ils puissent se rendre au lien de rassemblement qui leur est indiqué.

La chaussure doit itre surtout l'objet d'une grande attention. Les forestiers sarent mieux que personne combien il est difficile de supuroter la marche, si lon nest pas bien rhaussé. Aussi derront-ils conserver toujours, pour le cas de mobilisation, une paire te souliers déjajportés. afin de ne pas se mettre en route avec une chanssure nenve qui pourrail les blesser.

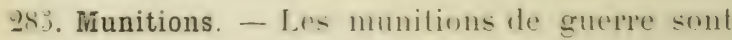
dilivres aux chasseurs forestiers par le service de lartillerie. sur la demande des conservateurs. lorsque lies compacnies ne sont pas mobilisées. 
Il est alloue, par an ef par homme insrit sur les controbles, vingl cartouches pour les exercices de lir.

Ces cartouches ne peurent ifre employes a ancun aufre usage; elles doivent itre mises en reserve si les exercices de lir n'ont pas lieu.

Ces munitions, ćlant exposcies à salterer par l'humidité, seront serrées dans un lieu see el a l’abri du leu.

Les préposés peuvent receroir en outre un parquet de huit cartouches leur appartenant pour leur défense personnelle et les besoinsdu service. Ces cartouches ne donnent lieu à aurun remboursement.

286. Ghangements de résidence. - En cas de changement de résidence, les cartouches de tir non encore consonmées et celles de réserve seront laissées par le préposé sortant à son successeur. Le procisverbal dinstallation fait mention de cette remise. Les cartouches appartenant au préposé sortant sont reprises par le préposé entrant qui en rembourse le prix.

Le préposé sortant qui ne quitte pas la conservation emporte son arme ainsi que les accessoires (sabre-baïonnelte, fourreau et nécessaire darmes) ; sil change de conservation, il remet ces objets au chef de cantomement, qui rérifie suils sont en bon état. (Girc. no 257.)

Les effets de grand équipement sont emportés par 
le garde sortant, quelle que soit sa destination. Les préposés de l'administration des forèts forment, au point de vue militaire, une catégorie spéciale de non-disponibles. Aussi sont-ils affranchis de lobligation imposée à tous les hommes inscrits sur les contròles de larmée de faire connaitre leurs changements de domicile aux autorités municipales et de faire viser leurs titres par la gendarmerie.

Mais les préposés (qui abandonneraient la carrière forestière, soit à titre léfinitif, yar suite de démission ou derérocation, soit à titre temporaire, par suite de suspension ou de mise en disponibilité, rentrent dans le droit commun et sont assujettis aux dispositions de larticle 34 de la loi du 27 juillet 187.2. C'est à eux qu incombe l'obligation de faire commaitre leur domicile à la mairie de leur nouvelle résidence. lls sont soumis aux conditions de la classe de recrutement a laquelle ils appartiennent par leur àge.

287. Feuilles de route. - Les chasseurs forestiers voyagent à quart de place sur les voies ferrés lorsqu'ils sont déplacés pour le service mililaire (exercices te tir. rerues, mancurres, inspections d'armes, ete.): pour quils jouissent de cet aranlage. il est indispensable quils soient munis de feuilles de route. 
Ces fenilles deur sond remises par leurs chefs an mème lempsque les ordres de déplacement. (Cir. 2.'ś) 288. Médaille militaire. - line allocation anmuelle: de 100 francs est accordér amx préposés domaniamx el communaux dérorés de la médaille militaire au litre de chasseurs forestiers qui ne recoivent aurme rémunération pour celte distinction, sur le budget. de la Légion dhonneur. Celte allocation n'est pas soumise à relenue pour le service des pensions; plle est due aux préposés retraités aussi bien qü à ceux en actirite de service. (Cire. 11128 juin 189.).) 


\section{CHAPITRE XII}

\section{RECRUTEMENT. AVANCEMENT. ENSEIGNEMENT}

Garles inmaniaux. - Gardes cantonniers, - Garles communaux.

- Cominations. - Brigadiers. - Conditions davancement. Candidatures.

Ecole secondaire des Barres.-Conditions du roncours, - Rigime de l'Ecole. - Examens. - Ecole pratique des Barres.

289. Gardes domaniaux. - Leur recrutement est réglé par un arrèté ministériel du 29 mai 1902. (Cire. I" (i3't.) Mais cet arrité doit itre combiné arec les dispositions de la loi sur le recrutement de larmée du 21 mars 1905, complite par un règlement d'administration publique du 26 aoù 190ङ. Les principes le la matiere peurent ètre résumés comme il suit.

Les candidats sont divisés en deux catégories : d'une part les candidats militaires, auxquels la loi accorde un droit de préférence; d'autre part les can. diduts ordinaires, qui ne peuvent itre pourrus demplois qu à défaut de candidats militaires. 


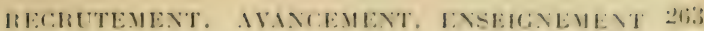

La tolalite des emplois de gardes domaniaus du sepvice actif est réservée anx soldals de fontes armos ayant accompli au moins quatre ans de service, ed ayant oblenu, en raison de leur maniere de sorvir, lavis favorahle du Comscil de régiment, puis un bullelin de santé imdiquanl lem aptilude physique ; enfin un certifical d'aptitude professionnelle. La mode doblention de ce certifical est ainsi drerminé par un règlement d’administration publiqun du 26 août 190 .

Il est passé chaque année à ect effel une série d'examens, à une date fixée pour toute la France el l'Algérie, par le Ministre de la Guerre. Ces examens comportent quatre épreures écrites: copie, dictér. rédaction, arithmétique. Les candidats subissent de plus une interrogation d'un quart d'heure sur les éléments de la grammaire française, de larithmétique et de la géographie. Le Ministre détermine la circonscription de chaque centre d'examen; au chef-lieu de chaque circonscription, les examens sont passés devant une commission présidée par un officier supérieur, composée de trois membres militaires et de deux membres cirils. La Commission apprécie le résultat des épreuves. Le certificat d'aptitude professionnelle n'est délivré que si la moyenne des notes obtenues est égale ou supérieure à 60 pour 100 du nombre total de points que le candidat peut 
obtenir. La liste des candidats est transmise avec les pièces justificatives au Ministre de la Guerre, qui fait établir les certificats avec mention de la date et de la morenne des notes obtenues. Il est donné connaissance aux intéressés du résultat des examens.

Les demandes en rue de l'obtention d'un emploi peurent être formulées soit par des militaires en activité de service, soit par d'anciens militaires qui ont quitté larmée. L'àge limite est de quarante ans, à compter de lexpiration du trimestre qui suiva celui au cours ituquel le bénéfice de la loi aura été réclamé.

290. Il est dressé rhaque année un état de prérision dı nombre des emplois dont la racance est à présumer dans le cours de l'année suirante. Cet état de prérision est notifié à tous les corps de troupe et porté à la comnaissance des candirlats par les chefs de corps.

Au commencement de chaque trimestre, les chefs de corps adressent au ministre de la Guerre les dossiers de demandes des candidats dont le lemps de service expire dans le trimestre suivant.

Le rlassement des candidats est opéré par une Commission qui siege au ministipe de la finerre et dont fait partie un dílégur du ministre de l'Agriculture. Cr classement a lieu par ordre de mérite, et en 


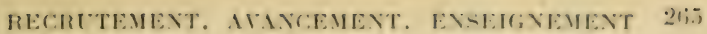

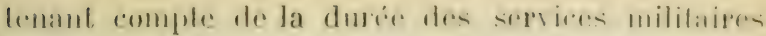
effectifs, sans toutefois que ceux-ri puissent ifre complés pour plus de quinze ammér.

29). Les nominations doivent être liales dans lordre de classement adophe par la Commiscion el transmis par elle aux alminislrations inferessios. Elles sont insérées au Journal officiel.

sil éfait nommé des titulaires di des emplois sans tenir comple de l'ordre de classement, les interessís pourraient se pourroir derant le Conseil d'Etat statuant au contenticux; ces pourvois sont dispensés de la constitution d'un avocat.

292. Les nominations aux emplois ne peuvent aroir lieu plus de trois mois arant l'expiration légale du temps de service du candidat.

En cas d'insuffisance d'emplois, les candidats son autorisés à attendre au corps, pendant un an, leur nomination à l'emploi quils ont sollicité ou accepté.

293. - Les militaires remplissant les conditions pour obtenir un emploi, qui ont quitté le service sans l'avoir sollicité, peurent néanmoins, dans les cinq ans qui suivent leur libération, adresser une demande d'emploi par l'intermédiaire de la gendarmerie. Le général commandant la suludivision śtablit alors leur dossier et les convoque, s'il y a lieu, pour subir les examens professionnels.

Les militaires réformés ou retraités par suite de 
blessures ou infirmités contractées au service peurent profiter des dispositions qui précèdent, quel que soit le temps passé par eux au service, s'ils renplissent les conditions d'àge et d'aptitude fixées par l'emploi qu'ils sollicitent. (Loi du 21 mars 190ב, art. 69 à 75 .)

29'. Les places laissées libres à défaut de candidats militaires sont attribuées aux fils d'agents ou de préposés domaniaux ou mixtes, îgés de plus de 2ŏ ans et de moins de 3ว̆, ayant satisfait à la loi sur le recrutement de larmée, sachant lire, écrire, rédiger un procès-rerbal, faire les quatre règles de l'arithmélique et commaissant les éléments du système métrique. (Arrèté ministériel du 11 déc. 1886, circ.n³7ö.)

Les demandes, sur papier timbrí, sont adressées au conservateur. Le canclidat doit joindre à sa demante: un extrait légalisé de son acte de naissance, un certificat constatant qu'il a satisfait à la loi sur le recrutement de l'armée, un extrait de son casier judiciaire: un certificat de bonne conduite, bonne vie et morurs, délirré par le maire de la commune; un certificat d'un médecin assermenté constatant qu'il est suffisamment robuste pour remplir un service pinible. Le conservateur désigne l'agent chargé le faire passer an candiclatlexamen sur les matieres exigées par l'arrêté de 1886.

Peuvent aussi itre nommés à des postes doma- 


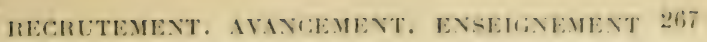

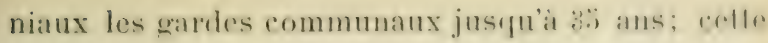

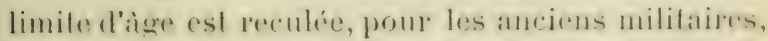
d'un lemps cogal a la durce de lemes services mililaires pourant entrer dans la liquidalion d'une pension de retraite.

Les ancions fieves diplomés de l'Eeole pralinur de sylriculture des barres n'ont pas it subir les épreures exigées des candidats ordinaires. Ils jrisentent leur demande par l'intermédiaire des acents locaux de lour risidence, qui derront fournir sm leur candidature des renseignements généram, notamment au point de vue de l'aptitude physique ot des aptitudes spéciales.

29:. Gardes sédentaires. - La totalité des emplois de ces gardes est róserve aux sous-rofficiers de loutes armes qui ont accompli au moins dix ans de service.

Les autres conditions (avis du conseil de régiment, certificat d'aptitude, formes de la demande) sont les mèmes que pour les gardes du service actif.

Pour les candidats ordinaires on doit suive ćgalement les mimes règles que pour le service actit.

296. Gardes stagiaires en Indo-Chine. - Ces gardes remplissent en Indo-Chine de vraies fonctions d'agent; ils ont un traitement colonial de 3.500 francs. (Dérret du 31 juillet 1896.)

I.es emplois de garles forestiers stagiaires en 
Indo-Chine sont riserrés anx mèmes conditions que pour les gardes de la métropole, et dans la proportion des trois quarts des racances, aux sousofficiers, Jrigadiers et caporanx de toutes armes qui ont accompli au moins quatre ans de service dans la métropole, et aux militaires de tous grades de l'armée coloniale ayant accompli quinze ans de service, dont dix au moins dans les colonies.

297. Gardes cantonniers. - Les emplois de gardes cantonniers sont réservés, pour la totalité, et dans les mimes conditions que pour les autres gardes, aux simples soldats de toutes armes ayant accompli au moins quatre ans de service.

A défaut de ces candidals, peurent itre admis les anciens militaires ayant quitté l'armée avec le grade de sous-officier, igés de 20 à 30 ans, ayant une bonne écriture, sachant rédiger un procès-rerbal, possílant les quatre règles de l'arithmétique et les éléments du système métrique.

Enfin, peurent aussi itre nommés cantonniers les fils des preposés domaniaux ou communaux satisfaisant aux conditions exigres des candidats ordinaires an poste de garle domanial.

Les cantonniers penrent itre nommés gardes après quatre ans de service, sur la proposition des conservateurs. (Arreté du 27 mai 1902.)

298. Gardes communaux. - La loi du 21 mars 1903 


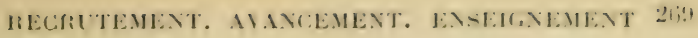

réserve igalement la totalite des postes de garder commmanx amx simples soldals de foules armos ayant accompli an moins quatre ans de service. dans les mimes comblitions que pour les gardes domaniaux.

A défaut de candidals militaires, les gardes communaux penvent ifre choisis parmi les jemes gens ayant satislait a la loi du recrutement, igrés de 203 it 30 ans, sachant lire et écrire el capablus de rédiger un procès-verbal.

Les garles communaux ayant au moins quatre ans d'exercice peuvent itre nommés gardes domaniaux, šils n’ont pas dépassé l’àge de 40 ans.

299. Nominations. - Les gardes domaniaux et les gardes mixtes quileur sont conplètement assimilés, les gardes cantonniers et les gardes-pèche sont nommés par le ministre de l'Agriculture, sur la présentation du direcleur des forits pour les postes de France et par le gourermeur général pour ceux de l'Algérie. (Décr. dı 26 juil. 1901.)

Les gardes communaux sont nommés par les préfets sur la présentation des conservateurs des forèts. (Décr. du 2.5 mars 185\%: Cireul. dı ' juillet 1866, 11021.)

300. Brigadiers. - Les emplois de brigadier ne peurent èlre domís qu'à des gardes ayant au moins deux ans d'exercice en cette qualité. Les emplois de brigadier du service actif sont réservés, dans la 
proportion de moitié, aux gardes sortis de l'enseignement technique et profussionnel des Barres avec une moỵenne générale de 14. (Arr. du 15̆ oct. 190亏ั.)

Le ministre nomme les brigadiers domaniaux et mixtes: les brigadier's communaux sont nommés par les préfets sur la proposition des conservateurs.

Le's brigadiers hors classe ne peuvent ètre choisis que parmi le's brigadiers de $1^{\text {re }}$ classe àgés d'au

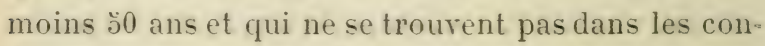
ditions roulues pour ètre portés au tableau d'arancement pour le grade de garde général stagiaire.

301. Conditions d'avancement pour le grade d'agent. - Le tiers des emplois de garde général est réservé aux préposés du service actif. (Décr. du 23 octobre 1883 .)

Pourront citre portés au tableau d'avancement pour le grade de garde général stagiaire les brigadiers qui compteront fuinze années de service dont cinq au moins dans le service actil. Le temps passé sous les drapeaux entre dans le décompte des années requises, dans la proportion de moitic de sa durée, sans que cette majoration fuisse exceler dix-huit mois. (Arr. du 10 janvier 190כ.)

Cette condition de dure de service n'est pas exirée pour les préposís qui ont subi arec sucés les examens de sortie de l'Ecole secundaire des Barres (voir $\left.\mathbf{n}^{\circ} 306\right)$. 
Les brigádiers candidats an gramle de garde gron:ral slagiare doivenl de plus ble en ardiviti de selviee (Arr. du 15 juin 1891): ils dwivent enlin lane preuve de lem aptitude aux lonclions d'agent en subissant 111 concours organise ainsi qu'il suil. (Arr. du 23 f'évrier 1905.)

3(1). Candidatures. - Les bripadiers remplissant les conditions d'ancienneté requise, yui sont candidats an grade de garde géméral stagiaire, en font la demande par voie hiérarchique avant le Aer juin de charfue annce. Le directemr génciral arrete la liste des lrigadiers devant prendre part à l'examen. Dans le courant d'octobre, les candidats sont convoqués au chef-lieu de la conservation pour y subir les épreurus ci-apres. Ils doivent y ètre rendus la reille du jour fixé pour l'examen : ils recoivent à cette oceasion les indemnités réglementaires de déplacement et ıle séjour.

Les épreures consistent en deux compositions érites faites sous la surveillanee de deux agents désignés par le conservateur et en exercices pratiques. Les compositions comprennent: 1" une dictée: 2" un rapport sur une question de service (gestion domaniale et communale, aménagements, exploitation, délits forestiers, de chasse, de pèche, travaux, dérichements, reboisement) : $3^{\circ}$ une composition d'arithmétique (les quatre regles, reggle de trois, 
systeme métrique). Les exercices pratiques portent sur un levé darpentage détacher d'un massif une surface déterminée et ourrir la ligne séparative; calculer la contenance, rapporter le plan).

En mème temps que les compositions sont enroyées à ladministration, le conservateur transmet, arec copie des feuilles de notes des intéressés, un rapport sur la conduite, la tenue, l'instruction profesciomnelle et l'aptitude à la direction d'un cantonnement de chacun des candidats.

Le comité d'arancement dresse la liste du classement et sur la proposition du directeur général le ministre arrite le nombre des brigadiers à porter au lablean davancement pour le grade de garde général stagiaire. (Arr. du 23 f'évrier 1903.

Les hrigadiers porlés au tableau d'avancement cont, surant les besoins du seprice, nommés gardes généraux stagiaires.

La durée le ce -lage est subordonnée au decré d'aptitude de ces agents et aux besoins du service. (Arr. du 25 juillet 1881.)

Les gardes généraux sont tous admissibles aux cmplois supérieurs, sans distinction d'origrine. (Déc. du 23 octolre 1883: Arr. min. du 7 férrier $188 \%$.)

303. Ecole secondaire des Barres. - L'administralion des forits a cré, sur son domaine des Bares-Tilmorin. une école destinée à com- 


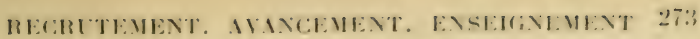

pleter l'instruction des preposés forestiers of it les preparer anx fonctions d'agents. Nul n’ent admis a celte école que par voie de comrours.

Sonl seuls admis a concourir lus gardes ef brigadiers foresliers, domaniaux of communanx, ayant moins de 38 ans an fer janvier de lanmie du concours ef devant compter au fer octohesesuirant trois années de service actif.

Il suffil de deux années de service arlif pour les élives diplomés de l'Erole pratipue des Barres. artuellement Ecole denseignement technique et pro. fessionnel (voir $\mathrm{n}^{\circ} 307$ ).

Le nombre des élèves à admettre à l'Ecole secondaire est égal à la moitié du nombre des élèves armis à l'École de Vancy. Décrel dı 16 octobre 1901.)

La durcée du cours d'études est de deux ans.

Les conditions du concours dadmission sont formulées dans un programme approuvé par le ministre de l'agriculture le 10 férrier 1897, programme que nous reproduisons in extenso dans l'Annexe qui ter. mine ce volume.

30ł. Régime de lécole. - Les préposés admis à la suite du concour's anmuel recoivent. s'ils ne l'ont déjà, le grade de brigadier. Ils conserrent la temue, l'armement et l'équipement des préposés forestiers, avec les insignes correspondant à leur grade; ils

Grye. - Surveillayce. 
restent soumis aux memes obligations professionnelles que dans le service actif.

Les élèves de l'Ecole secondaire doirent pourroir. sous le controble du directeur de l'établissement. à lemr nourriture et à leur entretien. Ladministration leur fournit : mobilier. literie, raisselle. ustensiles de tables et de cuisine. chauffage, éclairage. instruments, outils. livres. papier et plumes.

A leur arrirée. les préposés doirent ètre pourrus de leurs uniformes de grande et de petite tenue et du linge de corps dont suit le détail : 4 chemises. 6 paires de chaussettes. 3 ealecons. 6 mouchoirs.

L'uniforme de grande tenue est entretenu, commu il a été indiqué an paragraphe 277. an moyen de la retenue opérée sur le traitement.

30. Peines disciplinaires. - Ln conseil de discipline. composé du directeur et des professeurs de lEcole. se prononce sur le compte des élèves qui. far des fautes graves par leme inconduite habituelle ou lemr defaut dapplieation. se mettraient dans le cas d'être exclus de l'Ecole.

Lexelusion es prononée par le ministre sur la proposition du consid de discipline. transmise par 1. diereferme des forets avee son avis. le conseil d'administration entendu.

306. Examens. - A la fin des cours. les brugadiers bleves subissent devant le directeur et les pro- 


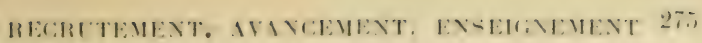

fussemes de l'Ecole rémuis en jury, sous la prósidence du directoul de l'alminislation on d'un arlmi.

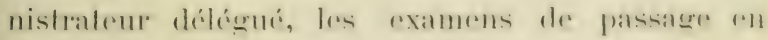
$f^{\text {ro }}$ division ou de sorlie.

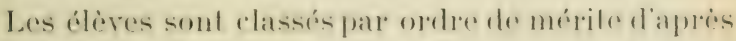
les résulfals de res examens ol les notes do l'ammé

Cenx qui onl salisfilit aux examens de sortir fonl

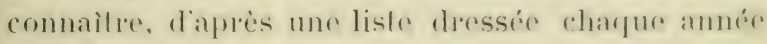
par l'administration. lesconsepvations où ils désirent spécialement ètre appelés. Ils sont. suivant les besoin du service, alfachés à une inspection en qualité de gardes généraux stagiaires. comme los blives de l'Ecole nationale forestière et les brignadiers sortant du rang. (Décr. du 23 octobre 1883; Arr. min. du 7 février 1884.)

Les préposés qui n’ont pas satisfait aux épremres de passage ou de sortie sont renvoyés dans le service actif avec le grade quils avaicht arant leur entrée à l'Ecole. Toutefois, le titre de brigadier peut être maintenu à ceux d'entre eux qui auront fiat preure d'assiduité ef de travail. Les préposés qui auraient eu une interpuption forcée de travail de plus de quarante-cinq jours consécutifs peurent être autorisés par le ministre, à titre exceptionnel. à redoubler une année des cours.

\section{Ecole d'enseignement technique et professionnel} des Barres. - Placée à côté de l'Ecole secondaire. 
elle portait précédemment le nom d'Ecole pratique de sylviculture. qui a été transformée en rertu d'un décret du 19 décembre 1903.

Elle a pour but de tonner aux gardes des eaux et forets. domaniaux ou communaux, foutes les connaissances qui leur sont nécessaires pour exercer leurs fonctions. Elle peut aussi receroir des auditeurs libres, français et étrangers.

Les gareles qui sollicitent leur admission à cette Eenle sont choisis sur la présentation des conserrateurs. sur le vu dépreuves permettant de se rendre compte de l'instruction des candidats fécriture, orthographe. systeme métrique), et de notes sur leurs mérites et leurs aptitudes.

Linseignement dure dix mois du (lö octobre au 15. aoùt; pendant ce temps les préposés domaniaux continuent à recevoir le traitement et lesindemnités afférents à leur poste. I la fin de l'année scolaire, les gardes sont lobjet d'un classement résultant de leurs notes. ceux d'entre eux qui ont obtenu la moyenne géncirale de l't sont proposés pour le grade de brigadier.

Le programme des études of le régime intérieur de cetle seole sont délailles dans l'arrèté ministericel du 17 janvier 190\%. (Cire. 659.) Vois anx Annexes. 


\section{CHAPITRE XII}

\section{SERVICE SÉDENTAIRE}

Garles sérlentaires. - Brigaliers sintendaires. - Alminislanlion centrale. - Commis temporaires.

308. Les employés allachés all service des bureanx des conservateurs et des inspecteurs sont désignés sous les dénominations de gardes, de brigarliers sédentaires el de commis temporaires.

Comme les préposés du serviresédentaire ne sont pas astreints à la prestation du serment of qüils ne sont pas officiers de police judiciaire, il n'est pas absolument indispensable quils aient 25 ans accomplis.

309. Gardes sédentaires. - Daprès l'arrêté du 29 mai 1902, lesconditions d'admission sont les mêmes que pour les gardes du service actif : mèmes conditions d'origine, d’âge et de capracité (roir n² 287.)

Pour ètre admis dans le service sédentaire. les 
candidats. qu'ils sortent de l'armée, du service actif ou du civil, doivent aroir une belle écriture, saroir lorthographe et connaitre assez bien larithmétique jour faire couramment les quatre règles; il est aussi à désirer quils sachent copier un plan.

Le traitement des gardes sedentaires est de 900 francs par an ; il est porté à 9.00 francs pour ceux qui ont la mérlaille forestière. Il leur est en outre alloué une indemnité de logement de l.50 francs par an. En Algérie le traitement des gardes sédentaires est de 1.195 francs. Les gardes et brigadiers sélentaires recoivent des fournitures de chanfage comme les préposés du serrice actif. Quand le bois ne peut leur etre délivé en nature, il leur est alloné une indemniti. qui dans aucun ras. ne peut dépassel 100 francs. (Cire, du 18 mars 1890. n² 48.1 Le traitement est soumis aux mèmes retenues que celui des

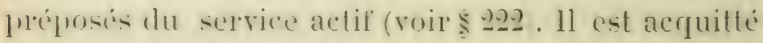
de la mème manière.

Les gardes sinlentaires font partie des compagrnies de chassours forestiers. sils sont en état de porter les armes (roir \$273).

Lec garles serlentaires ne penrent entrer dans le service actif quaprès qualre ans dexercice a moins qu ilsne se trourent dans les conditions imposées aus candidats militaires par l'arrète de 1902 (voir \$ 289); ils ne peuvent olre admis a concourir pour l'Ecole 


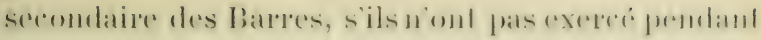
frois ans an moins les fonctions de garde dans lo. service actil'.

310. Brigadiers sédentaires. - LA fllimsís de ce grade lomplissent. daus les burreand des chels de service, les memes fonctions que les gareles: ils liemment les livers dordre et de computabilité, dressenl les citals el expédient la correspondance.

Les brigadier's sédentaires sont pris soil parmi les gardes sédentaires ayant au moins deux ans de service, soit parmi les gardes ou les brigarliers du service actif.

Le traitement de ces préposés est de 1.000 franc: jour la $3^{e}$ classe, de 1.100 francs pour la 2", de 1.200) pour la fre et de 1.300 francs pour lesbrigadiers hor's classe. (Circ. 26 arril $\left.1880, n^{\circ} 409.\right)$ Ils touchent en outre 100 francs par an à titre d’indemnité du logement, et leur chauffage comme il est dit au paragraphe 220. Le traitement des brigadiers médaillés est augmenté de כّ0 francs.

En Algérie, le brigadier comptable recoit 1.620 francs, le brigadier de $1^{\text {re }}$ classe 1.0000 francs, celui de 2 classe 1.37 .5 franes et celui de $3 "$ classe 1.250 francs. Tous les préposés français du service sédentaire ont droit à une indemnité de logement de כ̋00 franrs, indemnité qui est réduite à 400 francs 
pour les gardes sédentaires indigènes. (Déc. du 30 décembre 188ว.)

311. Les brigadiers sédentaires ne pourront entrer dans le service actif, arec leur grade, que lorsquils compteront ruatre années d'exercice dans ce grade. à moins quils n'aient déjà fait partie du service actif pendant deux ans au moins comme simples préposés.

Ils ne peurent aspirer au grade de garde général stagiaire que s ils comptent. au $1^{\mathrm{Fr}}$ janvier de l’anne lendant laquelle le tableau d'arancement est arrèté. quinze années de service dont cinq au moins dans la partie active (Circul. du 2.) janvier 1896), ni concourir pour l'Ecole secondaire des Barres, sils nont été pendant trois ans dans le service actif.

Ceus qui demandent à rentrer dans ce service reprennent te traitement afferent aux brigadiers de leur classe, du service actif.

312. Administration centrale. - Le's brigatlier's et cardes sidentaires, comme ceux du service actit. peuvent aspirer anx emplois de commis a l'administration centrale. sils ont au moins trois ans de services valables pour la retraite.

Les titres, classes et émoluments des commis at. tachés à ladministration centrale sont réglés ainsi qu ilsuit : commis 7 classe : 1.800 francs ; 6 elasse :

2.100 franes; 5 classe : 2.400 francs ; 4 classe : 


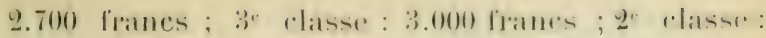
3.300 franes: fwe classe : 3.600 franes: classe averpliommelle: 4.000 iranes. (14riti min. 12 octohe 18!10.)

313. Commis temporaires. - Les commis l(1mpurairessonl choisis par les agents qui les omploirul et payés par eux aux moyen des fonds que ladministration allowe pour frais diecrilures.

Ces employés ne font pas partie du personnel de: ladministration des forets, ils ne sont pas compris dans les cadres des compagnies de chassemes forestiers. Il n'est lait aurume retenue sur lem salaire, ils nont aucun droit à une peusion de retraite.

Il n'y a pour ladmission descomnis temporaires aucune limite dàge. Les chefs de service peuvent choisir des jeunes gens encore mineurs ou des hommes déjà avancés en àge. L'administration leur laisse le choix de ces auxiliaires, quils peuvent d'ailleurs renvoyer dis quils nen sont plus satisfaits.

Les services rendus par les commis temporaires ne leur créent aucun droit à entrer dans ladministration. 


\section{CHAPITRE XIV}

\section{GARDES PARTICULIERS, GARDES-CHASSE ET GARDES-VENTE}

Gitrles particuliers. - Nonination. - Serment. - Compétence.

- Privilige de juridiction. - Proces-verbaux - Exploitations.

- Chasse. - Instruction professionnelle.

Ciurles-chussie. - Yomination. - Révocation, - Permis de chas-c

- Uniforme. - Renvoi.

Gurles-cente. - Tumination. - Serment. - Compétence. Procè-rerbanx. - Vérificalion de réserres. - Demandes de harts. - Délais dexploitation. - Regisire. - Permis dexp!oiter.

314. Gardes particuliers. - Les particuliers possesseurs de forits ont le droit de nommer des gardes qui exereent sur ces propriétés la meme surveillance que les préposés commissiomnes par ladministration des foreds sur les bois sommis au régime forestier.

Les commissions de gardes délivées par des particuliers derront itre rédigées sur timbre. (Voir Formule $\left.n^{\circ} 30.\right)$ 
Lilles sonl soumises it lemrecrislrement au droil fixe de 3 fr. $7 \%$.

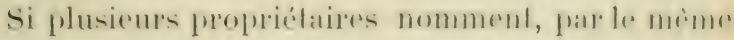
acter un seul garde pour leme bois il est dò autant de droits denregistrement quil y a rle proprexlaires distincls.

Les fonctions de garde particulier ne perment itre confies quà des hommes ayant 20.; ans accomplis.

Les gardes nommés par les particuliers devent clre agrés par le préfel ou le sous-préfed de l’arrondissement. (C. for., art. 117.)

Les demamles tendant a faire agreer les gardes particuliers sont déposées à la préfecture. Il en sera domné récépissé. Apres lexpiration du délai d’un mois, le propriétaire qui nama pas obtenu de réponse pourra se pourvoir devant le ministre. (Loi du 12 avril 1892.)

Les pieces à produre à l'appui de la demande sont : $1^{\circ}$ la commission délirrée par le ou les propriétaires; $2^{\circ}$ un extrait de lacte de naissance du candidat; $3^{\circ}$ un extrait du casier judiciaire.

L'extrait de l'acte naissance pent ète demandé soit au maire de la commune où est né le candidat. soit au greffier du tribunal de l'arrondissement dans lequel se trouve cette commune. Le coùt de cet acte est de $2 \mathrm{fr} .25$.

L'extrait du casier judiciaire doit ètre demandé 
par le candidat lui-mème au greffier du tribunal de l'armondisisment dans lequel il est né. Le coùt de cet extrait est de $1 \mathrm{fr}$. 25.

31 ö. Serment. - Les gardes particuliers ne peurent exercer leurs fonctions yuapres avoir prèté serment derant le tribunal de première instance. (C. for.. art. 117.)

Le tribunal ne peul refuser d'admettre a la prestalion de serment un garde particulier agréé par le sous-préfet. si dailleurs ce garde remplit les condilions d'àge et de caparité exigées par la loi.

Le serment que prètent les préposés commissionnés par les particuliers est le mène que celui des preposés de l'administration: il est assujetti aux memes formalités (roir $\$ 210)$. Toutefois. la commision ayant dù ètre rédigée sur timbre ef enregistree all préalahle. il n’y a pas liesu de la sommettre au timbre à l'extraordinaire.

316. Compétence. - Le garde forestier d'un partirulier est sans qualité pour constater les délits commis atl préjudice d'une autre persomme.

Sa compétence comme officier de police judiciaire est limitéc aux propriétés indiquées sur sa commission.

317. Privilège de juridiction. - L'acceptation par l’autorité administrative de préposés commissionnés par un ou plusieurs particulierset le serment qüils 


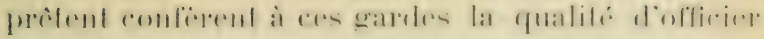
de polier juldeiaire: aussi jonissent-ils du priviliege

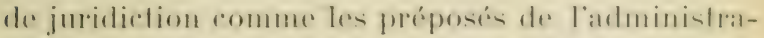
lion des forêts (voir \$266).

318. Révocation. - In carte particulin peut iोm

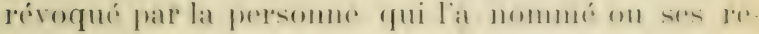
présentants légaux. Cefle rérocation soprepe jar le retrait de la commission.

Les prépets pouront, par dereision molivere le proprétaire ef le carde entendus on dument apperés. rapporter les arretés agréant les gardesparticulirs. (Loi du 12 arril 1892.)

Les gardes particuliers. n'exereant leurs fonctions que dans l'intérèt privé des partiruliers qui les nomment, ne sont pas agents du gourernement.

Véanmoins les violences et roies de fait exerées contre des gardes particuliers dans l'exercice de leurs fonctions sont considérées comme des actes de rébellion. parce que la qualité dofficier de police judiciaire leur donne une autorité spéciale. Pour que cefte autorité ne soit point méconnue, il importe que ces gardes soient toujours porteurs de la plaque qui est le signe distinctif de leurs fonctions.

319. Procès-verbaux. - Lees procès-rerbaux rédigés par les gardes particuliers font foi jusqu'a preure contraire. (C. for., art. 188.) 
Cesactes doirent ètre dressés sur papier timbré; ils sont, du reste, soumis aux formalités de l'affirmation of te lenregistrement. comme les procisrerbaux dressés par les garde's de l'administration.

Toutes les régles de la constatation des délits indiquées au chapitre Ie s'appliquent aux procesrerbaux dress s par les garles particuliers, à l'exception du droit de réquisition directe de la force publique, qui ne leur a pas été attribué.

Lorsfu'ils croient nécessaire de réclamer, pour la répression des délits. le eoneours de la foree publique, ils sont obligés de sialresser au maire ou di l'arljoint.

Les propis-rerbaux dresses par les gardes des bois des partieuliers doivent ètre, dams le délai d'un mois à dater de l'affirmation, remis au proeureur ou au juge de paix, suivant leur compétence. (C. for.. art. 191.)

La compétence des tribunaux correctionnels ou de ceux de simple police, en ee qui enneerne les de. lits eommis dans les bois de particuliers, se détremine d'apres la peine eneomrue. - Comme les gardes ne peurent savoir exactement les condamnations que lenis procis-rerbanx peurent entrainer, of eomme dailleurs ils ignorent la suite que les propriblaires des forits qu'ils surveillent reulent donner i) res actes. ils les transmeltent, aussitot apres l'en- 
registrement, soil an propriblaire lui-mene, suil at son régisseur.

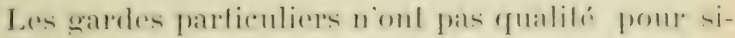

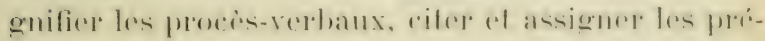

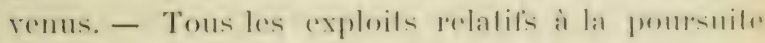
des délits rommis dans les bois des pardiculier's somb faits par ministère d'huissier.

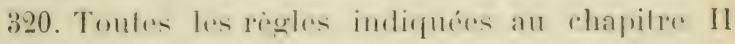
pom la comstatation des délits sappliquent an proces-rerbaux dresces par des gardes particuliers alexecplionde celles eomprisesdans les paragraphes

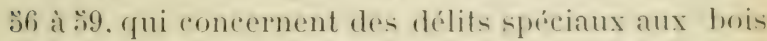
soumis au régime forestier.

321. Exploitations. - Les adjurlicataires des roupes assises dans les bois de particuliers ne sont pas soumis aux règlements qui régissent les exploitations dans les bois gérés par ladministration des forêts. Aussi toutes les règles examinéesdans le chapitre III sont-elles sans application en ce qui concerne le service des gardes particuliers.

La surveillance que res préposés ont à exerecer sur les exploitations consiste à faire exécuter les conrentions du marché passé enlre lacquéreur of le propriétaire, marché dont il convient quiil leur soit donné communication. - Toute infraction aux clauses de la yente doit ètre portée par le garde à la connaissance du propriétaire ou de son mandataire. 
322. Les sardes des bois particuliers procedent anx opérations de balivage et d'estimation des conpes de la mime maniere que les préposés de ladministration : ils dirigent. comme ces derniers, les travaux damélioration exécutés dans les forèts quils surveillent. Yous renroyons donc pour ces parties de leur service aux chapitres IX. X et $\mathrm{Xl}$ du tome Ier).

Lorspue les exploblations sont laites an comple des lunpreftaires. elles sont dirigées par les gardes yui surveillent les ourriers. dressent les états démargement et le plus sourent procèdent a la vente des produits facomés quand elle se fait an détail.

Les gardes remplisent alors les memes fonctions fue les gardes-rente : ils doirent comme eux tenir le comple exart : des jomrnés employees à lexploitation. des produits farcommes el des prix de vente. Il nest pas de meilleme ensedgnement pour un forestier que celui quil acruiert en diriegeant hui-mème lexplobitation des enupes, paree qüil se remel ainsi comple de foms les détails de lopréation el quil e'n roit les résulfats an proint de vue funancier et foreslier.

323. Chasse. - Les cartes particuliers nélant pas. comme ceux de larhministration, rangés dans la ratégorie des persommes à qui il ne pent itre déliver de permis de chasse, peurent chasser dans les bois 
confiés a leur surveillance, sils y soml anturisios par le proprictaire, ef si d'ailleurs ils ont ohtemu 1 m permis.

Celle faculte ne muil pas a leurs fonctions de surreillance, puisfüils peuvent les exereer en pareonl'ant leur triage; mais elle conduit somvent les gardes a négliger fous leurs anters devoirs pome soceuper exclusivement de chasser. Cuest un écueil qu un bon garde doit éviter. La chasse, qu un foreslier doit comnaître, nest pour lui quin aceessoire de son service. Son fusil doit servir à détruire les animaux nuisibles et à empècher la trop grande multiplication du gibiex; mais il ne fiut pas qu'il devienne un instrument de dérastation.

Quand le proprićtaire rient visiter le bois, il est bon quion puisse lui indiquer les cantons où le gibier est abondant (un coup de fusil heureux est ordinairement suivi d une bome gratification); pour cela il faut que les gardes comnaissent les habitudes des animaux saurages, quils favorisent leur reproduction, et qu'ils écartent arec soin les braconniers et surtout les colleteurs. Nous arons indiqué au chapitre IV les règles qui serrent à guider les préposés de ladministration dans cette partic de leur service; elles peurent d’autant mieux sappliquer aux gardes particuliers que ces derniers, ayant la facilité de chasser, portent plus d'intérèt à tout ce 
qui touche à la chasse et sont plus à mème dy consacrer leur attention.

32x. Instruction professionnelle. - La plupart des gardes particulier's se contentent de faire, dans les forèts confiées à leur vigilanee, des tournées jour la répresion des délits; mais il en est fort peu qui soceupent de la culture et de lexploitation des bois: ils sont gardes dans la stricte acception du mot, mais ils ne sont pas forestiers. Il serait fort à désirer que ces préposés, ausi bien que les propriétaires qui les emploient. comprissent toute l'utilité d'une instruction professionnelle qui les mettrait en citat de diriger les exploitations et d'éviter des fautes trop communes, causes de si grands dom. mages pour les forets. Il nest pas rare, en effet, de roir les bois des particuliers soumis, par suite de lignorance complete des propriétaires et de leurs gartess à des exploblations désastenses. Dans les uns. on coupe des taillis en pleine croissance : il serait lucratif de les laisier sur pied queldues années, mais on ne sait pas se rendre compte de cet avantage : dans dautres, on réserve des baliveaus sans arenir ou frop feu nomlereux, fandis quatlenrs on laisse le taillis dominé par une réserve surahondante qui arrête sa croissance.

Dans certaines contries on a applique à des fords de cheme le furelage réplé. morle de traitement que 
celle essence supporte mal, ef l'on a aimsi ruine des

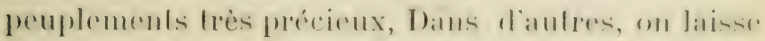

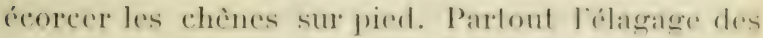

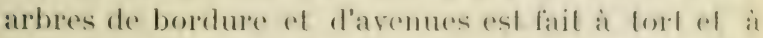
travers par les lermiers qui profitent du bois ; on ôte ainsi toule valeur anx lrones qui pourraiont elre ulilisés plus tard comme bois de charpente, si cers Ćlagages étaient bien faits. Enfin les repenplements artificiels, les assainissemente soml négligés, de quand les propriélaires ventent entreprendere quelques travaux de cette espece, ils leur reviemnent fort cher, faute parceux qui les font récuterdecomnaìtre les moyens économiques employés dans dautres pays. Tout cela narriverait pas si les gardes comnaissaient un peu leur mélier, of il leur serait facile d’y parrenir par l'étude des traités élémentaires de sylriculture, el surtout, fuand cela est possible, par la fréquentation des cours fails à l’École d'enseignement technique el professionmel organisé ans Barres en vertu du décrel du 19 décembere 1903 (roir $1^{\circ} 307$ ).

Le programme de ces cours, qui ont lieu chaque année, comprend toutes les connaissances techniques nécessaires à un garde. Lees condilions d'almission et le règlement de cefte école ont été fixés jar un arrèté ministériel en date du 17 janvirr 190 to dont. le lexte est reproduit dans lenAnnexes de ce volume. Nous ne saurions trop engager les grants pro- 
jriétaires de forèts à faciliter à leur's gardes l'accès le cet enseignement. le seul qui existe en France pour les éléments de lart forestier.

3ํ. Gardes-chasse. - Les fermier's de la chasse dans les bois de l'Etat peurent. aree l'autorisation du conservateur. instituer des gardes particuliers de la chasse dans leurs lots respectifs. (Cah. des charges, art. 26.)

326. Nomination. - Chaque fermier a qualité pour nommer ces gardes-chasse. qui doirent ètre acceptés par le conservateur.

Le grarele-chasse nommé par le lermier, accepté par le conservateur, doit en outre ètre agréé par le sous-préfet.

La nomination et la prestation du serment de ces gardes-chasse spéciaux sont soumises aux règles indiquées aux paragraphes 210-211.

327. Révocation. - Le conservateur a le droit dexiger le renroi de ceux de ces gardes-chasse qui compromettent ou entrarent le service des forèts. (Cah. des cliarges, art. 26.)

Ce droit est aboolu. Le conservateur n’a pas à justifier des motifo qui le déterminent à exiger le renvoi din garde-chasse. Le garde-chasse qui tire un lapin lorspune invitation de le renvorer a été adressec par le conservaleur au locataire commet un délit de chasse. 
328. Permis de chasse. - Les gardes-chasse particuliers sont autorises at porter dres armes it linu; il peuvent chasser sös sont mmis d'un permis of ils

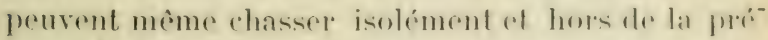
sence du fermier suls y sont auforisés par lui. (Calls. des charges, art. 26.)

329. Uniforme. - Il est interdil aux gartes-chasco nommés par les fermiers de la chases des bois de letat de porter un uniforme fui puisse être enonfondu avec celui des préposés forestiers. (Id.)

330. Renvoi. - Ces gardes-rhasse recoivent. jar le fait de leur nomination etdr la prestation deserment. le caractère defficier de police judiciaire, eomme les gardes particuliers nommés par les proprictaires. Ils jouissent comme eux du privilege de juridiction (roir \$\$ 2 20 ) ef leur sont entièrement assimilés pour tout ce qui concerne la constatation des délits.

331. Gardes-vente. - Tout adjudicataire qui reut avoir un facteur ou garde-rente doit le laire agréer par l'agent forestier chef de service, of assermenter devant le juge de paix. (C. for., art. 31.)

Ce garde-vente ne pourra itre parent ou allié du garde de triage ni des agents de la localité.

332. Nomination. - La nomination du garde-rente doit être faite sur papier timbré et enregistréc au prix de $3 \mathrm{fr}$. 7.). décimes compris. Cet acte est présenté à l'agent forestier chef de service qui y inscrit 
son risa. Cet agent peut refuser d'agréer le facteur désigné par ladjulicataire. Ce dernier n'a dans ce cas aucun recours contre cette décision.

333. Serment. - Le facteur agréé se présente derant le juge de paix, qui recoit son serment. Laccomplissement de cette formalité est mentionné sur lacte de nomination. Les frais de prestation de ce serment s'élèvent à $6 \mathrm{fr}$. 50 .

334. Compétence. - Le garde-rente est autorisé à à dresser des procès-rerbaux. tant dans les rentes yùi l'oüe de la cognée. - Ses procès-verbaux sont soumis aux mèmes formalités que ceux des gardes forestiers et font foi jusquà preuve contraire. C. fort., art.31.)

Les adjudicataires seront responsables de tout délit forestier eommis dans leur vente et à l'oüe de la rognce. si leurs facteurs ou gardes-rente n'en font leurs rapports. lespuels doirent etre remis à l'agent forestier dans le delai de cing jours. (C. for., art. 4...)

33\%. Procès-verbaux. - Les procés-rerbaux dressés par les facteurs doivent itre réguliers et probants, ce-d-a-dire qu'ils doivent réunir toutes les conditions de ralidite indiquées au chapitre rer.

Ln proces-rerbal incomplet ou annulé pour vice de forme ne lierait fas cesser la responsabilité de larljudicataire. - In proces-rertal résulier dressé par un farteur ne lait pas cesser cetteresponsabilité 
sil ne désigne pas lauteur du délil, on sil ne jutife pas des démarches ot diligences latiles pour le découvrir.

La dénonciation du délit laite par l'adjudieataire lui-mème ou par son larfenr anx préposís al agonls forestiers ne decharge pas ladjudicalaire de la lesponsabilité.

Cette responsabilité subsiste méme quand le délit a élé constaté par un procis-rerbal dressi par un garde forestier.

Le garde-vente na done pas à se préoceuper de savoir si les agents ou préposés de, l'administration des forèts ont en comnaissance des dólits commis dans les rentes ou a loüe de la cognée; ils doivent dabord constater eux-mèmes ces délits, qui, à défaut de cette constatation, sont mis à la charge de l'adjudicataire.

Pour que ce dernier soit mis a courell, il est indispensable que dans les cinq jours qui suivent le délit, son garde-rente l'ait constaté par un procésverbal régulier, alfirmé, enregistré el remis au chef de cantonnement.

Ce délai de cinq jours court à partir du jour où le délit a été commis, et non de celui où il a été constaté.

336. Nous avons indiqué au chapitre III les contraventions auxquelles l'exploitation des coupes 
peut dommer lieu; les facteurs, en lisant arec attention ce chapitre et les cahier's des charges relatifs aux adjudications, se rendront aisément compte de l'importance quils doirent mettre à surveiller non seulement les délinquants, mais encore plus rigou' reusement les ourriers.

Ces derniers. par la négligence qu'ils apportent à leur travail. occasiomnent sourent des poursuites qui retombent sur les adjudicataires, et les facteurs qui sont leurs représentants doirent chercher par tous les moyens à leur éviter les peines rigoureuses qüils encourent; pour cela, ils renverront des chanliers les omriers malarboits, négligents ou paresseux: ils reilleront à re qu'ils ne tëtournent pas des bois pour les enlevere en frande, à re quils n'allument pas de feux sur des points non désignés, et a re quils premnent toutes les précautions possibles pour éviter les incendies.

Les fonctions de facteurs ne se reduisent pas it relles de surveillants des coupes. Ils sont eneore chargés de la direetion des exploitations, du reglesment des salaires des omviers, de la délivrance et mème sonvent de la vente des hois exploités.

Ils doivent done se tenir au courant des prix des bois ef des diverses marehandises quon en tire. ef de la solvabilité des gens qui viennent chereher directement leur approvisiomement dans les coupes. 
337. Vérification des réserves. - C'rst all garde-

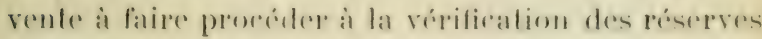
aussitôt apres l'adjudication of a signaler, avant

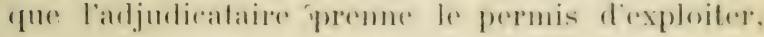
les crems qui onl pu ifre commises an marlelage.

\section{Demandes de harts. - Places à fourneaux. -} Pendant la durée des exploitations, les facterurs font, au nom des adjudicataires qu'ils représentent, les demandes en déliveance de harts (roy. formule $n^{\circ} 32$ ), celles de désignation des places a fourneaux, loges ef ateliers. Ces demandes sont adressées au chef de cantonnement.

339. Délais d'exploitation et de vidange. - Les demandes en désignation de chemins de vidange,celles de prorogation de délais d'exploitation et de vidange sont adressés au conservateur. Elles peufent itre remises aux agents locaux; reux-ci les transmettent arec leur aris au conservateur, qui seul a le droit d’accorder des délais ou de désigner des chemins autres que ceux portés sur l'affiche.

Toutes ces demandes derront être rédigées sur timbre. L'objet en sera indiqué aussi brièrement que possible. Les demandes en prorogation de délai feront connaître l'étendue des bois restant à exploiter, ou les quantités et qualités des bois existant sur le parterre de la coupe, les causes du retard 
dans l'exploitation ou la vidange et le délai qu'il sera nécessaire d'accorder. - Ces demandes doivent êtreformées vingt jours arant l'expiration des délais fixés par le cahier des charges.

3ł0. Les gardes-vente préparent les récolements en faisant ceindre les arbres de réserve d'un lien de paille; ils assistent à cess opérations, mais ils ne sont appelés à signer les procès-rerbaux que s'ils sont munis d'un pouroir régulier de l'adjudicataire.

341. Larticle 31 du Code forestier qui imposait, à tout adjulicataire de enupes assises dans les forets soumises an régime forestier, lobligation d'avoir un garde-vente assermenté, a été modifié en ce sens que la nomination du garde-rente n'est plus obligatoire mais facultative. Les adjudieataires peuvent donc se passer de garde-rente et se contenter davoir sur leurs coupes un facteur ou surveillant qui en dirige l'exploitation. Mais, si ce facteur niest pas agréé comme garde-rente et assermenté, il naura pas qualité pour constater les délits commistant dans la vente qu’à l'ouïe de la cognée. La responsabilité de l'adjudicataire sera done eomplete: consideration qui déterminera probablement beaucoup d'entre eux à user de la faculté qui leur est laissée de faire agréer un garde-rente pour en atténuer la gravité. 
la nomination dugarde-rente ncetant pas obliga-

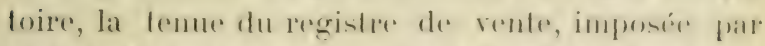

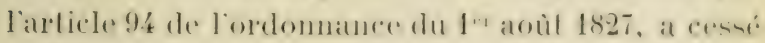
de l'être. 

ANNEXES 

1) EP A RTEMENT

de llléraull.

ARRONDIS. COMMUNAL de Saint-J'ons.

INSPECTION

de Montpellier.

CA T T N EMENT de Saint-Pons.

Coupe de bois de plus de 2 décim.Flagrant délit. Complicité.

Nota. Copier sur le livret du garde. Inscrire le numéro de la feuille sur laquelle celle copie est faite. Affirmer au plus tard le lendemain de la cloture del'acte.Faire enregistrer.

\section{MIRETIII GESERILE UES EIUX ET FORETS}

L'an mil huit cent quatre-vingttrois, le douze du mois de mars;

Nous soussigné N..,garde forestier a la résidence de Saint-Pons, assermenté et revêtu des marques distinc. tives de nos fonctions, certifions que, fai-ant notre tournée vers-ept heuredu matin, dans la forêt de Serignan appartenant it l'Etat, au cintonappelé la Haute-Sagne, sis au territoire de la commune de Saint-Pons, et dont le bois est âgé de 18 ans;

Nous avons aperçu un individu qui coupait à l'aide d'une hache des brins que deux autres personnes étaient occupées à façonner en bilie-. Nous étant approché, nous avons reconnu les nommé- Tarbouriech, Jean, ouvrier tisseur ; Lartigue, François, fil- mineur de Fulcrand, demeurant chez son père, et Jeanne Vergne, fille majeure, tous les trois deme urant à Saint-Pons. Nous avons mesuré les arbres ainsi exploités, qui sont au nombre de cinq, tous essence chène, dont trois de 3 décimètres et deux de 4 décimètres de tour, mesure prise sur les souches, les bois étant déjà façonnés et refendus. Le-sits arbres étaient verts et sains; leur valeur est de $4 \mathrm{fr} .50 \mathrm{c}$. Nous avons évalué à $20 \mathrm{fr}$. le dommage causé par l'abatage desdits bois. Nous avons saisi la hache du sieur Tarbouriech et les bois coupés en délit, que nous avons mar-qués de notre marteau particulier et laissés sur place.

En foi de quoi nousavons rédigé le jrésent procè-verbal que nous avons 


\section{$-304-$}

clos à Saint-Pons, le treize mars mil huit cent quatre-vingt-trois.

Signature du garde.

AFFIRMATION
SIGNIFICATION et

ASSIGNATION

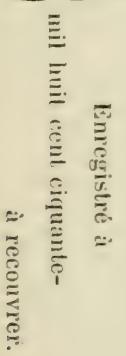

Par-devant nous juge de paix du canton de Saint-Pons a comparu le sieur $\mathbf{N}$.... garde forestier dénommé au rapport qui précède, lequel l'a affirmé par serment sincère et véritable, et a signé avec nous.

A Saint-Pons, le treize mars mil huit cent quatre-vingt-trois.

Sign. du juge de paix. Sign. du garde

L'an mil huit cent quatre-ringt-trois, le vingt du mois d'avril, à la requête de l'administration des forêts, poursuites et diligences de M. l'inspecteur des forèts à la résidence de Montpellier, lequel fait élection de domicile à Saint-Pons.

Nous soussigné N..., garde forestier, demeurant commune de SaintPon-, assermenté et revètu des marques distinctives de nos fonctions, ai signifié le procès-verbal d'autre part à :

$1^{\circ}$ Trabouriech, Jean, demeurant à Saint-Pons. en son domicile, parlant à sa personne ;

$2^{\circ}$ Lartigue, Francois, demeurant a Saint-Pon - en son domicile, parlant it Maldeleine Chassin, sa mère;

$3^{\circ}$ Larligue, Fulcrand, demeurant à $\hat{\Xi}$
$\overline{\overline{0}}$
$\stackrel{-}{-}$
$\overline{\overline{0}}$ Saint-Pons, en son domicile, parlant à sa femme;

$4{ }^{\circ}$ Jeanne Vergne, demeurant à Saint-Pons, en son domicile parlant à sa tante, ainsi déclarée. 
E.TAT DES FRAIS

Timbre. $\left\{\begin{array}{l}\text { du pr,-verb. } \\ \text { de la copie. }\end{array}\right.$ Enregrist. $\left\{\begin{array}{l}\text { du pr.-verb. } \\ \text { de la citat. }\end{array}\right.$

Ecrit. $\left\{\begin{array}{l}\text { Original de } \\ \text { la citation. } \\ \text { Cop.de l'ex. } \\ \text { Rôles non } \\ \text { compris le } \\ 1^{\mathrm{er}} \text {. }\end{array}\right.$

Myriam. parcourus.

TOTAL
Arec assignation à comparaitre le quinze mai mil huit cent quatre-vingttrois, a onzeheures du matin, et jours suivants, s'il y a lieu, par devant le tribunal correctionnel séant ì SaintPons, pour s'y voir condamner aux peines portées par la loi; et, afin yuil-nen ignorent, jai, aux -usnom. més, parlant comme dessus, laissé copie duditpoces-verbal of de lacte l'ifformation que du pré-ent exploit, dont le coùt est de dont acte

Signature du garde. 
DÉPARTEMEXT

de la Meuse

ARROSDIS. COYYUYAL

de Montmédy.

INSPECTION

de Montunedr.

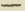

C. A XTOXXEMLXT

de Spincourt.

Conpe et enlere ment darlifes de plus le a decim.Pisite dumiciliaire - Sai-ie - Situlestret.

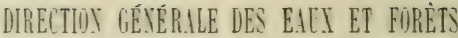

L'an mil huit cent quatre-vingt-cing, le dix du mois de mars,

Nous soussignés. M..., hrigadier desforèts à la résidence de Senon, et N..., garde forestier à la résidence de Loison, assermentés et revètus des marques distinctives de nos fonctions. certifions que, faisant notre tournée, rers onze heures du matin, dans la forêt de Senon, appartenant à la commune de Senon, au canton appelé la Réserve, sis au territoire de la commune de Senon, et dont le bois est âgé de quarante ans ;

Nous avons reconnu qu'il avait été récemment coupé à la scie et enlevé un chene vif deringuantecentimètre: de tour, mesure prise sur la souche. Le-traces de lenlevement se dirigeaient vers le chemin de Senon: nou- avons constaté que ledit arbre avait été trainé jusqu'au bord dudit chemin et avait été chargé sur une voiture dont les roues avaient laissé leur empreinte sur le bord du fossé. Convaincu-que cet arbre avait dù etre transporté au village de Senon, nous avons requis $\mathrm{M}$. le maire de cette commune de nous accompagner dans une vi-ite domiciliaire a larquelle nous avons procédé ledit jour en sa présence.

Nos perquisitions ont donné les résultats suivants :

Dans un hangar dépendant de la maison du sieur Sallier, François, cultivateur audit Senon, nous avons trouvé, caché dans un tas de paille, un chène de cinquante centimètres, mesure prise sur la découpe. Cet 
Nota. - Inscrire le numéro du livrel du brigadier.Faire deux expéditions du procès-verbal, en remetlre une au séquesIre; la deuxième, remise dans les 2 theures au greffe de la juslice de paix, en méme temps quel'on affirmera le procèsverbal. La mention de l'affirmation doit elre mise sur celle dernière expédition.

Faire enregistrer.

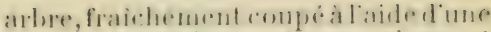
scie, présentait la mème couleur et la mème forme que la souche trouvée en forèt. Les morceaux d'écorce que nous avons pris sur la souche, comparés à l'écorce de l'arbre enlevé, ont

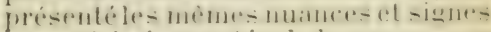
caractéristiques. $A$ insi, les crevasses des morceaux d'écorce pris sur la souche, se retrouvaient, avec leur forme et direction, sur l'écorce de l'arbre enlevé. Une gercure ancienne, que nous avons remarquée sur la souche, sereprodui-ait dans la même direction sur l'arbre trouvé chez le sieur Sallier; la mesure prise à un mètre de la section est de soixantecing centimètres.

Nous avons invité ledit Sallier à as. sister au rapatronage, ce à quoi il s est refusé. Interpellé sur lorigine de cet arbre, il nous a déclarél'avoir acheté d'une personne dont il n'a punous-rlire le nom. La valeur de l'arbre abattu est de $6 \mathrm{fr}$. - Nous avons estimé à $10 \mathrm{fr}$. le dommage occasionné par ce délit.

Ayant reconnu au moyen du rapatronage opéré à l'aide des morceaux détachés de la souche, que l'arbre trouvé chez le sieur Sallier était celui dont nous avions suivi la trace, nous avons marqué de notre marteau les deux extrémités dudit arbre et lavons saisi et fait transporter chez le sieur Michel, secrétaire de la mairie, que nous avons déclaré séquestre et qui s'est engagé à le représenter à toute réquisition légale. Yous luiavons remis copie du présent procès-rerbal, qu'il a signé avec nous ainsi que la copie qui lui a été remise et que celle destinée au greffe.

Fait et clos à Senon, les jours, mois et an que dessus, à deux heures du soir.

Sign. du maire.

Sign. duséquestre. Sign. desgardes. 
AFFIRMATIOY

SIG NIFICAT ION

et

AFSIGXATIOX
Par devant nous, maire de la commune de Senon, ont comparu les sieurs M..., brigadier des forêts, et N..., garde forestier, dénommés au rapport qui précède, lesquels, après que lecture leur en a été par nous faite, l'ont affirmé par serment sincère et véritable et ont signé avec nous.

A Senon, le onze mars mil huit cent quatre-vingt-cing, à neuf heures du matin.

Sign. du maire. Sign. des garc̉es.

Lan mil huit cent quatre-ringt-cinq, le quinze du mois d'avril, à la requète de ladministration des forèts, poursuites et diligences de M. l'inspecteur. des forêts à la résidence de Montmédy, lerguel fait élection de domicile à Montmédy.

Nous soussigné N.., brigadier forestier, demeurant commune de Senon, assermenté et revètu des marques distinctives de nos fonctions, ai signifié le procé-rerbal dautre part à

$1^{\circ}$ Sallier, François, demeurant à Senon, en son domicile, parlant à Nicolas Maupin, son voisin, n'ayant trouré personne audomicile de la partie :

Avec assignation à comparaitre le premier mai mil huit cent quatrevingt-cinq, à onze heures du matin, et jours suivants, s'il y a lieu, par devant le tribunal correctionnel séant à Nontmédy, pour s'y voir condamner aux peines portées par la loi ; afin quiil n'en ignore, j'ai au susnommé, parlant comme de-sus, laissé copie tant dudit procès-verbal et de l'acte d'affirmation que du présent exploit, dont le coùt est de dont acte,

Signat. du garde. Signat. du voisin. 
If: CONSERTATION

INSPECTION

de Montmedy.

CA TTON NEMEXT de spincourl.

\section{B.IIGIIIE}

de Senon.

Charges de famillé.

Position de fortune.

Est-ce un délinquant d'habitude ? Est-il en état de récidive ?.......

Le délinquant-at-il élé soumis ou s'est-il montré récalcitrant lorsqu'on Ini a déclaré procésverbal?.......

Réputation du délinquant comme homme privé dans le pays qu'il habite.

Valeur des objets enlerés........

Nature etvaleur de ; l'instrument saisi. .

Estimation du , dommage réel causé

Renseignements ? divers. ........
EXEMPLE $N^{0} 2^{\text {lis }}$

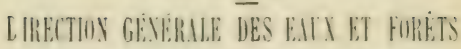

BUILETIN HE RENGEIG NEMENTA

sur le sieur Sallier 'Francois) ìgé d'environ 30 ans, demeurant à Senon, contre lequel il a été verbalisé à la date du 10 mar's 188 a par les sieurs N..., brigadier forestier, et N..., garde forestier, suivant procès-verbal $\mathrm{n}^{\circ}$.

Trois jeunes enfants et sa mère, qui est infirme.

Posside une maison el un champ, le tout estimé $6.0 j 0$ francs.

Il n'est pas délinquant d'habitude et n'est pas en récidive.

Il s'est montré récalcitrant lorsquion lui a déclaré procès-verbal. mille.

Il passe pour un honnête père de fa-

\section{Six francs.}

Néant.

Dix francs.

Le prévenu demande à transiger.

Le 10 mars 1885 .

Le Brigadier forestier. (Signature du brigadier.) 
DÉPARTEMEX̃T

de l'Hérault.

ARRONDIS. COMMUNAL

de Saint-Pons

IXSPECTION

de Montpellier.

CANTONNEMENT

de Saint-Pons.

Coupe et enlèrement de bois de moins de 2 décim. - Saisie non effectuée d'instruments de délit.

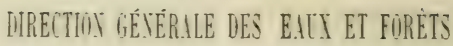

L'an mil huit cent quatre-vingt cinq, le trois du mois de mars,

Nous, soussigné, N...,garde forestier à la résidence de la Salvetat. assermenté et revètu des marques distinctives de nos fonctions, certifions que, faisant notre tournée, vers sept heures du matin, dans la forèt du Devez, appartenant à l'Etat, au canton appele Travers-des-Faus, sis au territoire de la commune de la Salvetat, et dont le bois est âgé de onze ans;

Nous arons rencontré les sieurs Goutines. Joseph, cultivateur, célibataire, lemeurant chez Jean Goutines. son père, fermier aux Esclats, et $\mathrm{Pa}$ rot, Nicolas, domestique dudit Jean Goutines, lesquels avaient coupé à la serpe et emportaient chacun une -harge à dos de brins verts, de moins de 2 décimètres de tour, essence chêne et hètre. La valeur des dites charges est de $1 \mathrm{fr}$. l'une; le dommage causé au peuplement est de $6 \mathrm{fr}$. Nous avons requis les sieurs Goutines et Parrot de nous faire la remise des serpes dont ils étaient porteurs, ce à quoi ils se sont refusés. Nous leur avons déclaré la saisie desdits instruments évalués à 3 fr. l'un, ainsi que du bois dont ils sont demeurés en possession.

Fait et clos à la Salvetat, le trois mars mil huit cent quatre-ringt-cing. 
SIGNIFICATION

et.

Assignation
Lan mil huilcent quatre-ving-cinq, le huit du mois de mai, a la ré quète de l'Administration des forêts, poursuites el diligenees de M. l'inspecteur des forèts ì la résidence de Montpellier, lequel fait élection de domicile a Saint-Pons:

Je, soussigné, N.... garde forestier, demeurant commune de la Salvetat, assermenté et revêtu des marques distinctives de nos fonctions, ai signifié le procès-verbal d'autre part à:

$1^{\circ}$ Goutines, Joseph, cultivateur, demeurant à la ferme des Esclats (la Salvetat), en son domicile, parlant à son valet de ferme, ainsi déclaré;

$2^{\circ}$ Goutines, Jean, fermier, demeurant aux Esclats (commune de la Salvetat), en son domicile, parlant àson valet de ferme ainsi déclaré;

$3^{\circ}$ Parrot, Nicolas, cultivateur, demeurant à la Salvetat, parlant à M. le maire de la Salvetat, qui a signé loriginal et la copie, n'ayant trouvé personne au domicile de la partie.

Avec assignation à comparaitre le

heure du et jour's suivants, s'il y a lieu, par-devant le tribunal correctionnel séant à voir condamner aux peines portées par la loi ; et afin qu'ils n'en ignorent, j'ai, aux su-nommés, parlant comme dessus, laissé copie tant dudit procès-verbal et de l'acte d'affirmation que du présent exploit, dont le coùt est de

dont acte.

Signat. du garde. Signat. du maire. 
$6^{\circ}$ CONSERVATION

DÉPA RTEMENT

des Ardennes.

ARRONDISS. COMHUNAL

de Sedan.

Ler CANTONNEMENT

de Sedan.

INSPECT1ON

de Sedan.

Mutilation. - Piécidive.
EXEMPLE $N^{0} 4$

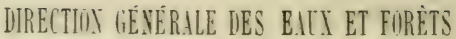

L'an mil huit cent quatre-vingt-deux le six du mois d'avril.

Nous soussigné, N..., garde forestier à la résidence de Montdieu, as. sermenté et revêtu des marques distinctives de nos fonctions, certifions que, faisant notre tournée vers six heures du matin, dans la forèt du Nontdieu, appartenant à l'Etat, au canton appelé les Grandes-Mollières, sis au territoire de la commune du Montdieu, et dont le bois est àgé de cinquante ans :

Nous avons trouvé le sieur Martin Lanty, ouvrier tisseur, demeurant à Tannar. lequel était occupé à mutiler un pin vif de $1^{\mathrm{m}}, 20$ de circonférence, mesure prise à un mètre du sol, pour en extraire du bois gras; l'entaille faite à l'aide d'une hache atteint le cœur de l'arbre et entrainera sa perte. Nous avons saisi l'instrument du délit et le bois gras déjà extrait, dont la valeur est de $1 \mathrm{fr}$.

Le sieur Lanty, Martin, est en récidire, avant été condamné par suite du procès-rerbal dressé par nous le 4 janvier dernier, $n^{\circ} \ldots$

Fait et clos au Montdieu, le sept arril mil huit cent quatre-vingt-deux.

Signature du garde. 
$16^{\circ}$ CONSERVATION

DE EARTEMENT

de la Meuse.

ARRONDISS. COMMUNAL de Montmédy.

INSPECTION

de Montmédy.

C A NTONNEMENT de Spincourt.

Enlèvement de faines.
EXEMPLE N ${ }^{\circ} 5$

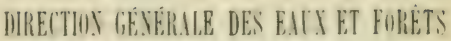

Lan mil huit cent quatre-ving t-cinq le douze du mois de novembre;

Nous, soussigné, N..., garde forestier à la résidence d'Arrancy, assermenté el revitu des marque-distinctives de nos fonctions, certifions que faisant notre tournée, vers sept heures du matin, dans la forêt d'Arrancy, appartenant à l'Etat et à la commune, au canton appelé la Réserve, sis au territoire de la commune d'Arrancy, et dont le bois est âgé de soixantedix ans;

Nous avons rencontré Jeanne Sardoux, fille mineure de Francois, journalier à Longuyon, qui ramassait et avait ramasse dans une hotte une charge de faines, dont nous estimons la valeur à $1 \mathrm{fr}$. Nous avons saisi et répandu sur le sol les faines ainsi enlevées, et avons rédigé le présent procès-verbal que nous avons clos à Arrancy, les jour, mois et an que dessus.

Signature du garde. 
6. CONSERVATION

DÉPARTEMENT

de la Marne.

ARROFDISS. COMMUNAL

d'É pernay.

IXSPECTIOY

d'Épernay.

CANTONXEMENT

de Cézanne.

Enlìvement de feuilles mortes.Complicité-Saisie. - Séquestre.
EXEMPLE N॰6

\section{DIRECTIIYY GEEYÉR.LL IES EILX ET FURËTS}

Lan mil huit cent quatre-ringt-cing le dix du mois de mars,

Nous soussigné, N..., garde forestier à la résidence de l'Etoile, assermenté et revêtu des marques distinctives de nos fonctions, certifions que faisant notre tournée, vers quatre heures du soir dans la forêt de Traconne appartenant à l'Etat, au canton appelé les Cercliers, sis au territoire de la commune de Bricon, et dont le bois est âgé de quarante ans.

Nous avons rencontré les nommés Lauth, Jacques, journalier ; Metzinger, François. fils mineur de Jacques; Frantz Mosennann, ouvrier cardeur, et Fritz Keller, fils mineur de Christine keller. demeurant chez sa mere; tous domiciliés à Barbonne, lesquels étaient oceupés à ramasser avec des ràteaux et à charger sur une voiture attelée d'un cheval des feuilles mortes propres à faire de la litière.

Nous avons reconnu la roiture et le cheval pour appartenir au sieur Jacques Metzinger, et nou- les avons saisis ainsi que le chargement des feuilles mortes, dont la valeur est de 5 francs.

Nous avons constitué séquestre le sieur Nicolas. aubergiste à Barbonne. Le cheval saisi est sous poil bai et marqué de balsanes aux jambes de devant : la voiture est une charrette ordinaire en assez bon état; le harnachement est vieux et usé. Le dit sieur Nicolas ayant accepté le dépót de ces divers objet - et s'étant 
engagé a les représenter à toutes réquisitions, nons lui avons délivré copir du present arte, qu'il a signé avec nous ainsi que la copie qui lui a été remise et celle qui sera déposée au grefle.

Fait et clos à la maison forestière de I'Etoile, le dix mars mil huit cent quatre-vingt-cinq, à sept heures du soir.

Sign. du séquestre. Sig. du garde. 
de la Côte-d'Or.

ARROKDISS. COMYUNAL

de Semur.

I NSPECTION

de Semur.

CA T TON XEMEXT de Montbard.

Extraction el enlevement de pierres - Voiture à deux chevaux.

L'an mil huit cent quatre-vingt-trois, le six du mois de juin.

Nous soussigné, N..., garde forestier à la résidence de Flavigny, assermenté et revêtu des marques distinctives de nos fonctions, certifions que, faisant notre tournée vers huit heures du matin dans la forèt de Flavigny, appartenant à l'Etat. au canton appèlé la Grande-Tranchée sis au territoire de la commune de Flavigny et dont le bois est àgé de dix-huit ans.

Nous avons trouvéle sieur Regnat, Pierre, domestique du sieur Reveilhon. Joseph, propriétaire, demeurant a Flavigny. lequel chargeail de pierres extraites du solforestier une voiture attelée de deux cheraux: le sieur Regnat, interrogé, nous a déclaré qu'il avait été envoyé par soñ maitre pour extraire de la pierre de la carrière voisine, mais que l'ayant trouvée obstruée, il avait cru pouvoir faire son chargement dans la carrière de la forèt. Nous avons estimé à $2 \mathrm{fr}$. la valeur des pierres enlevées; le dommage causé au sol forestier est de $3 \mathrm{fr}$.

Vu la solvabilité notoire du dit Reveilhon, nous nous sommes abstenu de saisir la voiture, les chevaux et le chargement.

Fait et clos à Flavigny, les jours, mois et an que dessus. 
de la Meuse.

ARRONDISS. COMMUNAL

de Montmédy.

INSPECTION

de Montmédy.

CA N TON N M ENT de Spineourt.

Faux chemins. Bois de moins de dix ans.

L'an mil huit cent quatre-vingtdeux. le trois du mois de novembre ;

Nous soussigné, N..., garde forestier à la résidence de la maison forestière du Hat-Fourneau, assermenté et revêtu des marques distinctives de nos fonctions, certifions que, faisant notre tournée, vers sept heures du matin, dans la forèt de Mangiennes, appartruant il letat, au ranton appele la Queue-de-l'Etang, sis au territoire de la commune de Billy, et dont le bois est àgé de trois ans;

Nous avons trouvé le sieur Chassing, Nicolas, meunier à Billy, conduisant à traver's la coupe de l'exerrice 1878 une voiture attelée d'un cheval; il avait parcouru dans les jeunes taillis une longueur de $150 \mathrm{mi}-$ tros et endommagé ungrand nombre de jeunes pousses. Nous avons éralué à $6 \mathrm{fr}$. le dommage occasionné au peuplement. Le sieur Chassing nous a déclaré qu'il avait voulu prendre lancien chemin de vidange pour raccourcir sa route, mais que, nayant pu le retrouver, il cherchait à regacner le grand chemin.

Fait et clos à la Maison forestière, les jour, mois et an que dessus. 
$16^{\text {e }}$ CONSERVATION

DÉPARTEM E X T

de la Meuse.

ARRONDISS. COMYUSAL

de Montmédy.

IXSPECTIOY

de Monlmédy.

CANTOXNEMENT de Spincourt.

Feu à distance

prohibée.
EXEMPLE NO 9

\section{JURECTIIYY GÉYÉRLLE dES EITY ET FURETS}

L'an mil huit cent quatre-vingtdeux, le cinq du mois d'avril,

Yous soussigné, N..., garde forestier à la résidence de Loison, assermenté et revètu des marques distinctives de nos fonctions, certifions que faisant notre tournée vers 7 heures du matin, dans la forèt de Hingry, appartenant à l'Etat, au canton appelé Hingry-Sorel, sis au territoire de la commune de Loison, et dont le bois est àgé de huit ans.

Nous avons trouvé les sieurs Francois, Simon, fils mineur de Pierre, journalier : Jean Mauprat, fils mineur de Jeanne Favier, veuve Mauprat, et Juliette Zarret, fille mineure, domestique du sieur Barthe, Jean, tous domicilie- audit Loison. lesquels araient allumé et entretenaient avec des bois morts un feu établi à 30 mètres de la forèt. Ces bois enlevés de la forèt, ainsi quil résulte de l'areu desprévenus et des traces laissées par eux, fortaient moins de 2 décimétres de tours ; ils ont été évalués à une charge d'homme d'une valeur de $25 \mathrm{c}$.

Dont procès-verbal clos à Loison, le six avril mil huit cent quatre-vingtdeux. 
2Se CONSERVATION

DÉPA R T M E T

de l'Aveyron.

ARRONDISS. COMHUNAL d'Espalion.

I NSPECION

de Rodez.

CANTONNEMENT d'Espalion.

Refus de secours en cas d'incendie.
EXEMPLE $N^{\circ} 10$

DIRETTIN GRERKALE DES EALX ET FURETS

L'an mil huit cent quatre-vingt-six, le dix du mois de mars ;

Nous soussigné, N..., garde forestier a la residence de la maison forestière d'Aubrac, assermenté et revètu des marques distinctives de nos fonctions, certifions que, faisant notre tournee vers huit heures du soir dans la forèt d'Aubrac appartenant à l'Etat, au canton appelé GrandBois d'Aubrac, sis au territoire de la commune de Saint-Chély, et dont le bois est àgé de trente ans;

Nous avons apercu un commencement d'incendie qui venait de se déclarer surle bord du chemin de César. Nous nous sommes immédiatement rendu dans les villages voisins pour obtenir du secours, et nous avons requis le sieur..., propriétaire, demeurant aux Enfrux, de venir aider à éteindre l'incendie, ce à quoi il s'est refusé, disant qu'il y aurait bien assez de monde sans lui. Ledit sieur... est usager dans la forêt domaniale.

Nous avons rédigé de son refus le présent procès-verbal, que nous avons clos et signé à la maison forestière d'Aubrac, le onze mars mil huit cent quatre-vingt-six. 
3. CONSERVATION

DÉPARTEMENT

de la Côte-d'Or.

ARROTDISS, COYYOXAL

de Semur.

IXSPECTION

de Semur.

CANTOXNEMEYT

de Saulieu.

Fonstrurtion de harague.
EXEMPLE $N^{0}$ iा

L'an mil huit cent quatre-vingtdeux, le trois du mois davil,

Nous soussigné N.... garde forestier à la résidence de la maison forestière de Charny, assermenté et revètu des marques distinctives de nos fonctions, certifions que, faisant notre tournce vers deux heures du soir, au canton appelé la Còte, sis au territoire de la commune de MontSaint-Jean;

Nous avons reconnu qu'il venait l'être construit récemment, à la distance de 340 mètres environ de l'extrémité ouest de la forêt domaniale de Charny, une baraque en pierres et planches, située près de la carriere de pierres exploitée par le sieur Francois N..., carrier, demeurant à Mont-Saint-Jean; ladite baraque est sise sur un terrain appartenant au sieur Jean Singlet, propriétaire audit Iont-Saint-Jean.

Nous nous sommes transporté son domicile et, lui ayant demandé -i la baraque avait été construite par lui, il nous a été répondu qu'i avait loué le terrain au sieur Fran cois N... et que c'était ce dernier qui avait établi la loge destinée au service de la carrière. Ladite loge est couverte en tuiles et munie d'une fenètre et d'une porte fermantà clef elle est inhabitée et parait emplorée seulement à renfermer les outils et les provisions des ouvriers.

Fait et clos à la maison forestière de Charns, les jour, mois et an que dessus. 
$16^{\circ}$ CONSERVATION

DEPA RTEMENT de la Meuse.

ARRONDISS. COHMUNAL de Montmédy.

INSPECTION

de Montmédy.

\section{CANTON NEMENT} de Spincourt.

\section{Chantier} non autorisé.

L'an mil huil cent quatre-vingttrois, le domze du mois de mar-;

Nous, soussigné, N..., garde forestier à la résidence de Loison, assermenté el revêtu des marques distinc. tives de nos fonctions, certifions que, faisant notre tournée vers heures du dans la forêt de Sorel, appartenant à l'Etat; au canton appelé Hingry-Sorel, sis au territoire de la commune de Loison, et dont le bois est àgé de ...;

Nous avons appris que le sieur Michel Stephan, demeurant au lieu dit Sorel, avait établi dans la maison qu'il tient en location du sieur Ber. trand, propriétaire, un atelier à débiter des lattes et du merrain, ladite maison élant située à moins de 180 mètres de la forêt domaniale de Sorel. Nous avons requis M. le maire de la commune de Loison de nous assister dans la visite, et, nous étant transporté avec lui audit lieu de Sorel, nous avons constaté qu'il y avait dans la cour intérieure du bâtiment quatre tronces prètes à ètre mises en ceuvre, tout l'outillage d'un atelier de fabricant de lattes et merrain, coutres, chevalets, etc., enfin une demi-treille ou 720 pièces environ de merrain assorti et façonné. Ayant demandé au sieur Stephan, présent à notre visite, s'il avait l'autorisation d'établir un atelier de fabrication, il nous a répondu qu'il ne croyait pas avoir besoin de permission pour faire façonner les bois qu'il achetait. 


\section{$-322-$}

Sur quoi nous lui avons déclaré que nous saisissions les bois tant façonnés qu'en grumes, déposés dans ledit atelier, et dont la désignation a été ci-dessus faite; nous avons apposé l'empreinte de notre marteau sur les quatre tronces et sur les douves supérieures du merrain empilé, et nous avons évalué la valeur totale desdits bois à $160 \mathrm{fr}$.

En foi de quoi nous avons dressé le présent procès-verbal, que M. le maire, présent à la visite, a signé avec nous.

Fait et clos à Loison, le 13 mars mil huit cent quatre-vingt-trois. Signat. du maire. Signat. du garde. 
$28^{\circ}$ CONSERVATION

DÉPARTEMENT

de la Haule-Loire.

ARRONDISS. COMYUNAL

d'Yssingeaux.

INSPECTION

du Puy.

CANTONNEMENT

du Puy.

Introduction de bois non marqués dans une scierie.
EXEMPLE $N^{0} 13$

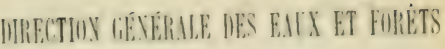

L'an mil huit cent quatre-vingt-trois, le douze du mois de mai ;

Vous, soussigné, M.... brigadierdes forèt-a la residence de Chambon, et S.... garde forestier id la résidence de saint Voy, assermenté- et revèlus des marques distinctives de nos fonctions, certifions que, faisant notre tournee vers neuf heures du matin,

Nous avons procédé à la vérification des bois déposés sur le rhantier de la scierie dite de Chanlet, situé à 1.224 mètres des bois communaux de Chambon et exploitée pour le compte du sieur N..., propriétaire audit lieu, par le sieur Pierre Caillé, son préposé. Nous avons reconnu que cinq des tronces gisant dans lintérieur du chantier nétaient pas revètues de l'empreinte de notre marteau, et avaient été introduites sans déclaration préalable.

En foi de quoi nous arons rédigé le présent procès-verbal, que nous avons clos et signé à Chambon, les jour, mois et an que dessus. 
$27^{\circ}$ CONSERVATION

DÉ P A R T EM E N T de l'Hérault.

ARRONDISS. COYMUNAL de Saint-Pons.

IXSPECTION

de Montpellier.

CA TTONXEMENT de Saint-Pons.

Pâturage. - Saisie. Séquestre.
EXEMPLE N ${ }^{\circ} 14$

\section{JURECTIOY gélÉRALE dES EICX ET Furêts}

L'an mil huit cent quatre-vingt-trois, le dix du mois de mai,

Nous soussigné N..., garde forestier à la résidence de la Salvetat, assermenté et revètu des marques distinctires de nos fonctions, certifions que, faisant notre tournée, vers sept heures du matin. dans la forèt de Devez, appartenant à l'Etat, au canton appelé les Sagnes, sis au territoire de la commune de la Salvetat, et dont le bois est âgé de six ans ;

Nous avons rencontré le sieur François Giraud, fils mineur de Pierre, cultivateur, demeurant à la Salvetat, lequel gardait à bâton planté un troupeau composé de trois moutons, une chèvre et une vache. Ces animaux araient séjourné longtemps dans le taillis et $\mathrm{y}$ avaient occasionné un dommage que nous avons évalué à $10 \mathrm{fr}$.

Nous avons saisi le troupeau et l'ayant conduit à la Salvetat, nous l'avons remis sous la garde du sieur Fulcrand Servien, aubergiste audit lieu, que nous avons désigné comme séquestre. La vache est sous poil roux vif avec une étoile blanche au front: la chèvre est blanche, marquée de noir et dépourvue de cornes; les moutons sout fraîchement tondus et marqués au fer de la lettre M.

Le sieur Servien ayant accepté la garde de ces animaux et s'étant engagé a les représenter à toute réquisition légale, nous lui arons remis copie du présent acte, qu'il a signée arec nous, ainsi que celle qui sera 
remise au greffe de la justice de paix.

Fait et clos à la Salvetat, les jour, mois et an que dessus, a onze heures du matin.

Sign. du séquestre. Sign. du garde. 
28 e CONSERVATION

DÉPARTEMENT

du Cantal.

ARROKDISS, COYMUNAL

de Saint-Flour.

CANTONNEMEXT de Saint-Flour.

Pâturage. IXSPECTION d'Aurillac.
EXEMPLE $N^{\circ} 15$

\section{DIRECTIiI géYÉRALE dES EIIT ET FüRĖTS}

L'an mil huit cent quatre-vingtdeux, le dix du mois d'aoùt,

Nous soussigné N..., garde forestier à la résidence de Saint-Urcize, assermenté et revètu des marques distinctives de nos fonctions, certifions que, faisant notre tournéevers sept heures du matin, dans la forêt de Saint-Urcize, appartenant à cette commune, au canton appelé PuechRégio. sis au territoire de la commune de Saint-Urcize, et dont le bois est àgé de huit ans ;

Nous avons trouvé deux vaches pâturant sans gardien. Cies animaux araient endommagé un grand nombre de cépées qui portent les marques des abroutissements. Nous évaluons à $10 \mathrm{fr}$. le dommage causé. Le propriétaire de ces vaches nous étant inconnu, nous les avons dirigées vers le village de Saint-Lreize, ounousles avons mises sous la garde du sieur..., aubergiste audit lieu, que nous avons déclaré séquestre, et qui s'est engagé à les représenter à toute réquisition légale; l'une des vaches est sous poil rouge-brun, l'autre pie noir et blanc. Le sieur..., invité par nous à signer le présent acte, nous a déclaré nesavoir signer; nous lui avons remis copie de notre procès-verbal, que nous avons clos à Saint-Lreize, le dix aoùt mil huit cent quatre-vingt-deux.

Signature du garde. 
$21^{\circ}$ CONSERVATION

DÉPAITEMEXT

des Deux-Sèvres.

ARRONDISS. COMMUN..L

de Melle.

INSPECTION

de Niort.

CANTONNEMENT

de Beauvoir.

Introduction de bestiaux dans des cantons en défends.
EXEMPLE $N^{\circ} 16$

\section{WIRECTIOS GIXEKR.LLE DES EILY ET FORËTS}

L'an mil huit cent quatre-vingttreize, le vingt-cing dumois de mars;

Nous, soussigné, N..., garde foreslier à la résidence de Lille, assermen. té et revètu des marques distinctives de nos fonctions, certifions que, faisant notre tournée vers sept heures du matin, dans la forèt des Usages, appartenant à la commune d'Arailles, au canton appelé Fosse-d'Argent, sis au territoire de la commune d'Availles et dont le bois est âgé de cinq ans;

Nous avons trouvé le nommé Poirier, Antoine, pâtre de la commune d'Availles, qui gardait à bàton planté dans ledit canton, non déclaré défen. sable, la quantité de cent vingt bètes à laine, formant le troupeau commun; nous avons estimé à $16 \mathrm{fr}$. le dommage causé par le pacage du trou. peau.

En foi de quoi nous avons rédigé le présent procès-verbal, que nous avons clos a Lille, le vingt-cinq du mois de mars mil huit cent quatrevingt-treize.

Signature du garde. 
$2 S^{\circ}$ CONSERVATION

DÉPARTEMENT

de la Haute-Loire.

ARRONDISS. COYYUNAL

de Brioude.

IXSPECTIOY

du Pus.

CANTONXEMENT

du Puv.

Introduction de bestiaux en nombre excédant celui indiqué par les proces - verbaux de défensabilité.
EX $\equiv M P L E N^{0} 17$

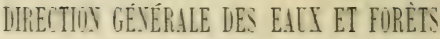

L'an mil huit cent quatre-vingt quinze, le dix du mois de juillet;

Nous soussigné, N.., garde forestier à la résidence de Venteuges, assermenté et revètu des marques distinctives de nos fonctions, certifions que, faisant notre tournée vers huit heures du matin, dans la forêt de Jalajoux, appartenant à la section de Chazettes, commune de Desges, au canton appelé Jalajoux, sis au territoire de la commune de Desges, et dont le bois est âgé de trente et un ans:

Nous avons trouvé le sieur H.... pàtre communal, gardant à bàton planté un troupeau composé de vingt. quatre tètes de gros bétail, savoir: dix-huil vaches et six taurillons, appartenant aux habitants de la section de Chazettes. Le canton de Jalajoux a été déclaré défensable par arrèté du is février 1 so', mais pour ringt et une tètes de bétail seulement; trois animaux y ont donc été introduits en con. travention. Nous avons, pour reconnaitre les proprietaires des bestiaux en excédant. dressé. daprès les indications du berger, la liste des différents propriétaires avec le nombre de-be-tiaux envorés au paturage par chacun deux, et nous étant transporté a la mairie nous avons comparé cette liste avec celle de répartition desanimaux admis au parcours, et nous avons reconnu que le sieur Jost, Antoine, cultivateur, demeurant à Chazetles, avait envoyé sept vaches au lieu de quatre, nombre qui lui est assigné. 
En foi de quoi nous avons redigé le present procis-verbal que nous avons clos el signé à Ventenges, le onze juillet mil huit cent quatre-vingt quinze. 
28 CONSERVATION

DÉPARTEMENT

du Cantal.

ARRONDISS. CJMMUNAL

de Murat.

INS PECTION

d'Aurillac.

CANTONNEMENT

de Nurat.

Coupe de réserves.
EXEMPLE $N^{\circ} 18$

\section{DIRECTIOY GÉYÉRALE DES EILI ET FoRÈTS}

L'an mil huit cent soixante-dix-neuf, le douze du mois de mars,

Nous soussigné, N..., brigadier forestier à la résidence de Montboudif, assermenté et revètu des marques distinctives de nos fonctions, certifions que, faisant notre tournée vers onze heures du matin, dans la forèt de Naubert, appartenant à l'Etat, au canton appelé Bouillas, coupe de l'exercice $1875,2^{\mathrm{e}}$ lot, sis au territoire de la commune de Condat et dont le bois est àgé de cent vingt ans;

Nous avons constaté que les ouvriers du sieur N..., marchand de bois, demeurant à.., adjudicataire du $2^{\mathrm{e}}$ lot de la coupe de 1875 , avaient abattu dans l'enceinte de ladite coupe, qui est marquée en délivrance, un sapin ne portant pas l'empreinte du marteau de l'Etat; nous avons mesuré cet arbre qui porte $1^{\mathrm{m}}, 60$ de circonférence, mesure prise à un mètre du sol, et nous l'avons marqué de notre marteau, ainsi que sa souche; la va. leur dudit sapin est de $9 \mathrm{fr}$.

Fait et clos à Montboudif, les jour, mois et an que dessus. 
$28^{\circ}$ CONSERVATION

UÉ P \# T EM E T

de l'Aveyron.

ARRONDISS. COMMUNAL

de Saint-Alfriyue.

IN SPECTION

de Rodez.

CANTOXYEMEXT

de Saint-Iffrique.

Outre-passe.
EXEMPLE N $N^{\circ} 19$

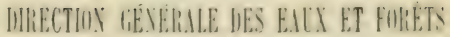

L'an mil huit cent quatre-vingtdouze, le douze du mois de mars.

Vous, soussigne-, N.... brigadier, el N.... gardefore-tier a la ré-idence de Nouzet et de Camarès, assermentés et revêtus des marques distinctives de nos fonctions, certifions que, faisant notre tournée vers huit heures du matin, dans la forèt de Guiral, appartenant à l'Etat, au canton appelé Guiral, sis au territoire de la commune de Saint-Pome-de-Cernon, et dlont le bois e-s àgé devingt-cing ans:;

Nous avons reconnu gue les ouvriers du sieur MI..., adjudicataire du deuxieme lot de la coupe de l'exercice de 1889 , araient depa-sé la ligne qui sépare à louest ladite coupe d'avec le restant du bois. Avant relevé de cornier en cornier la ligne d'arpentage, nous avons constaté que les ouvriers ont exploité à 10 mètres en dehors de ladite ligne et qu'ils ont abattu, savoir: deux charmes, dont l'un de 40 etl'autre de 60 centimètres de circonférence, un chêne de 60 centtimètres, mesure prise sur les souches, les arbres ayant été réunis à ceux de la vente; plus une quantité de brins de moins de 2 centimètres que nous arons éraluée à une charge de voiture à un cheval; les bois ainsi exploités en dehors de la coupe sont de mème àge, nature et qualité que ceux de ladite coupe, et nous avons estimé leur valeur, savoir: les deux charmes à 3 fr., le chêne à 2 fr., et les menus bois à $6 \mathrm{fr}$.

Fait et clos à Nouzet, le treize mars mil huit cent quatre-vingt-douze. 
$16^{\text {e CONSERVAT1ON }}$

DÉPARTEM ENT T

de la Meuse.

ARROKDISS. COMYUYAL

de Montmédy.

INSPECTION

de Montmédy.

CA YTONNEMENT

de Spincourt.

Vices d'exploitation

L'an mil huit cent quatre-vingt, le dix du mois de mars ;

Nous, soussignés N..., brigadier à Senon, et N..., garde forestier à la résidence de Billy, assermentés et revêtus des marques distinctives de nos fonctions, certifions que, faisant notre tournée vers deux heures du matin, dans la forèt de Billy, appartenant à la commune de Billy, au canton appelé la Réserve, sis au territoire de la commune de Billy, et dont le bois est âgé de vingt ans ;

Nous avons constaté que les ouvriers du sieur L..., adjudicataire de la coupe extraordinaire exploitée pour l'esercice de 1879 , abattaient un chène sans l'avoir préalablement ébranché, et sans le diriger dans sa chute au moven de cordes, ainsi qu'il est prescrit par les clauses spéciales. Ledit arbre a rompu dans sa chute trois brins de taillis de 20 à 30 centimètres de tour, marqués comme baliveaux: nous avon: évalué le dommage à $6 \mathrm{fr}$.

Fait et clos à Billy, les jour, mois an que dessus. 
3' CONSERVATION

DÉPAITEMENT

de la Cote-dor.

ARRONDISS. COMMUNAL

de Semur.

INSPECTION

de Semur.

CANTONNEMENT

de Saulieu.

Retard

de nettoiement.
EXEMPLE $N^{\circ} 21$

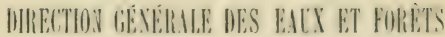

L'an mil huit cent quatre-vingt-six, le vingt du mois d'avril ;

Nous, soussignés, N..., brigadier forestier à la résidence de Nontberthault, et N..., garde forestier à la résidence de Courcelles, assermentés et revêtus des marques distinctives de nos fonctions, certifions que, faisant notre tournée vers neut heures du matin dans la foret de Courcelles, appartenant à la commune de Courcelles-Fresnois, au canton appelé les Ordinaires, coupe de l'exercice $\mathbf{1 8 8 5}$, sis au territoire de la commune de Courcelles, et dont le bois est àgé de vingt-cinq ans;

Nous avons parcouru la coupe exploitée pour l'exercice 1885 par le sieur N..., entrepreneur du faconnage et nous avons reconnu que le nettoiement pre-crit par l'article $23 \mathrm{du}$ cahier des charges générales n'a pas èté effectué. Les ronces et épines n'ont pas été extraites, ou l'ont été d'une manière incomplète ; nous avons compté plus de cent vieux étocs qui n'ont pas été ravalés.

Quoique ledit entrepreneur ait été prévenu à plusieurs reprises, il a négligé de faire exécuter ces travaux.

Nous avons, en conséquence, dressé contre lui le présent procès-verbal, que nous avons clos et signé à Courcelles, les jour, mois et an que dessus. 


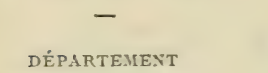

de la Côte-d'Or.

ARRONDISS. COMYUUNAL

de Semur.

INSPECTION

de Semur.

CANTOYNEMENT

de Saulieu.

Retard

d'exploitation.

\section{JIRECTIOYY GÉYÉRALE DES EATT ET FORETETS}

L'an mil huit cent quatre-vingt-six, le vingt du mois d'avril,

Nous soussignés N..., brigadier forestier, et N..., garde forestier à la résidence de saulieu. assermentés et revêtus des marques distinctives de nos fonctions. certifions que, faisant notre tournée vers huit heures du matin dans la forèt de Saulieu, appartenant à l'Etat, au canton appelé Champonin, sis au territoire de la commune de Saulieu, et dont le bois est âgé de trente ans;

Nous avons parcouru la coupe de l'exercice $1855, n^{\circ} .$. , de l'état d'assiette, deuxième lot, dont le sieur N..., marchand de bois, demeurant à Saulieu, s'est rendu adjudicataire, et nous avons constaté que l'exploitation n'en est pas terminée ; l'abatage du taillis n'était pas commencé sur un hectare environ de ladite coupe, et il reste encole sur pied trente chênes anciens, marqués pour ètre exploités. dans la partie ou le taillis a été abattu. Nous avons évalué à $1.500 \mathrm{fr}$. la valeur des bois demeurés surpied : nous en avons déclaré la saisie au sieur T..., facteur de la vente, avec défense den disposer daucune manière, et nous avons rédigé le présent procès-verbal, que nous avons clos et signé à Saulieu. les jour, mois et an que dessus. 
$16^{\circ}$ CONSERVATION

DÉPARTEMENT

de la Meuse.

ARRONDISS. COMMUNAL

de Montmédy.

INSPECTION

de í ontmédy.

C A N T ON N E M E N T

de Spincourt.

Défaut de permis. Chasse réservée.
EXEMPLE $N^{0} 23$

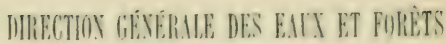

L'an mil huit cent quatre-vingl-six, le vingt du mois de septembre;

Nous, sous-igné, N..., garde forestier ì la résidence d'Ollieres, assermenté et revêtu des marques distinctives de nos fonctions, certifions que, faisant notre tournée vers neuf heures du matin, dans la forêt de Réchicourt, appartenant i la commune de ce nom, au canton appelé les Usages. sis au territoire de la commune de Réchicourt, et dont le bois est âgé de trois ans;

Nous avons entendu un coup de fusil, dans la direction duquel nous nous sommes immédiatement transporté. Nous avons apercu dans le taillis de la coupe de mil huit cent quatre-vingt-deux un chasseur occupé à recharger son fusil, et nous l'avons reconnu pour N..., fils mineur de II. N..., propriétaire, demeurant à Saint-Pierre-Villiers ; ledit sieur N... n'est ni fermier, ni co-locataire du droit de chasse dans les bois de Réchicourt. Il était accompagné d'un chien couchant et était armé d'un fusil double à piston, à canons damassés et crosse anglaise, arme que nous avons estimée à 150 fr. Invité à nous exhiber son permis de chasse, le sieur N... a déclarén'en pas avoir. Fait et clos à mois et an que dessus. 
CONSERVATION

DÉPARTEMENT

ARRONDISS, COYMUNAL

IXSPECTION

CANTONNEMENT

Chasse avec engins prohibés. - Temps défendu. - Refus de remettre les engins.

Nota. - Affirmer. Après l'affirmation présenter le procèsverbal au juge de paix dans les che/slieux du canton, au maire dans les autres communes, el réquérir la vente du gibier.
EXEMPLE N ${ }^{0} 24$

DIRECTIOS GÉXÉRALE DES EACX ET FORĖTS

L'an mil huit cent quatre-vingtcinq, le douze du mois d'arril ;

Nous soussigné, N..., garde forestier à la résidence de II..., assermenté et revêtu des marques distinctives de nos fonctions, certifions que, faisant notre tournée vers six heures du matin, dansle bois de Ravine. sis au territoire de la commune de SaintGeorges :

Nous avons apereu deux individus à nous inconnus qui chassaient à l'aide d'un trémail. Nous les avons invités à nous remettre les filets et le gibier dont ils étaient porteurs, ce à quoi ils se sont formellement re. fusés; ils ont aussi refusé de nous faire connaitre leurs noms et domicile-. Arant pris leurs signalements. afin de les reconnaitre plus tard, nous nous sommes établi en embuscade sur le bord du sentier, par lequel ils devaient nécessairement passer et assisté du garde champêtre requis par nous, nous avons attendu jusquà huit heures. Ayant parfaitement reconnu nos chas-ieurs, nous avons saisi le filet dont ils itaient porteurs. ain-i que le gibier capturé, consistant en six perdrix et trois cailles. - Les délinquants s'étant enfuis, après avoir abandonné leur filet et leur gibier, et personne narant pu nous donner dindication sur leur identité. nous avons invité le garde champêtre à se mettre sur leurstraces, et renvoré à une époque ultérieure la clòture de notre procèsverbal. 
21. CONSERVATION

DÉPARTEMENT

du Puy-de-Dôme.

ARRONDISS. COMUUNAL

fle Thiers.

INSPECTION

de Clermont.

CANTONNEMENT

d'Ambert.

Pèche de nuit. Temps prohibé.Poisson n'ayant pas la dimension.
EXEMPLE N ${ }^{\circ} 25$

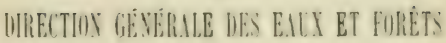

L'an mil huit cent quatre-vingtdouze, le quatre du mois de février ;

Nous, soussigné, N..., garde-pèche à la résidence de Maringues, assermenté et revètu des marques distinctives de nos fonctions, certifions que, faisant notre tournée, ver's huit heures du soir, sur les bords de la rivière d'Allier, au canton appelé la Grande-Saulaie, sis au territoire de la commune de Pont-du-Château ;

Nous avons apercu deux individus quipèchaient is laide d'une trouble en bouillant sous les berges avec une perche. Nous étant approché, nous les avons reconnus pour les nommés Bressot, Jean, et son fils Antoine, àgé de 18 ans, demeurant tous deux à Beauregard. Les mailles de leur filet, mesuréesparnous, ont dix millimètres de còté. Le poisson capturé consistait en : deux barbeaux de vingt-cing centimètres, trois gardons de vingt centimètres, et environ un demi-kilogramme de goujons, vandoises et ablettes, le tout valant $3 \mathrm{fr}$. Nous avons saisi le filet et les poissons et avons déclaré audit sieur Bressot procès-verbal pour infraction à la loi sur la pêche.

Fait et clos à Maringues, les jour, mois et an que dessus.

Signature. 
PROCÈS-TERBAL

de garde particulier

rédigé

sur une feuille

timbrée à 60 cent.

Coupe d'arbres de plus de deux décimètres. - Nuit. Scie.

\section{EXEMPLE $N^{\circ} 26$}

L'an mil huit cent quatre-vingtseize, le cinq du mois de mars, Nous soussigné..., garde des propriétés de II..., assermenté et revètu des insignes de nos fonctions, faisant notre tournée vers cinq heures du matin dans le bois de l'Essarl, au canton de la Grande-Conche situé sur le territoire de la commune de Bussolle et appartenant à M..., A vons entendu le bruit d'une scie à environ cinquante mètres du sentier sur lequel nous marchions. Nous étant approché, nous avons aperçu deux hommes occupés à scier un brin de taillis, mais l'obscurité de la nuit ne nous permettant pas de les reconnaitre, nous nous sommes mis en embuscade en attendant le jour pour les surprendre à la sortie du bois. Après une heure d'attente, nous les avons suivis et trouvés porteurs du brin qu'ils avaient scié et de la scie dont ils s'étaient servis. Nous les avons reconnus pour les nommés Jacquot, Pierre, métayer aux Essarts, et son fils, Antoine, àgé de dix-sept ans. Le brin de chène dont ils étaient porteurs a trois décimètres de tour, mesure prise sur la découpe. Interrogésurles motifs quil'avaient poussé à commettre ce délit. le père Jacquot a avoué qu'il avait besoin d'une ridelle pour son char et qu'il avait cru pouroir la couper dans le bois roisin sans faire grand dommage.

Le brin coupé a une valeur de un franc; le dommage causé à la propriété est de cinquante centimes. 


\section{$-339-$}

Nous avons saisi la scie el le brin coupé en délit, que nous avons mar. qué de notre marteau et laissé sur place.

En foi de quoi nous avons dressí

Affirmer, fuire en- le présenl frocès-verbal, que nouregistrer, porter an arons clos et signé les an, mois et régiseur ou uи propriétaire. jour que diatie part.

Signature du garde. 


\section{FORMULE No 27}

\section{RÉQUISITION}

L'an mil huit cent..., le... du mois de...

Nous soussigné (nom, prénoms et qualités) à la résidence de..., requérons, en vertu des dispositions de l'article 164 du Code forestier, .I. le qualité de l'agent de la force publique) de nous seconder dans l'exercice de nos fonctions, et à cet effet de nous faire accompagner immédiatement ou à lheure qu'on indiquera) par la force publique à sa disposition, dans les (tournées, recherches ou visites domiciliaires) auxquelles nous procéderons pour la répression des délits.

Le sieur... arant obtempéré à notre réquisition, nous lui arons remis un double du présent acte, que nous avons signé à..., les jour, mois et an que dessus.

Signature du préposé.

\section{FORMULE $N^{\circ} 28$}

\section{PROCES-VERBAL DE DÉLIVRANCE}

L'an mil huit cent..., le... du mois...

Nous (noms et qualités) à la résidence de..., avons, en vertu de l'autorisation de II. le conservateur des forèts, en date du..., délivré dans la forèt... de... au canton de..., en présence du garde du triage, au sieur (nom du conces. sionnaire ou de son représentant),

La quantité de (indiquer la nature et la qualité des produits déliurés),

A charge par ledit sieur (nom du concessionnaire) demeu. rant à..., de verser à la caisse du... la somme de (en toutes lettres) et d'acquitter les droits de timbre et d'enregistrement du présent procès-rerbal, qu'il a signé avec nous.

A le

Signature du brigadier. Signature du garde du triage.

Signature du concessionnaire. 


\section{FORNIULE $N^{\circ} 29$}

\section{DÉCLARATION INE PERTE IEE MAND.IT}

Je, sous.igné..., déclare avoir perdu le mandal 11 '... 'n date $d u$. . . . montant à la somme de. .. . et que ce mandat na pas efé paré, ainsi quil résulle de lattestation ci-jointe donnee par ir. L.. complable, charce du paiement.

Je demande qưil me soit délirré un duplicala dulit mandat.
A
le
19

\section{FORMULE $N^{\circ} 30$}

\section{COMMISSION DE GARDE PARTICLLIER}

Je, soussigné....... demerirant ì....... nomme, par le présent acte. le sieur....., garde des fropriétés en nature de bois, prairies et terres arables que je possede sur le territoire des communes de....

Jautorise en conséquence leilit..... à constater, dès qu il aura rempli les tormalités exigées par l'article 117 du Code forestier, tous les délits et contravention $=$ portant atteinte à mes droits de propriété.

Fait à , le 19 . 
$-3 \frac{4}{2}-$

$\stackrel{2}{0}$

ב⿱

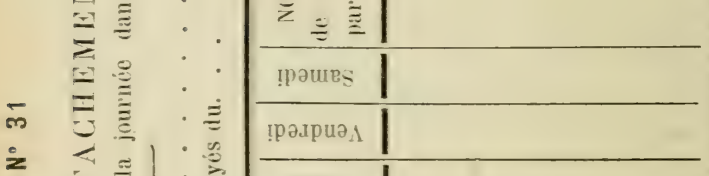

$\equiv$

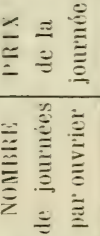

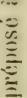

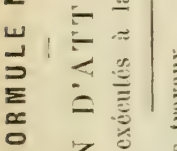

14 250

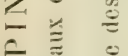

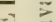

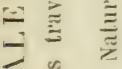

$\sum \leqslant$

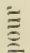

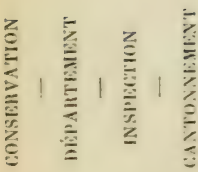

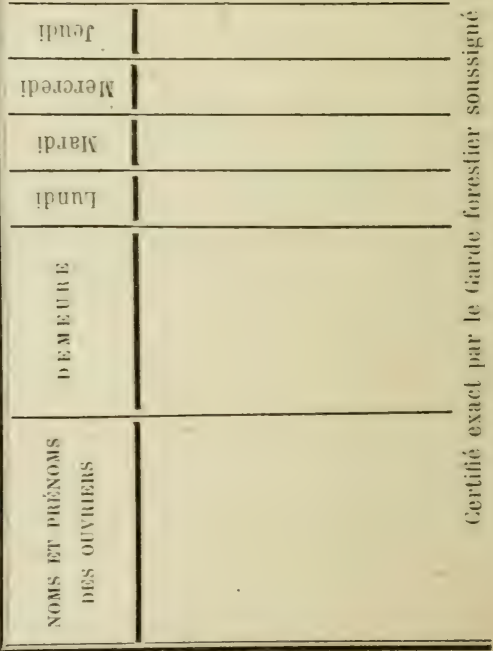


$21^{\circ}$ CONSERVATION

INSPECTION

d (l)

CANTONNEMENT

Déliurance de harts.

EXERCICE 19

indiquer les diverses espèces de harts.

No

DU SOMMIER deśmenús produits.
EXEMPLE $N^{\circ} 32$

No visé pour limbre au droit de à recouvrer.

, le

19 .

Le Receveur

\section{DEMANDE DE IIARTS}

Le soussigné à , adjudicataire , foret

, demeurant de coupe de , lot, art. de l'affiche de l'exercice 19 , demande l'autorisation de faire couper par les nommés demeurant à , la quantité de harts nécessaire à l'exploitation de dite coupe, et dont le détail approximatif est ci-dessous :

Harts àt

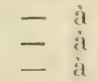

Il déclare, en outre, charger le sieur son facteur, de constater avec le garde du triage, les quantités délivrées.

A, le

19.

\section{ADMINISTRATIOA DES FORETS}

L'inspecteur des forêts, soussigné, autorise le sieur

à faire couper les quantités de harts demandées, en se conformant aux conditions imposées par le chef du cantonnement, qui demeure chargé de l'exécution du présent.
A.
, le
19.

No - Recu et transmis au sieur forestier, à pour surveiller l'exécution.
A

$$
\text { Le . le }
$$
des forêts, 
* Indiquer les direrses espèces de harts.

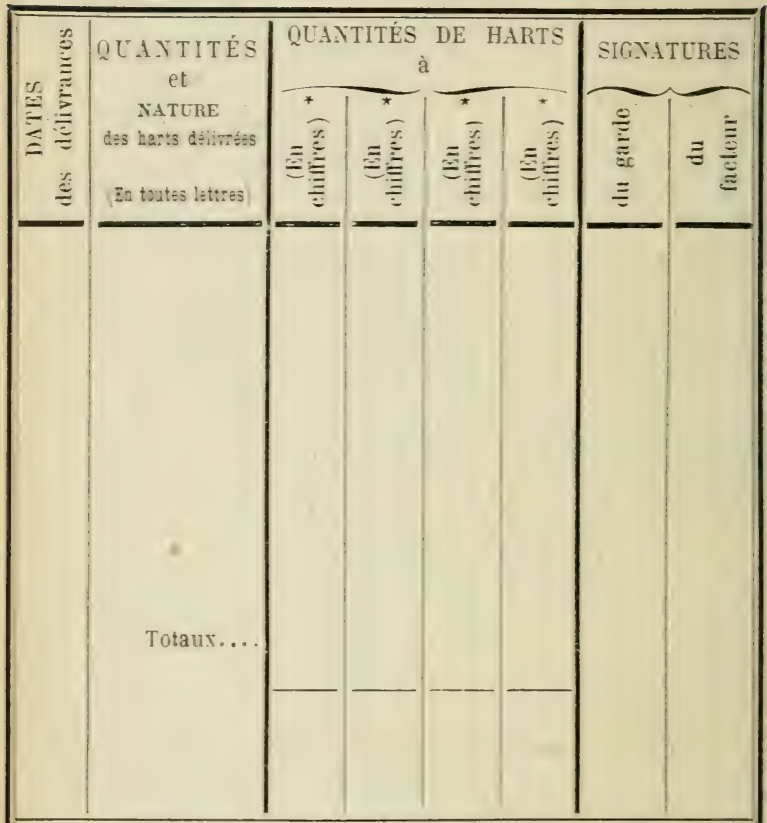

Vu et Virmble frar le 1 des furets, à

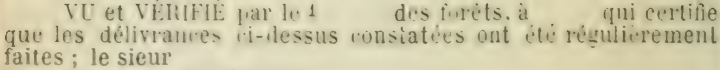
derra payer en conséquence:

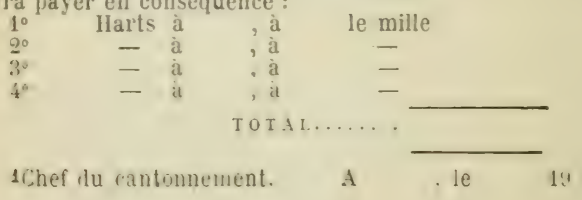




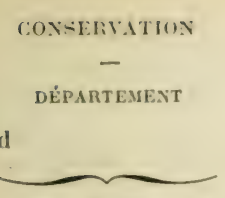

(1) Nom, prénoms, siluation administrative et résidence.

2) Nom, prénoms, qualité el demeure.

3) En totalité ou dans la proportion des.... trois quarts. quatre cinquiemes, etc.).

\section{FORMULE N 33}

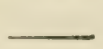

MLITAIHE

(Décret

du 2 avril 1875)

M111:II.I-1T16.V

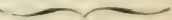

Je, sonssigné (1)

retenu hor's de ma résidence en exé. cution du décret de molsilisation militaire du... domne a (s)

pouvoir d'émarger, de lombluret recevoir pour moi et en mon nom I3) le montant desmandats delivrés ou it déliver pour mon traitement civil, d'en donner bonne of raliable quittance, substituer,
A
, le
19.

Signalure.

Vu pour légalisation de la signature du $\mathrm{S}^{\mathrm{r}}$

A

, le 19. Le Conservateur des forêts.

Nota. - Le présent pouroir est établi sur papier libre. (Art. 19 du règlement des finances du 26 décembre 1866.) 


\title{
FORMULE $\mathrm{N}^{\circ} 34$
}

\section{Acte de vente sous seing privé d'une coupe de taillis sous futaie.}

Entre les soussignés $\mathrm{N}$..., propriétaire, demeurant à.... dune part, et X... marchand de bois, demeurant à.. d'autre part. il a été conrenu ce qui suit:

II. X... rend à II. X... la coupe du bois de.... n $n^{\circ}$ t de l'aménagement..., lot $\approx$ contenant... hectares... ares... et limitée :

\author{
au nord par... \\ au couchant par... \\ au midi, par... \\ au levant, par...
}

Sous la réserve de... chènes... hètres... ormes... anciens.

de... chènes... hêtres... érables... cadels.

de... chênes... hêtres... frênes... modernes

de... chênes... hêtres... divers... baliveaux

Tous les arbres réservés sont marqués au pied du marteau du vendeur portant les lettre- "...; savoir: les anciens et les baliveaux d'une seule empreinte, les cardets de trois et le-modernes de deux empreintes juxtaposées.

Sont en outre réservés les arbres de limites. corniers et parois; savoir:

.... corniers, dont... chênes et... charmes.

... parois dont... chènes et... érables,

Lesdits arbres prortent au pied et au flanc l'empreinte du marteau du vendeur.

L'acquéreur est tenu de respecter tous les arbres ré-

1. Si le hois est amenagé, on indiguera le numém de la coupe.

2. Si la roupe est dirisie en plusieurs lols. on indiguera le numéro du lot.

3. si, an lieu d'iniliales. le marteau porte des armoiries, on 


\section{$-347-$}

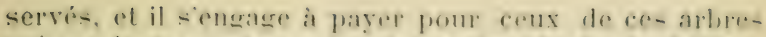
qui seraient eompies on brisis pendant la duree de l'exploilation et par le fail dn vendeur, de ses ourrire $=01$ voituriers, les indemnités suivantes:

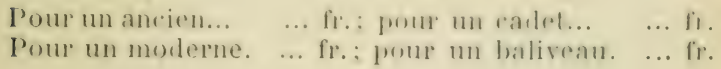

L'arquiseur s'enciage, en outre, a faire couper le- boia la cognere of ausis pris de terre que po-sible a farre ravaler les étors a extraire les rumes. ipines et autres morts-bois a faire élrancher sur joiel. avant labalage, tous les arbres abandonnés. ef it néroreer sur pied aucun des bois de la vente', le tout sou- peine de dommages-intérèts.

Il soblige a terminer labatage du taillis el les fulaieavant le 15 arril $19 . .$. le facomage et lempilage des ramilles et bois de feu avant le 15 jum suivant, et la vidange arant le $1^{\circ}$ arril..., it peine de payer une indemnité de ... fr. pour chaque jour de retard:

La vidange seffectuera par les chemins de... La réparation des ponts. ponceaux, barrieres, glaris, fossis bordiers endommagés par le fail de la ridange, sera a la charge de lacquéreur, qui derra en nutre faire fouir et régaler les places des ateliers, baraques et lieux de dépùt.

Lacquéreur lirrera au domicile du rendem el sans frais pour ce dernier... stère- de bois de chauffage de

remplacera le mullettres par cenx ri : nrmoiries du venteur.

1 Quand larinereur autori-cra lerorcensent. il fandra supprimer cette derniere clanse et modifier les delais d'abatace et de façonnage. qui derront ètre prorogés. suirant les lienx. jusquau $1^{\text {er }}$ ou au is juin pour l'aliatage el au 1 -r juillet pour l'empilatre.

Si l'usage du pays est d'écurcer les taillis surpieulil conviendra de stipuler qu'il sera pratiqué au pied le chaque brin une incision annulaire. afin que lécorce de la sonche ne soit pas enlevée avec celle de la tige. Il faulra. en outre. oblimer lacinureur à faire abaltre les hrius immédiatement apris lécoreement. Cetle clause est très importante. cai il arrive souvent que les wurriers laissent sur pied les brins écorcés. qui continuent à végeter, ce qui amèn? lappauris-ement de la suuche et, par suite, des rejets qu'elle doit produire. 


\section{$-348-$}

qualité marchande, et au domicile du garde... stères du mème bois et... et bourrées de... de tour.

I a présente rente est faite, sans garantie de contenance, moyennant le prix de... fr., payable par quart, savoir :

Le premier quart de. . . . fr. le... $19 \ldots$

Le deuxième quart de . , . " le... 19...

Le troisième quart de . . . " le... $19 \ldots$

Le quatrième et dernier quart de " le... 19...

pour lesquelles sommes lacquéreur fournira quatre lettres de change ou billets à ordre. parables à..., aux époques ci-dessus fixées.

Lacquéreur s'oblige à donner bonne et ralable caution solidaire de l'exécution du présent acte. laquelle caution devra en conséquence endosser les lettres de change et billets à ordre, ci-dessus mentionnés.

Il soblige, en outre, à parer les droits d'enregistrement. du présent acte, ain $\rightarrow \mathrm{i}$ que les frais et doubles droits, sil y a lieu.

Fait double à..., le... mil neuf cent...

(Signature du vendeur.) (Signature de l'acquéreur.) N... 


\section{$-396-$}

N" 35

\section{PROGRAMME DES CONDITIONS D'ADMISSION}

DES PRÉPOSÉS A L ÉCOLE SECONDAIRE U'EXSEIGYYMEXT PROFESSIONNEL

Arrèté par le Ministre de I.Agriculture le 11) férrier $18: 1$.

\section{CONDITIONS ET REGLES D ADMISSION}

\section{ARTICLE PREMIER}

Chaque année, au mois de février, les Conservateurs font connaitre les préposés quilis jugent aptes à devenir gardes généraux et qui leur paraissent en situation de subir avec succès les examens du concours dadmission à l'École secondaire d'enseignement professionnel.

Ne peuvent ètre compris dans l'état de présentation établi à cet effet que les préposés ayant moins de 35 ans d'àge $a u 1^{\text {er }}$ janvier de l'année du concours et devant compter au $1^{\text {er }}$ octobre suivant trois années de serrice actif. Il suffit de deux ans de service actif pour les élèves diplòmés de l'École pratique de sylviculture des Barres.

Il est établi pour chaque préposé, à l'appui de sa demande, un rapport détaillé dans lequel les titres du candidat sont constatés et appréciés successivement par ses différents chefs hiérarchiques; ce rapport est accompagné du relevé des services et de la copie des feuilles de notes en ce qui concerne les préposés communaux. 
Les dossier ain-i constitués sont transmis à la Direction des eaux et forèts.

ART. 2.

Le Irirecteur des forèts arrète annuellement la liste les préposés admis à prendre part au concours d'admis. sion à l'École secondaire.

Ce concours comprend des compositions écrites et des examens oraux.

Les candidats reçoivent, à cette occasion, les indem. nités réglementaires de déplacement et de séjour.

\section{Compositions écrites.}

ART. 3.

Les composition - écrites servent à établir un premier classement destiné à exclure des examens oraux les candidats insuffisamment instruits, puis à déterminer, concurremment avec ces examens. le classement par ordre de mérite des candidats.

ART. 4 .

Dans la seconde semaine d'aoùt, le- candidats sont convorués pour subir les épreures écrites au ;chef-lieu de la conservation dont ils dépendent. Ils doivent y ètre rendus la veille du jour fixé pour ces examens.

\section{ART. 5 .}

Les agent - chargés de surveiller les compositions sont désignés par le Directeur des forèts.

Les sujets des compositions et les imprimés nécessaires sont envorés au conserrateur sou-plis cachetés.

Les compositions écrites ont lieu partout le mème jour; elles comprennent : 
${ }^{\text {or }}$ jour (séance du malin):

$1^{\circ}$ Une dictée;

$2^{\circ}$ Une composition francaise iettre, rapport ou comple rendu).

(Séance de relevée) :

30 Lne composition de mathématiques rentrant dans les conditions du programme pour les épreuves orales:

2॰ jour :

4 L'n des-in linéaire, mis au net à une échelle déterminée d'un croquis coté.

ART. 6.

L'enveloppe renfermant charue sujet de compo-ition est décachetée à l'ouverture de charque séance par les agents délégués, en présence des candidat réunis pour subir l'épreuve à laquelle le sujet se rapporte.

\section{ART . 7.}

Toutes les compositions sont faites sur des feuilles à tètesimprimées, délivrées au candidat au commencement de la séance. Chaque candidat, en recevant sa feuille, appose son nom sur la tète imprimée, il signe à l'endroit indiqué sur cette tète; un des agents délégués appose immédiatement son visa.

\section{ART. 8 .}

Il est accordé aux candidats :

$1^{\circ}$ Pour relire la dictée : un quart d heure;

$2^{\circ}$ Pour la composition française : trois heures;

$3^{\circ}$ Pour la composition de mathématiques: troisheures;

$4^{\circ}$ Pour la composition en dessin : quatre heures. 
ART. 9 .

A l'expiration du temps accordé pour chaque composition les feuilles sont remises aux agents chargés de la surveillance. Ces fonctionnaires apposent leur visa par paraphe sur chaque feuille, immédiatement au-dessous de a dernière ligne écrite par le candidat; ils forment, après chaque séance, un paquet des compositions et ladressent immédiatement à la Direction des forèts avec un procès-rerbal rendant compte de tous les incidents qui ont pu se produire et faisant notamment connaitre si tous les candidats ont remis leurs compositions.

ART. 10 .

Les compositions sont soumises au jugement des correcteurs nommés par le Directeur des forèts: avant de faire remettre les compositions aux correcteurs, le Directeur fait détacher de chaque feuille la tète imprimée sur laquelle se trouve le nom et la signature du candidat. Les noms sont remplacés par des numéros d'ordre.

Les parties détachées restent sous scellés.

ART. 11.

Les compositions sont cotées, par les correcteurs, d'un numéro de mérite compris dans l'échelle de o à 20.

Toute cote inférieure à 10 pour l'orthoĝraphe déterminera à elleseule l'exclusion, qui atteindra également tout candidat convaincu de fraude.

ART. 12.

Les corrections terminées, il est dressé un état général portant les numéros d'ordre des compositions, avec 
lindication des poles dommes a chacumb d'elles, de lours

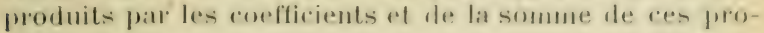
duils.

Toutes los ropies diun mime randilal ont le minne muméro dorble qui rorrespond an nom de ce prémsé.

Il est dresse moe liste de tous ces mumeros, par ordre de mérite, diaprès la somme tolale de's points oblenus.

Cette liste esl soumise au Minislre qui délermine, pour lannée, le nombre des admissibles aux épreuves orales.

\title{
ART. 13.
}

Immédiatement apres la décision du Ministre, les noms des candidals sont portés sur la liste de classemenl it l'aide des numéros d'ordre inscrits sur les tèles imprimées.

La liste des candidats adnissibles aux ipreures orales établie par ordre alphabétique est notifiéc par l'intermédiaire des Conservateurs.

\section{Examens oraux.}

\author{
ART. 14.
}

La Commission chargéc de faire passer les examens oraux est composée de trois membres nommés par le Ministre de l'Agriculture, savoir : un Administrateur-V'́rificateur général ou un Conservateni des forèts. Président ; et deux agents, Inspecteurs ou Inspecteurs adjoints.

Les examens se passent devant chaque examinateur séparément ; ils portent sur les matières ci-apıès :

\section{Arithmétique}

Numéralion. - Opérations sur les nombres entiers. - Théorèmes relatifs à la multiplication et à la division.

Grýe. - Surveillance. 
Divisibilité. - Caractères de divisibilités par 2 et 5.4 et 25,8 et 125,9 et 3 . - Application de la divisibilité : preure par 9 de la multiplication et de la division.

Nombres premiers. - Plus grand commun diviseur. Décomposition d'un nombre en ses facteurs premiers. Plus petit multiple commun à plusieurs nombres.

Frartions. - Opérations sur les fractions ordinaires. - Fractions décimales. - Opérations sur les nombres décimaux. - Réduction des fractions ordinaires en fractions décimales et réciproquement. Fractions décimales périodiques.

Système métrique. - Mesure du temps et division de la circonférence. - Degrés de longitude et de latitude.

Carré et rarine carrée. - Extraction de la racine carrée

Rapports. - Proportions. - Règles de trois, dintérèt et diescompte.

- Partage-proportionels: mélanges et alliages.

\section{Géométrie et Gubage.}

Ligne droite et plan. - Angles. - Droites perpendiculaires.

Triangles. - Triangle i-ocèle. - Cas d'égalité des triangles.

Perpendiculaires et ohliques. - Triangles rectangles. - Cas d'égalité.

Droites parallèles.

fomme des angles d'un triangle, diun polygone convere.

Parallélogrammes.

Cercle. - Corde. - Arc. - Sécante. - Tangente. -

Positions relatives de deux cercles.

Mesure des angles.

Problèmes élémentaires sur la droite et le cercle.

Lignes proportionnelles.

Propriétis des bistectrices d'un triangle.

Triangles semblables.

Polygones semblables.

Triangle reclangle: Propriétés de la perpendiculaire 
abaissée du sommet de langle droit sur lhypoténuto. - Relations entre les cólés.

Propriétés, en re qui concerne le cercle, des sicantes ou tangentes issues d'un meme point.

Diviser une droile en parties proportionnelles a des droites données. - Onalrieme proportionnelle.

Moyenne proportionnelle.

Polygones réguliers. - Carré. - Octogone. - Ilexa. gone. - Triangle équilatéral.

Similitude de-polygones régulier-s. - Rapport de leurs périmètres.

Mesure des aires : Carré. - Rectangle. - Parallélogramme. - Triangle. - Trapeze. - Polygone quelconque.

Rapport des aires de deux polygnnes semblables.

Rapport de la circonférence au diamètre. - Aire du cercle. - Aire du secteur circulaire.

Transformer un polygone quelconque en un triangle équivalent.

Construire un carré équivalent à un triangle ou à un rectangle donné, à la somme ou à la différence de deux carrés donnés.

Du plan et de la ligne droite dans l'espace.

Perpendiculaire et oblique à un plan.

Parallélisme des droites et des plans.

Angles dièdres. - Plans perpendiculaires entre eux.

Mesure des volumes. On se bornera à donner la définition des diver's solides et l'expression de leur rolume sans démonstration.)

Prisme. - Parallélipipède. - Cube. - Prramide.

Tronc de pyramide.

Cylindre droit à base circulaire.

Còne droit à base circulaire. Trone de cône.

Sphère.

Exercices numériques sur les volumes.

Mesure des ròles de bois empilés. - Cubage des troncs darbres abattus ou sur pied : en grume, au quart sans déduction, au cinquième déduit.

Volume d'un tas régulier de pierres cassées par décomposition en parallélipipèdes, prismes et pyramides. 


\section{Histoire de France depuis la mort de Henri IV jusqu'à nos jours.}

\section{Louis XIII.}

Régence de Marie de Médicis.

Richelieu : Lutte contre les prolestants et les grands. - Accroissement de l'autırité rovale. - Lutte contre la Maison d'Autriche : période française de la guerre de Trente ans.

Louis XIV.

Régence d'Anne d'Autriche. - Mazarin. - Fin de la guerre de Trente ans. - Traité de Westphalie. - La Fronde. - Fin de la guerre contre l'Espagne.

Règne personnel de Louis XIV. - Ses grands ministres : Colbert, Louvois. Lionne.

Guerre de dérolution et guerre de Hollande ; première coalition.

Faules de Louis XIV. - Provocations à lEurope; révocation de l'Edit de Nantes.

Guerre de la Ligue d'Augsbourg et guerre de la succession d'Espagne.

Les grands hommes deguerre du règne de Louis XIF : Condé, Turenne Luxembourg. Catinat, Vendòme, Villars, Duquesne, Tourville.

Fortification des frontières: Vauban.

Les grands écrivains du xrıie siècle.

L'époque de Richelieu : Corneille. Descartes, Pascal.

Lépoque de Louis XIV: Racine, Molière, Boileau, La Fontaine. Mme de Sévigné, Saint-Simon, Bossuet, Fénélon, Bourdaloue, Massillon.

Provinces réunies à la France sous les règnes de Louis XIII et de Louis XIV.

Louis XV.

Régence du duc d'Orléans. - Le srstème de Law. Le duc de Bourbon. - Le cardinal Fleury.

Guerre de la succession de Pologne et de la succession d'Autriche. - Guerre de Sej)t ans.

Choiseul.

Provinces réunies il la France sous le règne de Louis XV. 
Les grands érivains du $\mathrm{xum}^{\circ}$ siecle; Vollaire, Montesqieu, Rousseau, Buffon.

Louis XVI.

Turgot et Malesherbes. - Essais de réformes. - Vecker.

Guerre d'Amérique.

Embarras financiers. - Convocation des états gréeraux.

Les états généraux el l'Assenblée constituante. - Suppression de lancien régime et constitution du nouvel état de choses.

LAssemblée législative. - L'émigration. - Chute de la royauté.

La Convention. - Le Comité de Salut public. - La Terreur. - Soulevements intirieurs. - Guerre de Vendée.

Lutte contre l'Europe. - Les armées et les généraux de la République.

Le Directoire. - Campagnes d'Ilalie et d'Egypte. Les coups d'Etat. - Le 18 brumaire.

Le Consulat. - Constitution de l'an VIII. - Réorganisation administrative. - Le Concordat.

Marengo, Hohenlinden.

L'Empire.

Institutions de l'Empire. - La Légion d'honneur. - La noblesse d'empire. - Le code civil. - L'université. Travaux publics.

Austerlitz, Iéna, Eylau, Friedland.

La Grande armée, les généraux de l'Empire.

Fautes de Vapoléon. - Le blocus continental. - Lutte contre le Pape. - Guerre d'Espagne.

Essling et Wagram.

Campagnes de Russie et de Saxe. - Campagne de France. - L'invasion.

La première Restauration et les Cent jours.

Waterloo et Sainte-Hélène.

Congrès de Vienne.

Seconde Restauration. - La France de 1815 à 1830. Louis XV1II et Charles X. - Principaux ministres. Guerre d'Espagne. -- Intervention en faveur des Grecs. 
- Navarin. - Expédition d'Alger. - Rérolution de 1830. Louis-Philippe.

Charte de 1830. Principaux ministres.

Conquète de l'Algérie. - Politique extérieure.

Révolution de Février.

République de 1848 .

Napoléon I1I.

Gouvernement intérieur. - Guerres de Crimée et d'Italie. - Expéditions du Mexique, de Sırrie et de Chine.

Guerre franco-allemande.

La République. - Constitution de 1875 .

Les savants et les grands écrivains du $\mathrm{xix}^{\mathrm{e}}$ siècle.

NoтA. - On sattachera principalement aux causes et à la succession des événements sans s'astreindre à retenir une grande quantité de détails.

En ce qui concerne plus spécialement l'histoire des guerres. on pourra se contenter des notions ci-après : causes de la guerre. puissances engrgées dans la lutte, régions où se sont faites les campagnes. noms des généraux les plus illustres qui y ont pris part. noms des batailles les plus importantes, traités qui les ont terminees, résultats pour la france et ses adversaires.

\section{Géographie de la France et de ses Colonies}

\section{$1^{\circ}$ France.}

Situation. - Dimensions. - Superficie. - Les rotes: mers, golfes, detroits, caps iles, principaux ports.

Frontières de terre.

lielief du sol : Mas-if central et Cévennes, Alpes, Jura, Vosges, Pyrénées. - Principaux sommets, cols. Grandes plaines et grandes vallées.

Les grand- fleuves: Rhone. Garonne, Loire, Seine, Meuse. - Principaux aflluents. - Régions et villes im. portantes traversies. - Lacs. - Fleures secondaires.

Climat et principales productions.

Anciennes provinces. - Départements et chefs-lieux.

- Villes importantes.

Principaux canaux et chemins de fer. 
$2^{\circ}$. Colonies el pays de protectoral.

Algorie el Tunisie : montagnes, rivieres, produrlions. - Villes principales. - Departements algeriens.

Senégal. - soudan et golle de Guinée. Conen frangais.

\section{- Obock.}

Madagascar. - Possesions dall- l'océan Indien.

Cochinchine et Tonkin. - Aman el Cambodere.

Possessions dans l'Hindoustan.

Possessions en Océanie ot en Anérique.

\section{Topographie : planimétrie et nivellement.}

Tracé des lignes sur le terrain.

Mesure des longueurs.

Mesure des angles. - Éruerre. - Pantomitre. - riraphonètre. - Buussole. - Vérification de ces instruments.

Rapport des longueurs. - Echelles.

Rapport des angles. - Rapporteur.

Levé el rapport dun plan: levé au mètre; levé à l'équerre; levé au graphometre; levé à la boussole. Tenue des croquis.

Calcul des surfaces.

Assiette d'une coupe d'une contenance donnée. - Tolérances admises.

Prolonger une ligne au deli d'un obstacle. - Mesurer la distance entre un point accessible et un point inaccessible, entre deux points inaccessibles.

Usage d’un plan à une échelle déterminée, pour se guider en forèt, pour me-srer une longueur ou calculer une surface.

Nivellement topographique. - Niveau à perpendicule. - Nireau à bulle dair. - Niveau deau. - Eclimètre. Mires. - Levé d'un plan avec nivellement. - Détermination de niveau. 


\section{Service des préposés.}

Il s'agit uniquement du service ordinaire et non des services spéciaux des aménagements ou du reboisement.)

Préposés domaniaux, mixtes, communaux, cantonniers.

Installation d'un préposé. - Serment. - Marteau. Cession d'objets divers.

Incompatibilités diverses. - Prohibitions.

Surveillance des délits.

Circonstances qui caractérisent les divers délits dont suit l'énumération et renseignements que le préposé doit avoir soin de recueillir :

Enlèvement de produits autres que le bois. - Passage en forèt avec des instruments propres à couper le bois. - Passage en forèt avec voitures ou animaux. - Feu en forèt ou à distance prohibée. - Pefus de secours en cas d'incendie. - Coupe ou enlèvement de bois de 2 décimètres el au-dessus. - Coupe ou enlèvement de bois de moins de 2 décimètres. - Arrachage de plants. - Mutilation, écorcement. - Enlèvement de chablis ou bois de délit. - Pâturage.

Etablissement - ou constructions à distance prohibée.

Délit- commis par les adjudicataires ou entrepreneurs de coupes. - Exploitations avant la délivrance du permis. - Outrepasse. - Coupe de réserves. - Travaux dans les coupes avant le lever ou aprè- le coucher du soleil. - Ecorçage sur pied non autorisé. - Contravention aux clauses du cahier des charges relatives au mode d'abatage ou au nettoiement des coupes. - Etablissement sans autorisation de loges. ateliers ou fourneaux à charbon. - Vidange par des chemins non désignés. - Inobservation des délais de coupe ou de vidange. - Feu allumé hors des loges ou ateliers. - Introduction d'animaux non muselés. - Dépòt de bois étrangers à la vente. - Délits commis à louie de la cognée.

Délits commis par les usagers au paturage, au pacage ou à la glandée. - Introduction de bestiaux sans décla- 
ralion de délen-abilite. - Inimanx destinis an rommeree. - Besliaux non marqués. - Be-liamx hor- decantons défen-ableset des chemins dé-ignés. - be-liamx non réunis en frompeam eommun, - Pestianx en nombre excédant.

Délit- commis pal les u-agers an bois. - Exercice de l'usage sans délivance. - Exploilation sans enlrepreneur. - Emploi de crochets et de ferrement- pour le bois mort. - Vente des bois d'usage.

Défrichement des bois particuliers.

Frande en matiere de tabac-el d'allumeltes chimiques.

- Police du roulage.

Constatation des délits.

Proces-verbaux. - Ecriture. - Sienalure. - Cloture.

\section{- Affirmation. - Enregistrement.}

Saisie. - Séquestre. - Arre-tation. - Visiles domiciliaires. - Réquisition de la foree publique. - Délinquants inconnus. - Foi due aux procès-verbaux. - Témoignages.

Renseignements sur les délinquants.

Citations et significations.

Coupes.

Préparation diune coupe en vue de son arpenlage ou de son martelage.

Divers modes de martelage.

Ròle du préposé pendant le cours du martelage.

Renseignement- que le prépusé doit tenir à la disposition desagents, - il- lui sunt demandés: E-timation du taillis ou du sous-bois. - Rendement de la coupe voisine et qualité de ses bois. - Chemins existants devant servir à la vidange et chemins nouveaux à désigner. Travaux à impo-er à ladjudicataire ou à l'entrepreneur.

Exploitations. - Dispositions du cahier des charges relatives à l'exploitation et à la vidange.

Récolement. - Préparation du récolement. - Faits ou renseignements à signaler aux agents.

Ventes.

Divers modes de vente. - Vente en bloc sur pied. Vente par unités de marchandises. - Vente après exploi.. tation. 
Ventes auxquelles les brigadiers assistent par délégation de l'Inspecteur pour remplacer le chef de cantonnement. - Formalités relatives à ces rentes.

Produit - accidentels. - Chablis. - Bois morts et bois dépérissants.

Menus produits.

Délivrance à prix dargent: Prix payable avant délirance. - Prix parable après dénombrement.

Délivrance movennant journées de travail.

Travaux.

Travaux effectués par entrejrise. - Dispositions du cahier des charges générales relatives à l'exécution.

Travaux effectués au compte de l'Etat. - Tenue des feuilles d'attachement.

Travaux imposés sur les coupes.

Travaux des concessionnaires.

Chasse.

Proces-rerbaux de chasse. - Formalités qui leur sont spéciales.

Pèche.

Proces-rerbaux de perche. - Pèche sans autorisation.

Principaux délits de pèche.

Barrage empichant le passage les poisons. - Usage de drogues ou ippats de nature a enirrer le poisson. ou à le détruire.

Périodes pendant le-quelles la pèche est interdite.

Dimen-ions- des peis-rn- yui peurent ètre pèchés.

Filets autorisis; dimension-des mailles.

Filets et engins prohibés.

Pirche en temp- prohibe-: par de-s procédés on an moyen d'engin- prohibés; an moven de tilet autorisis pour le poisson de petite espèce.

Peche, colportage ou rente de poissons nayant pas les dimensions prescrites.

Poissons pour appàts vivants.

Portion-ile comrs dleau ré-ervie-pour la reproblution.

Sai-ie des filet s et antres instrunents de peche prohibée ainsi que du prois-son pèché en délit. 
ART. 15.

La commision se transporte, sil y a lien, suceres-ivement dans les diflerents centres dexamens de-ierné - is cet effet.

Le Directem ales foris lat conmailre, entemps opportun, les centres désignís et la date a laquelle doivent commencer les examens dans chacun de ces centres.

ART. 16.

Le tour dexamen des préposes arlmis aux epreuves orales est délerminé par le Président de la Commision. Ceux d'entre eux qui, sans motifs ralables, ne se présentent pas lorsquils sont appelés, peuvent ètre exclus du concours.

ART. 17 .

Les examens sont publics, mais pour les agent s et préposés forestier strulement, l'entrée des salles restant interdite à toute autre personne.

ART. 18.

Les examen s roulent sur les matières indiquées à l'article 14 et les eximinateurs posent, dans les limites du programme, toutes les questions qu'ils jugent nécessaires pour s'éclairer sur le degré d'instruction des candidats.

\section{ART. 19 .}

Chayue examinateur attribue aux réponses des candidats dans les divers parties sur lesquelles il les a interrogés une cote numérique comprise dans l'échelle de 0 à 20. Cette cote est multipliée ensuite par le coefficient correspondant. 


\section{$-364-$}

ART. 20.

Immédiatement après la clòture des opérations dans chaque centre dexamen. le Président de la Commission en fait connaitre le résultat au Directeur des forèts.

\section{Coefficient. - Classement.}

ART. 21

Les coefficients sont fixés ainsi qu'il suit:

Compositions.

Dictée.

Composition française $: \therefore .: 15$

Composition de mathématiques. . . . . . . 1i 4.5

Composition en dessin . . . . . . 8 ?

Examens oraux.

Arithmétique .

Géométrie et cubage.

Histoire

Géographie.

Toposraphie: Planimetrie et nivfliement:

Service des préposés.

Le produit de chacun de ces coefficients par la cote de mérite représente le nombre de points obtenus par le candidat dans chacune des divisions du programme. La somne de- produits ainsi formé- détermine le rang de ce canrlidat sur la liste définitive du classement.

ART. 22.

Ne sont pas compris dans le classement les candidats qui ne réuniront pas - un nombre de point $=(1.000)$ égal à la moitié du nombre total maximum. 


\section{AnT. 23.}

Apres la clolure de- opreralion- de la commo--ion, fe

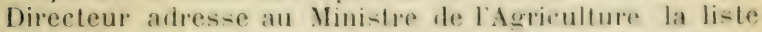
par ordre de mérite des andidats recommus ardmi-sibles.

Le Ministre de l’Agriculture nomme éleves de licole secondaire d'enseignement prolessionnel, dans lordre de classement étahli par celte liste, le nombre des candidats admissibles qu’il juge nécessaire pour les hesoins du service. 



\section{REGLEMENT}

RELATIF A L'ORGANISATION ET AU FONCTIONEMEXT DE L'BCOLE D'ENSEIGNEMENT

TECINIQUE ET PROFESSIONNEL DES GARDES DES EAUX ET FORÊTS (Arrêté ministériel du 17 janvier 190/)

\section{BUT ET ADMISSION}

Article premirn. - I école instituée aux Barres, commune de Vogent-sur-Ternisson Loiret), par décret du 19 décembre 1903 , a pour but de donner aux gardes des Eaux et Forèts toutes les connaissances d'ordre technique ou professionnel qui leur sont nécessaires pour exercer leurs fonctions.

Ant. 2. - L'école est ouverte aux gardes des Eaux et Forêts du -ervice domanial et du service communal. Elle peut aussi receroir des auliteur: libres français ou étrangers.

Art. 3. - (Modifié par arrèté du 28 octobre 1904). L'admission des gardes à l'Ecole d'en-eignement technique et professionnel des Barres a lieu par roie de concours.

Dans le courant du mois de mai, les conservateurs des Eaux et Forèts tran-mettent avec leur avis, les demandes des préposés sollicitant leur admission à l'Ecole. 
Le Directeur général des Eaux et Forèts arrète la li-le des gardes admi- à prendre part au concours.

Dans la première quinzaine d'aoùt, les candidats sont conroqués pour subir les épreures au chef-lieu de la Conservation ou de l'Inspection dont ils dépentent. Ils devront y ètre rendus la veille du jour fixé pour les exaunens.

IIs recerront, à cette occasion, les indemnités réglementaires de déplacement et de séjour.

I.es épreuve- comprennent uniquement des composilions écrites, sous li surveillance de deux agents désignés par le Conservateur.

Les sujets des compositions et les imprimés nécessaires sont enroyés au conserrateur sous plis cachetés

Les compositions comprennent :

\section{Première séance.}

$1^{\circ}$ Une dictée :

$2^{\circ}$ Lne composition sur un sujet visant le service des préposés (délits forestiers, de chasse et de pèche, travaux, exploitations, défrichements, reboisements.)

\section{Deuxième séance}

Une composition d'arithmétique portant sur les quatre règles, les règlos de trois et le système métrique.

Lienveloppe contenant chaque sujet de composition est décachetée à l'ouverture de chaque séance par les agents délégués, en présence des intéresiés.

Toutes les compositions sont faites sur des feuilles à têtes imprimées, délivrées aux candidats au commencement de la séance. Chacun d'eux, en recerant sa feuille, inscrit son nom sur la tète imprimée et signe à l'endroit indiqué ; un des aggents délégués appose immédiatement son visa.

Il est accordé aux candidats :

Pour relire la dictée: un quart d'heure. 


\section{$-369-$}

Pour la composition sur le -reviee despripo-i- : deux heures.

Pour la composition d'arithmetipue : deux heure-.

Les feuilles sont, a lexpiration de er lemps, remises aux agents rhargés de la surveillance, qui le- visent andessous de la derniere ligne et les adressent sons enveloppe, au Directeur général de- Eanx et Foréts, en rertifiant, sous leur propre re-ponsabilité, que le- épreuves ont été sinceres et en rendant compte. sil y a lieu, des incidents qui se sont produits.

Les compositions sont sounises aux corpectenr- nommés par le Directeur général des Eaux el Forêt- qui lecotent dans l'échelle de o à 20.

Les coefficients ci-apres sont appliques aux différentes épreuves, savoir: :

\section{Dictée}

Service des préposés

Arithmétique.

Ant. 4. - Les gardes des Eaux et Forèts désignés pour suivre les cours à l'Ecole d'enseignement technirque et professionnel recoivent, à l'aller et au retour, pour frais de route, les indemnités réglementaires.

Art. 5. - Les gardes sontcasernés à l'école, qui fournit gratuitement le logement, la literie (sauf les draps), le chauffage, l'éclairage. les ustensiles de cuisine et de table, les soins médicaux.

Ils mangent ensemble et sont organisés en mess, administré par une commission de trois dentre eux nommés à l'élection, renouvelable tous les trois mois.

Les dépenses sont parées chaque mois par le président de la Commission, '†ui doit soumettre au visa du directeur le registre des dépenses, en joignant les quitances des fournisseurs.

Art. 6. - Les gardes mariés peurent ètre autorisés à habiter Nogent-sur-Vernisson, à leurs frais; mais ils loivent prendre part à tous les travaux.

Grye. - Surveillayce. 
Art. 7. - Les gardes domaniaux ou mixtes, détachés à l'Ecole d'enseignement technique et professionnel, continuent à recevoir le traitement et les indemnités afférents à leur poste.

Les gardes communaux continuent, avec le consentement des communes intéressées, à recevoir les émoluments attachés à leur triage.

Les frais occasionnés par les tournées d'exercices pratiques sont à la charge de l'Administration.

Aвт. 8. - Le- auditeur's libres habitent Nogent-surVernisson, où ils pourvoient à leurs frais à leur logement. leur nourriture et leur entretien. Les dépenses de tournées sont à leur charge.

ART. 9. - Les gardes el auditeurs libres admis à l'école sont soumis à toutes les règles de discipline indiquées dans un règlement approuré par le conseiller d'Etat. Directeur grénéral des Eaux et Forèts.

\section{ENSEIGNEMENT}

Ant. 10. - La durée des études est de dix mois; elles commencent le 15 octobre et sont terminees le 15 aoùt. L'enseignement technique, professé à l'école. est complété par un enseignement professionnel donné sur le terrain.

Ant. 11. - Lienseignement technique, auquel sont consacré- quatre jour's par semaine, embrasse les cour: et matières ci-après :

$1^{\circ}$ Des notion-trè- élémentaires sur la sylviculture et les repeuplements artificiels. le- aménagements, Te débit et l'exploitation des bois, 30 leçons ;

$2^{\circ}$ Les parties du droit res-ortissant au service des gardes et en particulier l’étude des délits et lesprocèsverbaux, 20 leçons);

3. Larithmétique, la mesure des surfaces et des rolumes, 20 leçons;

$4^{\circ}$ La topographie, réduite à l'arpentage à l'équerre 


\section{$-371-$}

et at la bouscole, an rapport diun plan, an raleal des surfaces, all nivellement a ladede du nivean d eatl, an tratr d'une ligne avec une pente on une orientalion domer. 15 lecons;

5) Lres notions elementaires sur les travanx execulésoit dan- les forels, soit dan- les perimetre- de re-tanration des montagnes, 25 leçons;

6. La chasse et le braconnage : le grbier, son blevage. son entretien et sa prolection: le- animaux nui-ilbleleur destruction el le piégeage; les oiseaux utiles, leur protection, 10 leçons;

$7^{\circ}$ La peche et le loracomnage des rivieres; la protertion du poisson: la pisciculture, 10 leçons:

S La langue frangaise : orthographe, rédaction, jo lecons.

Ant. 12. - Lenceignement profes-ionnel sapplique it toutes les branches du service des garles: il est donmi en forèt pendant les tournées ellectuées dans les forêts voisines. On y consacre deux jours par semaine.

Les gardes, accompagné- de l'adjudant de surveillance, sunt conduits sur le terrain par un profes-seur dr. lécole; ils prennent part directement aux opérations de toute nature effectuées dans les forèts de Montargi-: dOrléans et de Fontainebleau. Ils effectuent des travaux topographiques aux environs des Barres.

Ils prennent part sur le domaine aux travaux manuelde culture et d'entretien des pépinières.

Ils s'y livrent à l'élevage du gibier et au piégeage de: animaux nuisibles.

Ils font de la pisciculture dans l'étang du domainc des Barres.

Enfin ils exécutent des exercices militaires sous lir direction d'un officier de l'armée active désigné par le Ministre de la guerre.

Art. 13. - Les gardes sont, à la fin de lannée sculaire, lobjet diun classement résultant des notes d.: l'année. Cieux d'entre eux qui auront obtenu unr moyenne générale de 14 seront proposés pour le grade de brigadier. 


\section{PERSONNEL}

Ant. 14. - La direction de l'école est confiée à un Conservateur des Eaux et Forèts dont l'autorité s'étend sur toutes les parties du service, de l'instruction et de ladministration. Un des professeurs est désigné pour suppléer le directeur en cas d'empèchement.

ART. 15. - Des agents des Eaux et Forèts, dont le nombre est fixé par le Ministre, aidés au besoin d'auxiliaires étrangers, donnent aux gardes des Eaux et Forèts l'enseignement technique et professionnel. Ln adjudant est chargé de la surveillance.

ART. 16. - Pour assurer la marche régulière de l'établis-ement, il est institué un conseil d instruction composé du directeur et des agents attachés à l'école. Ce conseil est appelé à donner son avis sur tout ce qui concerne les méthodes dinstruction et le service intérieur. 


\section{TABLE ALPHABÉTIQUE}

Acte de vente, 346.

Adjudication :, 125, 167, 169.

Administration centrale. 280.

Admission dans les húpitaux, 205.

Affiches en placard, 161.

- en cahier, 167.

- annotées, 172.

- transport d', 168.

Affirmation, 4, 104, 304.

Affouagères (coupes), yt.

Age des bois. 9.

- des délinquants, 12.

Algérie, uniforme, 251.

Appareils de pêcherie, 130.

Arbres (coupes d'), 31, 36 .

Armement, 256 .

Arrachis de plants, 38.

Arrestations, 22, 105.

Ateliers à faconner le bois, 52,87 .

Attachement (calepin d'), 155, $3 \div 2$.

Altributions (partage d'), 124.

Automobiles, 74 .

$\Lambda$ vancement, 270.

Barrages 130.

Baraque (construction de), 52 , 320.

Bateaux (visites des), 140, 142.

Battues, 118.

Bestiaux (commerce de), 6 ' .

Bêtes de somme introduction dans les bois), 45, 327 .

Bicyclettes, 74 .

Bois d usage (emploi des), 99. - mort (ramassage du), 100.
Bonification, 2't'.

Braconnage, 110.

Brigadiers, 196, 269, 279.

Bris de reserves, 81.

Bulletins de renseignements. 28, 3ง9.

Cahier des charges, 83, 109.

Caisse des retraites pour la vieillesse. 239.

Calepin d'attachement, 155, 342.

Candidatures, 271.

Cantons réservés, 135.

Certificat de vie, 237.

Cession d'objets divers, 181.

Châblis (enlevement de), 42.

Changements de résidence, 19l, 259

Chantier non autorisé, 52,321 .

Chasse (compétence), 102.

- modes de), 107.

- permis de), 105, 288.

- (réservée,), 108.

Chasseurs forestiers, 2:8.

Chauffage des préposés, 185, Chemins ordinaires, 40.

- faux, 89.

Chèvres (parcours) des), 64 .

Citations, 145 .

Clochettes, 63 .

Clôture des procès-verbaux, 3.

Colportage, 140.

Commerce de bestiaux, 64 .

Commission des préposés de l'administration des forêts, 175.

- des gardes particuliers, 282, 341.

- des gardes-chasse, 292. 
Commission des gardes-vente, 293.

Commis temporaires, 281.

Compétence des préposés de l'administration des forêts, $102,145$.

- des garde pêche, 121.

- des gardes particuliers, 282.

- des gardes-rente, 293.

Complicité, 10, 303, 314 .

Concours d'admission à l'Ecole des Barres, 272, 349, 367 .

Congés, 202.

Conseils, 9, 17, 28.

Constatation des délits, 1, 29, $101,125$.

Constructions à distance prohibée, 52. 3ํㅡ.

Copies des procès-verbaux, 17, 147.

Correspondance, 213.

Coupe de bois (délits de), 3o, $36,303,306,310$,

- de plants, 38 .

Coupe à blane étoc, 68 .

- de réserves, 79,330 .

Coupes affouagères, 96 .

Cours d'eau non navigables. 121.

Cours d'eau navigables, 123.

Date des procès-verbaux, 8 .

Défrichement des bois particuliers, 66.

- des bois communaux, 70 .

Dégradations, 71 .

Délais d'exploitation et de vidange, $90,297,316$.

Délinquants inconnus, 23.

Délit llagrant, 10. 303.

- à l'ouĩe de la cognée, 9 t.

Délivrance de menus produits. 162.

Demande de harts, $997,343$.

Dépôt illicite de bois, $9 \dot{4}$. - de lempreinte du marteau. 176,323 .

Dimensions des poissons, 138.

Domicile des délinquants, 11 .

Domiciliaires (visites), 18, 105, 306 .

Dommages causés par le gibier, 116.
Droits de parcours, 59.

- à pension, 224.

- de suite. 108.

- d'usage, 59.

- droit de pêche, 120.

Ecobuage, 48.

Ecole secondaire des Barres. 272,349 .

- d'enseignement technique professionnel des Barres, 275 . $36 \pi$.

Ecorcement d'arbres, 41 .

- sur pied, 87.

Ecriture des procès-rerbaux, ․

Elagages, 51.

Elères libres, $3: 9$.

Emploi des bois d'usage, 99.

Empoisonnement, 1:31.

Engins prohibés de chasse. 10 t. 336 .

- de pèche, 13, 136.

Enlèvement de bois, 30,36 , - de châblis, 42.

- de bois de délits 42 .

Enlèrement de graines, 43 . 313.

Enlèrement de feuilles mortes $43,30\}$.

Enregistrement des actes d'adjudication, 171 .

Enregistrement des citations, 152.

- des commissions, 177, 982 293, 341.

- des procès-verbaux, 6.

Entretien de l'uniforme, 254 .

Equipement, 256.

Elang. 122.

Etat de frais, 179.

Examens d'admission à l'Ecole des Barres, 258.

Exceptions, 135, 137, 141.

Extraction des produits des forèts, 43, $313,314,316$.

Faconnage des ramiers, 83.

Faux chemins, 89,317 .

Feuilles mortes, $43,166,314$.

Feuilles de procis-verbaux, 212.

Fenilles de route, 260.

Feux, $48,88,319$.

Filets de peche, 130 . 
Flagrant délit, 10, 303.

Foi due aux procés-verbaux, $2 \cdot 4,985$.

Fourneaux à charbon, 88 .

Fourniture des eflets dhabillement, 253.

Frais d'adjudication, 169.

- de cilation, 152.

- de séquestre, 18.

Franchise postale, 214.

Garde séparée, 62.

Gardes (recrutement des) domaniaux, 262.

- cantonniers, 268.

- communaux 268.

- sédentaires, 267.

- stagiaires en Indo-Chine, 267.

Gardes particuliers, 123, 282.

Gardes-chasse. 292.

Gardes-pèche, 125, 207, 262.

Gardes sedentaires, 277.

Gardes-vente, 293.

Gibier (dommages causés par le), 116.

Gratifications, 117, 126.

Habillement, entretien, 192, 254.

Haches (port de), 40.

Harts (demande de), 297, 343.

Hôpitaux militaires, 205 .

Identité, 35.

Incendie, 49.

Incompatibilités, 216.

Inconnus délinquants, 23.

Indemnités, 192.

Indications caractéristiques, 13.

Injures, 72.

Inseription maritime, 143.

Installation, 178.

Instruction professionnelle,290.

Introduction de voitures et bêtes de somme dans les forèts, 46, 327, 328 .

Jardins des gardes, 183.

Juridiction (privilège de),217,284

Ligne flottante, 126.

- dormante, 129.

Liquidation des pensions, 227 .

Livret d'ordre, 210.
Loges at ateliers, 87.

Louveterie, 117.

Maisons forestieres, 179.

Majorations, 227.

Maudats (pertes de), 191, 345.

Mariages, 205.

Marques des bestiaux, fi.3.

Marques de respect, 222.

Marteau des adjudicalaires, 79 .

- des gardes, 176, 212.

Maximum, 228.

Médaille forestière, 206.

- militaire, 260.

Menaces, 79.

Menus produits (délivrance dé), 15.5.

Nenus prorluits (vente rle), 162.

Minimum, 229.

Modes de chasse, 107.

- d'exploitation, 83.

- de calcul des pensions, 229.

- de pêche, 137.

Moutons (pacage des), 64.

Munitions, de guerre, 258.

Musellement des animaux, 90 .

Mutilation d'arbres, 41, 312.

Neltoiement des coupes, 85 .

Nomination des préposés de l'administration des forêts, $168,269$.

- des gardes particuliers,282.

- des garde chasse, 292.

- des gardes-vente, 293.

Noms et prénoms des délinquants, 11.

Noms et qualités, 10.

Notifications, 146.

Nuit (délit de), 9.

- (travail de), 85.

- (pêche de), 134 .

Objets divers (cession d'), 181.

Orphelins, 226.

Ouỉe de la cognée, 9'x, 294 .

Outre-passe, 82, 311.

Paiement des frais, 18.

Panage, 184.

Parcours (droit de), 59.

Partage d'attributions, 124.

Partage sur pied, 97. 
- Pâturage (délits de) 57, 32' $\mathbf{z}, 326$. $327,328$.

- des vaches des préposés. 183.

Pêche de nuit, 14 .

Pêche sans autorisation, 126.

- à la ligne, 128.

Pêches permises, 136.

- interdiles, 137.

- louées, 141.

- extraordinaires, 142.

Peines disciplinaires, 220.

Pensions, liquidation, 227.

Permis d'exploiter, 77.

- de chasse, 105, 293, 317.

Perte de mandat, 191, 323.

Personnel, 174 .

Placard (affiches en), 167, 168.

Plants (coupe et arrachis de),38.

Plaques, 213.

Ports de haches, scies, 40.

- d'engins prohibés, 139.

Pouvoir pour toucher un mandat, 34 .

Prime pour la destruction des loups, 118.

Privilège de juridiction, 217, 284 .

Procès-verbaux (écriture), 2.

- (signature), 3 .

- (clò̉ture), 3 .

- (affirmation). 4.

- (enregistrement), 6 .

- (ransmission), 7 .

- (rédaction), 8.

- date), 8.

- (feuilles de), 212.

- (modèles de), 303 à 338.

Programme des conditionsd'admission à l'tecole secondaire des Barres, 349.

Programme de l'École pratique des Barres, 349 .

Prohibitions, 216.

Qualités, 10.

Rébellion, 72 .

Récidive, 12, 312.

Récolements, 84 .

Recrutement. 262.

Rédaction des procès-verbaux, 8.

Refus de concours, 21.
Refus de secours en cas d'incendie, 51, 319.

Remise des copies de procèsverbaux, 147.

- des adjudications, 172.

Réquisitions à la force publique, 22, 340 .

Réserves (abatage de), 79, 330, (bris de), 81 .

Résidence (fixation de la), 215 .

Piésidence (changement de), 191, 259.

Résidus industriels. 133.

Respect (marques de), 222.

Responsabilite, 218.

Retard d'exploitation, 90, 333.

Retenues sur les traitements, 187.

Retocage, 34.

Retraites (conditions d'admission à la), 224.

- (caisse des) pour la vieillesse 289.

Rouissage, 133.

Roulage, 74 .

Saisies, 14,104,125, 306, 310, 31 \& 324.

Sivie, $33,40$.

Scieries. 55, 323.

Semis, 38.

Séquestre, 15, 306, 314, 32ł.

Serment, 176, 284, 294.

Service militaire, 247.

Signature des procès-verbaux, 3.

Signification, 146, 304.

Souchetage, 34 .

Suite idroit de), 108.

Tabacs, 72. 192.

Tarifs militaires, $2 \geq 9$.

Témoignage, 27.

Temps prohibé (chasse en), $100^{\circ}$ - (pèche en), 134.

Tenue (petite), 199.

Tolérances, 165

Traitement, 186, 250.

Transcription du serment, 177.

Transmission des procès-verbaux, 6 .

Transport d'affiches, 168.

Travail de nuit, 85 .

Travaux en régie, 15 . - par entreprise, 156. 
Travaux imposés aux adjudicaLaires, 158.

Travaux exéculés par les prestataires, 160. - par les préposés, 161.

Uniforme, 250, 253.

Usage (emploi des bois d'), 99. - (exercice des droits d'), 59 .

Usage de la scie, 33.

Usurpations, 71.

Vaches des préposés, 183.

Vente et colporlage, 140;

Vélocipèdes, 196.
Ventes de menus produits, 167.

Ventes (modicle d'acte de), 3 biti.

Vérification de réserves, 297.

Veuves, 225.

Vices d'exploitation, 83, 332,

Vidange (délais de). 90, 297.

Visites domiciliaires, 18, 105, $301 i$

- des bateaux, 140, 142.

Voitures (introduction de) dans les bois. 46 .

Vols de bois, 39. 



\section{LUCIEN LAVEUR ÉDITEUR}

13, rue des Saints-Pères, PARIS $\left(\mathrm{VI}^{\circ}\right)$.

\section{EXTRAIT \\ 1) $\mathrm{U}$ \\ GATALOGUE GÉNÉRAL \\ Envoi franco contre mandat-poste}

\section{REVUE DES EACX ET FORÉTS Annales fores-} tières fondées en 1812. - Économie foretière. Reboisement. - Commerce des bois. - Chasse. Louvelerie. - Pèche. - Pisciculture. - Régime des eaux. - Jurisprudence, etc. - Paraissant le $1^{\text {er }}$ et le 15 de charque mois, en deux fascicules de chacun deux feuilles in-8 raisin. - Prix de labonnement, toujours annuel, du $1^{\mathrm{rr}}$ janvier au 31 décembre: France, $\mathbf{1 5} \mathrm{fr}$. (avec l'Annuatre des Eaux el Forêts, 18 fr.). Etranger, $\mathbf{2 0} \mathrm{fr}$. Les années parues, depuis 1862 , se vendent: chaque année, $15 \mathrm{fr}$. - Ln prix spécial sera fait pour une demande de plusieurs années.

A XNC AUR DES EACX ET FORTE. - Ln vol. in-1s. de 368 pages environ, relié en toile souple. - Contenant. pour chaque année, le tableau complet du personnel de l'Administration des Eaux et Forèts et du service de l'Algérie, la liste des promotions de l'École nationale des Eaux et Forèts et de l'École serondaire 
d'enseignement professionnel et de nombreux documents statistiques. Cet annuaire est remis aux abonnés français parant l'abonnement de $\mathbf{1 8} \mathrm{fr}$., et aux abonnés étrangers parant l'abonnement de $\mathbf{2 0} \mathrm{fr}$. 11 ne se vend pas séparément.

TABLE MLPHABTREE des matières contenues dans la Revue des Eaux et Forêts. - $1^{\text {re }}$ série : années 1862 à 1856,1 vol. in-s raisin $\left(9^{6}\right.$ pages, broché, $6 \mathrm{fr}$. $2^{\mathrm{e}}$ série : années 188 - à 1902.1 vol. in-8 raisin (116 p.), liroché

$4 \mathrm{fr}$. Les deux tables ci-dessus, prises ensemble . . . $8 \mathrm{fr}$

CODE DE LA LÉGISLATIOX FOPESTIËRE. - Lois. - Décrets. - Ordonnances. - Avis du Conseil d'État et règlements en matière de forèts iFrance et Colo. nies, pèche fluviale. chasse et louveterie, dunes et landes, montagnes, etc., par A. Ptтох. Deuxième édition entièrement refondue etmise à jour. par Ch. Grorot (Directeur et Professeur de droit à l'École nationale des Eaux et Forèts . 1 vol. in-8 (xir-100't pages), relié toile

GOMUNTARE DE LA LOI FORESTIERE ALGÉRIEXXE, promulguée le 21 février 1903, par Ch. Gr rot (Directeur et Professeur de Droit à l'École Nationale rles Eaux et Forêts). - 1 vol. in-8 carré (xvi-3.56 pages), broché .

ร $\mathrm{fr} .50$

I I MASOY DL GIRDE. - Totion- d'hygiène, d'économie dome-tique et dagriculture à l'usage des gardes forestiers ou particuliers et des petits ménages, par l. Poccis. Ourrage couronné par la Société nationale d'Agriculture. - 1 vol. in-18 (vir-25' pages), aree 142 gravures, relié toile.

$3 \mathrm{fr}$. 50

r B.IGE ET ESTIMARUN DES BOIS. - Futaies. Taillis. - Arbres abattus ou sur pied, avec des notions pratiques sur le débit, la rente et la fabrication de tous les produits des forets. - Tarif de cubage 
des bois en grume ou equarris. - Tables de conversion, par A. (Gotrisitd) - 1 vol. in-18 (18? jateres), cartonné

Ifr. 50

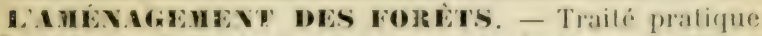
te la conduite des exploilations de forcts en taillis et en futaie, par Alfred PeTox. 1 vol. in-18 (xul-218 pages), orné de vignelles, relié toile.

$3 \mathrm{fr} .5()$

ECONOUE NOREQTHER, par (i. HTFE, inspecteur des Eaux et Forèls, professeur à l'École nationale des Eaux et Forèts. - Tome Ir. liutilité des forèts. - P'ropriété et législation forestières. - Politique forestiere. - La France forestiere. - Statistiques. Ln rolume in-8 raisin ( $\mathrm{x}-422$ pages). Broché.

$10 \mathrm{fr}$.

Tome II. Dendrométrie. - La formation du prorluit forestier. - Estimations et expertises. Ln vol. in-8 raisin (xvi-48' pages), avec 126 figures. Broché.

$10 \mathrm{fr}$. Le tome III paraitra en 1906.

\section{TRAITÉ DENPLOITATOA COMHERCIME DES}

BOIS, par Alphonse Matney, inspecteur des Eaux el Forèts. - Tome Ier. Constitulion. - Défauts et maladies des bois. - Conservation. - Emmagasinage el traitements préservatifs. - Exploitation des bois. Les transports. Préface de M. Datbrée, directeur général des Eaux et Forèts. 1 vol. in-8 carré de xvir- 492 pages, avec 377 figures, dont 8 planches en chromolithographie. Prix, broché . . . . $15 \mathrm{fr}$. Le tome deuxième et dernier paraîlra ì laulomne 19o6. Il traitera des meilleurs emplois des bois, de leur débit, de leur valeur et des usages commerciaux reçus en France et dans les principaux pays étrangers.

LES FRICHES DE LA HACTE-MARME, leur mise en valeur par des travaux forestiers pastoraux : Pineraies et parcs de pàturages. - Aménagements des pàturages communaux. - Syndicats de reboisernent et syndicats pastoraux. - Application du crédit agricole aux travaux ruraux, par E. CARDOT, inspecteur des Eaux et Forèts. Brochure in- 8 raisin 24 pages! $-1 \mathrm{fr}$. 
LIDÉ FORESTIÈRE DANS LHISTOIRE, par L.-F. Te-sier, in-pecteur des Eaux et Forèts. Brochure in-8 raisin ( $2 S$ pages!.

INFLUENCE DES ECLARCIES dans les peuplements réguliers de sapin, par E. Crrf, inspecteur adjoint des Eaux et Forèts. attaché à la station des recherches de l'Ecole nationale des Eaux et Forèts. Brochure in- 8 raisin (122 pages, avec 4 4́ figures et 41 tableaux. $3 \mathrm{fr}$.

\section{SECTIONS TRANSTERSALES DE 120 ESPÈCES}

DE BOIS, par André ThIL, inspecteur des Eaux et Forits. -6 planches $32 \times 2$, comprenant 120 sections le bois indigènes et exotiques, avec une notice explicative de 46 pages. En carton.

$10 \mathrm{fr}$.

TRIITÉ PRATIQUE DU REBOISEMENT et du gazonnement des montagnes. par P. Demoxtzer. Deuxième édition, revue et augmentée. 1 vol. in-s cavalier (xxxir-52s pages;, orné de 105 figures . . . $15 \mathrm{fr}$.

\section{LA VALEE DE BARIEGS ET LE REBOISEUENT.} Les torrents, le désastre de 1897 , les aralanches, par A. Camparise insperteur-aljuint des Eaux et Forêts). Un volume grand in-s jésus 190 pages 1 , arec 32 reproductions en phototypie, broche . . . . . . 3 fr.

\section{LA SYLVICULTRE A LEXPOSITION DE 1900 ,} par A. Bougret DE LA Grye. membre de la Société centrale digriculture de France. Brochure in-S carré (40 pages) .

$1 \mathrm{fr}$.

\section{LE PROPIIET MRE PLANTELR. SEMRR ET PLAX-}

TER. - Choix des terrains. Semis. Plantations fores. tières et d'agrément. Entretien des massif's. Elagage. - De-cription el emploi des essences forestières indigrènes et exoliques, ete. - Traité pratique et économique du reboisement et de-plantations des pares et jardins, par D. Casxos, laureat du prix d'honneur de -rlviculture en Sologne. Troisième édition, rerue et 
corrigér. - 1 vol. ins (vma-3s' pages, orné de sis. gravures, broché . . . . . . . . fi fr.

L'I IRT IDE P.INTEIR. - I'lantationz en général. I'lanlitions en butte. - Traité pratique sur l'art d'élever en pipiniere el de planter a demeure les arbres foresliers. frutiers el d'agrément, par le baron H.- L. de. M.mtatral, traduit sur la troisieme édition allemande jar J.-13. St mple, revu par (:. Gorkt. - 1 vol. in-s (256 pases), orné de 16 vignettes, relié toile. $3 \mathrm{fr} . \mathbf{5 0}$

LES OISEIUX UIIES ET LES OISEAIX NISIBLES AIX CHAMPS, JIRIISS, FORE'S, PI. I. TITIONS, VItiNes, par II. DE L.I Blanchere. - 1 vol. in-1S (rur-3ss pages), orné de 150 grarures, relié toils.

$4 \mathrm{fl}^{\circ}$.

\section{LES RIVAGEURS DES FOIRETS ET DES IIBIRES}

DALIGNEUEVT. par II DE LA Blaxchère et le Dr Eugène Robert. Sixieme édition, revue et considérablement augmentée. - 1 vol. in-1S (3gs pages), aver: 162 grav. sur bois, relié toile.

$1 \mathrm{fr}$.

\section{LES ANIMACXES FORETS mammifères, oiseaux .} - Zoologie pratique aupoint de vue de la chasse et de la sylviculture, à l'usage des chasseurs, agents forestiers, propriétaires, gardes forestiers, gardes-chasse, etc., par R. Cabarrcs. - 1 vol. in-18 (vill-2so pages), orné de 8 q gravures sur bois, cartonné . 2 fr. 50

LA DISPARITION DU CHẼE et l'introduction des résineux dans les taillis-sous-futaie. - Les essences auxiliaires : le bouleau, par H. Rosemoxt. Brochure in-8 raisin (47 pages).

$1 \mathrm{fr}$.

LE PEL PLIER. - Histoire. - Variétés. - Culture. Utilité. - Maladies. - Insectes nuisibles. - Remèdes. - Exploitabilité. - Produits. - Emploi. par L. BreTox-Borxard. - 1 vol. in-8 carré (ril-213 pages) orné de 9 - illustrations et de 2 planches coloriées, broché. 
LA PISCICLLTIRE, fluviale et maritime en France Culture de l'écrevisse et des sangsues. Elevage. Repeuplement des rivières. Description des poissons. Pèche. Alimentation. Lois et règlements sur la pèche. par Jules Pizzeta, suivi de l'Ostréiculture en France, législation sur la pèche maritime, statistique, etc., par II. DE Box. - In-18 (vin- $4-2$ pages), arec 212 gravures, cartonné

LES POISSONS DEAC DOCCE. - Synonymie. Description. Ineurs. Frai. Pèche. Iconographie des espèces composant plus particulièrement la faune française, par H. Gervais et R. Botlart, attachés au muséum, arec une introduction par Paul Gervais, membre de l'Institut. - 1 beau vol. grand in-8, orné de 60 chromotypographies et 56 vignettes, broché . . $30 \mathrm{fr}$.

\section{LA PÊCHE FLCUILE ET LADUINISTRATION} DES EATX ET FORETS, par Fernand Deroye (inspecteur des Eaux el Forêts, docteur en droit). - 1 rol. in-S raisin (xvI-32S pages).. . . . . . . $5 \mathrm{fr}$.

A TRA VERS IE JAPOX. - Climat. - Géologie. Hỵdrographie. - Régions. Administration et École forestières. - Forèts domaniales et particulières. Routes. - Flottage. - Reboisements. - Plantations. - Description. - Emploi des essences résineuses et feuillues, par L. UssèLE. - 1 vol. in-S carré (vIII-1;2 pages), orné de go vignettes et d'une carte, tiré à 500 exemplaires sur papier du Japon . . . . . 20 fr.

I TRAVERS LA TCXISIE. - Étude sur les oasis, les dunes, les forèts, la flore et la géologie, par Léopold Barabax. - 1 vol, in- 8 carré vill-228 pages. orné de vignettes et d'une carte . . . . . . $12 \mathrm{fr}$. 


SD

373

B68

1906

ptie.2

Forestry
Bouquet de La Grye, Amédée Guide du forestier 11. éd., rev.

\title{
UNIVERSITY OF TORONTO LIBRARY
}

\section{$96300]$}

\author{
LIBRARY \\ FACULTY OF FORESTRY \\ UNIVERSITY OF TORONTO
}




\section{Lucien LAVEUR, Éditeur, 13, Rue des Saints-Pères; Paris}

Traité d'Exploitation Gommerciale des Bois, par ALPhONSE MATHEX (Insperteur des Eaux et Forêts). - Tome I. Constitution. - Détauts et Maladies des Bois. - Conservatiwn, Emmagasinage et Traitements préservatifs. - Exploitation des Bois. - Les Transpcrts, - In volume in-8 carré de XVIII-488 pages, avec 377 figures, dont 8 planehes en ehromolithographie, broché.... 15 fr.

Le Tome II et dernier paraitra ì l'automne-1906. It traitera des meilleurs emplois des bois, de leur débit, de leur valeur, etc.

Les Maladies des Plantes cultivees, des arbres fruitiers et forestiers, occasiounées par le sol, l'atmosphère, les parasites, etc.; par A. D'ArBoIs DE JUBa TNYILLE (Conservateur des foréts) et $\mathrm{J}$. Vesque (Préparateur au Muséum). - Un volutuse, 48 vignettes et 7 planehes en couleurs... $4 \mathrm{fr}$.

Reboisement et Gazonnement des Montagnes. Traité pratique, par P. DEMONTZEX. - 2 e éditiun. Un fort volume in-8, 105 gravures....... $15 \mathrm{fr}$.

Code de la législation forestière. - Lois. - Déerets. - Ordonnances. - Avis du Conseil d'Etat et règlements eu matiére de forêts (France et Colonies), perhe fluviale, chasse et louveteric, dunes et landes, montagnes, etc., par A. Puton. $2^{c}$ édition entièrement refondue et miseà jour par CH.Gurot, Directeur et Professeur de droit à l'Ecole nationale des Eaux et Fo. rêts. Un volume in-18 (XII-1004 pages). Relié toile......... $7 \mathrm{fr}$.

L'Art de planter. - Traité pratique de l'art d'élever en pépinère et de planter les arbres forestiers, fruitiers et d'agrément, par MasTEUFFEL; revu par L. GOUËT (Directeur de lEtablissement darboriculture aux Barres). 3० édition, avec 16 gravures. Relié.. 3 fr. 50

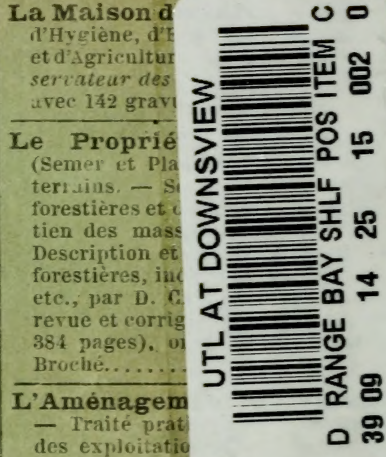

lis et en futar

TON (virecteur de I'Ecole forestière) $-2^{e}$ édition, avee gravures. Relié............... 3 fr. 50

Les Ravageurs des Forêts et des arbres d'alignement. - Histoire naturelle, moeurs, dégâts des insectes, moyens de les combattre et dle restaurer Ies plautations, par H. DE LA BLANChíre et par EUG. ROBERT. - 6e édition. Un volume, avee 162 gravures. Relié.... $4 \mathrm{fr}$ :

Les Animaux des Forêts (Mammiferes et Oiseaux):-Zoologie pratique au point de vue de la Chasse et de ia Sylvieniture, par R. GABARRUS (Sous-Inspecteur des Foréts). -20 éditiou. Un volume, orné de 84 vignettes.

Helié................. 2 fr. 50

Manuel de Gubage et d'estimation des bois en futaies, taillis, arbres abattus ou sur pied. Notions pratiques sur le débit, la vente et la fabrication de tous les produits des forêts ; tarif de cubage des bois en grume ou équarris. Tables de conversion, par A. GoURSAUD (Inspecteur des Poréts). - 5o étition. Un colume. Relié.................. 1 fr. 50 